


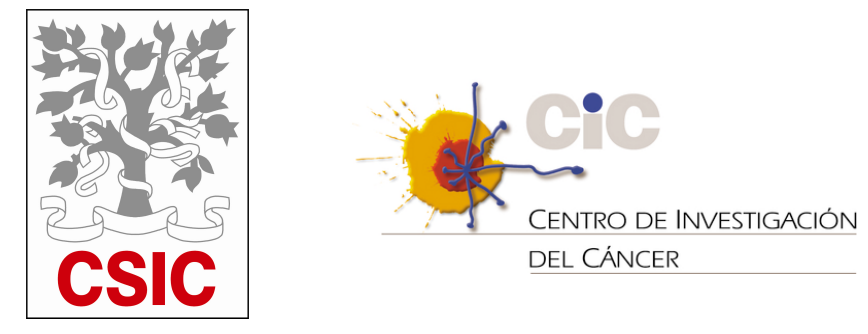

VNiVERSIDAD DSALAMANCA

CENTRO DE INVESTIGACIÓN DEL CÁNCER

UNIVERSIDAD DE SALAMANCA

DEPARTAMENTO DE MICROBIOLOGÍA Y GENÉTICA

\section{Regulación de la desubiquitinación de PCNA en Schizosaccharomyces pombe}

TESIS DOCTORAL

Laura Viñas de la Cruz

Salamanca, 2013 


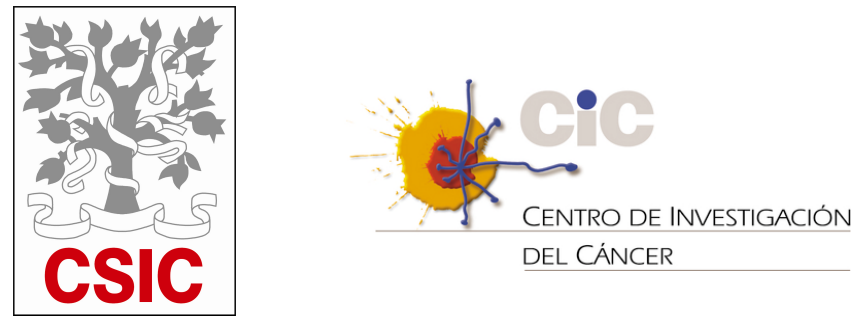

VNiVERSiDAD D SALAMANCA

D. Andrés Avelino Bueno Nuñez, Catedrático del Departamento de Microbiología y Genética de la Universidad de Salamanca,

\section{CERTIFICA:}

Que la memoria titulada "Regulación de la desubiquitinación de PCNA en Schizosaccharomyces pombe" presentada por la licenciada LAURA VIÑAS DE LA CRUZ, ha sido realizada bajo su dirección en el Instituto de Biología Molecular y Celular del Cáncer, USAL/CSIC, y que reúne a su juicio, originalidad y contenidos suficientes para que sea presentada ante el tribunal correspondiente y optar al grado de Doctor por la Universidad de Salamanca.

Y para que así conste a efectos legales, expide el presente certificado en Salamanca a 21 junio de 2013.

Andrés Avelino Bueno Nuñez

Director de la tesis 

A los que nunca dejan de apoyarme, a mis padres, a mi hermana... y a mi abuela 

La vida es un viaje, no un destino. 



\section{TABLA DE CONTENIDOS}

Glosario de abreviaturas v v

Índice de Figuras vii

Índice de Tablas $\quad$ ix

Introducción 1

1. Rutas de reparación del daño en el ADN 2

1.1 Reparación por escisión de base BER 2

1.2 Reparación por escisión de nucleótidos NER 3

1.3 Reparación de apareamientos erróneos MMR 4

1.4 Reparación de roturas de doble cadena 4

2. Checkpoints 5

3. Tolerancia 6

3.1 Una perspectiva histórica $\quad 8$

3.1.1 Inicios en E.coli 8

3.1.2 Primeros descubrimientos en eucariotas 9

3.2 PCNA 9

3.2.1 Descubrimiento de PCNA 10

3.2.2 Estructura 11

3.2.3 Interacciones y funciones de PCNA 11

3.3 Ubiquitinación 14

3.4 Señal de activación y requerimientos moleculares de la tolerancia 16

3.4.1 Activación de las rutas de tolerancia al daño 16

3.4.2 Ruta TLS 18

i. Polimerasas TLS 18

ii. Desarrollo del mecanismo TLS 22

iii. Replicación de la lesión. Modelo de dos polimerasas 24

iv. Reincorporación de las polimerasas replicativas 25

3.4.3 Ruta error free 26

3.5 Elección de ruta 28

3.6 Tolerancia en otros eucariotas 29

3.7 Problemas de ambas y conclusión final de tolerancia 30

3.8 Desactivación de las rutas de tolerancia al daño 31

3.8.1 DUBs 31

3.8.2 Desubiquitinación de PCNA 33

i. Usp1 33

ii. Ubp10 34

3.9 Tolerancia y cáncer 34 
1. Análisis de la ubiquitinación de PCNA en deleciones simples de UBPs

1.1 La acumulación de PCNA ubiquitinado, no es específica del daño por MMS

1.2 La acumulación de formas ubiquitinadas de PCNA en los mutantes $\triangle u b p 2$ y $\triangle u b p 16$ desaparece al eliminar el daño del medio

2. Análisis de la ubiquitinación de PCNA en mutantes dobles de UBPs

2.1 Los dobles mutantes $\Delta u b p 15 \Delta u b p 16$ y $\Delta u b p 5 \Delta u b p 16$, acumulan más cantidad de PCNA modificado que los mutantes simples

3. Fenotipos de sobre-expresión de UBPs en S. pombe

4. Localización de las UBPs

5. Eliminación de Ubp2 y Ubp5 de nuestro estudio

6. Análisis del triple mutante $\Delta u b p 5 \Delta u b p 15 \Delta u b p 16$

7. Sobre-expresión del resto de UBPs nucleares 58

8. Análisis del triple mutante $\triangle u b p 12 \triangle u b p 15 \Delta u b p 16$

8.1 Bloqueo y liberación con MMS en $\Delta$ ubp12 $\Delta$ ubp15 $\Delta$ ubp16 $\quad 59$

9. Análisis de las versiones catalíticamente inactivas de Ubp15 y Ubp16 60

10.PCNA interactúa in vivo con las UBPs Ubp15 y Ubp16 62

11.Ubp16 desubiquitina PCNA in vitro

12. Consecuencias celulares de la ausencia o de la sobre-expresión de las desubiquitinasas de PCNA

12.1 Consecuencias de la sobre-expresión de las UBPs 65

12.2 Consecuencias de la falta de las UBPs 68

13.Complementación en S. cerevisiae 69

13.1 Las células de S. cerevisiae que sobre-expresan Ubp16 de S. pombe, también son muy sensibles a agentes que dañan el ADN 70

14.Análisis de la ubiquitinación de PCNA a lo largo del ciclo celular $\quad 71$

14.1 Análisis en los mutantes simples y dobles de las UBPs 74

14.2 Análisis del triple mutante $\triangle u b p 12 \Delta u b p 15 \Delta u b p 16$

\section{Discusión}

1. Ubp12, Ubp15 y Ubp16: desubiquitinasas de PCNA 83

2. Ubp16: principal enzima desubiquitinante de PCNA 83

3. Ubp15: papel secundario en la desubiquitinación de PCNA 84

4. Ubp12: tercera desubiquitinasa de PCNA 85

5. $\triangle u b p 12 \triangle u b p 15 \Delta u b p 16 \quad 85$

6. Ubp2: ¿implicada o no en la tolerancia al daño? 87

7. Ubp5: proteasa no relacionada con la tolerancia 88

8. Desubiquitinación de PCNA en S. pombe 88 
9. Ubiquitinación-desubiquitinación y ciclo celular. 89

10. Relación entre desubiquitinasas y polimerasas TLS 90

11.Ubicación de la desubiquitinación $\quad 90$

$\begin{array}{ll}\text { Conclusiones } & 91\end{array}$

Materiales y Métodos $\quad 93$

1. MICROORGANISMOS Y MEDIOS DE CULTIVO 93

1.1 Microorganismos $\quad 93$

1.2 Medios de cultivo 93

2. TÉCNICAS DE TRANSFORMACIÓN EN LEVADURAS Y BACTERIAS 98

3. ENSAYOS DE SENSIBILIDAD A AGENTES GENOTÓXICOS 99

3.1 Ensayo de gota en S. pombe 99

3.2 Ensayo de gota en S. cerevisiae $\quad 99$

3.3 Ensayo en placas microtiter para S. pombe 99

4. SINCRONIZACIÓN DE CULTIVOS $\quad 100$

i. Sincronización en la Fase G1 100

ii. Sincronización en la Fase G2 100

iii. Sincronización en Fase $S \quad 101$

iv. Sincronización del cultivo en G2 por elutriación 101

5. TÉCNICAS DE MANIPULACIÓN DE ÁCIDOS NUCLEICOS 101

5.1 Construcción de plásmidos de ADN recombinante 101

5.2 Aislamiento de ADN plasmídico a partir de células de E. coli 101

5.3 Aislamiento de ADN genómico de S.pombe y de S. cerevisiae 101

5.4 Determinación de la concentración de ácidos nucleicos 103

5.5 Digestión de ADN con endonucleasas de restricción 103

5.6 Tratamiento de fragmentos de ADN con fosfatasa alcalina 103

5.7 Electroforesis de fragmentos de ADN 103

5.8 Purificación y ligación de fragmentos de ADN 104

5.9 Reacciones de amplificación de ADN (PCR) 104

i. Lista de oligonucleótidos utilizados 104

5.10 Secuenciación de ADN 120

5.11 Extracción de ARN total y RT-PCR 120

6. CITOMETRÍA DE FLUJO (FACS) 120

7. TÉCNICAS DE PROTEÍNAS 121

7.1 Preparación de extractos proteicos 121

i. Preparación de extractos proteicos de S. pombe:

condiciones desnaturalizantes 121

ii. Preparación de extractos proteicos de S. cerevisiae:
condiciones desnaturalizantes

iii. Preparación de extractos proteicos de S. pombe:
condiciones nativas 
7.2 Valoración de la concentración de proteína en los extractos totales 122

7.3 Electroforesis de proteínas en SDS-PAGE

7.4 Análisis de proteínas por la técnica de Western blot

7.5 Tinción con Azul de Coomassie

7.6 Inmunoprecipitación

7.8 Anticuerpos utilizados

7.9 Purificación de proteínas a partir de células de E. coli

7.10 Ensayo in vitro de desubiquitinación de PCNA por Ubp16

4. MICROSCOPÍA

8.1 Microscopía de contraste de fases

8.2 Microscopía de contraste interferencial y de fluorescencia

8.3 Tinciones de núcleos y septos

8.4 Micromanipulación

\section{TRATAMIENTO INFORMÁTICO DE SECUENCIAS Y PRESENTACIÓN}

\section{DE DATOS}

9.1 Tratamiento informático de secuencias de ADN y proteína

9.2 Presentación de datos

Apéndice 


\section{Glosario de Abreviaturas}

A

ADN: Ácido desoxirribonucleico

ADNc: ADN complementario

AF: $\quad$ Anemia de Fanconi

ARN: Ácido ribonucleico

ATP: Adenosín trifosfato

B

\begin{tabular}{ll}
\hline BER: & $\begin{array}{l}\text { Reparación por escisión de } \\
\text { base }\end{array}$ \\
BSA: & Albúmina sérica bovina \\
C & \\
\hline$c d c:$ & Ciclo de división celular
\end{tabular}

D

\begin{tabular}{ll}
\hline DAPI: & $\begin{array}{l}\text { diclorhidrato de 4,6-Diami- } \\
\text { dino-2-fenilindol }\end{array}$ \\
DO: & Densidad óptica \\
DUBs: & Desubiquitinasas
\end{tabular}
$\boldsymbol{F}$
FACS: Fluorescence-Activated Cell Sorting "citometría de flujo"

G

GFP: Proteína verde fluorescente

GST: Glutation-S-Transferasa

\section{H}

HU: Hidroxiurea

\section{I}

IP: Inmunoprecipitación

\begin{tabular}{ll}
$\boldsymbol{K}$ \\
\hline kDA: $\quad$ Kilodalton
\end{tabular}

M

$\mathrm{mA}: \quad$ miliamperio

mM: milimolar

MM: $\quad$ Medio mínimo

MMS: Metil metano sulfonato

MMR: Reparación de apareamientos erróneos

\begin{tabular}{ll}
$\boldsymbol{N}$ & \\
\hline NER: & $\begin{array}{l}\text { Reparación por escisión de } \\
\text { nucleótido }\end{array}$ \\
NES: & $\begin{array}{l}\text { Secuencia de exportación } \\
\text { nuclear }\end{array}$ \\
NLS: & $\begin{array}{l}\text { Señal de localización nu- } \\
\text { clear }\end{array}$ \\
NQO: & 4-Nitroquinolina 1-óxido \\
$\boldsymbol{O}$ & \\
\hline ORF: & Fase de lectura abierta
\end{tabular}




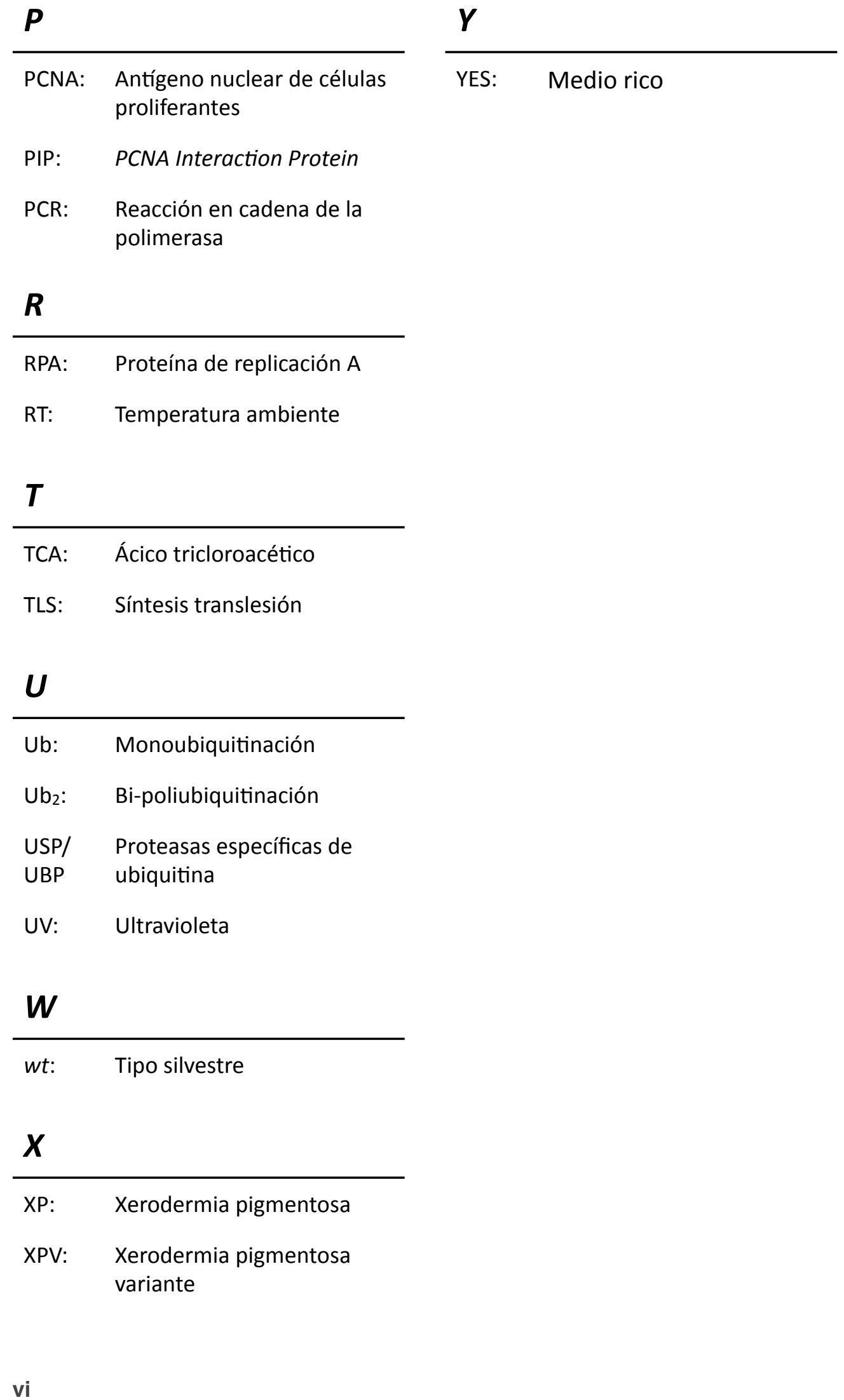




\section{Índice de Figuras}

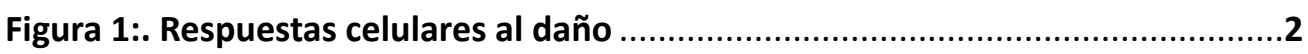

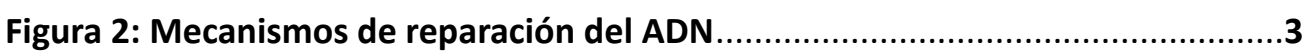

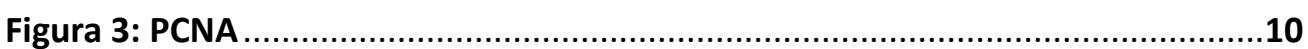

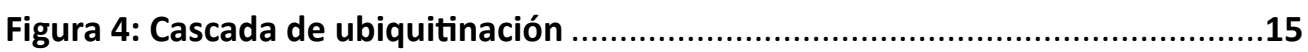

Figura 5: Señal de activación de las rutas de tolerancia; papel de RPA ..................17

Figura 6: Esquema general de ubiquitinación y SUMOilación de PCNA, y la activa-

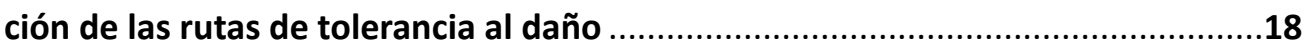

Figura 7: Dominios estructurales de las polimerasas humanas de la Familia Y......20

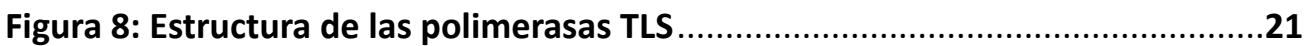

Figura 9: Modelo de replicación por TLS en células eucariotas ............................25

Figura 10: Desarrollo de la vía error free de la tolerancia al daño ..........................28

Figura11: Análisis del estado de ubiquitinación de PCNA en los 16 mutantes simples de UBPs en $S$. pombe

Figura 12: Los fenotipos observados en los mutantes $\Delta$ ubp2 y $\Delta$ ubp16 no son específicos del daño con MMS

Figura 13: Las formas modificadas de PCNA en los mutantes $\triangle$ ubp2 y $\triangle$ ubp16 desaparecen al eliminar el MMS del medio

Figura 14: Análisis bioquímico de los mutantes dobles de UBPs .46

Figura 15: Ubiquitinación de PCNA en los mutantes que sobre-expresan Ubp2, Ubp5, Ubp15 y Ubp16

Figura 16: Ubp16 desubiquitina a PCNA en ausencia de Ubp15, mientras que Ubp15 no es capaz de hacerlo eficientemente en ausencia de Ubp16

Figura 17: Localizaciones de Ubp2, Ubp5, Upb15 y Ubp16

Figura 18: Analisis por microscopía de fluorescencia de las desubiquitinasas Ubp15 y Ubp16.

Figura 19: Ubp2 no es capaz de desubiquitinar las formas monoubiquitinadas de PCNA.

Figura 20: Análisis de la proteasa Ubp5: localización y estado de ubiquitinación de PCNA 55

Figura 21: Análisis del estado de ubiquitianción de PCNA en el triple mutante

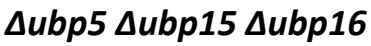

Figura 22: La sobre-expresión de la UBP nuclear Ubp12 disminuye la ubiquitinación de PCNA en S. pombe 
Figura 23: Análisis de la ubiquitinación de PCNA en el triple mutante $\triangle 4 b p 12$

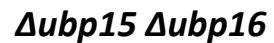

Figura 24: Analisis del estado de ubiquitinación de la abrazadera en el mutante uubp12 $\Delta$ ubp15 $\Delta$ ubp16 al eliminar el daño del medio

Figura 25: Las versiones catalíticamente inactivas de las proteínas Ubp16 y Ubp15 no son capaces de desubiquitinar a la abrazadera deslizante

Figura 26: Ubp15 y Ubp16 interaccionan con PCNA tanto en células asíncronas como en las dañadas con MMS .

Figura 27: Ubp16 desubiquitina a PCNA in vitro .64

Figura 28: Ensayo de sensibilidad de las cepas que sobre-expresan las UBPs. .66

Figura 29: Ensayo de sensibilidad a MMS y cisplatino de los mutantes simples

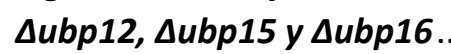

Figura 30: Ubp16 de S. pombe desubiquitina PCNA de S. cerevisiae. .70

Figura 31: Ensayo de sensibilidad de la levadura de gemación . .71

Figura 32: La ubiquitinación de PCNA en la levadura de fisión no es específica de Fase $\mathrm{S}$ . .72

Figura 33: La acumulación de formas modificadas de PCNA en el mutante $\triangle$ ubp16 es específica de Fase $S$.

Figura 34: La acumulación de formas modificadas de PCNA en el mutante $\triangle$ ubp15, también es específica de Fase $S$

Figura 35: Análisis de la ubiquitinación de PCNA en el mutante $\triangle$ ubp15 $\triangle$ ubp16 77

Figura 36: Análisis de la ubiquitinación de PCNA en el mutante $\triangle$ ubp12 $\Delta u b p 15$ $\triangle$ ubp16

Figura 37: Modelo propuesto para la regulación de la desubiquitinación de PCNA en S. pombe.

Figura 38: Células carentes de las proteasas Ubp8 y/o Ubp16, acumulan mayor cantidad de histona H2B ubiquitinada. .129

Figura 39: Análisis de la ubiquitinación de PCNA a lo largo del ciclo celular en el mutante $\triangle$ ubp16 cdc10-129. 130

Figura 40: Análisis de la ubiquitinación de PCNA a lo largo del ciclo celular en el mutante $\triangle$ ubp15 $\triangle$ ubp16 cdc25-22. 131

Figura 41: Cepas carentes de Ubp2 muestran una gran sensibilidad a MMS .132 


\section{Índice de Tablas}

Tabla 1: ADN polimerasas eucariotas de la familia Y.

Tabla2: Localizaciones e interacciones proteicas de las UBPs de S. pombe..

Tabla 3: Cepas de S. pombe utilizadas en este trabajo. .94

Tabla 4: Cepas de S. cerevisiae utilizadas en este tabajo 97

Tabla 5 Cepas de $E$. coli utilizadas en este trabajo. 97

Tabla 6: Vectores y plásmidos utilizados en este trabajo .125

Tabla 7: Anticuerpos utilizados en este trabajo 125 



\section{Introducción}

El ADN, tal y como se espera del material portador de la información genética de la célula, es una molécula altamente estable. Sin embargo, esa estabilidad se encuentra constante e inevitablemente en peligro, por agentes de diferente naturaleza que dañan su estructura. Asegurarse de que estos daños no pasen a generaciones posteriores por medio de la replicación, será primordial para asegurar la integridad del genoma y por lo tanto la supervivencia celular.

Para conseguir tal propósito, las células han evolucionado con la capacidad de detectar y propagar esas señales de daño, activando distintas rutas moleculares. Estas rutas, denominadas colectivamente como "Respuestas al daño" (Figura 1), están constituidas por:

6. Rutas de reparación: Primera línea de defensa de la célula contra muchos tipos de lesiones. Actúan principalmente sobre el dúplex de ADN y se basan en la escisión y resíntesis posterior de la secuencia dañada, utilizando para ello la información codificada por la cadena complementaria.

7. Checkpoints: También llamados "controles de comprobación". Son los mecanismos encargados de producir un retraso en la progresión del ciclo celular cuando existe algún problema, dando así a la célula el tiempo suficiente para solventarlos.

8. Rutas de tolerancia al daño: Nombre bajo el que se incluyen todos los mecanismos que capacitan a la célula para continuar una replicación que se encuentra bloqueada o parada, por la existencia de algún tipo de daño que altera la estructura del ADN.

Conocer el funcionamiento exacto de estas rutas, se ha convertido en los últimos años en uno de los centros de la investigación básica del cáncer, ya que la desregu- 
lación de los componentes de las mismas, se traduce en la mayoría de los casos en el desarrollo de tan temida enfermedad. Aunque el trabajo llevado a cabo para el desarrollo de esta Tesis Doctoral, se centra en el campo de la tolerancia al daño, comenzaremos este capítulo explicando brevemente el funcionamiento de las otras rutas.

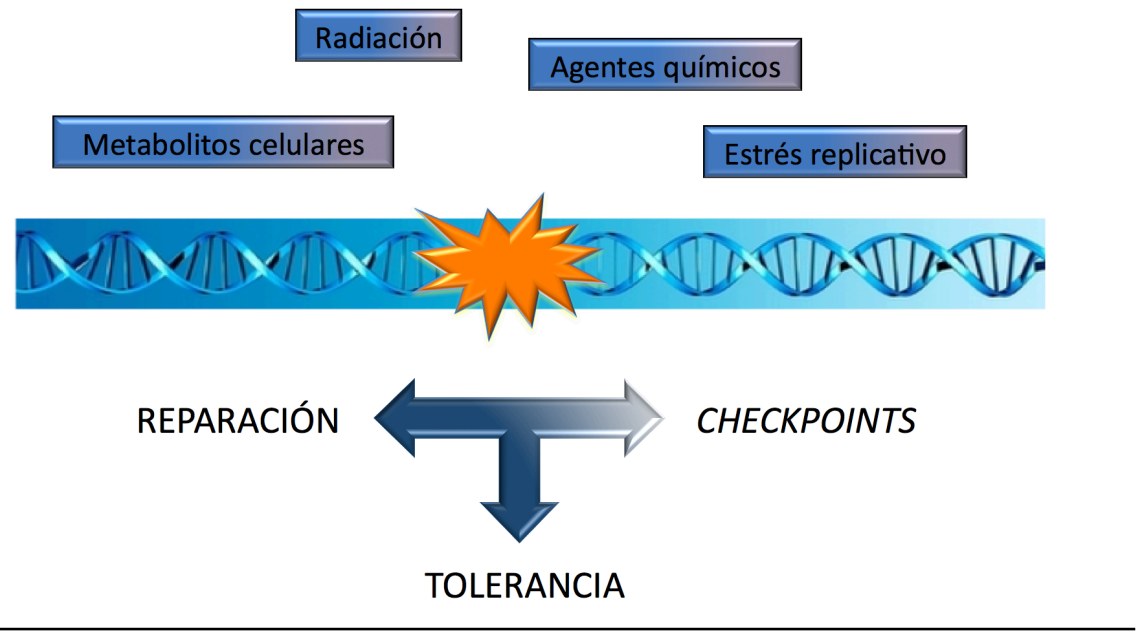

Figura 1: Respuestas celulares al daño. Ilustración esquemática de las distintas respuestas posibles de las células, ante la presencia de daño en el ADN.

\section{Rutas de reparación del daño en el ADN}

Son varios los mecanismos de reparación de los que dispone la célula para hacer frente a diferentes tipos de daños (Figura 2). De forma general se distinguen entre sí en el tipo de daño que reconocen, el momento del ciclo celular en el que actúan y en la maquinaria enzimática que utilizan. Sin embargo, a pesar de estas diferencias, todos ellos comparten el mismo esquema general de actuación, consistente en la identificación y eliminación del fragmento de ADN dañado, restablecimiento de la secuencia original a través de una ADN polimerasa (la cual utilizará la hebra no dañada como patrón) y por último, en la unión de la brecha formada por medio de una ADN ligasa.

\subsection{REPARACIÓN POR ESCISIÓN DE BASE: BER}

El mecanismo de reparación por escisión de base o BER (del inglés $\underline{B} a s e$ Exxision Repair), se ocupa de corregir diferentes tipos de lesiones que afectan a una sola hebra del ADN. Todas las lesiones reparadas por esta vía, tienen en común la producción de modificaciones poco voluminosas en el ADN, que afectan levemente al apareamiento de bases y que por lo tanto, no distorsionan mucho la estructura de la doble hélice. Ejemplos típicos de lesiones reparadas por esta vía son: la presencia de bases modificadas químicamente por alquilación, oxidación, o desaminación (Lindahl and Wood 1999); la inserción de bases modificadas por una ADN polimera- 
sa (dUTP, 8-oxodGTP) (Dianov et al. 1992; Singhal et al. 1995); la pérdida espontánea de una base generando sitios abásicos (Fortini et al. 2003); así como roturas de ADN de cadena sencilla (Lindahl 1990).

El desarrollo de este mecanismo se lleva a cabo por una batería de enzimas, las ADN glucosilasas, que se encargan de identificar y eliminar la base dañada. Como consecuencia de esta eliminación, se generará un azúcar desoxirribosa sin base nitrogenada, que será eliminado a continuación por una AP endonucleasa. La ADN Polimerasa $\beta$ será la encargada de sintetizar el oligonucleótido que falta para que a continuación, una ADN ligasa, se encargue de sellar la muesca (Sancar et al. 2004).

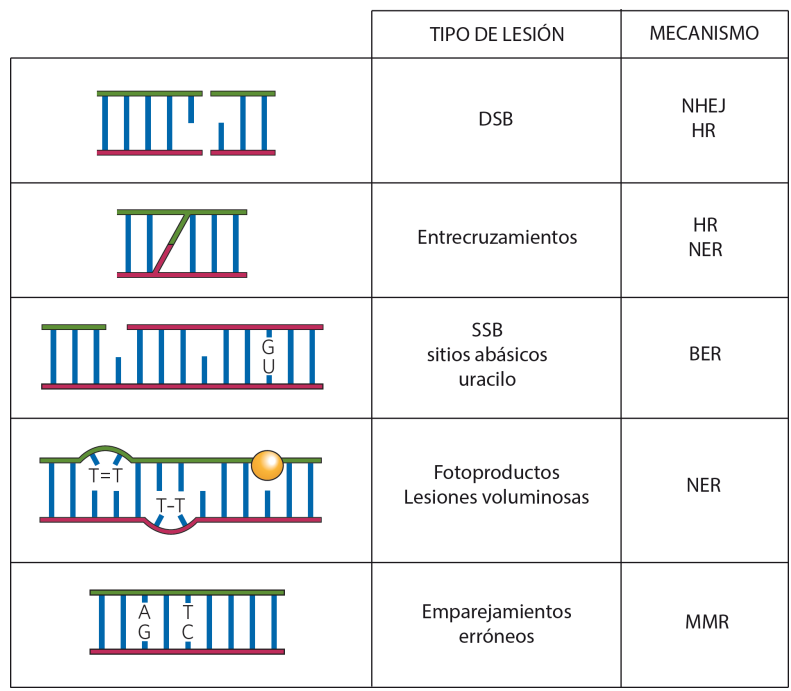

Figura 2: Mecanismos de reparación del ADN: Representación esquemática de los diferentes tipos de daño que puede sufrir el ADN, así como de las rutas de reparación que se encargan de ellos. Las celdas señaladas con el asterisco rojo, hacen referencia a la posibilidad de utilizar (además de los mecanismos indicados) las rutas de tolerancia al daño, en caso de que dichas lesiones se encuentre durante la Fase $\mathrm{S}$ del ciclo celular. Figura modificada de Bergink \& Jentsch 2009.

\subsection{REPARACIÓN POR ESCISIÓN DE NUCLEÓTIDO: NER}

Al igual que BER, este mecanismo de reparación actúa sobre lesiones que solo afectan a una de las dos cadenas del ADN, sin embargo, a diferencia de él, las lesiones sobre las que actúa son voluminosas y sí distorsionan la estructura de la doble hélice. Como ejemplo de lesiones reparadas por esta vía, se encuentran las que se generan a través de la reacción covalente de las bases nitrogenadas con grandes moléculas de hidrocarbonos (como el compuesto carcinógeno benzopireno), o con varios dímeros de pirimidinas (T-T, T-C y C-C) generados por acción de la luz solar.

Aunque se han descrito dos tipos de NER (del inglés Nucleotide Exxision $\underline{\text { Repair) en }}$ función de dónde se localice la lesión, el desarrollo de la reparación será el mismo en ambos casos. Tras la identificación del problema, una serie de helicasas desenro- 
Ilarán la doble hélice, generando una burbuja de unos 30 pares de bases alrededor de dicha lesión. A continuación, la hebra no dañada será recubierta por la proteína replicativa A o RPA (del inglés $\underline{R}$ eplication Protein $\underline{A}$ ), dejando a la hebra dañada desnuda para que pueda ser reconocida por nucleasas específicas de esta ruta, que se encargarán de hacer cortes a ambos lados de la lesión, eliminado el fragmento de 30 pares de bases. Finalmente, un proceso de síntesis y ligación posterior, resultará en una reparación exitosa (Friedberg 2001).

Este mecanismo ha sido muy bien caracterizado, ya que la mutación de cualquiera de las proteínas implicadas en esta ruta, conllevará al desarrollo de la enfermedad conocida como Xerodermia Pigmentosa (XP). XP es una enfermedad autosómica recesiva, que confiere a los pacientes que la presentan, una mayor predisposición a desarrollar cáncer de piel como consecuencia de la exposición a la luz ultravioleta. La existencia de esta enfermedad por lo tanto, pone de manifiesto la trascendencia de NER en la reparación del daño producido por luz ultavioleta.

\subsection{REPARACIÓN DE APAREAMIENTOS ERRÓNEOS: MMR}

MMR (del inglés Mis $\underline{M} a t c h \underline{R}$ epair), es el mecanismo encargado de restaurar los errores producidos durante la replicación, eliminando los nucleótidos incorrectamente incorporados por las ADN polimerasas, así como los fragmentos nucleotídicos producidos como consecuencia del deslizamiento de éstas cuando replican secuencias repetitivas o durante la recombinación (Jiricny 2006). Esta falta de coincidencia será reconocida y eliminada por la acción de varias proteínas diferentes, algunas de las cuales también están presentes en NER (Schofield and Hsieh 2003). La maquinaria de replicación hará entonces un segundo intento con el fin de replicar el ADN correctamente.

\subsection{REPARACION DE ROTURAS DE DOBLE CADENA}

Las lesiones que afectan a las dos hebras de la doble hélice, son muy peligrosas para la célula por no disponer de ninguna hebra libre de daño para llevar a cabo la reparación. Las roturas de este tipo se producen de manera fisiológica durante la replicación y la meiosis (Shinohara and Ogawa 1995; Michel et al. 1997), pero también se pueden producir por efecto de la radiación ionizante (Morgan et al. 1996; Ward 2000), agentes oxidantes, errores en las rutas de reparación, así como por productos del metabolismo celular (Karanjawala et al. 2002). Disponer de rutas de reparación para estas DSB (del inglés $\underline{D}$ ouble Strand $\underline{B}$ reak), será vital para las células, ya que si no se reparan, estas roturas darán lugar a pérdida de material genético y muerte celular, o a reordenamientos cromosómicos que deriven en carcinogénesis (Mills et al. 2003).

Los mecanismos de los que dispone la célula para reparar estas DSB son dos: la recombinación homóloga o HR (del inglés Homologous Recombination) y la unión de 
extremos no homólogos o NHEJ (del inglés Non- $\underline{H}$ omologous Ennd-Joining), siendo este último el mecanismo de reparación más sencillo.

A través de la recombinación homóloga, las células repararán el fragmento de ADN dañado, utilizando la información genética de la cromátida hermana o del cromosoma homólogo. Para ello dispondrán de unas proteínas de recombinación especiales, que serán capaces de reconocer y acercar entre sí las zonas de homología entre dos cromosomas. Una vez próximas dichas zonas, el cromosoma dañado será reparado a través de un proceso de replicación, utilizando como molde la información genética del cromosoma no dañado. Este hecho garantizará que no se produzca ningún cambio en la secuencia del cromosoma dañado.

Por otro lado, el mecanismo NHEJ, más sencillo que el anterior, yuxtapone directamente los extremos rotos de los cromosomas, para unirlos a continuación sin ningún tipo de homología, aunque produciendo eso sí, la perdida de uno o más nucleótidos en el punto de unión. Es por este motivo, que a este mecanismo de reparación se le considera mutagénico.

La preferencia por un mecanismo u otro es diferente en cada tipo celular. Así, mientras que en las células de mamíferos el mecanismo predominante a lo largo de todo el ciclo celular es NHEJ (estando la HR restringida a Fase S tardía y G2) (Lieber 2008), en las levaduras lo es la HR (aunque en G1, NHEJ es el mecanismo predominante) (Aylon et al. 2004; Ferreira and Cooper 2004; Ira et al. 2004; Sonoda et al. 2006).

\section{Checkpoints}

Ya que es vital para la célula mantener el ADN intacto y sin daños de una generación a la siguiente, no es de extrañar que éstas dispongan de más de un mecanismo para conseguir tal fin. Aparecen así en escena los mecanismos denominados checkpoints.

Parece implícito hablando de "daños" en el ADN, que lesiones en la estructura de éste sean los únicos problemas que desencadenan la activación de los checkpoints. Sin embargo, para la célula existen muchas otras situaciones problemáticas que conllevan a la activación de estos mecanismos.

Existen por lo tanto diferentes tipos de checkpoints, en función de cuál sea el problema y en qué momento del ciclo celular tengan lugar. A pesar de estas diferencias, todos ellos se pueden describir como cascadas de señalización para regular la progresión por el ciclo celular, con el fin de asegurar la estabilidad del material genético, así como su replicación y distribución adecuada, además de garantizar el mantenimiento de la homeostasis interna. 
Ya que no es objeto de esta tesis aportar ningún dato más acerca de los checkpoints, a continuación explicaremos sólo sucintamente los principales tipos descritos.

- Checkpoint de daño al ADN: Se activa cuando se detectan roturas o alteraciones en la estructura normal de la cadena de ADN, con el fin de parar el ciclo celular y reparar el ADN si es posible. Este checkpoint evita la transmisión de mutaciones a las células hijas y por lo tanto, contribuye al mantenimiento de la estabilidad genómica de dichas células.

- Checkpoint de G1: Existe un punto denominado Start en levaduras (del inglés, inicio) y Punto de Restricción en células animales. En dicho punto, la célula "decide" si inicia un ciclo de división o no, teniendo en cuenta que el tamaño celular sea el correcto y que haya suficientes nutrientes en el medio; coordinando así la división celular con el crecimiento y las condiciones ambientales. El checkpoint de esta fase, será el encargado de determinar si esas condiciones son o no las adecuadas.

- Checkpoint de replicación o de estrés replicativo: Se activa en respuesta a determinados problemas que afectan (en ausencia de daño directo al ADN) a la replicación, pudiendo inducir incluso su parada.

- Checkpoint de G2: Es el encargado de impedir la entrada en mitosis si la célula no ha alcanzado el tamaño necesario o si las condiciones del medio son desfavorables. Además, también bloqueará el ciclo celular si la replicación no se ha completado normalmente.

- Checkpoint de mitosis: en realidad son varios los puntos de control que existen en esta fase. Su función consiste en impedir la división celular si los diferentes pasos que se tienen que producir en esta fase, no han ocurrido correctamente. Por ejemplo, el checkpoint de metafase retrasará la segregación de los cromosomas, si estos no se han alineado correctamente en la placa metafásica.

\section{Tolerancia}

El último de los mecanismos de los que dispone la célula para asegurar su superviviencia una vez se vea comprometida la integridad del genoma, es el conocido como Rutas de tolerancia al daño.

Como su propio nombre indica, las rutas que se esconden bajo este nombre darán a la célula la capacidad para continuar la progresión por el ciclo celular, "tolerando" el daño, en lugar de "reparándolo" (Lehmann 2002; McGlynn and Lloyd 2002). A priori, la adquisición de estos mecanismos por parte de la célula a lo largo de la evolución, no parece ser muy ventajoso por todos los riesgos que conlleva continuar dividiéndose en presencia de lesiones que alteren la secuencia del genoma. 
Sin embargo, si recordamos que los mecanismos de reparación, ni son infalibles, ni son capaces de activarse cuando la célula se está replicando (ya que actúan principalmente sobre el dúplex de $A D N$ ), entenderemos por qué la ganancia de estos mecanismos ha constituido un enorme logro para la célula.

Las rutas de tolerancia al daño requieren un escenario especial para su activación. Dicho escenario está constituido por una Fase $\mathrm{S}$ en la que existen, independientemente de su etiología, lesiones que han provocado un bloqueo o parada de la replicación. Este estancamiento se debe a que las polimerasas replicativas, Pol$\delta$ y Pole, no son capaces de pasar por los sitios dañados, ya que cualquier tipo de lesión en el ADN, provocará un cambio estructural en su geometría, que no podrá ser acoplado en el centro activo de estas polimerasas (Baynton and Fuchs 2000). Esta situación de "parada", es tremendamente problemática para la célula, ya que un estancamiento prolongado de las horquillas de replicación, puede generar colapsos de horquillas, roturas de doble cadena, anomalías cromosómicas, inestabilidad genómica, acabando incluso en muerte celular. Que las células tengan o no la capacidad de terminar dicha replicación, será por lo tanto determinante para la superviviencia celular (Paulsen and Cimprich 2007; Cimprich and Cortez 2008).

Los mecanismos de tolerancia al daño, son los mecanismos encargados de otorgar a la célula esa capacidad para terminar con una replicación bloqueada, ofreciendo para ello dos alternativas distintas: la vía error prone o TLS (acrónimo del inglés Trans-Lesion Synthesis, Síntesis a través de lesiones) y la vía error free o de intercambio de molde.

Estas dos opciones difieren entre sí en su potencial para causar mutaciones. Así, en la primera de las opciones, conocida como Síntesis a través de lesiones (TLS), el ADN dañado será replicado a costa de intercambiar las polimerasas replicativas estancadas, por otro tipo de polimerasas especiales (Shcherbakova and Fijalkowska 2006) que sí serán capaces de replicar ese ADN, aunque no necesariamente con mucha fidelidad (Pages and Fuchs 2002); de ahí que también se conozca a esta ruta como vía error prone (Lehmann et al. 2007; Waters et al. 2009). A través de la segunda opción, la célula utilizará alternativas de replicación consistentes en evitar replicar directamente el ADN dañado, utilizando en su lugar como molde el ADN complementario. Este mecanismo asegurará la no introducción de mutaciones en la célula, de ahí que también se le conozca como vía error free (Michel et al. 2001; Cox 2002; McGlynn and Lloyd 2002; Heller and Marians 2006).

Aunque la mayoría de las aportaciones hechas en el campo de la tolerancia provienen de los últimos 10 años, hay que irse mucho más atrás en el tiempo, para encontrar los primeros trabajos que hablaron de la existencia de estas nuevas rutas celulares. 


\subsection{Una perspectiva histórica}

\subsubsection{Inicios en $E$. coli}

En 1968, Paul Howard-Flandes y Dean Rupp, publicaron los resultados obtenidos en el estudio de la replicación del ADN, en células de Escherichia coli expuestas a radiación ultravioleta; una de las causas que provoca parada en la replicación debido a la formación de fotoproductos. Flandes y Rupp observaron que después de la radiación, el ADN era inicialmente sintetizado como pequeños fragmentos discontinuos, convirtiéndose después en piezas de mayor peso molecular y de igual tamaño al observado en las células no irradiadas. A partir de estas observaciones postularon que, una vez provocado el bloqueo de la replicación por la formación de fotoproductos, ésta se reiniciaba a continuación aguas abajo de los sitios dañados que produjeron el arresto, pero dejando huecos justo enfrente de dichos sitios.

Bryn Bridges y Evelyn Witkin, especularon posteriormente que los espacios propuestos por Rupp y Howard-Flandes, podrían ser los sitios donde se generan las mutaciones que se sabe están asociadas a la radiación UV (Bridges 2005). Además, Witkin ya había demostrado previamente, que las mutaciones inducidas por radiación UV, no aparecían en las células portadoras de una mutación puntual en el gen LexA (gen encargado de regular la Respuesta SOS bacteriana), hecho que no parecía tener ningún efecto sobre la replicación discontinua observada por Flandes y Rupp (Witkin 1967). A raíz de estos resultados, Bridges y Witkin especularon que este proceso replicativo (hoy tolerancia) de fragmentos de ADN dañados, constaba de dos eventos diferentes, uno de los cuales es mutagénico ("error prone" en palabras de Witkin) y el otro libre de errores.

La siguiente aportación se realizó en el campo de la tolerancia error prone y vino de la mano de Miroslav Radman. Radman, en un trabajo publicado en 1974, postuló por primera vez la hipótesis de que en las células existe además de la replicación normal o "vegetativa", otro tipo de replicación "inducible" que se diferencia perfectamente de la primera y que requiere algunas funciones específicas. Trabajos genéticos posteriores identificaron los primeros genes que, fuera de la ruta SOS, parecían tener un papel directo en el mecanismo error prone, ya que células con dichos genes mutados, no presentaban las mutaciones inducidas por radiación UV. Estos genes fueron denominados umuC y umuD (del inglés $\underline{U V}$ non-mutable) (Kato and Shinoura 1977; Steinborn 1978; Steinborn 1979).

Los siguientes trabajos en el campo no aparecieron hasta 1990, momento en el que Harrison Echols y colaboradores, describieron que las proteínas codificadas por los genes umuC y umuD, eran modificadores de la polimerasa replicativa Pol III de $E$. coli, encargados de relajar su centro activo para que ésta fuese capaz de replicar el ADN dañado (Echols and Goodman 1990; Echols and Goodman 1991; Rajagopalan et al. 1992). Esta visión de "modificadores", no cambió hasta finales de los 90, cuando se demostró que estas proteínas en realidad no eran modificadores de las 
polimerasas replicativas, sino polimerasas per se (Reuven et al. 1999; Tang et al. 1999) pertenecientes a una gran familia de polimerasas especiales también identificadas en eucariotas (McDonald et al. 1997; Roush et al. 1998).

\subsubsection{Primeros descubrimientos en eucariotas}

El descubrimiento de la existencia de las rutas de tolerancia en eucariotas, tuvo lugar en 1981, al demostrar L. Prakash, que la replicación discontinua de ADN, posterior al tratamiento con UV, también existe en la levadura de gemación Saccharomyces cerevisiae. Prakash observó además, cómo en ausencia de NER, células mutantes en Rad6 y Rad18, no eran capaces de rellenar las brechas formadas (inducidas por luz UV) en la hebra recién sintetizada (Prakash 1981). A partir de este momento, rad $^{+}$se convirtió en el miembro fundador del grupo epistático de genes del mismo nombre.

El siguiente paso en el entendimiento de las rutas de tolerancia al daño, se dio con el descubrimiento de que el gen $\mathrm{rad}^{+}$codificaba una proteína conjugadora de ubiquitina (E2) (Jentsch et al. 1987) y que precisamente esta actividad enzimática era determinante para el buen funcionamiento de estas rutas (Sung et al. 1991). Trabajos posteriores en la identificación de un complejo estable entre Rad6 y Rad18 (Bailly et al. 1994), en la descripción de Rad18 como una ubiquitina ligasa E3 (Saurin et al. 1996), así como en la identificación de la diana de dicha ubiquitinación, PCNA

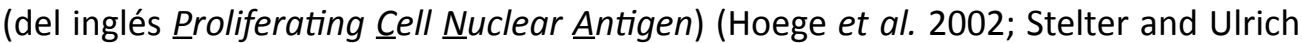
2003; Ulrich 2004), terminaron de establecer las bases moleculares de las rutas de la tolerancia al daño.

A partir de este momento saldrán a la luz muchos trabajos científicos, que corroborarán la importancia del papel de PCNA en el desarrollo de los mecanismos de tolerancia al daño. Es por ello que conocer a este antígeno nuclear, así como a la modificación post-traduccional que sufre, la ubiquitinación, se convertirá en algo imprescindible para entender el desarrollo de dichos mecanismos.

\subsection{PCNA}

PCNA o antígeno nuclear de células proliferantes (codificado por pol30 $0^{+}$y por $p c n 1^{+}$ en las levaduras de gemación y fisión respectivamente), es un homotrímero con forma de anillo, que actúa como una abrazadera deslizante sobre el ADN (Krishna et al. 1994; Fukuda et al. 1995; Bowman et al. 2004; Sakurai et al. 2005). Sirve como plataforma para una plétora de proteínas con múltiples funciones sobre el ADN, siendo una parte esencial para el desarrollo de las mismas. De todas las proteínas con las que interactua, probablemente las más famosas sean las polimerasas replicativas $\delta$ y $\varepsilon$, siendo totalmente necesario para que dichas polimerasas sean capaces de sintetizar miles de nucleotidos; motivo por el cual también se le conoce como factor de procesividad. 


\subsubsection{Descubrimiento de PCNA}

Sus orígenes fueron diversos, ya que fue identificado en distintos trabajos como proteínas diferentes. Fue descubierto por primera vez hace 35 años por Miyachi y colaboradores, como un antígeno en pacientes con Lupus Eritematoso (Miyachi et al. 1978). Por otro lado, en 1980, Bravo y Celis, descubrieron una proteína ácida que se expresaba de manera diferencial a lo largo del ciclo celular, por lo que le dieron el nombre de "ciclina" (Bravo et al. 1982). Dos años más tarde, Mathews y colaboradores, descubrieron que el "antígeno" y la "ciclina" eran en realidad la misma proteína. Ya que el nombre de "ciclina" fue asignado a otro tipo de proteínas, la abrazadera pasó a llamarse a partir de ese momento como PCNA.

A

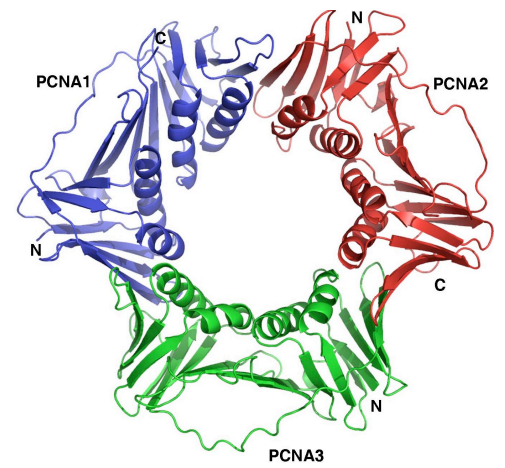

C
Humano

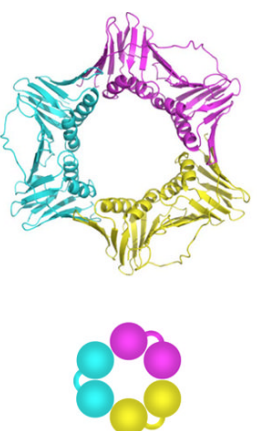

B

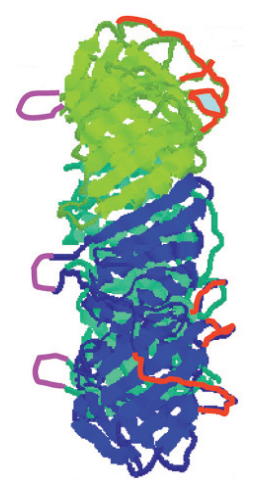

\section{Eubacterias}

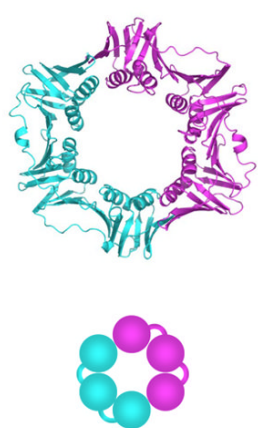

bacteriófago RB69

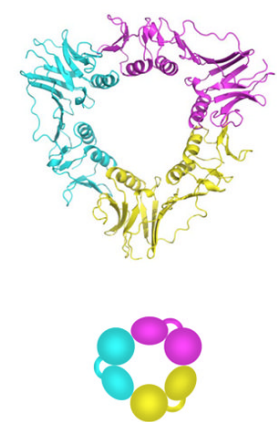

Figura 3: PCNA: A: Estructura en forma de anillo de la abrazadera deslizante, a partir de la unión de tres monómeros iguales. Como se observa, la parte interna del anillo está formada por hélices $\alpha$, mientras que la parte externa está constituida por láminas $\beta$. B: Vista lateral de PCNA, con los dominios de interconexión representados en naranja. Como se muestra en la figura, todos ellos sobresalen hacia el mismo lado de la abrazadera, la llamada Cara Frontal o Cara C de PCNA; cara por la que se producen todas las interacciones proteicas descritas hasta el momento. C: Estructura de la abrazadera en distintos sistemas. Aunque todos ellos presentan una disposición en anillo, las unidades por las que éste está constituido, son diferentes en cada caso. Figura modificada de Bloom 2009. 


\subsubsection{Estructura}

PCNA pertenece a la familia de las abrazaderas $\beta$. Está estructural y funcionalmente conservado tanto en procariotas como en eucariotas. Aunque apenas existe similitud entre las secuencias aminoacídicas (solo un 35\% entre levaduras y humanos), estudios cristalográficos ponen de manifiesto que en todos los organismos tiene una estructura tridimensional increíblemente parecida (Krishna et al. 1994; Naryzhny 2008), formando un anillo (homodímero en eubacterias, homotrímero en eucariotas y en el fago T4 y heterotrímero en arqueas) (Majka and Burgers 2004) (Figura 3) con simetría pseudohexamérica que rodea al ADN y que le permite deslizarse libremente en ambas direcciones.

El PCNA de eucariotas está organizado por lo tanto por tres monómeros iguales que se agrupan formando una estructural toroidal (Figura 3A). Cada monómero de PCNA, tiene dos dominios globulares similares, unidos entre sí por un dominio largo y flexible llamado dominio de interconexión. Una disposición cabeza-cola de los 3 monómeros, formará la ya conocida estructura en anillo de PCNA, en la cual se diferencian dos caras, una interna formada por hélices $\alpha$ y un externa formada por láminas $\beta$. Aunque la carga neta de PCNA es negativa, el anillo interno está cargado positivamente debido a su riqueza en residuos de arginina y lisina (10 por subunidad), hecho que garantiza un agarre eficiente entre la abrazadera y el dúplex de ADN cargado negativamente. Se estima que la estructura general del anillo trimérico de PCNA mide $\sim 30 \mathrm{~A}$ de espesor, $\sim 34 \mathrm{~A}$ en el diámetro interno y $\sim 80 \mathrm{~A}$ en el externo (Krishna et al. 1994; Gulbis et al. 1996).

En el anillo de PCNA se distinguen además dos caras bien diferenciadas. Una frontal y otra posterior, siendo la frontal la que contiene los dominios de interconexión y la que soporta todas las interacciones con las proteínas, ya que hasta el momento, ninguna interacción en su cara posterior ha sido identificada (Figura 3B).

\subsubsection{Interacciones y funciones de PCNA}

PCNA está desprovisto de actividad enzimática stricto sensu, por lo que las funciones que desempeña en la célula, radican en su papel como plataforma móvil para un sinfín de factores que actúan de forma concomitante con el ADN (Warbrick 2000; Maga and Hubscher 2003). Hasta la fecha se han identificado más de 100 proteínas que interactúan con PCNA (siempre por su cara frontal) sin modificar, o con alguna de sus formas modificadas (Moldovan et al. 2007). En la mayoría de estas proteínas se encuentra un dominio conservado denominado "caja PIP" (del in-

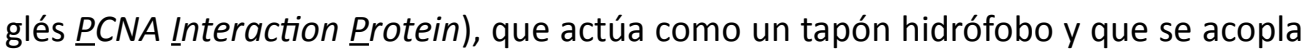
en el bolsillo hidrófobo de PCNA, el cual se encuentra enterrado bajo el dominio de interconexión (Gulbis et al. 1996; Bruning and Shamoo 2004). El elemento central de esta caja PIP es un péptido con la secuencia $Q \times x \Psi$ (siendo $\Psi$ cualquier residuo hidrófobo como $\mathrm{L}, \mathrm{H}, \mathrm{O} \mathrm{I}$ ), flanqueado en su extremo $\mathrm{C}$-terminal por la secuencia $x x \theta \theta$ (siendo $\theta$ alguno de los residuos aromáticos $\mathrm{F}$ o $\mathrm{Y}$ ) y en su extremo $\mathrm{N}$-termi- 
nal, por la secuencia KAx (Xu et al. 2001). Además, algunas de estas proteínas con cajas PIP, también utilizarán regiones adicionales para interaccionar con PCNA.

Es importante destacar que todas las proteínas que contienen cajas PIP, se unen a la misma región de PCNA (es decir, al bolsillo hidrófobo, al bucle del dominio de interconexión y a las regiones vecinas), por lo que la unión de estas proteínas será competitiva y excluyente. Sin embargo, ya que PCNA es un homotrímero, teóricamente será posible que varias proteínas con caja PIP se unan simultáneamente a PCNA.

\section{Funciones de PCNA:}

A partir del descubrimiento de estas interacciones, se han desarrollado muchos trabajos, con el fin de descubrir de qué manera está involucrada la abrazadera en distintos procesos celulares. A continuación, describiremos brevemente el papel que juega en alguno de ellos:

i. Replicación del ADN: Estimulando por un lado a las polimerasas replicativas $\delta$ y $\varepsilon$, y por otro coordinando el procesamiento y la unión de los fragmentos de Okazaki (Chapados et al. 2004; Pascal et al. 2004).

ii.Tolerancia al daño: Su ubiquitinación en el residuo K164, será la señal necesaria para la activación de las dos rutas de la tolerancia al daño. Los requerimientos moleculares y el desarrollo de cada una de estas dos vías, será descrito en el siguiente apartado.

iii. Prevención de la re-replicación: La replicación debe iniciarse una sola vez por ciclo celular en cada origen de replicación, para prevenir fenómenos tales como inestabilidad genómica o aneuploidía. Así, con el fin de evitar la re-replicación, la célula separa temporalmente el "licenciamiento" del inicio de la replicación (Diffley 2004), a través de varios mecanismos. Uno de estos mecanismos es la degradación por ubiquitinación de la proteína Cdt1, siendo esta degradación, dependiente de la interacción de dicha proteína con PCNA (Arias and Walter 2006). Cdt1 contiene una "caja PIP" a través de la cual interacciona con la abrazadera, de tal manera que, defectos en dicha interacción, se traducirán en una pérdida de ubiquitinación de Cdt1, estabilización de ésta y re-replicación.

iv. Prevención de la recombinación de cromátidas hermanas: A través de la modificación de la abrazadera por SUMO (del inglés Śmall Ú biquitin-like Modifier). Se ha observado que incluso en ausencia de daño en el ADN, tanto en la levadura de gemación, como en Xenopus y en células de pollo (aunque en estos últimos en menor medida), existe una pequeña fracción de PCNA que durante Fase $\mathrm{S}$ está modificada por dicha proteína (Hoege et al. 2002; Leach and Michael 2005; Arakawa et al. 2006). Dicha modificación ocurre en el residuo K164, el mismo en el que se produce la ubiquitinación que activa las rutas de tolerancia al daño. Sin embargo, PCNA de $S$. cerevisiae, también puede ser SUMOilado en el residuo K127 (que a diferencia de K164 es parte de un motivo consenso de SUMOilación, pero que no está presente en el 
PCNA de otros organismos (Ulrich 2007a)) localizado dentro del dominio de interconexión.

El fin de dicha modificación también ha sido un tema sujeto a debate. Por un lado se ha propuesto que dicha modificación es necesaria para activar las rutas TLS al igual que la ubiquitinación, solo que para determinados lugares dañados (Stelter and Ulrich 2003). Mientras, por otro lado, diversos estudios genéticos han puesto de manifiesto cómo la SUMOilación de PCNA, inhibe la reparación del ADN si la vía regulada por Rad6 no es funcional (Hoege et al. 2002; Pfander et al. 2005). En efecto, la SUMOilación de PCNA en la levadura de gemación (en cualquiera de los dos residuos mencionados), produce el reclutamiento de la helicasa Srs2; proteína antirrecombinogénica, por interrumpir la formación de los filamentos Rad51, cruciales para una recombinación homóloga exitosa (Papouli et al. 2005; Pfander et al. 2005; Watts 2006; Ulrich 2007b). Al parecer, la recombinación entre cromátidas hermanas dependiente de Rad52, representa una de las vías de recuperación para las horquillas paradas. Sin embargo, esta vía se mantiene bajo estricto control, por la SUMOilación de PCNA y el consiguiente reclutamiento de la helicasa Srs2 (Pfander et al. 2005). El motivo de este control, se debe a que el empleo de la recombinación como solución a las horquillas paradas, puede ser perjudicial para la célula, por conducir a la aparición de grandes reordenamientos cromosómicos deletéreos para la célula (Lambert et al. 2005). Por lo tanto, la formación del complejo PCNA-SUMO-Srs2, funcionará como un guardián encargado de impedir la recombinación entre cromátidas hermanas, quizá facilitando así el uso de las vías de tolerancia.

Quizá sea significativo que estando la SUMOilación de la abrazadera conservada en células de vertebrados (aunque de forma residual), en ellas no exista ningún homólogo de la helicasa Srs2 (Leach and Michael 2005; Arakawa et al. 2006). Aunque hasta el momento no se ha descubierto cuál es entonces la función de esta SUMOilación, sí se ha sugerido que distintas actividades antirecombinogénicas podrían estar reclutadas en eucariotas superiores por dicha modificación (Moldovan et al. 2007).

Por otro lado, la helicasa Srs2, sí está conservada en la levadura de fisión aunque sin el dominio que determina su interacción con SUMO. Este hecho sugiere que la regulación de la helicasa en dicha levadura, debe ocurrir por una vía diferente a la SUMOilación, hipótesis apoyada por el hecho de que en S. pombe no parece existir SUMOilación de PCNA (Frampton et al. 2006).

\section{v. Reparación de ADN dañado: a través de las rutas:}

- Reparación de apareamientos erróneos o MMR: no sólo porque interaccione con todas las proteínas implicadas en esta ruta, coordinando el reclutamiento ordenado y progresivo de todas ellas; si no porque la orientación de su carga (con la cara frontal situada hacia el extremo creciente de la hebra recién sintetizada) es imprescindible para la identificación de la lesión (Umar et al. 1996; Kadyrov et al. 2006; Modrich 2006). 
- Reparación por escisión de base o BER: ya que al igual que en MMR, PCNA interacciona con todas las proteínas implicadas en esta ruta, marcando el orden de intervención de las mismas (Oyama et al. 2004; Xia et al. 2005). Es importante destacar además, que al igual que con las polimerasas replicativas, PCNA es capaz de estimular la actividad de todas estas proteínas (Tsuchimoto et al. 2001; Unk et al. 2002).

- Reparación de escisión de nucleótidos o NER: debido a que PCNA interacciona con XPG (una de las endonucleasas que intervienen en este proceso) a través de la caja PIP que contiene. Sin este dominio, XPG no será capaz de interaccionar con la abrazadera, por lo que las células portadoras de esta mutación, no serán capaces de activar NER (Gary et al. 1997).

vi. Ensamblaje de cromatina: Aunque el mecanismo exacto se desconoce actualmente, las histonas de los nucleosomas parentales, son transferidas directamente a las dos hebras hijas durante la replicación. Para obtener el número original de nucleosomas, preservando así el estado de la cromatina, la mitad de los nucleosomas de las cadenas hijas deberán ser formados de novo desde histonas sintetizadas durante la Fase S. Diferentes chaperonas serán las encargadas de llevar a las histonas recién sintetizadas a los sitios de ensamblaje de la cromatina. Una de estas chaperonas es CAF-1, la cual presenta una caja PIP a través de la cual interacciona con PCNA. De nuevo, células mutantes en esta interacción, no serán capaces de focalizar correctamente a CAF-1 en la cromatina y por lo tanto presentarán defectos en el silenciamiento de genes (Zhang et al. 2000).

vii. Cohesión de las cromátidas hermanas: a través de su interacción con Eco1, proteína encargada de dicha cohesión. Una vez más la interacción entre ambas proteínas, se dará por medio de la caja PIP presente en Eco1. En ausencia de este dominio, Eco1 no podrá localizarse en la cromatina para desempeñar su función, por lo que las cromátidas hermanas no podrán cohesionar y la viabilidad celular se verá seriamente comprometida (Moldovan et al. 2006).

\subsection{Ubiquitinación}

La Ubiquitina es una proteína de 76 aminoácidos que está, como su propio nombre indica, extraordinariamente conservada a lo largo de la evolución (Glickman and Ciechanover 2002). La unión de esta pequeña proteína a sus sustratos, se produce mediante una cascada de reacciones enzimáticas que también está muy conservada.

El proceso de ubiquitinación comienza con la activación de la ubiquitina, mediante la formación dependiente de ATP, de un enlace tioéster entre el grupo carboxilo de la glicina del extremo C-terminal de la ubiquitina, con una cisteína de la enzima activadora de la ubiquitina, también denominada E1. En un segundo paso, la ubiquitina se transfiere, también mediante un enlace tioéster, a un residuo de cisteína de la 
enzima conjugadora de ubiquitina o E2. Finalmente, en una reacción catalizada por la proteína ubiquitin-ligasa o E3, se forma un enlace peptídico entre el extremo carboxilo terminal de la ubiquitina y el grupo $\varepsilon$-amino de un residuo de lisina de la proteína sustrato (Hershko and Ciechanover 1998) (Figura 4).

Esta cascada enzimática puede detenerse aquí formando un conjugado monoubiquitinado, o puede repetirse sucesivamente hasta sintetizar un conjugado formado por la proteína sustrato y una cadena de ubiquitinas. Estas cadenas se pueden formar de diferente manera, en función de cuál de los 7 residuos de lisina (K6, K11, K27, K29, K33, K48, y K63) se utilicen para unir a las ubiquitinas entre sí. La utilización de uno u otro dará a la proteína etiquetada un papel diferente dentro de la célula. Por todos estos motivos, la ubiquitinación posee una mayor complejidad y versatilidad, que la modificación post-traduccional por excelencia hasta la fecha, la fosforilación (Welchman et al. 2005).

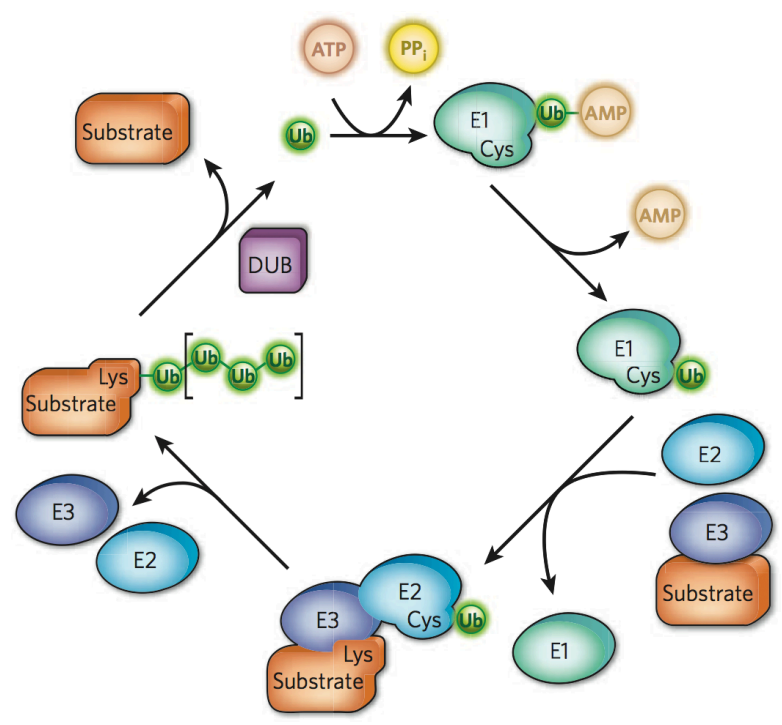

Figura 4: Cascada de ubiquitinación. A través de dicha cascada, la proteína diana quedará marcada con una o con varias moléculas de ubiquitina, en un proceso dependiente de ATP en el que participan tres enzimas: E1 o proteína activadora de ubiquitina, E2 o proteína conjugadora de ubiquitina y E3 o proteína ubiquitina ligasa. Además, enzimas especiales denominadas DUBs, serán capaces de revertir dicha modificación post-traduccional. Adaptada de Hochstrasser 2009.

Aunque la ubiquitinación en su origen fue descrita como una señal post-traduccional, que marcaba a las proteínas hacia un inevitable destino degradativo vía proteasoma (Goldberg and Rock 1992; Coux et al. 1996; Zachariae and Nasmyth 1999), hoy sabemos que esto sólo es así, si la proteína diana es marcada con una cadena de ubiquitinas unidas entre sí a través del residuo K48. El resto de uniones no canónicas, ya sea a través de alguna de las otras lisinas presentes, o a través de la adición de una única molécula de ubiquitina al sustrato (Ikeda and Dikic 2008), traerán consigo la activación de distintas vías no degradativas. 
Dos ejemplos de uniones no canónicas ocurren en la abrazadera deslizante. En primer lugar, PCNA puede ser exclusivamente monoubiquitinado, pero además, en segundo lugar, también puede ser poliubiquitinado a través de uniones K63. En ambos casos, dichas modificaciones post-traduccionales, conllevarán a la activación de vías no degradativas; de tal modo que la monoubiquitinación de la abrazadera, conllevará a la activación de la vía TLS de la tolerancia al daño y la poliubiquitinación, a la de la vía error free.

Al igual que el resto de modificaciones post-traduccionales, la ubiquitinación también posee su proceso antagónico, la desubiquitinación. Las proteínas encargadas de llevar a cabo este proceso, conocidas como desubiquitinasas (DUBs), serán descritas en profundidad más adelante.

Conocidos ya los protagonistas moleculares de la tolerancia, así como la modificación post-traduccional que la regula, la ubiquitinación, pasaremos a continuación a explicar en detalle el funcionamiento de las dos rutas de la tolerancia al daño.

\subsection{Señal de activación y requerimientos moleculares de la tolerancia}

Como ya se ha mencionado en el apartado anterior, la célula dispone de dos alternativas diferentes para rescatar las horquillas de replicación estancadas, sin tener que reparar la lesión que produjo el bloqueo de las mismas (Lehmann 2002; McGlynn and Lloyd 2002). Estas alternativas difieren entre sí, en la precisión con la que rellenan la posición opuesta a la lesión, de ahí que sean llamadas como vía error free y vía error prone.

Dada la diferente naturaleza de estas dos vías, parece implícito que los requerimientos moleculares de cada una de ellas tengan que ser distintos. Sin embargo, aunque así es en última instancia, es importante constatar que no lo es en el origen de las mismas, ya que tanto la señal de activación, como las proteínas que transmiten dicha señal, son las mismas en ambas rutas.

Todos los datos moleculares que se describan a partir de este momento (salvo que se indique lo contrario), se referirán a la levadura de gemación $S$. cerevisiae, ya que las herramientas genéticas disponibles en este organismo modelo, han permitido el análisis más detallado de todos y por lo tanto la mejor caracterización de estas rutas.

\subsubsection{Activación de las rutas de tolerancia al daño}

Durante una Fase $S$ sin daños, se produce una sincronía total entre el avance de la helicasa que desenrolla el ADN y las polimerasas replicativas. Sin embargo, cuando se produce una lesión que altera la estructura del ADN (ya sea causado por daño endógeno o exógeno), se produce un desacople entre las actividades de dichas pro- 
teínas, ya que mientras que la helicasa no se ve afectada por la lesión, las polimerasas se quedarán atascadas por la incapacidad de acoplar sus centros activos a esas estructuras distorsionadas del molde (Byun et al. 2005). Dicho desacople originará un fragmento de ADN de cadena sencilla que rápidamente será recubierto por la proteína RPA (Iftode et al. 1999; Fanning et al. 2006; Zou et al. 2006), constituyendo así la única señal necesaria para que se activen las rutas de tolerancia al daño (Figura 5).

El siguiente paso en la transmisión de la señal, vendrá dado por la acumulación de la E3 Rad18 en esos sitios estancados (Davies et al. 2008). Debido a la gran afinidad que presenta esta E3 por PCNA y por la E2 Rad6, se formará un complejo proteico entre ellos, que resultará en la monoubiquitinación de la abrazadera en el residuo K164 (Figura 6) (Hoege et al. 2002; Stelter and Ulrich 2003). Esta modificación posttraduccional, la monoubiquitinación de PCNA, será la única señal necesaria para la activación de la vía error prone de la tolerancia al daño. Sin embargo, para la activación de la ruta error free, será necesario un paso más, consistente en la poliubiquitinación de la abrazadera a través de uniones ubiquitina-K63, por acción del complejo formado por las E2 Mms2-Ubc13 y la E3 Rad5 (Hoege et al. 2002) (Figura 6).

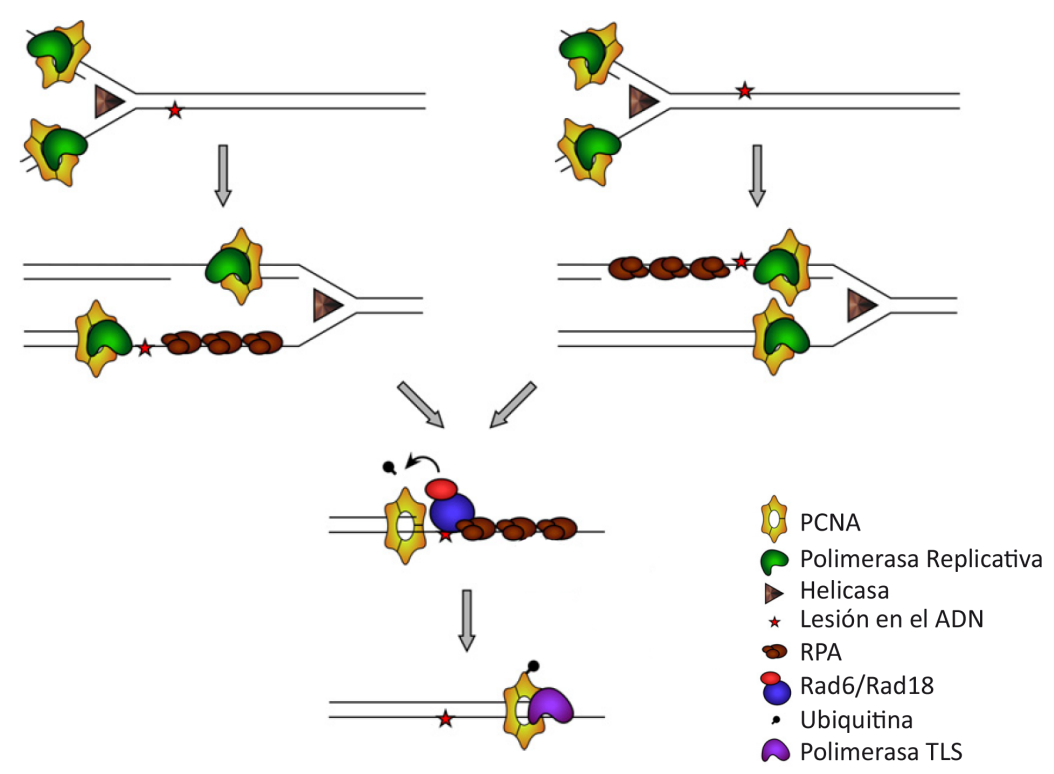

Figura 5: Señal de activación de las rutas de tolerancia; papel de RPA. La presencia de lesiones en la hebra molde, provoca un desacople entre las funciones de la helicasa y la ADN polimerasa (izquierda), formándose un fragmento de ADN de cadena sencilla que será recubierto por la proteína RPA. Alternativamente, la maquinaria de replicación puede continuar (derecha) dejando un hueco en la hebra hija, que de igual modo será recubierto por RPA. En ambos casos, la acumulación de dicha proteína, producirá el reclutamiento del complejo Rad6/Rad18, para ubiquitinar a la abrazadera deslizante, con el fin de activar las rutas de Tolerancia al daño. Figura modificada de Ulrich 2009. 


\subsubsection{Ruta TLS}

Como ya se ha descrito, la síntesis a través de lesiones o vía error prone, es una de las opciones que tiene la célula, para continuar con una replicación bloqueada por la presencia de lesiones que no pudieron ser reparadas antes de Fase S. Estas lesiones suponen una barrera para las polimerasas replicativas, por su incapacidad para acoplar sus centros activos a estas lesiones (Byun et al. 2005), pero no para unas polimerasas especiales llamadas polimerasas TLS, que sí serán capaces de hacerlo (Friedberg 2005). Estas polimerasas especiales, serán la clave para el correcto desarrollo de esta alternativa de la tolerancia al daño.

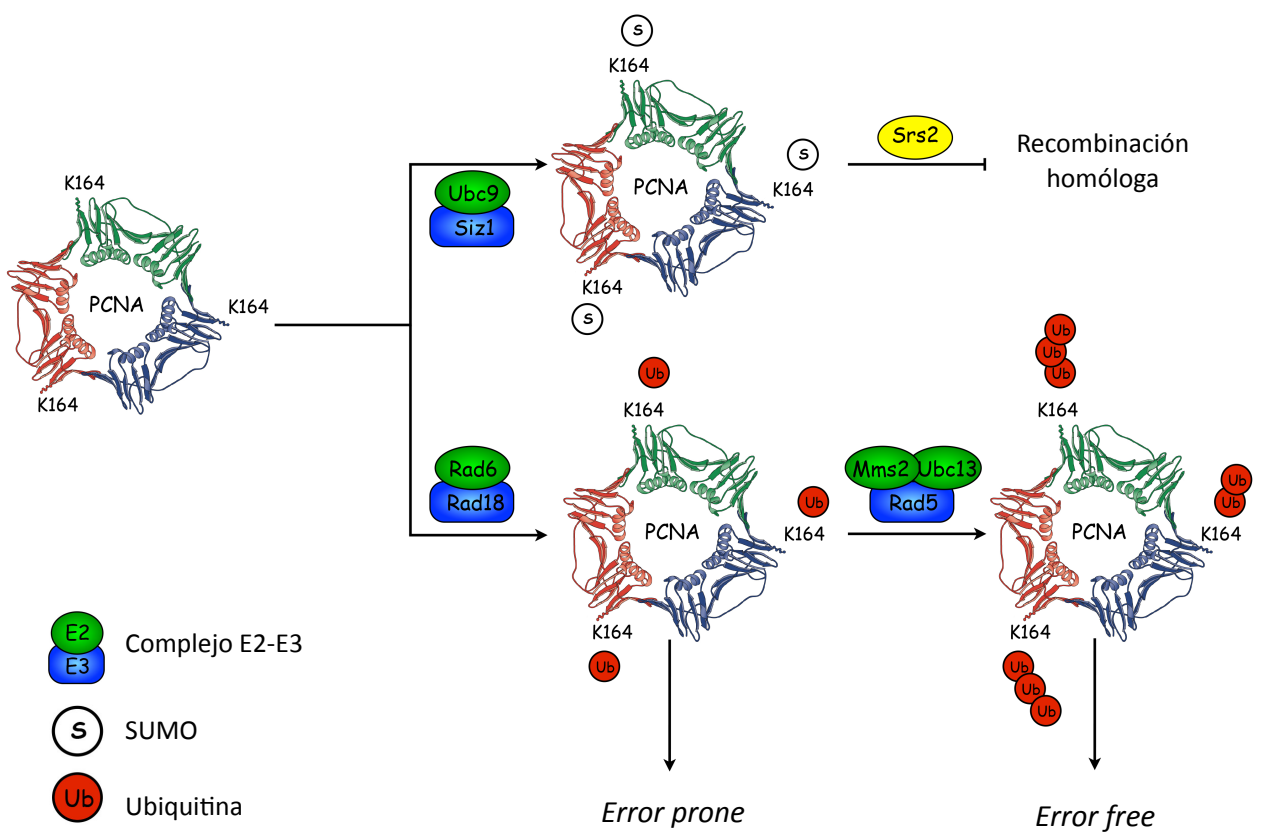

Figura 6: Esquema general de ubiquitinación y SUMOilación de PCNA, y la activación de las rutas de tolerancia al daño. Todas las proteínas que se indican pertenecen a la levadura de gemación Saccharomyces cerevisiae.

\section{i. Polimerasas TLS}

En base a las relaciones filogenéticas, las ADN polimerasas han sido agrupadas en 6 familias distintas llamadas: A, B, C, D, X e Y; siendo la Y la familia que acoge a todos los miembros de las polimerasas TLS de todos los organismos, excepto a Pol $\zeta$, que pertenece a la Familia B (familia en la que también se encuentran las polimerasas replicativas $\alpha, \delta$ y $\varepsilon$ ). La singularidad de esta familia, radica en su capacidad para replicar ADN a través de lesiones (Ohmori et al. 2001; Prakash et al. 2005), sin embargo, la fidelidad con la que abordan tal fin, será diferente en cada una de las polimerasas, aunque en términos generales, será mucho menor que la que presentan las polimerasas replicativas (Kunkel 2004). 
Para ser capaces de replicar un molde dañado, las polimerasas TLS disponen de unas características únicas y especiales. Sin embargo, como polimerasas que son, también compartirán con el resto las siguientes propiedades:

- Mecanismo de polimerización. Como el resto de polimerasas, catalizan el ataque nuleofílico del grupo $3^{\prime} \mathrm{OH}$ del desoxirribonucleósido monofosfato (dNMP) en posicion $3^{\prime}$ de la cadena que está siendo sintetizada, conocida como iniciador o cebador, sobre el fosfato $\alpha$ del desoxirribonucleótido trifosfato (dNTP) que va a ser incorporado.

- Necesitan la existencia de un extremo iniciador o cebador que aporte el grupo 3'OH.

- Utilizan desoxirribonucleótidos para llevar a cabo la polimerización del ADN, mediante la incorporación de un residuo dNMP a la cadena cebadora, con la posterior liberación de una molécula de pirofosfato.

- Necesitan la presencia de dos iones metálicos divalentes, preferentemente $\mathrm{Mg}^{2+}$ (Steitz et al. 1994), que actúen como cofactores en dicha reacción.

- Realizan la síntesis del ADN de manera unidireccional, desde el extremo 5' al extremo 3' de la cadena de ADN.

- Se pliegan en forma de mano (Beard and Wilson 2003), presentando los tres dominios característicos de todas las polimerasas: "palma" (base de contacto con el ADN), "dedos" y "pulgar" (encargados de regular la interacción con el nucleótido entrante). Sin embargo, a pesar de esta estructura conservada, también presentan una serie de diferencias que serán determinantes para su función durante la replicación en presencia de daños. Estas diferencias serán explicadas en el siguiente apartado.

\section{Estructura de las polimerasas TLS}

Además de los tres subdominios estructurales ya descritos: "palma", "dedos" y "pulgar", las polimerasas TLS presentan un cuarto subdominio denominado "meñique" (para continuar con la analogía de "mano") solo presente en ellas (Ling et al. 2001).

El núcleo catalítico de estas polimerasas está formado por los primeros 250-350 residuos, los cuales constituyen los tres subdominios presentes en todas las polimerasas (Yang and Woodgate 2007) (Figura 7). Dichos subdominios presentan tanto diferencias como similitudes importantes con los de las polimerasas replicativas. Por ejemplo, aunque no exista ningún tipo de homología en la secuencia aminoacídica, el subdominio "palma" está muy conservado al resto de las familias, ya que los tres grupos carboxilos esenciales para la catálisis, se encuentran estructuralmente localizados en el mismo lugar (Yang 2005). Respecto a las estructuras de los subdominios "pulgar" y "dedos", éstas varían ampliamente en las diferentes familias de polimerasas, aunque tanto su ubicación en la estructura terciaria, como sus funciones en la interacción con el ADN y con los sustratos de nucleótidos, están conserva- 
das. Probablemente, una de las diferencias más importantes en estos subdominios sea su tamaño, siendo los de estas polimerasas significativamente más pequeños (Yang and Woodgate 2007).

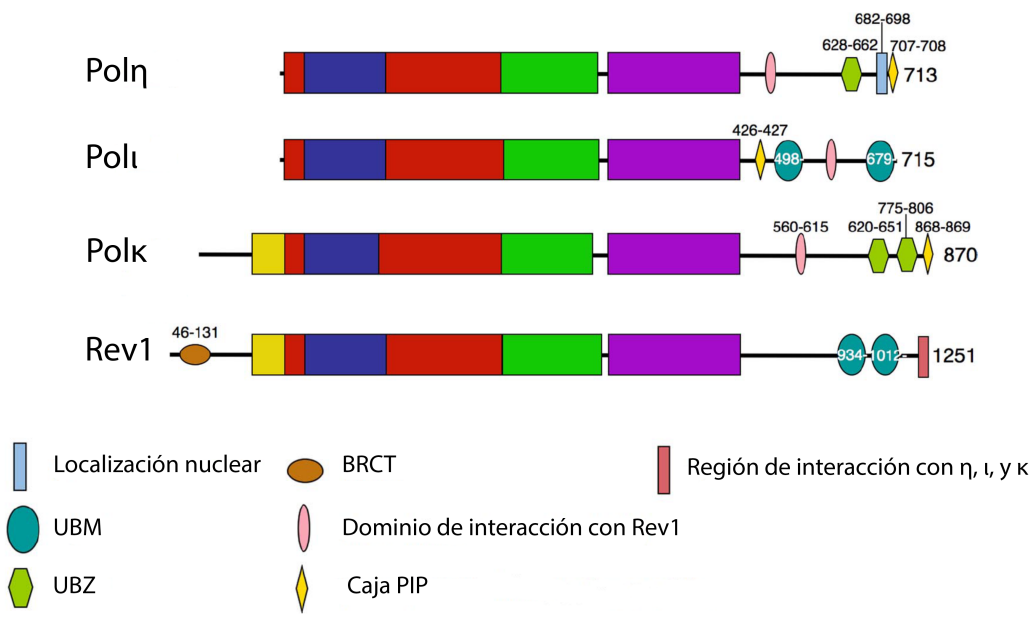

Figura 7: Dominios estructurales de las polimerasas humanas de la Familia Y. En rojo, azul y verde, se representan los subdominios "palma", "dedos" y "pulgar" respectivamente. La región representada en morado, se corresponde con el subdominio específico de esta familia, el subdominio "meñique". Además, todas ellas representan dominios adicionales necesarios para desempeñar distintas funciones. En la parte de abajo de la figura se muestra la leyenda de cada uno de estos dominios. Figura modificada de Yang \& Woodgate, 2007.

En el extremo $C$ terminal del núcleo catalítico de estas polimerasas, se encuentra el subdominio característico de esta familia, el subdominio "meñique" (Ling et al. 2001; Trincao et al. 2001). Está formado por unos 100 residuos y su disposición varía mucho de unas polimerasas a otras (Silvian et al. 2001; Uljon et al. 2004), otorgando así probablemente diferentes funciones a las mismas (Ling et al. 2003; Rechkoblit et al. 2006). Sin embargo, a pesar de que este subdominio sea el específico de esta familia de polimerasas, la capacidad de incorporar nucleótidos en frente de moldes no aptos para las polimerasas replicativas, no viene dada por él, si no que se debe a la presencia de amplios sitios catalíticos preformados, capaces de acomodar fácilmente los grupos químicos voluminosos del molde de ADN dañado (Figura 8) (Ling et al. 2001). Esta característica estructural, sí es la que constituye la gran diferencia entre las polimerasas replicativas y las de la Familia Y.

Al poseer este "amplio" sitio activo, estas enzimas no solo son tolerantes a la hora de acomodar lesiones voluminosas en él, si no que también lo son a la hora incorporar pares de bases que no cumplen las estrictas reglas de apareamiento de Watson y Crick. En consecuencia, las polimerasas de la Familia Y, exhibirán una fidelidad más baja que las replicativas, haciendo de TLS un mecanismo a menudo propenso a errores. 

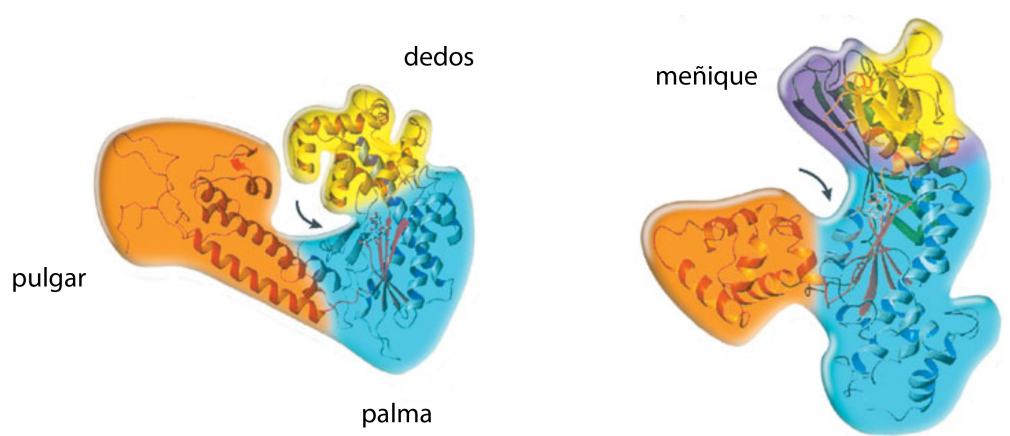

Figura 8: Estructura de las polimerasas TLS. Estructura tridimensional de una polimerasa de alta fidelidad (izquierda) y de una TLS (derecha). Como se observa, el sitio catalítico de la polimerasas TLS (indicado con una flecha), es mucho más amplio que el de las polimerasas de alta fidelidad. Esta característica estructural, es lo que otorga a estas polimerasas su capacidad para replicar moldes dañados, aunque también es lo que determina su tendencia a introducir mutaciones en el genoma. Figura modificada de Friedberg 2005.

En la Tabla 1 se muestran las polimerasas pertenecientes a la familia $Y$ en distintos

\begin{tabular}{|c|c|c|c|}
\hline \multicolumn{4}{|c|}{ Polimerasas TLS (Familia Y) } \\
\hline Denominación griega & H. sapiens & S. pombe & S. cerevisiae \\
\hline Poln (eta) & POLH & eso1 $^{+}$ & RAD30 \\
\hline Polı (iota) & POLI & - & - \\
\hline Polk (kapa) & POLK & $\operatorname{dinB}^{+}$ & - \\
\hline & Rev1 & Rev1 & Rev1 \\
\hline
\end{tabular}

Tabla 1: ADN polimerasas eucariotas de la familia Y.

organismos.

Además de la estructura relajada de sus centros activos, las polimerasas de la Familia $\mathrm{Y}$, presentan otra serie de características que resultarán imprescindibles para el correcto desarrollo del mecanismo TLS. Estas son:

- Ausencia de actividad exonucleasa 3'- 5' (Kunkel et al. 2003).

- Su tasa de error durante la replicación de ADN no dañado, es de $10^{-2}-10^{-4}$, mucho mayor que la de las polimerasas replicativas $\left(10^{-5}-10^{-7}\right)$ incluso 
cuando se elimina la función exonucleotídica de estas últimas (Bebenek and Kunkel 2004).

- Son enzimas distributivas. Característica que no cambia a pesar de su unión a PCNA. Esta propiedad es tremendamente beneficiosa para la célula, ya que si estas polimerasas fuesen procesivas (y por lo tanto capaces de continuar la replicación aguas abajo de la lesión que las incorporó), en la célula se introducirían muchas mutaciones que serían aún más perjudiciales para la célula que el propio daño. Las células usarán entonces, tanto regulación transcripcional como postraduccional, para mantener a estas polimerasas de baja fidelidad bajo estricto control, limitando así su acceso exclusivamente a las horquillas de replicación estancadas.

- Presentan más afinidad por PCNA monoubiquitinado que por PCNA sin modificar (al menos in vitro). Esta capacidad se atribuye a la presencia de dominios de unión a ubiquitina, UBM (del inglés $\underline{U}$ biquitin- $\underline{\text { Binding }} \underline{\text { Motif) }} \mathrm{o}$

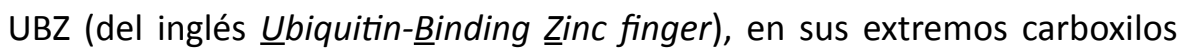
(Bienko et al. 2005; Guo et al. 2006; Plosky et al. 2006; Bomar et al. 2007) (Figura 7).

Aunque probablemente ya conozcamos a la mayoría de los personajes que actúan en el proceso de síntesis a través de lesiones, aún queda pendiente desentrañar de qué depende la elección de una polimerasa TLS u otra, así como todo lo que sucede a partir de la carga de la misma. En el siguiente apartado, describiremos todas las teorías corroboradas o simplemente hipotetizadas al respecto hasta el momento.

\section{ii. Desarrollo del mecanismo TLS}

En resumen de todo lo descrito hasta ahora:

Una vez detectado el daño, se originará un fragmento de ADN de cadena sencilla, debido al desacople producido entre la helicasa y la polimerasa replicativa. Este fragmento de ADN será recubierto por RPA, que reclutará a su vez a la E3 Rad18. La ubiquitina ligasa Rad18, junto con su E2 correspondiente, Rad6, ubiquitinarán a la abrazadera deslizante en el residuo K164. Esta modificación post-traduccional, producirá un intercambio entre la polimerasa replicativa y la TLS (aunque hasta el momento no se sabe de qué depende la elección de una polimerasa u otra, siendo éste uno de los temas sujetos a debate dentro de la tolerancia), debido probablemente a la afinidad de estas últimas por un PCNA modificado (Kannouche et al. 2004; Watanabe et al. 2004; Bi et al. 2006). La presencia de motivos de unión a ubiquitina en dichas polimerasas, apoya esta teoría (Figura 7).

Hasta el momento, 3 polimerasas TLS han sido descritas en S. cerevisiae, 4 en S. pombe y hasta 10 en mamíferos (Tabla 1). De todas ellas, ¿cuál será entonces la elegida por cada organismo en cada momento? ¿Dependerá la elección del tipo de lesión? ¿La afinidad por PCNA ubiquitinado será la misma en todas ellas? 
Una posible explicación para la existencia de varias polimerasas TLS en la célula, es que polimerasas diferentes, posean afinidades diferentes para cada tipo específico de daño. Esta propiedad ayudaría entonces a reclutar a la polimerasa apropiada en cada situación.

Aunque aún existen muchas incógnitas por resolver al respecto, evidencias experimentales han propuesto a dos polimerasas concretas, para la replicación de dos tipos de daños concretos:

1. Poln: es la polimerasa encargada de replicar los dímeros TT inducidos por radiación UV, introduciendo en la nueva hebra sintetizada dos nucleótidos consecutivos de adenina (Johnson et al. 1999). Este hecho pone de manifiesto en contra de lo descrito hasta ahora, que una polimerasa TLS es capaz de incorporar nucleótidos con total fidelidad, por lo que el mecanismo TLS llevado a cabo por esta polimerasa, será considerado como error free. La gran importancia de esta polimerasa y por ende de la función que realiza en TLS, queda demostrada por la existencia de la Xerodermia Pigmentosa Variante (XPV). XPV en una enfermedad variante de la XP, que como ella predispone a los pacientes que la presentan, a un riesgo 2000 veces mayor de padecer cáncer de piel respecto a la población normal (Kraemer et al. 1987). Sin embargo, a diferencia de ella, su aparición no está relacionada con la alteración de ninguna de las proteínas implicadas en NER, si no que se debe a una alteración en la polimerasa Poln (Masutani et al. 1999; Gratchev et al. 2003).

2. Rev1: Evidencias in vitro revelan a esta polimerasa como la enzima encargada de replicar moldes con sitios abásicos. Su capacidad polimerasa está restringida y se limita exclusivamente a incorporar una o dos moléculas de dCMP independientemente de la naturaleza del molde, lo que la hace idónea para replicar dichos sitios sin bases. (Lawrence 2004). Rev1 es por lo tanto una dCMP transferasa. Es importante destacar sin embargo, que la anulación de la actividad transferasa de Rev1 por mutagénesis dirigida en la levadura de gemación, no anula su requerimiento para la mutagénesis inducida por efecto de la luz UV (Otsuka et al. 2002; Lawrence 2004). Este hecho pone de manifiesto, que la implicación de Rev1 en TLS, va más allá de su función como dCMP transferasa. Además, se ha demostrado en sistemas humanos y de ratón, que Rev1 interacciona con multiples polimerasas TLS; en concreto con Poln, Polk, Polı, así como con la subunidad Rev7 de Polろ (Guo et al. 2003; Ohashi et al. 2004; Tissier et al. 2004), pero que no lo hace con polimerasas de la Familia $X$ como Pol $\beta$ o Pol $\mu$, lo que pone de manifiesto que dicha polimerasa es capaz de discriminar en sus interacciones con otras polimerasas. Todas estas interacciones, requieren solamente los últimos 100 aminoácidos del extremo carboxilo, estando esta región conservada en eucariotas superiores, aunque no en eucariotas inferiores (Figura 7). La observación de dichas interacciones entre Rev1 y 
las polimerasas descritas, ha sugerido la posibilidad de que dicha polimerasa actúe como un "intercambiador" de polimerasas especializadas, dentro del mimo evento TLS (ver más adelante) (Friedberg 2005).

Aunque se postula la hipótesis de que cada polimerasa TLS se ocupe de la replicación de un tipo concreto de lesión, no se ha establecido hasta el momento ninguna otra conexión polimerasa-daño.

Una vez incorporada la polimerasa TLS, para que el mecanismo se desarrolle con éxito, tendrán que darse a continuación los siguientes eventos: replicación de la zona dañada, recuperación de la estructura de la doble hélice, eliminación de las polimerasasa TLS y recarga de las polimerasas replicativas. Si todo esto sucede mediante el uso de una única polimerasa TLS, o en cambio son necesarias más (como apuntan las evidencias descritas de Rev1), es algo que aún está sujeto a debate, ya que aunque existen varias teorías al respecto, ninguna evidencia in vitro y/o in vivo ha conseguido demostrar cuál es la verdadera.

\section{iii.Replicación de la lesión. Modelo de dos polimerasas.}

La idea de que pueda necesitarse más de una polimerasa especial para lograr replicar la zona dañada, surge de la limitada procesividad inherente a estas polimerasas, así como de la ineficacia con la que algunas de ellas se extienden por moldes no dañados. Por ejemplo, evidencias in vitro han demostrado que Poln, tiene una baja probabilidad de disociarse cuando incorpora nucleótidos opuestos a dímeros de timina, pero una mayor probabilidad de hacerlo, una vez haya progresado unos pocos nucleótidos más allá de la lesión (McCulloch et al. 2004). Estas observaciones, unidas a las ya descritas para Rev1, han fomentado la idea de que al menos dos polimerasas puedan ser necesarias para el desarrollo del mecanismo TLS. Así, la hipótesis surgida al respecto, sugiere que en primera lugar, una polimerasa específica insertaría los nucleótidos necesarios justo en frente de la lesión, de ahí que a esta polimerasa se la llame "Polimerasa de Inserción". A continuación, una segunda polimerasa TLS, llamada "Polimerasa de Extensión", se encargaría de replicar varios nucleótidos aguas abajo de la lesión, con el fin de que la geometría estructural del ADN vuelva a ser la correcta antes de la incorporación de las polimerasas replicativas (ya que si esto no ocurriese, las polimerasas replicativas detectarían la estructura de ADN alterada y la eliminarían por medio de su actividad exonucleasa 3'-5', impidiendo por lo tanto una resolución exitosa del mecanismo TLS) (Friedberg 2005). El intercambio entre ambas polimerasas TLS, se llevaría a cabo a través del "intercambiador" Rev1 (Figura 9).

Aunque aún no existen evidencias directas de este cambio de polimerasas, ensayos in vitro han demostrado que, efectivamente, ciertas polimerasas TLS parecen ser más adecuadas para la extensión que para la inserción de nucleótidos (Woodgate 2001; Prakash and Prakash 2002; Friedberg 2005). De nuevo se espera que en los próximos años, evidencias in vitro e in vivo, consigan demostrar cómo ocurre dicho intercambio de polimerasas. 


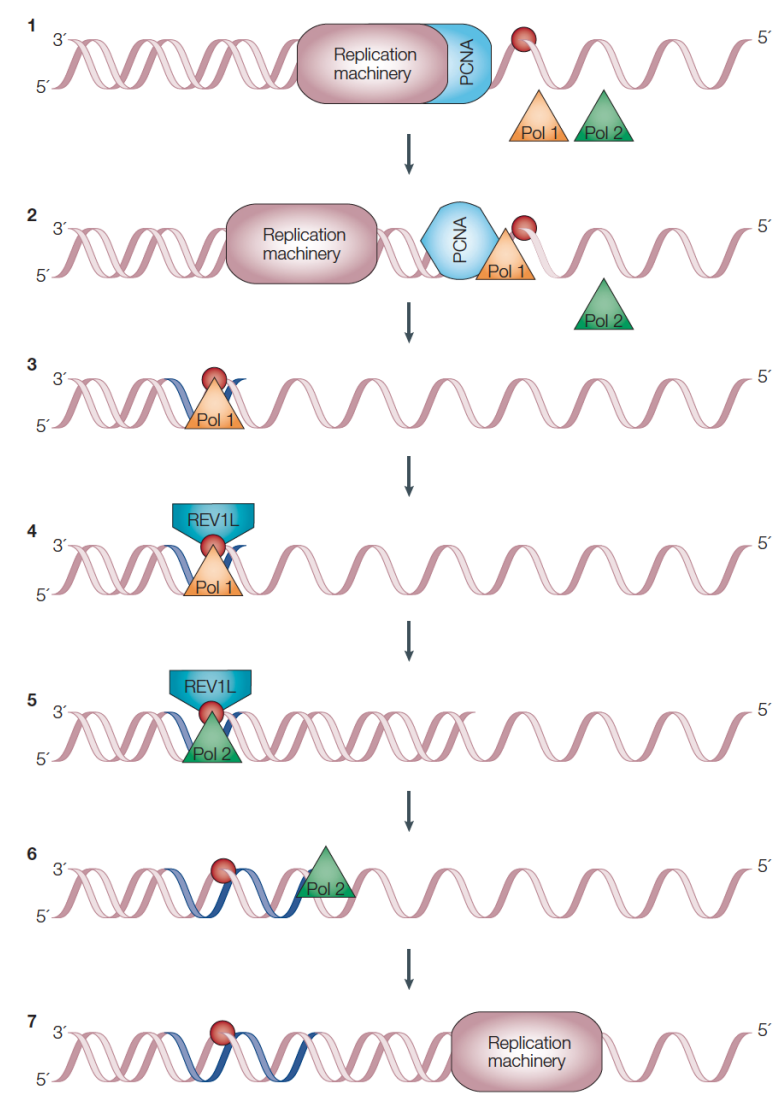

Figura 9: Modelo de replicación por TLS en células eucariotas. Una vez detenida la maquinaria de replicación, por la detección de algún tipo de lesión en el ADN (1), se producirá la ubiquitinación de la abrazadera (no mostrado) con la consiguiente carga de la primera polimerasa especial (Pol 1) (2). (A partir de este momento no se mostrará la abrazadera, con el fin de simplificar el esquema). Dicha polimerasa, insertará exclusivamente los nucleótidos necesarios para replicar la lesión (fragmento azul del dúplex de $\mathrm{ADN}$ )(3), de ahí que se la conozca como "Polimerasa de Inserción". A continuación se producirá la unión de Rev1 (4), lo que provocará algún tipo de cambio conformacional en Pol 1, produciendo su eliminación del ADN para que a continuación, se produzca la carga de la segunda polimerasa TLS (Pol 2) (5). Esta polimerasa será la encargada de extender la replicación aguas abajo de lesión, hasta que la incorporación de las polimerasas replicativas no suponga un problema debido a su actividad exonucleasa (6) (fragmento azul del dúplex de ADN). Para terminar, se producirá un nuevo intercambio de polimerasas entre Pol 2 y la replicativa. Friedberg 2005.

\section{iv. Reincorporación de las polimerasas replicativas.}

Superada ya la lesión, el último paso del mecanismo TLS consistirá en cargar de nuevo a las polimerasas replicativas en el replisoma, eliminando por consiguiente a las TLS. Esta eliminación, será fundamental para que dichas polimerasas no introduzcan mutaciones en el genoma, debido a su baja fidelidad al replicar un molde no dañado. El momento en el que esto ocurra por lo tanto, será determinante para que la replicación en torno al molde dañado, se realice tanto con éxito como introduciendo el menor número de mutaciones posibles. 
Uno de los hechos que favorece este intercambio, es la ya mencionada alta probabilidad de las polimerasas TLS de disociarse de un molde no dañado. El segundo hecho, aunque aún no existen evidencias concluyentes al respecto, se cree que vendría dado por la reversión del proceso que produjo la carga de dichas polimerasas, es decir, la ubiquitinación de PCNA.

Las proteínas encargadas de catalizar dicha reacción de desubiquitinación, son las desubiquitinasas o DUBs (Deubiquitinating enzyme) (Kouranti et al. 2010). Hasta la fecha, 6 subfamilias diferentes de DUBs han sido descritas en humanos, estando 4 de ellas conservadas en la levadura de fisión.

En el último apartado de este capítulo, abordaremos la descripción de esta familia de proteasas, así como todos los datos publicados hasta el momento acerca de la desubiquitinación de la abrazadera.

\subsubsection{Ruta error free}

Se trata de la segunda alternativa existente dentro de los mecanismos de tolerancia al daño. A través de esta ruta, la célula utilizará la información genética codificada por la cromátida hermana recién sintetizada y carente de daño, para replicar la secuencia opuesta a la lesión (Cox 2002; McGlynn and Lloyd 2002) (Michel et al. 2001). Al evitar replicar directamente la zona dañada, no se introducen mutaciones en la nueva hebra, de ahí que a esta alternativa se la conozca como vía error free. (Cox et al. 2000; Marians 2000; Cox 2002; Courcelle et al. 2003; Michel et al. 2004). Este hecho hizo pensar en un principio, que esta estrategia sería la utilizada preferentemente por las células al enfrentarse a una replicación estancada (Berdichevsky et al. 2002), sin embargo, aunque actualmente se cree que esto no es así, aún no se ha logrado esclarecer qué determina la elección por parte de la célula de una vía u otra.

Aunque ya en su momento se había propuesto una rama libre de errores dentro de la vía RAD6, no fue hasta el descubrimiento de Mms2 cuando se confirmó su existencia (Broomfield et al. 1998). Hasta ese momento se sabía que mutantes Rad6 y Rad18 eran defectuosos en las dos vías de la tolerancia y que mutantes Rev lo eran solo en la vía mutagénica (Prakash et al. 1993). Sin embargo, ningún gen había sido identificado para operar solamente en la vía libre de errores. El descubrimiento de Mms2, supuso por lo tanto el inicio del asentamiento de las bases moleculares de esta ruta.

Células carentes de esta proteína son sensibles a una amplia gama de agentes que dañan el ADN. Además, a diferencia del mutante $\Delta r e v 3, \Delta M m s 2$ muestra un aumento masivo en la tasa de mutaciones espontáneas; incremento dependiente de funciones REV. Este hecho sugiere por lo tanto, que las lesiones normalmente atendidas por la vía libre de errores, pueden pasar a serlo por la ruta TLS (Broomfield et al. 1998; Brusky et al. 2000). Además, el doble mutante $\Delta M m s 2 \Delta r e v 3$, es comparable al mutante único $\Delta$ rad18 (Broomfield et al. 1998; Xiao et al. 1999), lo que co- 
rrobora la idea de que Rad6 y Rad18 son necesarias para ambas vías y que Mms2 lo es sólo para la vía libre de errores.

Mms2, codifica una proteína conjugadora de ubiquitina E2 homóloga a las UBC, pero que a diferencia de ellas, carece del residuo activo cisteína (Broomfield et al. 1998). Forma heterodímeros con Ubc13, de forma que el fenotipo de los mutantes Mms2 son indistinguibles de los Ubc13 (Brusky et al. 2000). Su E3 correspondiente es Rad5, proteína con un dominio "dedo anular" que interactúa tanto con Ubc13 como con Rad18 (Ulrich and Jentsch 2000). El complejo formado por Mms2, Ubc13 y Rad5, tiene como sustrato a PCNA monoubiquitinado y formará cadenas de ubiquitina unidas entre sí a través del residuo K63 (Xiao et al. 1998; Hofmann and Pickart 1999). EI PCNA poliubiquitinado resultante, será la señal que active la ruta libre de errores (Figura 7), al igual que el monoubiquitinado lo hacía con la TLS.

Hasta el momento no existen evidencias significativas que demuestren de qué modo opera esta vía, debido en gran parte a que aún se tiene una comprensión muy limitada acerca de la estructura detallada de las horquillas de replicación. Sin embargo, se especula que pueden ser dos los mecanismos utilizados por la célula para evitar replicar el molde dañado. Estos son: cambio de molde por invasión de la cromátida hermana y regresión de la horquilla de replicación (Broomfield et al. 2001) (Figura 10).

\section{Invasión de la cromátida hermana:}

A través de esta estrategia, la célula sustituirá temporalmente la hebra molde dañada por la hebra hija complementaria recién sintetizada, a través de una invasión directa de la misma. Después de esta invasión, la maquinaria de replicación sintetizará el ADN necesario para replicar la zona dañada con total fidelidad. Para finalizar, se producirá la resolución de la unión de Holliday formada, con el fin de volver a una situación normal (Higgins et al. 1976) (Figura 10).

\section{Regresión de la horquilla de replicación:}

Además, o como alternativa al modelo anterior, las horquillas de replicación estancadas pueden sufrir un reordenamiento estructural conocido como Regresión de la horquilla de replicación. A través de este proceso, las hebras molde originales pueden volver a hibridarse produciéndose una extrusión de las dos hebras recién sintetizadas, que dará lugar a la formación de un dúplex corto entre ellas. Esto generará una estructura llamada "pata de gallo" (Postow et al. 2001; Atkinson and McGlynn 2009), estructura de cuatro vías en la cual la síntesis de ADN es intercambiada desde la hebra dañada, a la hebra homóloga recién sintetizada. La inversión de esta estructura reconstituirá una horquilla de replicación normal, en la cual la replicación del ADN tendrá operacionalmente replicado el sitio de la lesión (Figura 10). Los detalles de la formación y resolución de esta estructura de "pata de gallo", aún no se han dilucidado. 

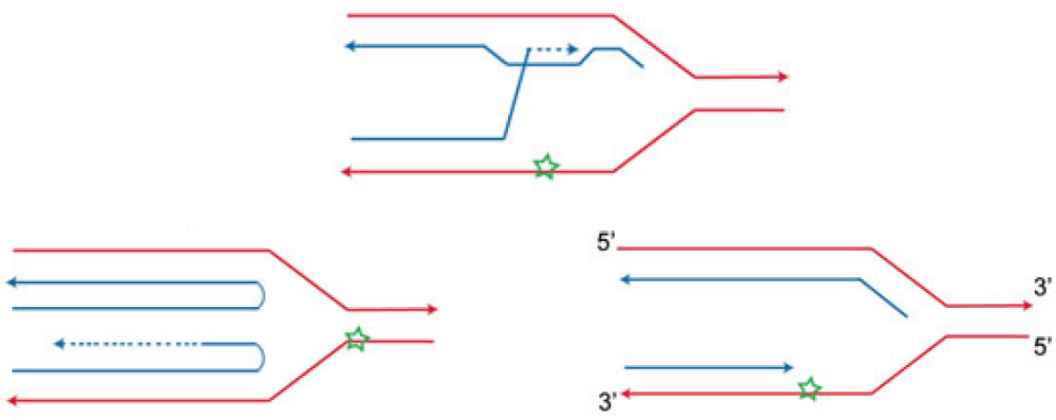

Figura 10: Desarrollo de la vía error free de la tolerancia al daño. Aunque aún no existen evidencias experimentales significativas que atestigüen de qué modo opera esta vía, se han propuesto dos mecanismos diferentes: reversión de la horquilla de replicación (izquierda) e invasión de la cromátida hermana (derecha). Para descripción, ver texto.

Por cuál de estas estrategias se desarrolla la vía error free, es otras de las cuestiones sin respuesta dentro de los mecanismos de tolerancia y es que en los últimos años, varias han sido las publicaciones publicadas en ambos sentidos.

La evidencia experimental de la existencia de estructuras de "pata de gallo" en eucariotas, viene de un informe (Blastyak et al. 2007) en el que se demuestra la actividad helicasa de Rad5, actividad que facilita la regresión de la horquilla de replicación. Como contraste, varias revisiones (Cobb and Bjergbaek 2006; Klein 2006; Branzei and Foiani 2007) sugieren que el checkpoint de daño al ADN, actúa para prevenir la regresión de la horquilla de replicación bloqueada, por lo que según estos informes, la vía libre de errores estaría mediada por el proceso de intercambio de molde. Se espera que en los próximos años se consiga aclarar cuál es el modus operandi de este vía.

Aunque aún no se sepa cómo se desarrolla esta alternativa de la tolerancia al daño, es importante destacar el hecho de que está conservada en todos los eucariotas, ya que homólogos de Mms2 (Oh et al. 1994; Xiao et al. 1998), Ubc13 y Rad5 (Motegi et al. 2006; Unk et al. 2006) se han encontrado desde levaduras hasta humanos (Pastushok and Xiao 2004). Además, la supresión de dichos genes en eucariotas superiores, da lugar al mismo fenotipo que los mutantes correspondientes de levadura (Ma et al. 1998; Andersen et al. 2005).

\subsection{Elección de ruta}

Una vez descritas las vías TLS y de intercambio de molde, el siguiente paso lógico en la descripción de los mecanismos de la tolerancia al daño, consistiría en explicar cómo se produce el cambio entre la vía error prone y la error free, y por otro lado, qué determina la elección por parte de la célula de un mecanismo u otro. Sin em28 
bargo, una vez más, aunque sí que existen diferentes trabajos que intentan arrojar algo de luz al respecto (se ha demostrado en la levadura de gemación que las lesiones inducidas por radiación UV son mayoritariamente repicadas por TLS (Daigaku et al. 2010), hasta el momento no existe ninguna evidencia concluyente que explique totalmente ninguna de las dos incógnitas.

Respecto al cambio de vías (error prone por error free), se ha postulado precisamente, que la poliubiquitinación de PCNA debe ser el condicionante físico para dicho cambio, ya que las cadenas de ubiquitina, puede bloquear el acceso de las polimerasas TLS al propio molde de ADN (Bienko et al. 2005; Plosky et al. 2006). Este hecho facilitaría además, la incorporación de las proteínas que median esta ruta, probablemente por su afinidad por un PCNA poliubiquitinado.

Por otro lado, en Chang 2006 y Motegi 2008, se ha descrito cómo la poliubiquitinación de PCNA se observa en cantidades crecientes de daño al ADN, estando en Xenopus correlacionado con la acumulación de RPA en la hebra simple de ADN (Chang et al. 2006; Motegi et al. 2008). Además, en S. cerevisiae se ha observado cómo Rad18 y Rad5 interactúan entre sí, a través de los mismos dominios necesarios para la formación de sus respectivos complejos ubiquitinantes (Ulrich and Jentsch 2000). Sobre la base de esta y otras observaciones, se ha hipotetizado que la interacción entre ambas E3, puede ser lo que determine el cambio de mono a poliubiquitinación de PCNA (Ulrich and Jentsch 2000), aunque aún no existen evidencias experimentales concluyentes al respecto. Una vez más, se espera que en los próximos años se aporten más datos en este campo.

\subsection{Tolerancia en otros eucariotas}

Como se mencionó al principio del apartado de tolerancia, salvo las excepciones señaladas, la mayoría de los datos moleculares aportados en este capítulo se refieren a la levadura de gemación S. cerevisiae. Sin embargo, es importante dejar constancia de que estas rutas se han mantenido desde procariotas hasta eucariotas y que dentro de los eucariotas, los mecanismos moleculares que las orquestan, están conservados en todos ellos.

Es por ello que a modo de resumen, a continuación haremos un pequeño repaso de las principales similitudes y diferencias descritas en el resto de los organismos modelo.

Aunque la ubiquitinación de PCNA fue descrita por primera vez en la levadura de gemación, dicha modificación post-traduccional parece estar conservada en todos los organismos estudiados hasta ahora. De hecho, el sitio de unión para la ubiquitina, el residuo K164, se mantiene en todas las abrazaderas eucariotas analizadas (mamíferos, pollo, rana y levadura de fisión, (Kannouche and Lehmann 2004; Watanabe et al. 2004; Leach and Michael 2005; Arakawa et al. 2006; Frampton et al. 2006; Simpson et al. 2006), aunque el resto de la secuencia sea muy diferente en cada organismo. 
Respecto a la levadura de fisión, aunque ya se han identificado homólogos de todas las enzimas de conjugación de ubiquitina para la abrazadera, se ha observado cómo la ubiquitinación de la misma no ocurre de igual modo a la levadura de gemación. Así, las células de $S$. pombe a diferencia de $S$. cerevisiae, ubiquitinan a la abrazadera durante una Fase $S$ sin daño exógeno, además de en $G 2$ en presencia de daños (Frampton et al. 2006).

En extractos de huevos de Xenopus laevis existen datos contradictorios acerca de cómo y cuándo ocurre la ubiquitinación de la abrazadera. Así, por un lado, en Leach 2005 se ha descrito la existencia de monoubiquitinación durante una Fase $S$ sin daño exógeno, apareciendo sólo las formas diubiquitinadas en presencia de daño. Sin embargo en Chang 2006, se documenta que tanto la mono como la poliubiquitinación de PCNA, son dependientes de la existencia de daño en el ADN. Aunque las razones de esta discrepancia aún no se han resuelto, se piensa que estas variaciones podrían deberse a que tanto el organismo como las condiciones utilizadas no son exactamente las mismas.

En cuanto a mamíferos, mientras que la monoubiquitinación de PCNA inducida por daño es fácilmente observable, y como tal ha sido identificada en muchos trabajos (Hoege et al. 2002; Kannouche and Lehmann 2004; Watanabe et al. 2004), la poliubiquitinación de la abrazadera, especialmente en células humanas, ha generado mucha controversia hasta que logró identificarse por Chiu y colaboradores (2006), probablemente debido a que es mucho menos prominente que la monoubiquitinación. Sin embargo, una vez demostrada, durante mucho tiempo se pensó que dicha modificación era exclusiva de células malignas, ya que hasta el trabajo de Brun y colaboradores (2010) no consiguió demostrarse su presencia en fibroblastos no transformados.

Al igual que en la levadura de gemación S. cerevisiae, en ninguno de los organismos modelo mencionados, ha conseguido demostrarse cómo operan cada una de las vías de la tolerancia, así como la elección por cada una de ellas.

\subsection{Problemas de ambas y conclusión final de tolerancia}

Con la descripción de los dos mecanismos de tolerancia al daño, ha quedado demostrado que aunque son totalmente necesarios para evitar las consecuencias de una replicación estancada, también son muy peligrosos por las graves consecuencias que ambas rutas pueden tener para la célula. Por lo tanto, independientemente de la alternativa que escoja la célula para replicar el ADN dañado, es imprescindible que, una vez superada la lesión, la maquinaria de replicación vuelva a la normalidad, a fin de evitar los problemas que desencadenaría el uso constante de estos mecanismos.

Por un lado, TLS es una fuente constante de inestabilidad genética, debido a la acción mutagénica de las polimerasas que median esta ruta. Limitarlas por lo tanto a la replicación del ADN dañado, será fundamental para mantener la estabilidad del 30 
genoma. Por otro lado, un fallo en el intercambio de molde, puede inducir lesiones más graves como por ejemplo rearreglos por recombinación homóloga, que pueden ir asociados a transformaciones malignas (Hanahan and Weinberg 2000). Limitar por lo tanto estos mecanismos de tolerancia exclusivamente a las situaciones necesarias, contribuirá a mantener un perfecto equilibrio entre supervivencia celular y estabilidad genómica.

\subsection{Desactivación de las rutas de tolerancia al daño}

Como ya se ha descrito, la señal que activa las dos vías de la tolerancia al daño es la ubiquitinación de PCNA. Esta señal por lo tanto, una vez solventado el problema, tendrá que desaparecer para que la célula pueda volver a una replicación normal.

Tratándose de "ubiquitinación", parecía lógico pensar en degradación vía proteasoma como primera opción, sin embargo, dado que la cadena de ubiquitinas se produce por uniones K63 en lugar de K48 (uniones descritas para la degradación vía proteasoma), esta opción no debía ser la responsable de la eliminación de dicho PCNA modificado; por lo tanto, había que pensar en otra opción.

El descubrimiento de las desubiquitinasas, puso de manifiesto que la ubiquitinación, como el resto de modificaciones post-traduccionales, también era un proceso reversible. Pensar por lo tanto en la existencia de una o varias desubiquitinasas de PCNA, parecía ser la opción acertada para la eliminación de dicha señal de activación. De hecho, hasta el momento, ya se han encontrado dos proteínas con esta función: Usp1 en humanos (Huang et al. 2006) y conservada también en ratón (Kim et al. 2009) y Ubp10 en la levadura de gemación (Gallego-Sanchez et al. 2012). El trabajo llevado a cabo para el desarrollo de esta tesis, demostrará quienes son las encargadas de hacerlo en la levadura de fisión S. pombe.

\subsubsection{DUBs}

En las células humanas, la desubiquitinación está controlada por una familia de proteasas denominadas DUBs, formada por unas 100 proteínas diferentes (Amerik and Hochstrasser 2004; Nijman et al. 2005), cuya función en la mayoría de los casos es desconocida. Estas proteínas están conservadas en todos los eucariotas, aunque el número de miembros en eucariotas inferiores no es tan grande como lo es en las células humanas.

Enzimáticamente, las DUBs son las proteasas encargadas de escindir el enlace isopeptídico existente entre diferentes ubiquitinas unidas entre sí (rompiendo en mónomeros las cadenas de ubiquitina), o bien entre la ubiquitina y la proteína sustrato (Wilkinson 1997). Por lo tanto, sus funciones generales estarán relacionadas con el mantenimiento de la homeostasis de ubiquitina, así como con el control de la estabilidad de sus proteínas sustrato. 
Aunque de forma general se puede dividir a esta gran familia de proteasas en dos grupos diferentes: cisteínas proteasas y metalo proteasas, la profunda caracterización de sus secuencias así como de sus estructuras, ha establecido una división en 6 familias diferentes. Estas son: proteasas específicas de ubiquitina (USPs o UBPs para células humanas o levaduras respectivamente), ubiquitina C-terminal hidrolasas (UCHs), proteasas de tumor de ovario (OTUs), proteasas de Machado-Joseph (nombre de una enfermedad autoinmune), metaloenzimas JAB1/MPN/Mov34 (JAMMS) y la última descubierta, la subfamilia MCPIP (Komander et al. 2009; Reyes-Turcu et al. 2009; Liang et al. 2010).

Todas las familias a excepción de la familia JAMM, son cisteínas proteasas. El número de miembros de cada familia es muy diverso, siendo la USP/UBP la familia más numerosa, con más de 50 miembros en células humanas (Quesada et al. 2004), y 16 tanto en la levadura de gemación como en la de fisión (Kouranti et al. 2010). Sus funciones celulares están supeditadas al sustrato que desubiquitinan y aunque en los últimos años se han descubierto muchos de ellos, la gran mayoría continúan siendo una incógnita. Aún así, hasta la fecha ya se pueden atribuir a esta gran familia de DUBs, funciones tan importantes como regulación del ciclo celular, reparación del ADN y remodelación de la cromatina.

Un ejemplo de la importancia de la desubiquitinación se da en la vía de la Anemia de Fanconi (AF), ruta encargada de mediar la resolución de entrecruzamientos en el ADN (daños altamente citotóxicos para la célula), de tal forma que la deficiencia en uno de los 13 genes implicados en la ruta de la AF, resultará en la hipersensibilidad a agentes de entrecruzamiento del ADN.

La mayoría de las proteínas identificadas en la vía de la $A F$, constituyen una única y gran multi-subunidad E3 ubiquitina ligasa, a excepción de FANCD2 y $\mathrm{FANCl}$, que son los sustratos correspondientes de esta E3 multimérica. Tras su ubiquitinación, estas proteínas se desplazan a la cromatina (Garcia-Higuera et al. 2001; Meetei et al. 2003; Smogorzewska et al. 2007) posiblemente para ayudar a resolver estos entrecruzamientos, aunque la función exacta que desarrollan en este paso y en los siguientes continúa siendo una incógnita.

La enzima encargada de desubiquitinar FANCD2 y FANCl es Usp1 (Nijman et al. 2005; Smogorzewska et al. 2007) y su pérdida resulta en la ubiquitinación de ambas proteínas incluso en ausencia de daño. Células de pollo "knock out" para Usp1, son hipersensibles a agentes de entrecruzamiento de ADN, rasgo característico de la Anemia de Fanconi (Oestergaard et al. 2007; Kim et al. 2009), sugiriendo que la desubiquitinación FANCD2 y $\mathrm{FANCl}$ debe ser crucial para la reparación de este tipo de daños. 


\subsubsection{Desubiquitinación de PCNA}

\section{i. Usp1}

Huang y colaboradores, demostraron que Usp1 también era la proteína responsable de la desubiquitinación de PCNA monoubiquitinado en humanos. Como ya se mencionó, en células humanas al igual que en levaduras, la monoubiquitinación de la abrazadera desencadena la activación de la vía TLS mediada por las polimerasas especiales. El hecho de que exista un proteína que regule el proceso a la inversa, apunta a que dicha desubiquitinación, será determinante para la eliminación de dichas polimerasas, con la consiguiente recarga de las replicativas. La evidencia de que en células deplecionadas para Usp1, exista un aumento significativo de mutagénesis tanto espontánea como inducida, corrobora esta hipótesis (Huang et al. 2006).

Usp1 presenta un peculiar sistema de degradación dependiente de luz UV. Basándose en este dato, se propuso el siguiente modelo de regulación de TLS en humanos. En ausencia de daño, PCNA monoubiquitinado es desubiquitinado de forma constitutiva por Usp1, con el fin de controlar el acceso de las polimerasas TLS al replisoma. Tras una exposición a luz UV, la diana de Usp1 cambiará desde PCNA a su propio dominio G-G C-terminal, produciéndose una auto-escisión con posterior degradación proteosomal de dichos fragmentos auto-escindidos. Esta degradación, producirá un aumento en el nivel de PCNA monoubiquitinado y por lo tanto en el de los eventos TLS, debido al reclutamiento de las polimerasas especiales.

A pesar de los datos contradictorios publicados acerca de la existencia o no de poliubiquitinación de PCNA en fibroblastos humanos, Brun y colaboradores demostraron recientemente (2010) su existencia, así como el hecho de que Usp1 también es la DUB encargada de la desubiquitinación de esta modificación de PCNA.

La degradación de Usp1 parece ser dependiente del tratamiento con luz UV, ya que no se ha observado tras el tratamiento con otras drogas como MMS (Metil $\underline{\text { Metano }}$ Sulfonato) o Mitomicina C. Sin embargo, bajo esas condiciones, sigue existiendo un aumento de PCNA monoubiquitinado, por lo que es posible que otras proteínas DUBs aún no descubiertas, estén implicadas también en la regulación de procesos TLS.

La existencia de Usp1 también se ha confirmado en otros eucariotas superiores como en ratón, Xenopus o pez cebra (Huang et al. 2006). Kim y colaboradores (2009) construyeron el modelo knock out de ratón para esta proteína, con el fin de averiguar las posibles consecuencias fisiológicas de la falta de desubiquitinación. Tal y como se esperaba, ratones Usp1 -/- mostraron un claro aumento tanto en la monoubiquitinación de FANCD2 como en la de PCNA. Además de dichos datos bioquímicos, estos ratones también presentaron una alta tasa de letalidad perinatal, depleción de células germinales masculinas, infertilidad, hipersensibilidad al agente "croslinkeante" Mitomicina C e inestabilidad cromosómica. Además, estos ratones eran considerablemente más pequeños que sus hermanos de camada wt (del inglés 
Wild Iype) (Kim et al. 2009; Fox et al. 2011). A pesar de todos datos, aún queda por determinar si estos ratones muestran un incremento en la frecuencia de mutaciones puntuales y una incidencia de cáncer incrementada, como sería de esperar por los datos in vitro descritos anteriormente.

\section{ii.Ubp10}

Recientemente nuestro laboratorio ha identificado a Ubp10, una de las proteínas desubiquitinadoras de la histona H2B junto con Ubp8 (Emre et al. 2005; Gardner et al. 2005; Schulze et al. 2011), como la proteasa encargada de desubiquitinar las formas mono y poliubiquitinadas de PCNA en S. cerevisiae. A pesar de ser la proteína equivalente a Usp1 de humanos (al menos en lo referente a desubiquitinación de P(NA), el trabajo de Gallego y colaboradores ha demostrado que la regulación de ambas proteínas, y por ende de la tolerancia, es diferente en ambos organismos. Por un lado, Ubp10 no se degrada tras la exposición a luz UV como lo hace Usp1, si no que sus niveles permanecen constantes. Por otro lado, Ubp10 parece ser la única proteasa que desubiquitina PCNA en la levadura de gemación, ya que formas ubiquitinadas de PCNA se acumulan en células $\triangle u b p 10$ tras ser expuestas a diferentes daños como luz UV, MMS, HU (hidroxiurea) o 4NQO (4-nitroquinolina 1-óxido), algo no observado en las células deplecionadas para Usp1 (Huang et al. 2006).

Aunque no se haya demostrado fehacientemente un modelo de intercambio de polimerasas, basado en la regulación de la ubiquitinación de PCNA por ubiquitinasas y desubiquitinasas, sí se ha demostrado que la interacción entre PCNA y la polimerasa Rev1 aumenta en células $\triangle u b p 10$, dato que secunda la hipótesis de que es el estado de ubiquitinación de PCNA lo que regula el acceso de las polimerasas TLS al replisoma. De nuevo se espera que futuros trabajos proporcionen los datos concluyentes para confirmar esta hipótesis.

\subsection{Tolerancia y cáncer}

Como ya se ha mencionado, la tolerancia es una respuesta biológica fundamental frente al daño por garantizar la progresión de una replicación bloqueada. Además, como el resto de respuestas celulares al daño, la desregulación de sus componentes producirá inestabilidad genética, siendo ésta la base para el desarrollo de muchos procesos tumorales.

Aunque aún no se sabe qué determina la elección de una vía u otra, ni qué porcentaje de daños se resuelve por cada una de ellas, se cree que es muy probable que en células tipo silvestre, dichos porcentajes se mantengan en un equilibrio dinámico. Sin embargo, en células de levadura defectuosas en la vía error free, se ha observado un aumento de hasta 30 veces en la tasa de mutaciones espontáneas, lo que en células eucariotas superiores se interpretaría como una gran predisposición al cáncer (Andersen et al. 2008). A raíz de este resultado, se postuló que la vía error prone podría constituir una importante fuente de inestabilidad genética y cáncer 
(Lawrence and Hinkle 1996), sin embargo, aún no existen pruebas evidentes al respecto.

La prueba más clara de una relación directa entre TLS y tumorigénesis, vino de la mano del descubrimiento de la polimerasa Poln, cuyo gen se encuentra mutado en todos los pacientes con XPV. Ya que Poln co-localiza con Rev1 (Kannouche et al. 2002; Tissier et al. 2004), Polı y PCNA monoubiquitinado (Watanabe et al. 2004), es muy probable que estos genes también estén relacionados con el cáncer (Andersen et al. 2008).

Aunque hasta la fecha no se haya identificado ninguna otra relación directa entre un estado hereditario propenso al cáncer y la mutación de alguna otra polimerasa TLS, sí se ha observado cómo en determinadas líneas celulares tumorales, los niveles de dichas polimerasas, o de sus transcritos, están alterados respecto a los de las células normales. Así, en varias líneas celulares de cáncer de pulmón, se han observado niveles aumentados de Polk, sugiriendo un papel para esta polimerasa en la promoción de la inestabilidad genética y cáncer (J et al. 2001). Sin embargo, por otro lado, diversos estudios en cánceres de pulmón, estómago, colon y recto, han revelado niveles de transcripción muy bajos para las polimerasas $\eta, \mathrm{l}, \mathrm{k}$ у $\zeta$ (Pan et al. 2005).

Además de los niveles alterados de polimerasas, en las células cancerígenas también se han descrito niveles alterados en la cantidad de uno de los principales protagonistas moleculares de estas rutas, PCNA. Naryzhny y colaboradores (2007) demostraron tras el análisis de muchos cultivos celulares, que las células cancerígenas presentan niveles significativamente más altos de PCNA que las células normales, siendo incluso este valor indicador del pronóstico en varios tipos de cáncer (MorellQuadreny et al. 1998; Czyzewska et al. 2004) .

A pesar de estos datos ya plenamente objetivables, es evidente que aún se necesita mucha investigación para determinar los roles que la tolerancia juega en el desarrollo del cáncer. Una vez más, se espera que los próximos años, la plena caracterización molecular de estas rutas aporte más datos al respecto y que por lo tanto, pueda orientar incluso en el desarrollo de nuevas dianas terapéuticas. 



\section{Objetivos}

1. Identificar la o las enzimas que desubiquitinan PCNA mono y poliubiquitinado en K164, en la levadura de fisión Schizosaccharomyces pombe.

2. Caracterizar bioquímicamente a estas proteínas y estudiar su localización subcelular durante el ciclo de división celular.

3. Estudiar las cepas mutantes carentes de estas proteínas, así como a las cepas que las sobre-expresan, para así profundizar más en el entendimiento de los mecanismos de control de las rutas de tolerancia al daño. 



\section{Resultados}

Una de las grandes cuestiones que permanecen abiertas dentro de los mecanismos de tolerancia al daño, es cómo se limita el tiempo de residencia de las polimerasas TLS al replisoma. El descubrimiento de la existencia de desubiquitinasas de PCNA, Usp1 en células humanas (Huang et al. 2006) y Ubp10 en S. cerevisisae (GallegoSanchez et al. 2012), reveló que dicha limitación, probablemente podría llevarse a cabo por medio de procesos de desubiquitinación de la abrazadera. Sin embargo, se ha observado que a pesar de su conservación, la implicación y regulación de estas proteasas es diferente en cada organismo. Así, mientras que Usp1 desubiquitina a PCNA de forma constitutiva (Huang et al. 2006), Ubp10 lo hace durante Fase S y sólo tras eliminarse el daño que provocó la ubiquitinación de dicha abrazadera (Gallego-Sanchez et al. 2012). Además, Usp1 de humanos dispone de un sistema de auto-escisión que se activa en presencia de radiación ultravioleta. Esta auto-escisión, se traducirá en un aumento de PCNA ubiquitinado, probablemente con el fin de reclutar a las polimerasas TLS capaces de replicar el ADN dañado fruto de dicha radiación. Es importante subrayar que este mecanismo sólo parece actuar en presencia de luz UV y que en la levadura de gemación no se ha observado en ninguna situación.

Hasta la fecha, ninguna proteasa de ubiquitina había sido identificada en S. pombe como la ortóloga de Usp1 o Ubp10 y por lo tanto, como la encargada de desubiquitinar a PCNA en la levadura de fisión. Identificar a la o a las proteínas capaces de hacerlo en dicha levadura, ha constituido el objetivo principal de esta tesis.

Casi una centena de DUBs han sido identificadas en humanos hasta el momento. Se trata de cisteínas o metalo proteasas altamente conservadas, agrupadas en 6 subfamilias diferentes en función de la estructura de su dominio catalítico. Estas son: proteasas específicas de ubiquitina (USPs o UBPs), ubiquitina C-terminal hidro- 
lasas (UCHs), proteasas de tumor de ovario (OTUs), proteasas de Machado-Joseph (nombre dado a una enfermedad autoinmune), metaloenzimas JAB1/MPN/Mov34 (JAMMS) y la última descubierta, la subfamilia MCPIP (Komander et al. 2009; ReyesTurcu et al. 2009; Liang et al. 2010). La diversidad de núcleos catalíticos, sumada al elevado número de proteínas pertenecientes a esta gran familia, pone de manifiesto la implicación de estas proteasas en múltiples procesos celulares como endocitosis, regulación del ciclo celular, reparación del ADN y remodelación de la cromatina, además de su implicación en muchas rutas celulares que frecuentemente se encuentran alteradas en cáncer (Hussain et al. 2009; Komander et al. 2009; ReyesTurcu et al. 2009; Fraile et al. 2012).

En contraste con las células de mamíferos, en el genoma de $S$. pombe se codifican solamente 20 DUBs, pertenecientes a cuatro de las cinco subfamilias existentes (UCH, USP/UBP, OTU, y JAMM). Ya que las desubiquitinasas encargadas de la desubiquitinación de la abrazadera, tanto en células humanas como en la levadura de gemación pertenecen a la subfamilia USP/UBP, centramos nuestra búsqueda en los 16 miembros que componen esta familia en la levadura de fisión.

\section{Análisis de la ubiquitinación de PCNA en deleciones simples de UBPs}

Con objeto de identificar a la o a las proteínas responsables de la desubiquitinación de PCNA en la levadura de fisión, se construyeron cepas mutantes, carentes de cada una de las 16 UBPs (siguiendo el protocolo de transformación con Acetato de litio descrito en Materiales y Métodos), con el fin de analizar por Western blot el estado de ubiquitinación de la abrazadera en cada una de ellas.

Para ello se partió de $40 \mathrm{ml}$ de cultivos crecidos de forma asíncrona a una temperatura constante de $30^{\circ} \mathrm{C}$, de cada una de las deleciones de las UBPs, junto con una cepa tipo silvestre como control. Una vez alcanzada la fase exponencial, se dividió a cada cultivo en dos. A una de las mitades se le añadió MMS 0.01\% durante 3 horas, y a la otra mitad se la dejó creciendo en las mismas condiciones. Pasadas esas 3 horas, se recogieron 8 DO (Densidades Ópticas) de cada uno de los cultivos y se procedió a la preparación de los extractos proteicos totales con TCA (del inglés IriChloroacetic Acid, ácido tricloroacético), tal y como se describe en Materiales y Métodos. $4 \mu \mathrm{l}$ de los extractos totales de cada muestra, fueron analizados por Western blot para analizar el estado de ubiquitinación de la abrazadera. Por medio del anticuerpo anti-PCNA (anticuerpo policlonal de conejo cedido por el Dr. Lehmann, Universidad de Sussex, UK), que reconoce específicamente tanto a PCNA como a sus formas modificadas (datos publicados en Frampton 2006 y confirmados por nosotros en Figura 11A), detectamos el estado de ubiquitinación de PCNA en cada uno de los mutantes, pudiendo comparar así las diferencias existentes entre cada uno de ellos respecto al wt. En la Figura 11 se muestra el resultado de los Westerns 
A

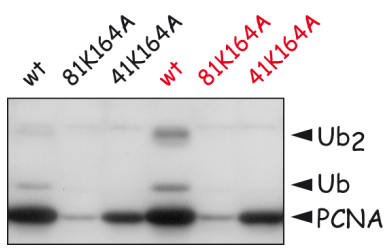

B

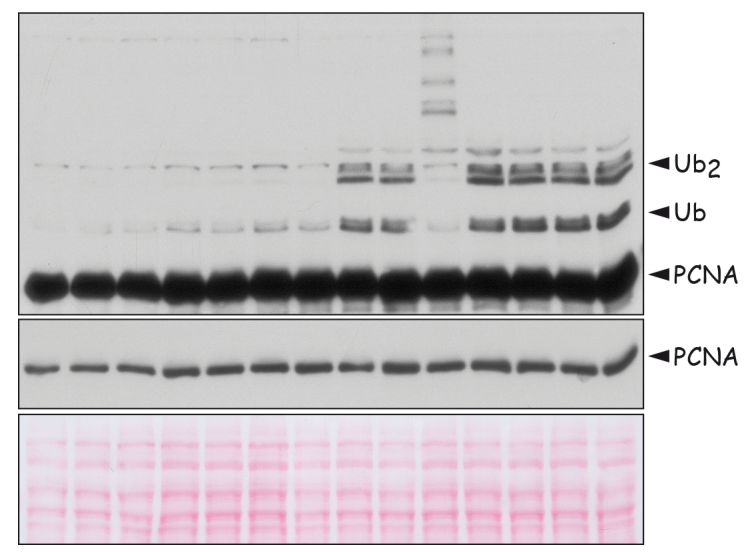

C
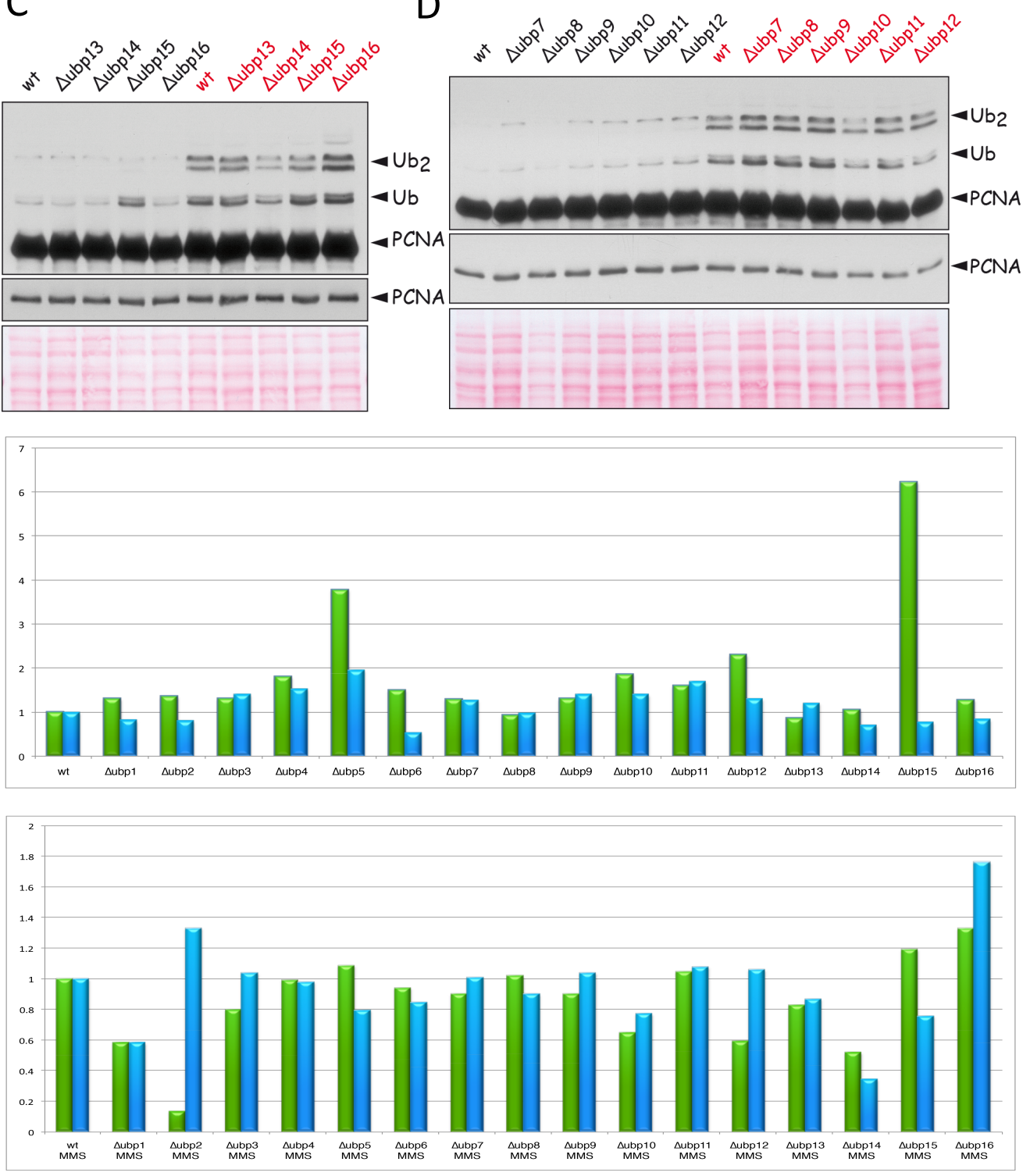
Figura11: Análisis del estado de ubiquitinación de PCNA en los 16 mutantes simples de UBPs en S. pombe. A: Experimento llevado a cabo con dos mutantes diferentes pcn1K164A, el primero expresado bajo el promotor más débil nmt81 (muestra 81K164A) y el otro bajo el intermedio nmt41 (muestra 41K164A). Ambos mutantes son incapaces de ubiquitinarse por tener el residuo K164 mutado a alanina, por lo que nos servirán para identificar qué bandas corresponden a las formas monoubiquitinadas de PCNA (nombradas con Ub) y cuáles a PCNA poliubiquitinado (nombradas en general como $U_{b_{2}}$ ). El experimento fue realizado en YES, medio en el que los promotores $n m t$ está apagados por contener tiamina, de ahí la diferencia de PCNA observada entre el $w t$ (tipo silvestre) y los dos mutantes (más en el primero ya que la represión del promotor $n m t 81$ llega a ser prácticamente total en presencia de tiamina). Las muestras cargadas a la izquierda y nombradas en "negro", corresponden a células recogidas en fase exponencial sin ningún tratamiento, mientras que las cargadas a la derecha y nombradas en "rojo", corresponden a células tratadas durante 3 horas con MMS $0.01 \%$. Como se observa, las bandas señaladas con Ub y Ub2, no aparecen en ninguno de los dos mutantes. B, C, y D: Westerns blots realizados a partir de los extractos proteicos preparados con TCA de los 16 mutantes simples de $S$. pombe, carentes de cada una de las 16 proteínas pertenecientes a la subfamilia UBP. Las muestras nombradas en "rojo" se corresponden de nuevo con las células tratadas con MMS $0.01 \%$. Esta nomenclatura se mantendrá a lo largo de todo el manuscrito. La normalización y representación de las cuantificaciones de los mismos se muestran en los gráficos E y F. Para descripción de los resultados, ver texto.

blots realizados para el análisis de todos los mutantes simples de las UBPs, así como su cuantificación para una mejor visión del resultado.

Los experimentos fueron repetidos en al menos tres ocasiones y los gráficos mostrados representan la media aritmética de todos ellos. Debido al sistema de cristales utilizado en el laboratorio (Bio-Rad), solo 14 muestras pudieron ser analizadas a la vez, por lo que un total de 3 Westerns blots fueron necesarios para analizar los 16 mutantes. Las bandas correspondientes a las formas modificadas de PCNA (mono y poliubiquitinación) fueron cuantificadas por medio del programa Quantity One de Bio-Rad. Los valores obtenidos para cada uno de los mutantes se normalizaron frente a su control de carga (PCNA no modificado) y frente al valor correspondiente del $w t$ (mono o poliubiquitinado en cada caso), con el fin de hacer comparables todas las muestras entre sí y poder representarlas en 2 gráficos; mostrando por un lado todas las muestras sin dañar (Figura 11E) y por otro lado las dañadas (Figura 11F).

El análisis de las muestras no dañadas de los mutantes simples, reveló cómo la falta de la mayoría de las UBPs se traducía en una mayor acumulación de PCNA monoubiquitinado que el $w t$, siendo los mutantes $\Delta u b p 5, \Delta u b p 12$ y especialmente el $\triangle u b p 15$, los que mostraron los fenotipos más acentuados. Respecto a la cantidad de PCNA poliubiquitinado, no se observó ninguna diferencia significativa en ninguno de los mutantes.

Como ya se ha descrito, el daño implícito existente en Fase $S$ en $S$. pombe, es mucho mayor que el acaecido en S. cerevisiae (Ulrich 2007a), de ahí que en células 
asíncronas de la levadura de fisión, se observe una clara cantidad de PCNA monoubiquitinado, a diferencia de lo que ocurre en la levadura de gemación (Frampton et al. 2006). A partir de estas observaciones, se puede extrapolar que cualquier fallo en la progresión por Fase $S$, se traduce en una mayor acumulación de PCNA monoubiquitinado. Por este motivo, la acumulación de más PCNA monoubiquitinado en los mutantes mencionados, no tenía por qué deberse necesariamente a la implicación directa de estas proteínas en el proceso de desubiquitinación de PCNA, si no que podría deberse a algún tipo de defecto en su progresión por Fase S. Por lo tanto, aunque estos datos apoyaban la idea de que los procesos de ubiquitinación y desubiquitinación son necesarios para una correcta progresión a lo largo de ciclo celular (en este caso por Fase S), a priori no aportaban demasiado en la búsqueda de la proteasa encargada de desubiquitinar a la abrazadera.

El análisis de las muestras dañadas en cambio, sí aportó más información. Como se observa en la Figura 11, la falta de Ubp16 en la célula produce una mayor acumulación de PCNA tanto mono como poliubiquitinado, al igual que ocurre con su homóloga Ubp10 en la levadura de gemación (Gallego-Sanchez et al. 2012). Sin embargo, a pesar de este resultado "esperado", el fenotipo más curioso lo mostró el mutante $\triangle u b p 2$, ya que en ausencia de esta proteína se produce una acumulación de formas muy poliubiquitinadas de PCNA, formas no observadas ni en el wt ni en ninguno de los otros 15 mutantes. Respecto al resto de mutantes no hubo diferencias significativas.

Aunque aún estábamos lejos de poder asignar a estas proteínas una función directa en el proceso de desubiquitinación de PCNA en la levadura de fisión, los resultados iniciales sugerían que podían ser dos las UBPs encargadas de desubiquitinar a PCNA (a diferencia de lo descrito en S. cerevisiae, donde sólo una UBP parece estar implicada en el proceso, (Gallego-Sanchez et al. 2012)), de modo que, a raíz de los fenotipos observados, Ubp2 podría encargarse de desubiquitinar las formas más poliubiquitinadas de PCNA y Ubp16 del resto.

\subsection{La acumulación de PCNA ubiquitinado, no es específica del daño por MMS}

La acumulación de formas modificadas de PCNA en células humanas, como consecuencia de la auto-escisión de Usp1, solo se produce en presencia de luz ultravioleta (Huang et al. 2006). Sin embargo, en S. cerevisiae, la acumulación de dichas formas modificadas se produce en presencia de cualquier droga que, o bien dañe el ADN (MMS, NQO y Luz UV), o bien produzca un bloqueo en Fase $\mathrm{S}$ como la $\mathrm{HU}$ (Gallego-Sanchez et al. 2012).

Así, con el fin de averiguar si el fenotipo de acumulación observado en los mutantes $\Delta u b p 2$ y $\Delta u b b p 16$ de S. pombe, era o no específico del daño producido por MMS, decidimos analizar el estado de ubiquitinación de PCNA en dichos mutantes, cuando eran sometidos a la presencia de diferentes tipos de drogas (que al igual que el 
MMS producen una acumulación de cadenas sencillas de ADN durante Fase S (Davies et al. 2008)) y concentraciones de las mismas. Siguiendo el mismo diseño experimental que con el MMS, se recogieron las células y se prepararon los extractos proteicos para su posterior análisis por Western blot, donde pudimos observar, tal y como se muestra en la Figura 12, que la acumulación de formas modificadas de PCNA en S. pombe, no es específica de MMS, si no que al igual que ocurre en el mutante $\Delta u b p 10$ de $S$. cerevisiae, también aparece en presencia de otras drogas.

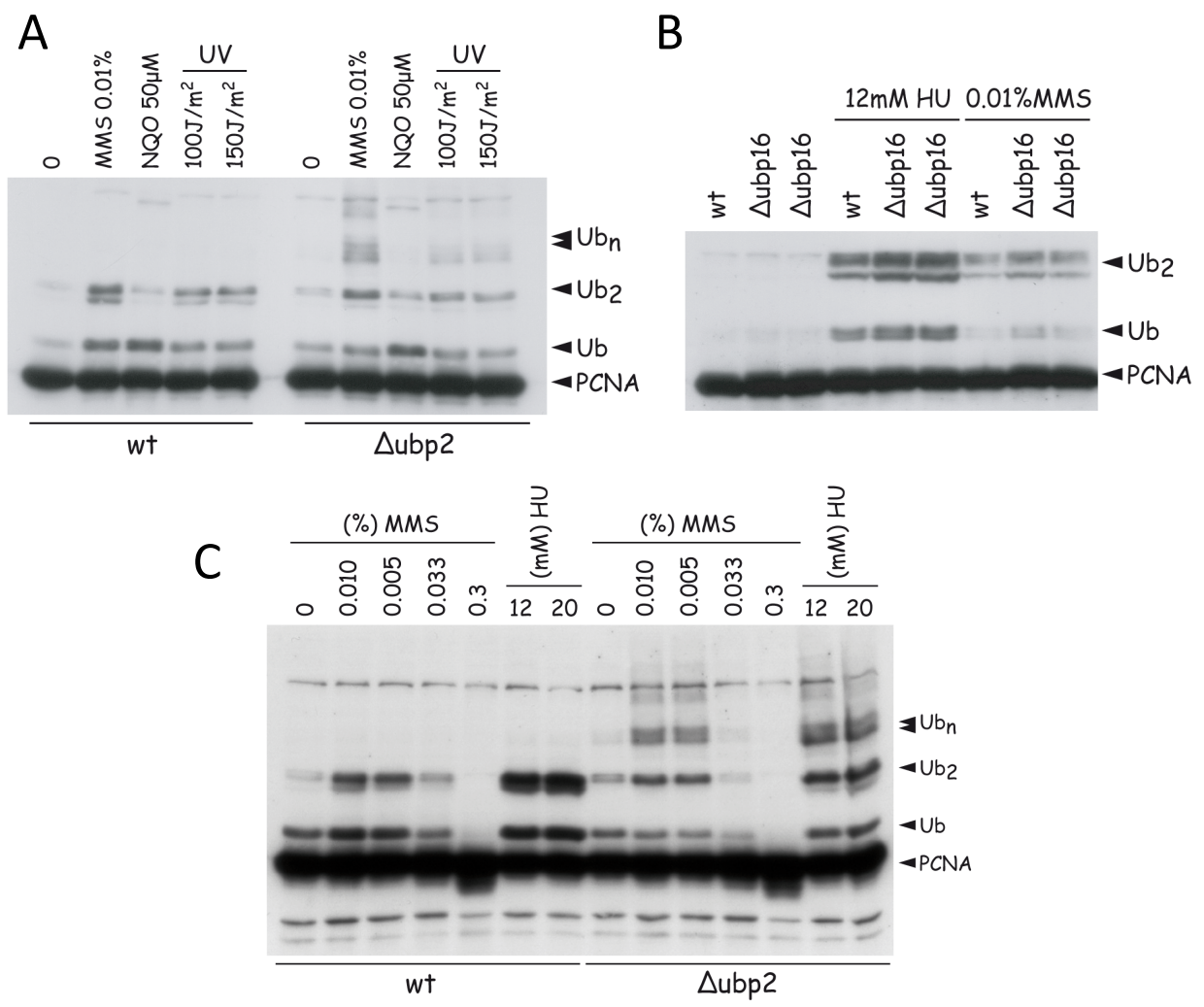

Figura 12: Los fenotipos observados en los mutantes $\Delta u b p 2$ y $\Delta u b p 16$ no son específicos del daño con MMS. Se obtuvieron extractos proteicos con TCA de las cepas delecionadas $\Delta u b p 2$ y $\Delta u b p 16$, previamente tratadas durante tres horas con MMS, $\mathrm{HU}, 4 \mathrm{NQO}$ y UV a las concentraciones y dosis indicadas. Las proteínas fueron separadas por electroforesis en SDS-PAGE, tras lo que se llevó a cabo la inmunodetección de PCNA con el anticuerpo policlonal anti-PCNA. Como se observa, el fenotipo de acumulación de los mutantes $\Delta u b p 6$ (A) y $\Delta u b p 2$ (B y C) es el mismo independientemente de la droga utilizada.

\subsection{La acumulación de formas ubiquitinadas de PCNA en los mutan- tes $\triangle u b p 2$ y $\triangle u b p 16$ desaparece al eliminar el daño del medio}

Con el propósito de comprobar si nuestra hipótesis de regulación para la desubiquitinación de PCNA en S. pombe era cierta (es decir, si Ubp2 y Ubp16 eran las únicas proteínas encargadas de desubiquitinar a la abrazadera, ocupándose Ubp2 de 
las formas más poliubiquitinadas y Ubp16 del resto), decidimos comprobar, si la acumulación de las formas modificadas de PCNA en las cepas delecionadas para esas proteínas, se mantenía constante al eliminar el daño del medio.

Para ello partimos de $40 \mathrm{ml}$ de cultivo en YES en fase exponencial, de cada uno de los mutantes de las UBPs junto con una cepa silvestre como control. Tras recoger las muestras correspondientes para su análisis bioquímico, se añadió MMS al $0.01 \%$ a cada uno de los cultivos, dejando crecer a las células en estas condiciones durante 3 horas. Una vez recogidas las muestras tras este tratamiento, se centrifugaron las células y se lavaron dos veces con YES, con el fin de eliminar todo el MMS del medio. A continuación se resuspendieron nuevamente en YES, y se mantuvieron creciendo en estas condiciones entre 3 y 6 horas, recogiendo las muestras para Western blot en los tiempos indicados en la Figura 13A. Una vez más, tanto la preparación de los extractos proteicos, como las condiciones del Western blot llevadas a cabo, fueron las mismas que en los experimentos anteriores.

A

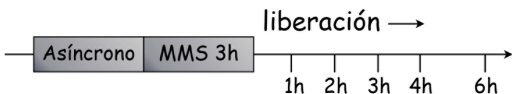

B

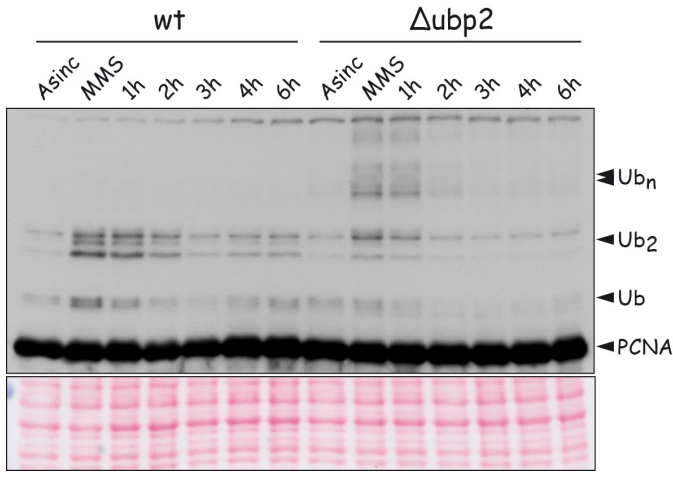

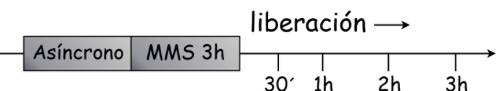

C

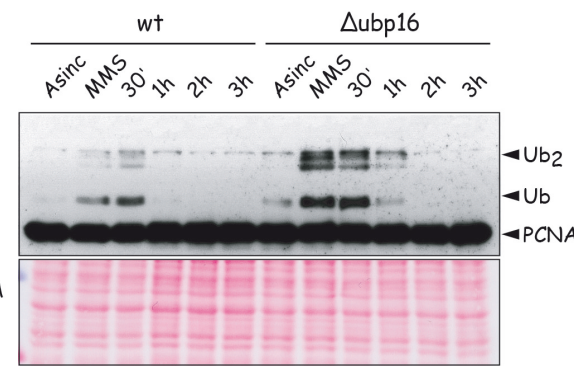

Figura 13: Las formas modificadas de PCNA en los mutantes $\Delta u b p 2$ y $\Delta u b p 16$ desaparecen al eliminar el MMS del medio. Se recogieron 8DO de cada cepa en los tiempos mostrados en A. Tras la preparación de los extractos proteicos, se procedió al análisis de los mismos, siguiendo las condiciones descritas previamente. En ambos casos ( $\mathbf{B}$ y $\mathbf{C}$ ) desaparecen las formas modificadas de PCNA, por lo que se deduce que la célula debe de disponer de otra UBP (o bien otro mecanismo de eliminación) capaz de desubiquitinar las formas modificadas de la abrazadera, aún en ausencia de Ubp2 y/o Ubp16.

En contra de lo esperado, el resultado del Western blot reveló que al eliminar el MMS del medio, desaparecían las formas modificadas de PCNA tanto en el mutante $\Delta u b p 2$ como en el $\Delta u b p 16$ (Figuras 13B y $13 \mathrm{C}$ ), por lo que probablemente alguna otra proteína no identificada en el cribado inicial, debía estar implicada en nuestra regulación a estudio; la desubiquitinación de PCNA. 


\section{Análisis de la ubiquitinación de PCNA en mutantes dobles de UBPs}

\subsection{Los dobles mutantes $\Delta u b p 15 \Delta u b p 16$ y $\Delta u b p 5 \Delta u b p 16$, acumulan más cantidad de PCNA modificado que los mutantes simples}

Tras averiguar que en los mutantes simples $\Delta u b p 2$ y $\Delta u b p 16$, el fenotipo de acumulación de formas modificadas de PCNA, no permanecía constante al eliminar el daño del medio, decidimos construir mutantes dobles de UBPs (mediante análisis de esporas al azar o selección de tétradas según el caso) con el fin de identificar alguna otra proteasa implicada en el proceso.

Todos los mutantes construidos fueron analizados bioquímicamente por Western blot, siguiendo el mismo diseño experimental que el llevado a cabo con los mutantes simples. Debido al elevado número de experimentos con resultados negativos, en la Figura 14 se muestra solamente el análisis de aquellos dobles mutantes en los que sí se producía una mayor acumulación de formas modificadas de PCNA respecto al $w t$ y a sus mutantes simples, siendo estos $\Delta u b p 15 \Delta u b p 16$ y $\Delta u b p 5 \Delta u b p 16$, aunque este último en menor medida.

A

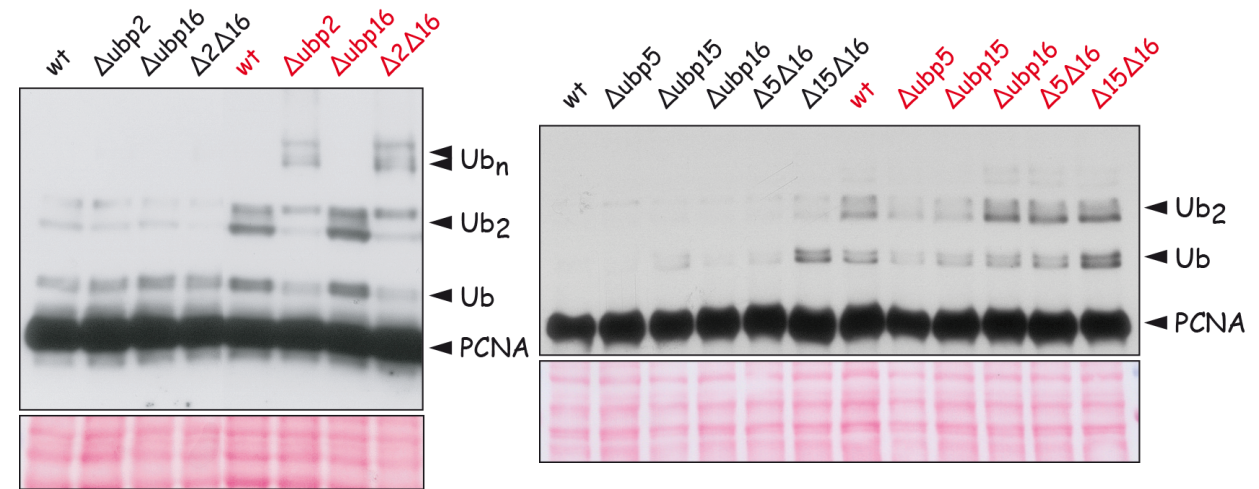

Figura 14: Análisis bioquímico de los mutantes dobles de UBPs. A: Tras analizar por Western blot el estado de ubiquitinación de PCNA en todos los dobles mutantes de UBPs, solo los aquí mostrados presentaron alguna diferencia respecto a las cepas parentales. B: El mutante $\Delta u b p 2 \Delta u b p 16$, presentó el mismo fenotipo que el mutante simple $\Delta u b p 2$, lo que hacía pensar que ambas proteínas actuaban en la misma ruta y que Ubp2 lo hacía en primer lugar. En ambos casos, las muestras dañadas con MMS, son las nombradas en "rojo".

Basándonos en el claro resultado de acumulación (tanto en presencia como en ausencia de daño) observado en el mutante doble $\Delta u b p 15 \Delta u b p 16$ (Figura 14A), decidimos considerar también a Ubp15 como una de las posibles proteasas encargadas de desubiquitinar a PCNA en la levadura de fisión. Asimismo, también incluimos a 
Ubp5, ya que aunque el fenotipo mostrado por el doble mutante $\Delta u b p 5 \Delta u b p 16$, no fue tan fuerte como el $\Delta u b p 15 \Delta u b p 16$, fue el único otro doble mutante en el que se observó un aumento en el estado de ubiquitinación de la abrazadera. Además, la alta similitud existente entre las proteínas Ubp5 y Ubp15, así como la descripción de un papel conjunto para ambas proteínas en la regulación de la endocitosis y de la polaridad celular, apoyó nuestra idea de considerarla como una de las posibles desubiquitinasas de PCNA en la levadura de fisión(Kouranti et al. 2010).

Respecto al análisis del doble mutante $\Delta u b p 2 \Delta u b p 16$, pudimos comprobar como se muestra en la Figura 14B, que presentaba el mismo patrón de ubiquitinación de PCNA que el mutante simple $\triangle u b p 2$, aunque ligeramente acumulativo, apoyando este resultado la hipótesis de que ambas proteasas actuaban en la misma ruta, y que Ubp2 lo hacía antes que Ubp16.

\section{Fenotipos de sobre-expresión de UBPs en S. pombe}

A pesar de que los resultados obtenidos en los análisis realizados (tanto con los mutantes simples como con los dobles) no eran muy concluyentes, todo hacía pensar que las proteínas encargadas de desubiquitinar a la abrazadera en la levadura de fisión, podían ser: Ubp2, Ubp5, Ubp15 y/o Ubp16. Así, con el fin de demostrar si estas proteínas poseían o no esta función in vivo, se construyeron cepas capaces de producir en exceso cada una de las UBPs mencionadas. Para ello, siguiendo el protocolo de transformación descrito en materiales y métodos, se introdujo delante

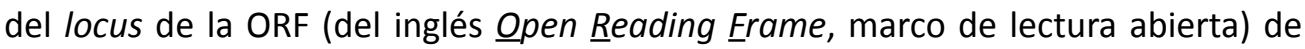
cada UBP mencionada, el promotor de sobre-expresión nmt1 (del inglés № Message in Ihiamine), promotor reprimible en presencia de tiamina e inducible en ausencia de ella.

Para llevar a cabo los experimentos de sobre-expresión, se partió de cultivos asíncronos crecidos a $30^{\circ} \mathrm{C}$ en Medio Mínimo (MM) más tiamina (condiciones en las que el promotor nmt1 está apagado), de células que sobre-expresaban cada una de las UBPs mencionadas junto con una cepa silvestre como control. Una vez alcanzada la fase exponencial, se recogieron las células por centrifugación y se lavaron tres veces con $\mathrm{MM}$ sin tiamina, con el fin de eliminar a ésta del medio. A continuación, se inocularon en MM sin tiamina para inducir al promotor, produciendo así la sobre-expresión de cada una de las UBPs. Después de 12-14 horas (dependiendo del experimento, tiempo suficiente para que se produzca la inducción de genes regulados por el promotor nmt1 (Maundrell 1990; Maundrell 1993)) en estas condiciones, se dividió a cada uno de los cultivos en dos. Mientras que a una mitad del cultivo se la mantuvo creciendo en las mismas condiciones, a la otra mitad se le añadió MMS $0.01 \%$ durante tres horas. Las muestras para el análisis bioquímico se tomaron en los tiempos indicados en la Figura 15A, recogiendo siempre en cada caso 8DO. Una vez más, para la obtención de los extractos proteicos se utilizó TCA, siguiendo el protocolo descrito en Materiales y Métodos. 
A

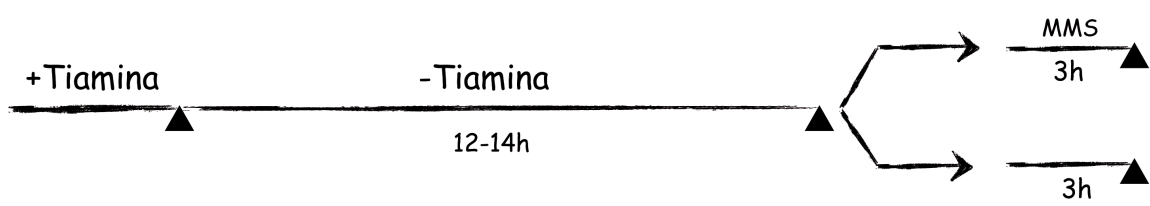

B

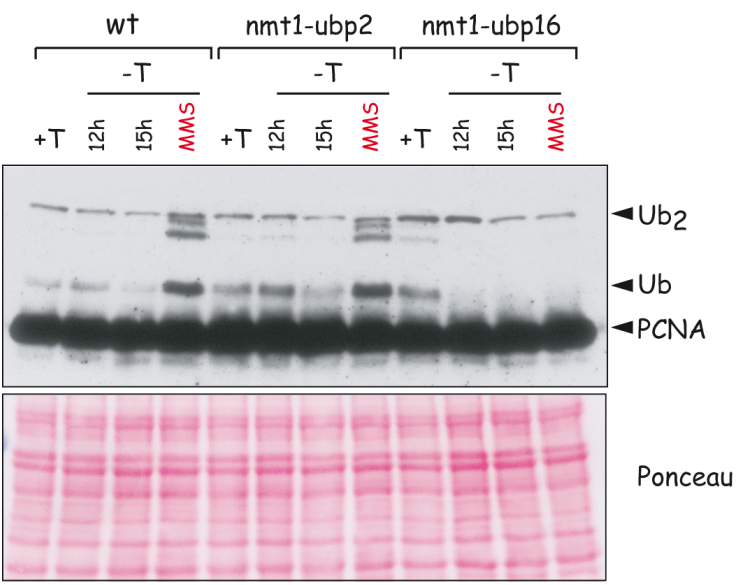

C

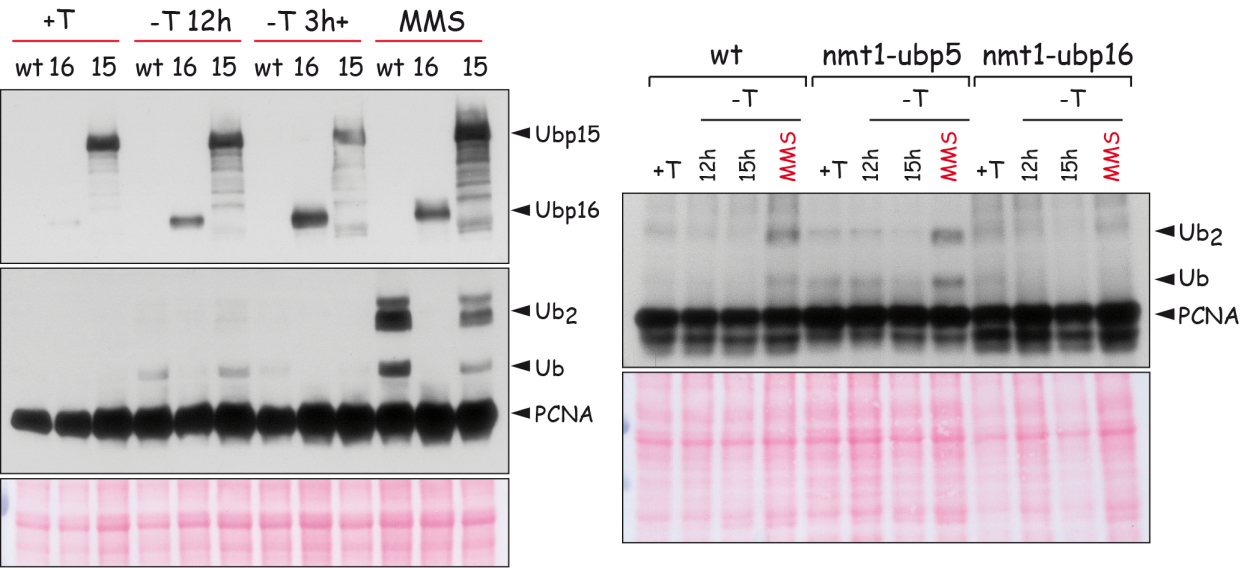

Figura 15: Ubiquitinación de PCNA en los mutantes que sobre-expresan Ubp2, Ubp5, Ubp15 y Ubp16. Construidas las cepas capaces de sobre-expresar las UBPs bajo el promotor $n m t 1$, se procedió a la recogida de muestras tal y como se muestra en el esquema $\mathbf{A}$, con el fin de averiguar el efecto que la sobre-expresión de dichas UBPs producía sobre el estado de ubiquitinación de la abrazadera. Ver descripción de los resultados en el texto. 
Como se muestra en la Figura 15B, en contra de lo esperado, la sobre-expresión de Ubp2 no produjo ningún descenso en las formas modificadas de PCNA, lo que nos hizo pensar que el fenotipo de acumulación de la deleción, no se debía a la implicación directa de esta proteína en el proceso de desubiquitinación de la abrazadera. La sobre-expresión de Ubp16 en cambio, sí tuvo un claro efecto, siendo muy visible en la muestra dañada, donde a diferencia de lo observado en las otras cepas ( $w t$ o nmt1-ubp2), sólo se observaba PCNA sin modificar. Este resultado a diferencia del anterior, sí nos hizo pensar que la implicación de Ubp16 en la desubiquitinación de la abrazadera, era directa.

El resultado de la sobre-expresión de Ubp15 por el contrario, no fue tan concluyente (Figura 15C). Y es que aunque sí se produjo un claro descenso en la cantidad de PCNA ubiquitinado, dicha modificación no llegaba a desaparecer por completo como en el caso de la sobre-expresión de Ubp16. La observación de este resultado, nos hizo pensar que esta proteína sí podría estar implicada en dicho proceso, pero de manera diferente a Ubp16; bien porque su papel no fuese tan relevante como el de ella (Ubp16), o bien porque no co-localizase por completo con el PCNA ubiquitinado.

Respecto a la sobre-expresión de la proteasa Ubp5 no pudimos sacar muchas conclusiones, ya que los resultados no eran repetitivos. Así, mientras que en algunos de los experimentos parecía ser capaz de desubiquitinar ligeramente a PCNA, en otros parecía no tener ningún efecto sobre la abrazadera (Figura 15D). Dada esta mezcla de resultados, decidimos no apartarla de nuestro estudio hasta conseguir evidencias más concluyentes.

Basándonos exclusivamente en los resultados positivos, es decir, en los obtenidos con la sobre-expresión de Ubp15 y Ubp16, decidimos comprobar si estas proteínas eran capaces de realizar su función en ausencia de la otra. Para ello, mediante micromanipulación, construimos cepas capaces de sobre-expresar una UBP en un fondo delecionado para la otra y viceversa. Una vez construidos estos mutantes, seguimos el mismo proceso que en el apartado anterior para producir la sobre-expresión de las proteínas a estudio. Una vez recogidas y procesadas las muestras, pudimos observar como se muestra en la Figura 16, que mientras que Ubp16 no necesita la presencia de Ubp15 para desubiquitinar eficientemente a PCNA, Ubp15 sí parece necesitar a Ubp16, ya que la desubiquitinación de la abrazadera por sobre-expresión de Ubp15, no es igual de eficiente en presencia que en ausencia de Ubp16.

Este resultado, sumado a los fenotipos más fuertes mostrados tanto por la deleción como por la sobre-expresión de Ubp16, nos hizo pensar que esta UBP era la principal proteasa encargada de desubiquitinar a PCNA en la levadura de fisión. 


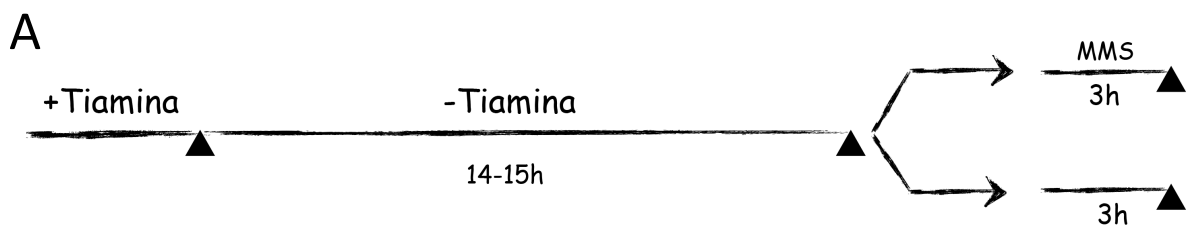

B

C

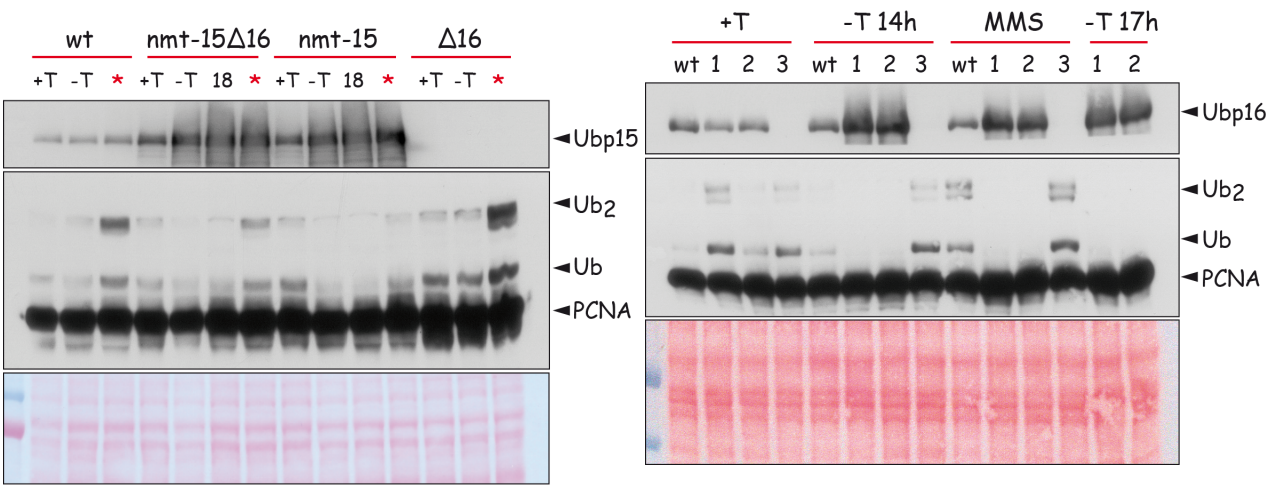

$+\mathrm{T}:$ + tiamina

- T: - tiamina (15h)

18: $18 \mathrm{~h}$ sin tiamina

* :MMS $3 \mathrm{~h}$
1: $n m t 1-u b p 16 \Delta u b p 15$

2: $n$ mt1-ubp16

3: $\Delta u b p 15$

Figura 16: Ubp16 desubiquitina a PCNA en ausencia de Ubp15, mientras que Ubp15 no es capaz de hacerlo eficientemente en ausencia de Ubp16. La recogida de muestras se realizó siguiendo el esquema general descrito en $\mathbf{A}$. En B, el tiempo de inducción sin tiamina fueron 15 horas. A partir de ese momento se dividió el cultivo en dos, añadiendo sólo a una mitad MMS durante 3 horas. La mitad del cultivo a la que no se le añadió MMS estuvo un total de 18 horas creciendo en MM sin tiamina, de ahí que a esa muestra se le haya nombrado como "18". El tiempo de inducción sin tiamina en $\mathbf{C}$ fueron 14 horas, estando la mitad del cultivo al que no se le añadió MMS, un total de 17 horas en MM sin tiamina.

\section{Localización de las UBPs}

Kouranti y colaboradores, publicaron en este momento un trabajo en el que describían tanto la localización, como las interacciones proteicas de cada una de las DUBs descritas en S. pombe, con el fin de asignarles una posible función en la célula. Ver Tabla 2 y Figura17.

Ya que la localización asumida para PCNA es nuclear, esperábamos que al menos en parte, la localización para "nuestras" UBPs también lo fuese. Y así ocurrió en el caso de Ubp16 (localizada exclusivamente en el nucleolo) y Ubp15 (localizada en el núcleo aunque en la fase no nucleolar, además de en diversas vesículas citoplasmáticas). Sin embargo, Ubp2 y Ubp5, presentaban una localización exclusivamente citoplásmática, estando aparentemente fuera por completo del núcleo. Este nuevo dato, añadido a los anteriores fenotipos contradictorios, arrojaba más dudas acerca 50 
de la implicación de estas proteasas en la desubiquitinación de la abrazadera, y es que ¿acaso era posible que proteínas no nucleares pudiesen desubiquitinar a PCNA directamente?

\begin{tabular}{|c|c|c|c|c|c|c|}
\hline \multicolumn{2}{|c|}{ S. pombe } & \multirow{2}{*}{$\begin{array}{l}\text { S. cerevisiae } \\
\text { DUB }\end{array}$} & \multirow{2}{*}{$\begin{array}{l}\text { H. sapiens } \\
\text { DUB }\end{array}$} & \multirow[b]{2}{*}{ Domains $^{\mathrm{a}}$} & \multirow[b]{2}{*}{ Localization $^{\text {b }}$} & \multirow[b]{2}{*}{ Interactors } \\
\hline DUB & UniProtKB & & & & & \\
\hline Ubp1 & Q9USM5 & Ubp12p & NA & USP, DUSP & CS (ER) & \\
\hline Ubp2 & Q9P3U0 & Ubp2p & NA & USP & c & Ucp6 \\
\hline Ubp3 & 094269 & Ubp3p & USP10 & USP & c & $\mathrm{Nxt3}$ \\
\hline Ubp4 & 060139 & Doa4p, Ubp5p & USP8 & USP & CS (endosomes) & Sfp47 \\
\hline Ubp5 & Q09879 & Ubp15p & USP7 & USP, MATH & CS (Golgi) & Ftp105 \\
\hline Ubp6 & Q92353 & Ubp6p & USP14 & USP, UBL & $\mathrm{N}$ & 265 proteasome \\
\hline Ubp7 & Q9P755 & Ubp11p & USP45 & USP & c & \\
\hline Ubp8 & Q09738 & Ubp8p & USP22 & USP, ZnF-UBP & $\mathrm{N}$ & SAGA subunits \\
\hline Ubp9 & Q9P7V9 & $\begin{array}{l}\text { Ubp9p, } \\
\text { Ubp13p }\end{array}$ & $\begin{array}{l}\text { USP12, } \\
\text { USP46 }\end{array}$ & USP & $\begin{array}{l}\text { N, CS (cell tips, } \\
\text { septum) }\end{array}$ & Bun62, Bun107 \\
\hline Ubp11 & Q9UUD6 & NA & NA & USP & M & Tom70 \\
\hline Ubp12 & O60079 & Ubp12p & USP4, USP15 & USP, DUSP & $\mathrm{N}, \mathrm{C}$ & \\
\hline Ubp14 & Q11119 & Ubp14p & USP5 & USP, ZnF-UBP, UBA & $\mathrm{N}$ & \\
\hline Ubp15 & Q9UTा1 & Ubp15p & USP7 & USP, MATH & $\mathrm{N}, \mathrm{CS}$ & \\
\hline Ubp16 & 074442 & Ubp10p & NA & USP & No & \\
\hline Uch1 & Q10171 & Yuh1p & UCHL3 & UCH & $\mathrm{N}, \mathrm{C}$ & \\
\hline Uch2 & Q9UUB6 & NA & UCHL5 & UCH & NE & 265 proteasome \\
\hline Otu1 & 013974 & Otu1p & YOD1 & OTU & $\mathrm{N}, \mathrm{C}$ & Cdc48 \\
\hline Otu2 & Q9UUK3 & Otu2p & OTUD6B & OTU & c & \\
\hline Sst2 & Q9P371 & NA & STAMBP & JAMM & CS (endosomes) & \\
\hline Rpn11 & P41878 & Rpn11p & PSMD14 & JAMM & NE & 265 proteasome \\
\hline
\end{tabular}

Tabla2: Localizaciones e interacciones proteicas de las UBPs de S. pombe. Adaptada de Kouranti 2010.
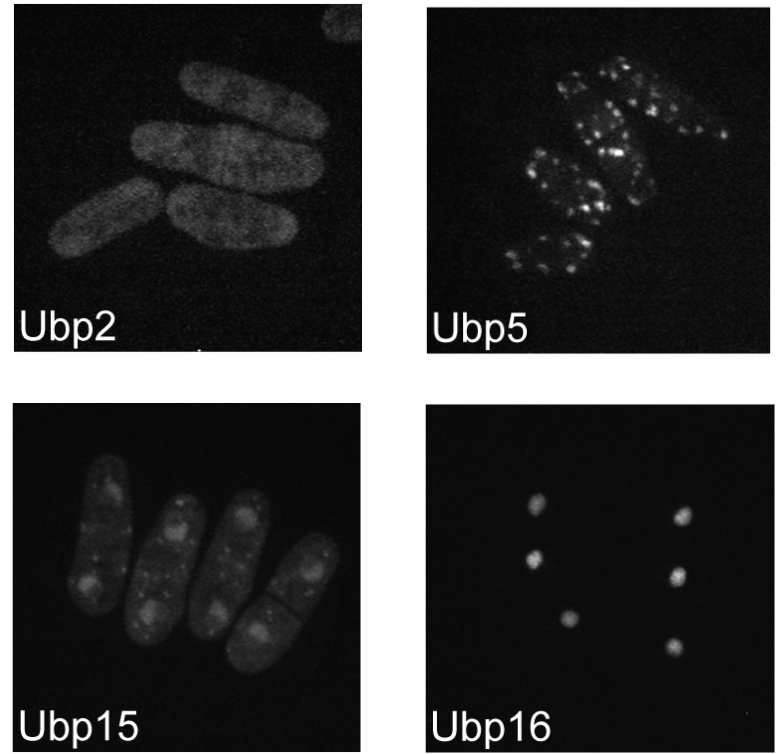

Figura 17: Localizaciones de Ubp2, Ubp5, Upb15 y Ubp16. Figura adaptada de Koutanti 2010. 
Ya que la localización de Ubp15 y Ubp16, sí se correspondía con la descrita para PCNA, decidimos ahondar más en el estudio de ambas proteínas, construyendo nuestras propias versiones etiquetadas de las mismas. Con el propósito de averiguar si dichas proteasas co-localizaban de algún modo, (algo esperado ya que nuestros resultados las revelaban como posibles desubiquitinasas de PCNA), construimos un mutante con las proteínas Ub15 y Ubp16 etiquetadas con GFP (del inglés Green Fluorescent Protein) y RFP (del inglés Red Fluorescent Protein) respectivamente. En contra de lo esperado, la observación de dicho mutante reveló que no existía co-localización entre las desubiquitinasas (Figura 18A).

Para un análisis más detallado de la localización de Ubp16, construimos un mutante con la proteasa etiquetada con GFP y con la proteína Cut11 (proteína localizada en la membrana nuclear) etiquetada con RFP. Tal y como se muestra en la Figura 18B, en ningún momento del ciclo celular la desubiquitinasa sale de su localización nucleolar.

A

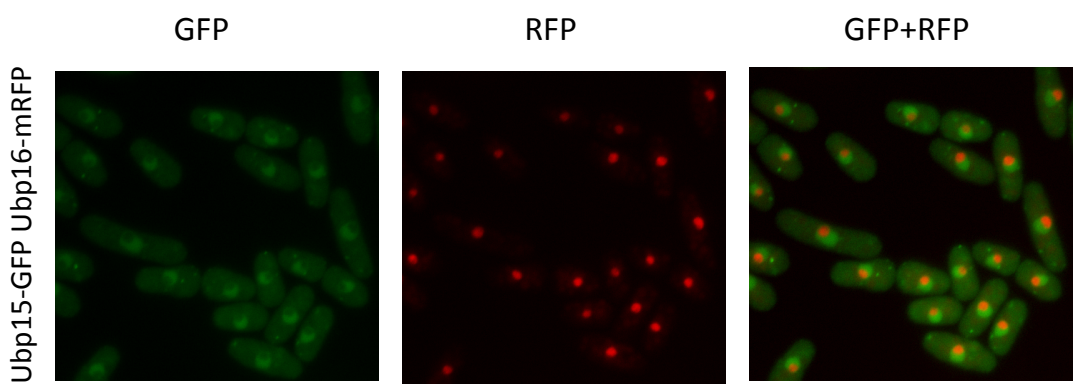

B

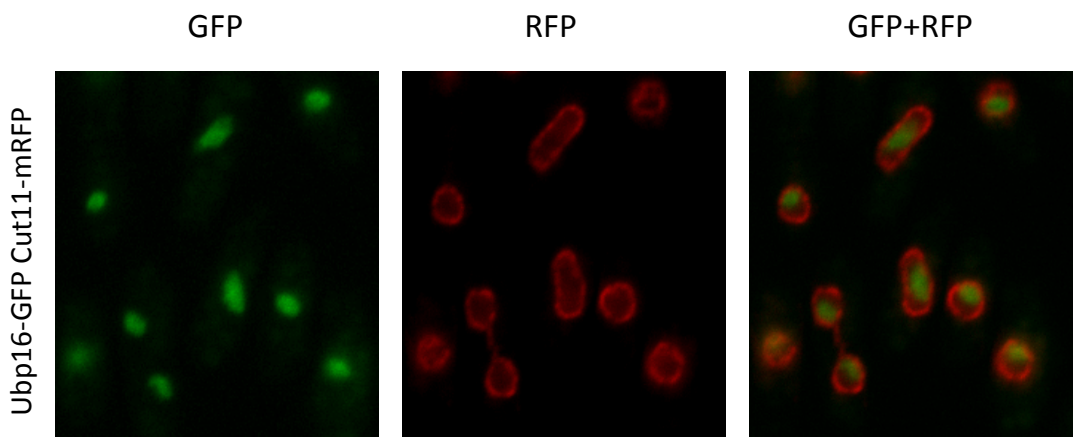

Figura 18: Analisis por microscopía de fluorescencia de las desubiquitinasas Ubp15 y Ubp16. Para descrición ver texto. 


\section{Eliminación de Ubp2 y Ubp5 de nuestro estudio}

A tenor de los resultados obtenidos para Ubp2 y Ubp5, era complicado decidir si se debía continuar o no con el análisis de estas proteínas. Es por ello que en este momento, nos planteamos la necesidad de diseñar algún tipo experimento, que respondiese de forma concluyente a la pregunta de si estas proteasas podían tener o no, una implicación directa en el proceso de desubiquitinación de PCNA en levadura de fisión.

\subsection{Ubp2}

Respecto a Ubp2, solo el fenotipo de acumulación de formas muy poliubiquitinadas de PCNA observado en la deleción, hacía pensar que su implicación era directa, ya que tanto el resultado de su sobre-expresión, como su localización citoplásmatica, hacían pensar lo contrario.

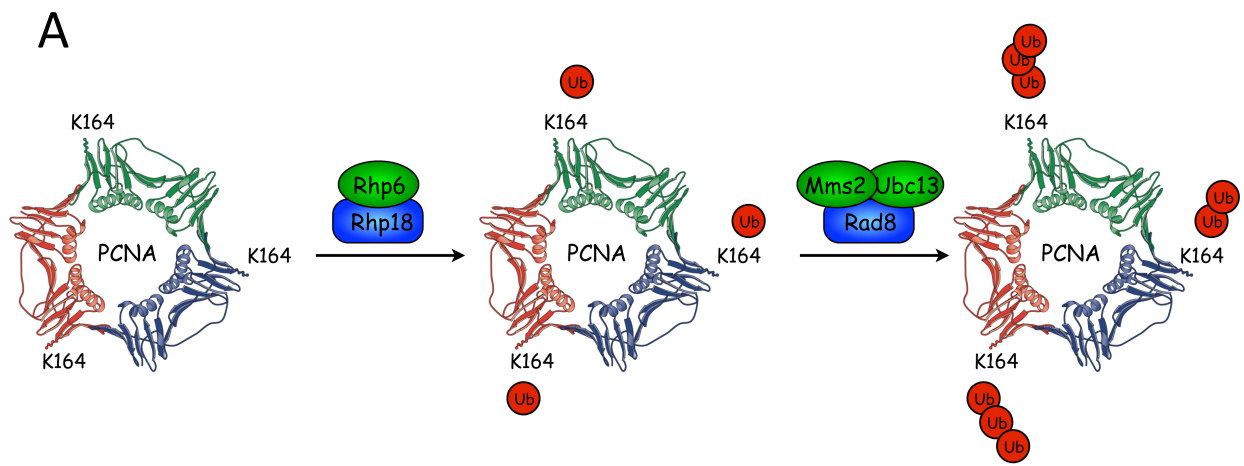

B

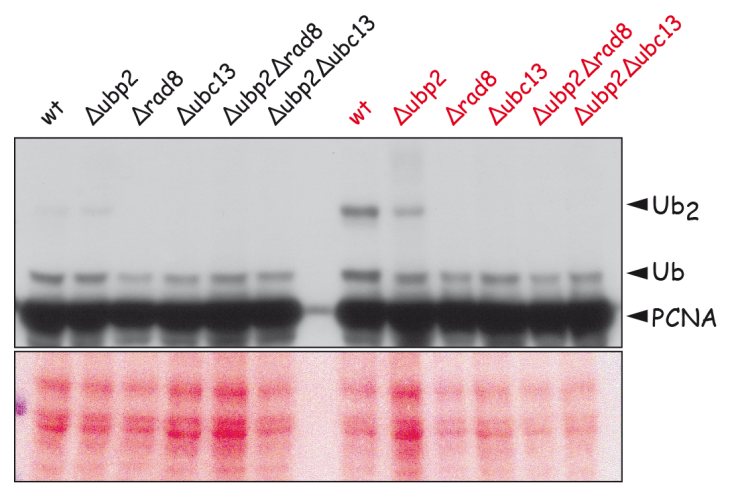

Figura 19: Ubp2 no es capaz de desubiquitinar las formas monoubiquitinadas de PCNA. A: Esquema de las proteínas implicadas en la ubiquitinación de PCNA en la levadura de fisión. B: Análisis de la ubiquitinación de PCNA en los mutantes descritos. Se recogieron muestras de cultivos asíncronos (izquierda en "negro") y de cultivos tratados durante 3 horas con MMS 0.01\% (derecha en "rojo"). Como revela el Western blot, la cantidad de PCNA monoubiquitinado en los mutantes simples $\Delta u b c 13$ y $\Delta$ rad8, es la misma que en los mutantes dobles $\Delta u b p 2 \Delta u b c 13$, y $\Delta u b p 2$ $\Delta$ rad8, lo que indica que la proteasa Ubp2 no es capaz de desubiquitinar las formas monoubiquitinadas de PCNA. 
Teniendo en cuenta que nuestro objetivo final era averiguar cómo PCNA volvía a su estado basal, es decir, desubiquitinado, para así recuperar una replicación normal (la llevada a cabo por las polimerasas replicativas $\delta$ y $\varepsilon$ ), nuestro máximo interés se centraba en aquellas proteasas capaces de desubiquitinar un PCNA monoubiquitinado. Ya que el resultado observado en el mutante $\Delta u b p 2$, hacía pensar que, en el caso de tener una implicación directa en este proceso, la tendría en la desubiquitinación de las formas poliubiquitinadas, decidimos construir mutantes que permitiesen intuir, si dicha proteasa podía o no estar implicada también en la desubiquitinación de PCNA monoubiquitinado, ya que de no ser así, optaríamos por la eliminación de dicha proteína de nuestro estudio. Los mutantes capaces de dar esa información, serían aquellos que careciesen tanto de la proteasa Ubp2, como de alguna de las E2-E3 encargadas de ubiquitinar el PCNA monoubiquitinado (Rad8, Mms2 o Ubc13).

Construidos los mutantes mediante micromanipulación, pasamos a analizar el estado de ubiquitinación de PCNA en los mismos, siguiendo el diseño experimental del escrutinio inicial. Como se muestra en la Figura 19, la cantidad de PCNA monoubiquitinado en los mutantes dobles $\Delta u b p 2 \Delta u b c 13$ y $\Delta u b p 2 \Delta$ rad8 es la misma que en los mutantes simples $\Delta u b p 13$ o $\Delta$ rad8 y no superior, como era de esperar si Ubp2 se encargase de desubiquitinar las formas monoubiquitinadas de PCNA. Por lo tanto, a raíz de este resultado decidimos abandonar el estudio de Ubp2 de nuestro trabajo.

\subsection{Ubp5}

En cuanto a Ubp5, solo el fenotipo del doble mutante $\Delta u b p 5 \Delta u b p 16$, nos hacía pensar que podía tener una implicación directa en nuestro proceso a estudio, ya que ni el resultado de su sobre-expresión (variaciones sutiles y variables) ni el de su localización (citoplásmática), apoyaban la hipótesis de que pudiese ser una de las proteasas encargadas de desubiquitinar PCNA en la levadura de fisión. Sin embargo, a pesar de estos datos nada concluyentes, debido a un dato más presentado en el trabajo de Kouranti y colaboradores, decidimos no apartarla de nuestro estudio.

Como ya hemos mencionado, la localización wt descrita para Ubp5 era citoplásmatica, sin embargo, Kouranti y colaboradores, observaron cómo en ausencia de Ftp105 (Ubp5 potential transmembrane protein of $105 k D a$, proteína descubierta por los autores por co-purificar siempre con Ubp5), Ubp5 presentaba una localización nuclear difusa (Figura 20A). Este resultado nos hizo pensar, que quizá una pequeña parte de Ubp5 podría localizarse de forma basal en el núcleo, aunque tan pequeña que ésta no pudiese ser detectada por microscopía. Es importante recordar que la localización descrita en dicho trabajo, se debe a una versión etiquetada de la proteína con GFP en su extremo carboxilo y que dicha etiqueta podría estar alterando la localización per se de la proteína.

Dentro de este contexto, nos planteamos la posibilidad de que quizá forzando su localización nuclear, podríamos averiguar si Ubp5 tenía o no un papel en el proceso de desubiquitinación de la abrazadera (aunque este fuese residual). Así, para lograr 54 
dicha localización, decidimos seguir dos estrategias diferentes, por un lado construyendo el mutante descrito $\Delta$ ftp105 y por otro añadiendo una señal de localización nuclear denominada NLS (del inglés Nuclear Localization Signal) a Ubp5. Además, siguiendo esta última estrategia de "etiquetas de localización", decidimos construir un mutante más con la señal NES (del inglés N uclear Export Signal) para Ubp5, con el fin de sacar la supuesta pequeña cantidad de proteasa localizada en el núcleo, y ver así su efecto sobre el estado de ubiquitinación de PCNA.

A
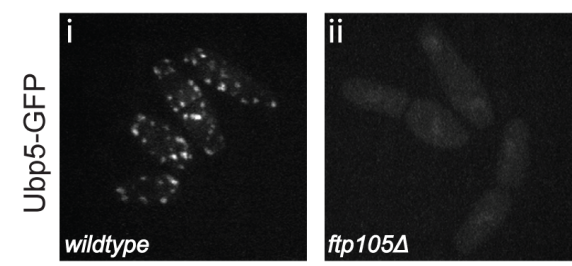

B

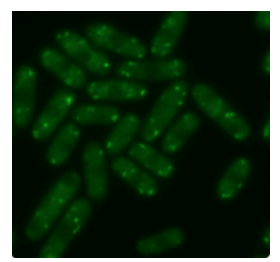

Ubp5-GFP

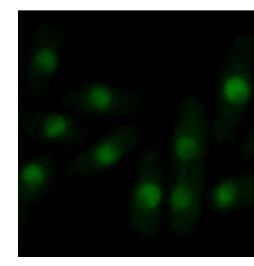

Ubp5-GFP-NLS

C

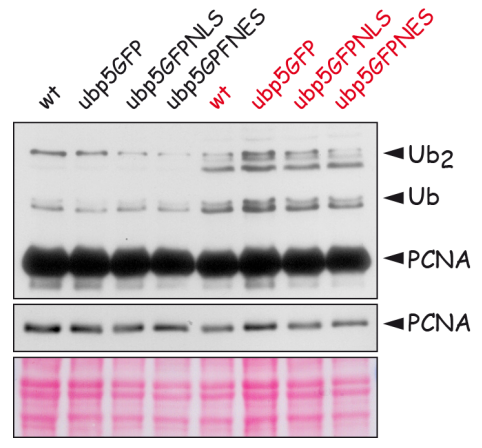

D

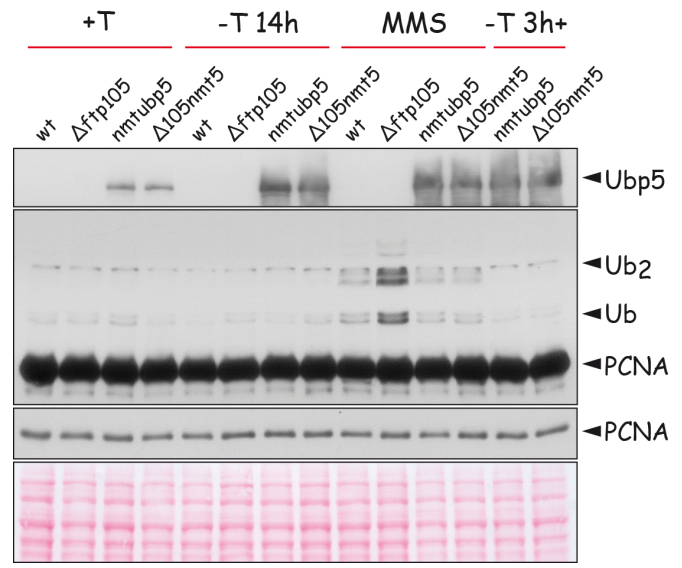

Figura 20: Análisis de la proteasa Ubp5: localización y estado de ubiquitinación de PCNA. A: La proteasa Ubp5 se encuentra localizada en el citoplasma en células $w t$, sin embargo, dicha localización parece depender de la proteína Ftp105, ya que en ausencia de ella, la proteasa presenta una localización nuclear difusa (Figura modificada de Kouranti 2010). Dicha localización, también se puede observar al añadir un señal NLS (B). C: Análisis de la ubiquitinación de PCNA en mutantes con señales NLS y NES que alteran la localización wt de la proteasa Ubp5. Los carriles en "rojo" se corresponden con las muestras tratadas durante 3 horas con MMS 0.01\%. Para la descripción del resultado ver texto. D: Análisis bioquímico del estado de ubiquitinación de la abrazadera en mutantes que presentan una localización nuclear para Ubp5 en condiciones de expresión normales ( $\Delta$ ftp105) y aumentadas (nmt1 ubp5 $\Delta f t p 105)$. Como en todos los análisis de sobre-expresión bajo el promotor $n m t 1$, se siguió el mismo diseño experimental que en los casos anteriores (ver esquemas Figura 15A y Figura 16A) . Para la descripción del resultado, ver texto. 
De nuevo, una vez construidos los mutantes $\triangle$ ftp105, ubp5-GFP-NLS y ubp5-GFPNES, procedimos al análisis del estado de ubiquitinación de PCNA en los mismos, con el propósito de confirmar la implicación o no de Ubp5 en la desubiquitinación de la abrazadera. Así, en caso afirmativo (es decir, en el caso de que Ubp5 desubiquitinase a PCNA), los mutantes con localización nuclear para Ubp5 ( $\triangle f t p 105$ y ubp5-GFP-NES) presentarían menor cantidad de PCNA ubiquitinado que el tipo silvestre; mientras que el que sacase a la proteasa del núcleo, presentaría el patrón contrario (es decir más cantidad de PCNA ubiquitinado que el tipo silvestre).

Como se muestra en la Figura 20C, el análisis de los mutantes ubp5-GFP-NLS y ubp5-GFP-NES, revelaba que la proteasa Ubp5 no debía estar implicada en el proceso de desubiquitinación de PCNA, ya que tanto el mutante "NLS" como el "NES" presentaban el mismo patrón y nivel de ubiquitinación de PCNA que el tipo silvestre. Sin embargo, el análisis del mutante $\Delta$ ftp105 no corroboró el resultado de los mutantes "etiquetados", ya que en contra de todo pronóstico, dicho mutante presentó más cantidad de PCNA ubiquitinado que el tipo silvestre (Figura 20D). Debido a la poca información disponible hasta la fecha de ambas proteínas (Ubp5 y Ftp105), no podemos descartar que este fenotipo de acumulación se deba solamente a una lenta progresión por Fase $S$ y no por una implicación directa de ambas en la regulación de la ubiquitinación de PCNA.

Ante la suma de tantos resultados negativos, parecía lógico pensar que Ubp5 no debía estar implicada en la desubiquitinación de la abrazadera, y que por lo tanto la debíamos eliminar de nuestro estudio. Sin embargo, ya que no estábamos completamente seguros de que esa fuese la decisión correcta, decidimos construir un mutante más cuyo análisis arrojase algo de luz a nuestro dilema.

El mutante elegido fue $n m t 1$ ubp5 $\Delta f t p 105$, mutante capaz de sobre-expresar Ubp5 en el núcleo. Como se muestra en la Figura 20D, las muestras tratadas con MMS de dicho mutante, mostraban mucha menos cantidad de PCNA modificado que las muestras tratadas del mutante $\Delta f t p 105$, resultado que apoyaba la idea de que Ubp5 podría ser una de las proteasas encargadas de desubiquitinar a PCNA. Por la tanto, a raíz de este resultado, decidimos no descartar a dicha proteasa de nuestro estudio.

\section{Análisis del triple mutante $\Delta u b p 5 \Delta u b p 15 \Delta u b p 16$}

A pesar de estos nuevos datos, tan endebles como contradictorios, decidimos dar un paso más en el análisis de Ubp5 construyendo el triple mutante $\Delta u b p 5 \Delta u b p 15$ $\triangle u b p 16$, barajando la posibilidad de que aunque su papel en la desubiquitinación de PCNA debía ser muy débil, sí podía ser crucial o al menos importante, en ausencia de las otras dos proteasas. 
Con el fin de demostrarlo, una vez construido dicho mutante por micromanipulación, analizamos cómo era en él el estado de ubiquitinación de la abrazadera, de tal forma que si se confirmaba nuestra hipótesis, dicho mutante presentaría mayor cantidad de PCNA ubiquitinado que el mutante doble $\triangle u b p 15 \Delta u b p 16$.

La construcción de dicho mutante fue muy complicada, posiblemente porque la falta de las tres UBPs altera muchos procesos celulares (como probablemente la segregación de esporas y de ahí la dificultad para conseguirlo). En efecto, una vez construido, pudimos observar cómo células carentes de las tres UBPSs, presentaban formas aberrantes (datos no mostrados), así como un crecimiento extremadamente lento. Sin embargo, a pesar de las dificultades que conllevó trabajar con este mutante, conseguimos analizar el estado de ubiquitinación de PCNA en él y compararlo con el de los mutantes dobles. Como se muestra en la Figura 21, a pesar de los fenotipos descritos, este mutante no presentaba mayor acumulación de PCNA ubiquitinado que los mutantes dobles, resultado que una vez más nos hizo pensar que Ubp5 no estaba implicada en la desubiquitinación de la abrazadera.

A partir de este momento, tras analizar todos los resultados obtenidos para Ubp5, sumado al hecho de la gran dificultad que conllevaba trabajar con el triple mutante $\Delta u b p 5 \Delta u b p 15 \Delta u b p 16$, decidimos, ahora sí, apartar a dicha proteína de nuestro estudio.

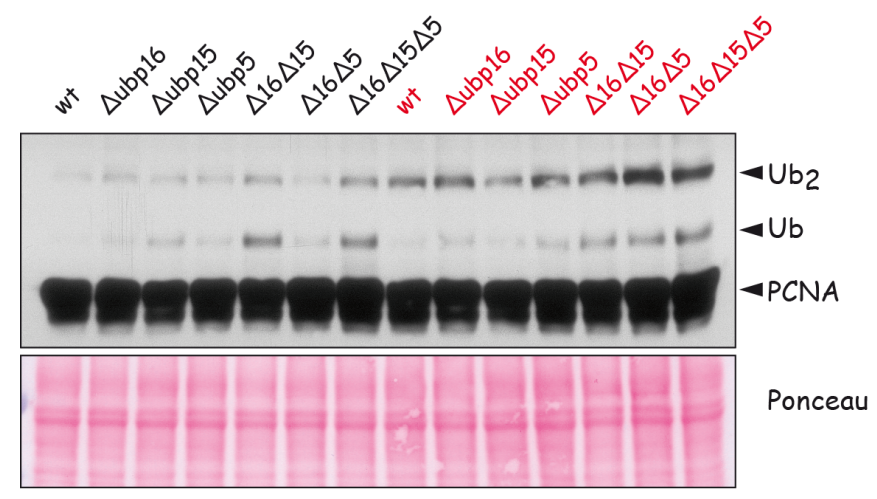

Figura 21: Análisis del estado de ubiquitianción de PCNA en el triple mutante $\Delta u b p 5 \Delta u b p 15 \Delta u b p 16$. Con el fin de averiguar si Ubp5 estaba implicada en el proceso de desubiquitinación de PCNA, construimos un triple mutante $\triangle u b p 5 \Delta u b p 15$ $\triangle u b p 16$. Las células fueron una vez más dañadas con MMS $0.01 \%$ durante 3 horas (muestras en "rojo"). La preparación de los extractos proteicos así como las condiciones de Western blot seguidas, fueron las mismas que en los experimentos anteriores. 


\section{Sobre-expresión del resto de UBPs nucleares}

Dado que los resultados obtenidos hasta el momento, no fueron en muchos de los casos concluyentes, temíamos haber obviado a alguna otra UBP sí implicada en el proceso a estudio, por no haber dado un fenotipo de acumulación claro en los cribados iniciales. Por eso, basándonos en las localizaciones descritas para las DUBs por Kouranti y colaboradores (Kouranti et al. 2010), decidimos comprobar qué ocurría con la ubiquitinación de la abrazadera cuando se sobre-expresaban en la célula cada una de las DUBs localizadas en el núcleo, es decir: Ubp6, Ubp8, Ubp9, Ubp12 y Ubp14.

Una vez más, para construir estos mutantes de sobre-expresión, se introdujo por transformación con Acetato de Litio el promotor nmt1 delante de cada ORF. Una vez hechas las comprobaciones pertinentes en cada uno de los transformantes, se procedió a la recogida de muestras y al análisis posterior de las mismas, siguiendo el mismo diseño experimental que con la sobre-expresión de Ubp16. Como se muestra en al Figura 22, sólo la sobre-expresión de Ubp12 produjo un descenso en la cantidad de PCNA modificado, por lo que a partir de este momento y en base a este resultado, Ubp12 fue considerada como la tercera posible desubiquitinasa de PCNA en S. pombe.

A

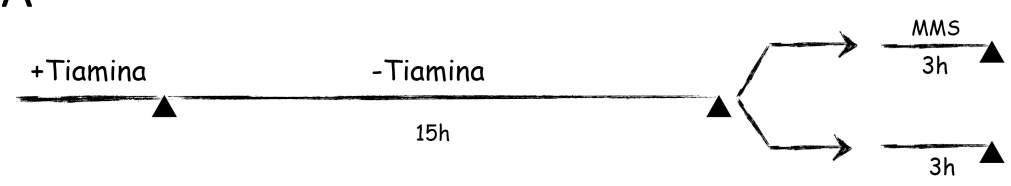

B

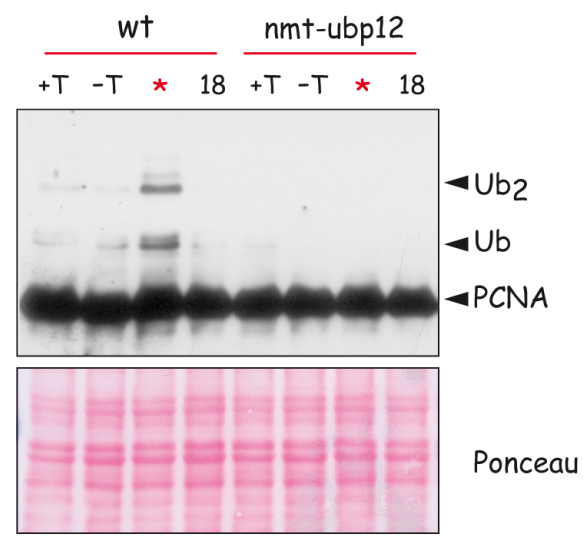

Figura 22: La sobre-expresión de la UBP nuclear Ubp12, disminuye la ubiquitinación de PCNA en S. pombe. Siguiendo el esquema mostrado en A, se recogieron muestras de células capaces de sobre-expresar Ubp12, así como de un wt como control. Como se muestra en B, la sobre-expresión de dicha proteasa (al igual que Ubp15 y Ubp16) es capaz de desubiquitinar a PCNA en condiciones de sobre-expresión. El carril mostrado en "rojo" se corresponde con las muestras tratadas durante 3 horas con MMS $0.01 \%$, y el carril " 18 ", se corresponde con las muestras crecidas durante un total de 18 horas $(15+3)$ en MM sin tiamina. 


\section{Análisis del triple mutante $\Delta u b p 12 \Delta u b p 15 \Delta u b p 16$}

A partir de este momento, basándonos en todos los resultados anteriores, decidimos centrar nuestro trabajo en el análisis de las UBPs 12, 15 y 16.

Ya que la deleción de Ubp12 no dio ningún fenotipo, ni sola ni en combinación con la de Ubp16 o Ubp15 (datos no mostrados), pensamos que su papel en la desubiquitinación de PCNA, debía ser menos importante que el de las anteriores, aunque quizá imprescindible en ausencia de ellas. Con el fin de averiguarlo, construimos el triple mutante $\Delta u b p 12 \Delta u b p 15 \Delta u b p 16$, para analizar el estado de ubiquitinación de la abrazadera en él, ya que de confirmarse nuestra hipótesis, este mutante mostraría mayor cantidad de PCNA ubiquitinado que los mutantes dobles.

Tal y como se observa en la Figura 23 (a diferencia del mutante $\Delta u b p 5 \Delta u b p 15$ $\triangle u b p 16$, donde no observamos más aumento de PCNA modificado), el triple mutante $\triangle u b p 12 \Delta u b p 15 \Delta u b p 16$ acumula más PCNA monoubiquitinado que el mutante doble $\triangle$ ubp16 $\triangle$ ubp15 (aunque curiosamente en él no se observa PCNA poliubiquitinado). Este resultado, sumado al fenotipo observado en la sobre-expresión, ratificaba la idea de que Ubp12 era la tercera proteasa encargada de la desubiquitinación de PCNA en la levadura de fisión.

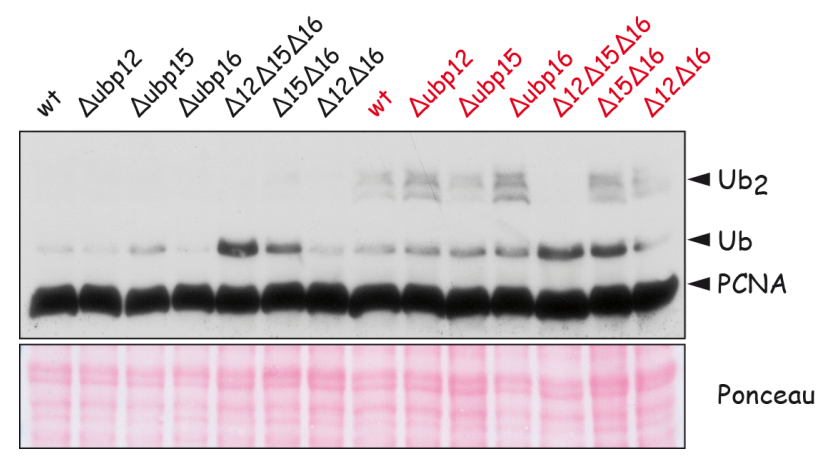

Figura 23: Análisis de la ubiquitinación de PCNA en el triple mutante $\triangle$ ubp12 \ubp15 $\Delta$ ubp16. Se recogieron muestras asíncronas y tratadas durante 3 horas con MMS $0.01 \%$, de las cepas $\Delta u b p 12, \Delta u b p 15, \Delta U b p 16, \Delta u b p 12 \Delta u b p 16, \Delta u b p 15$ $\Delta u b p 16, \Delta u b p 12 \Delta u b p 15 \Delta u b p 16$, así como de un wt como control. La preparación de extractos proteicos y condiciones de Western blot, fueron las mismas que las descritas anteriormente. Las muestras en "rojo" una vez más hacen referencia a las células tratadas con MMS.

\subsection{Bloqueo y liberación con MMS en $\Delta u b p 12 \Delta u b p 15 \Delta u b p 16$}

Como en los casos anteriores, después de comprobar la gran cantidad de PCNA modificado que se acumulaba en el triple mutante $\Delta u b p 12 \Delta u b p 15 \Delta u b p 16$, quisimos averiguar si dicha acumulación se mantenía constante en el tiempo, o como ocurría en el caso de los mutantes simples, desaparecía al eliminar el daño del me- 
dio. Para averiguarlo, tratamos con MMS $0.01 \%$ durante 3 horas al triple mutante y a una cepa silvestre como control, y a continuación, tras eliminar el daño del medio, recogimos muestras de las células creciendo en esas condiciones sin daño, hasta 6 horas después. Una vez procesadas las muestras y sometidas a un análisis de Western blot, pudimos comprobar en contra de lo esperado, que aunque no fue mucho el descenso observado, la cantidad de PCNA ubiquitinado no se mantenía completamente constante a lo largo del tiempo (Figura 24).

A

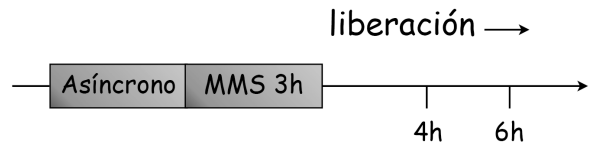

B

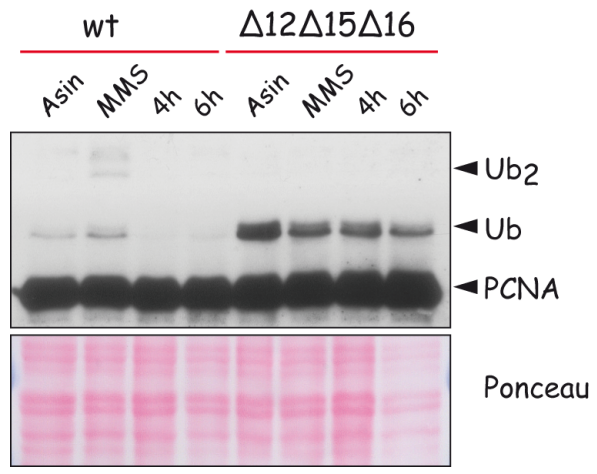

Figura 24: Analisis del estado de ubiquitinación de la abrazadera en el mutante \ubp12 $\Delta$ ubp15 $\Delta$ ubp16 al eliminar el daño del medio. Siguiendo el esquema descrito en $\mathbf{A}$, se tomaron 8DO de cada muestra y se procesaron como en los casos anteriores. Como se observa en $\mathbf{B}$, a las 6 horas de la liberación del MMS, el triple mutante presentaba un ligero descenso en la cantidad de PCNA modificado, sugiriendo la posibilidad de que algún otro proceso debía encargarse de la eliminación de dicho PCNA modificado.

\section{Análisis de las versiones catalíticamente inactivas de Ubp15 y Ubp16}

Como se mencionó al principio, Ubp16, Ubp15 y Ubp12 son cisteínas proteasas pertenecientes a la subfamilia de DUBs denominada USP/UBP. Ya que su dominio catalítico está muy bien caracterizado, se conoce cuál es el residuo de cisteína que les confiere la actividad catalítica a cada una de ellas.

Apoyándonos en este dato, decidimos construir versiones catalíticamente inactivas (CS) de dichas proteasas, con el fin de averiguar si éstas tenían una función directa o no, en el proceso de desubiquitinación de PCNA.

60 
La construcción de cada una de las cepas mutantes se consiguió clonando la ORF en el caso de Ubp16 y el ADNc en el caso de Ubp15 (ya que ésta posee dos intrones en su ORF), en el Plásmido pREP 3X, siguiendo los pasos descritos en Materiales y Métodos. A continuación, por mutagénesis dirigida, se mutó cada uno de los residuos de cisteína (C134 en Ubp16 y C239 en Ubp15) a residuos de serina catalíticamente inactivos. Una vez conseguidas las construcciones, se transformaron células carentes de cada una de las UBPs correspondientes, con el fin de tener en la célula sólo la versión proteica codificada por los plásmidos construidos.

Conseguidas las cepas mutantes y de nuevo siguiendo el mismo diseño experimental para la sobre-expresión de Ubp16, procedimos a la recogida de muestras y a su posterior análisis por Western blot. Tal y como se muestra en la Figura $\mathbf{2 5}$, la sobreexpresión de la versión inactiva de las proteínas Ubp15 y Ubp16, no es capaz de desubiquitinar a PCNA como lo hace la versión wt de las mismas, siendo de nuevo la muestra dañada el momento más claro para ver este resultado.

Los resultados para Ubp12 no se muestran, ya que en el momento de la redacción de esta tesis, no se habían conseguido los clonajes necesarios para la construcción de la versión CS de dicha proteína.

A

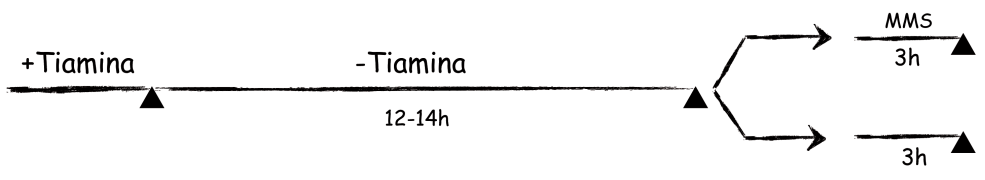

B

C

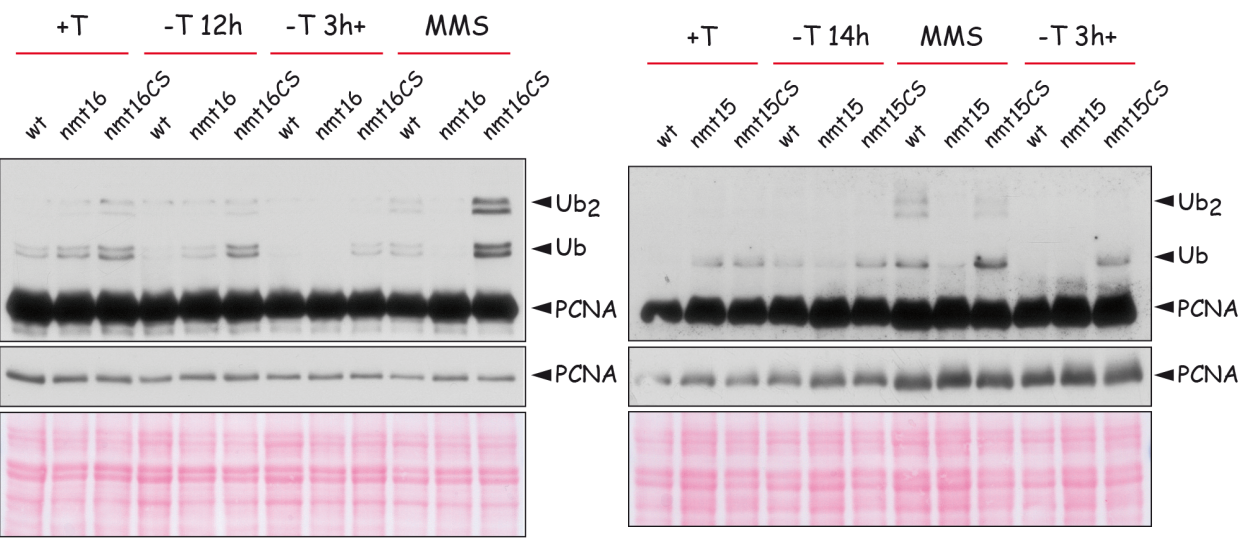

Figura 25: Las versiones catalíticamente inactivas de las proteínas Ubp16 y Ubp15 no son capaces de desubiquitinar a la abrazadera deslizante. Tras construir los transformantes CS por mutagénesis dirigida, se indujo su sobre-expresión siguiendo el esquema mostrado en $\mathbf{A}$. El análisis de Western blot (B y C) reveló que sólo la versión wt de ambas proteasas, era capaz de desubiquitinar PCNA. 


\section{PCNA interactúa in vivo con las UBPs Ubp15 y Ubp16.}

El siguiente paso para poder corroborar que estas proteínas tenían una función directa en el proceso de desubiquitinación de PCNA, era demostrar que existía una interacción física entre dichas proteasas y la abrazadera, tal y como se espera de un complejo enzima-sustrato.

Con el fin de demostrar dicha interacción, se construyeron cepas que contenían versiones etiquetadas de las proteínas implicadas (las UBPs con el epítopo 13Myc y PCNA con 3Flag).

A

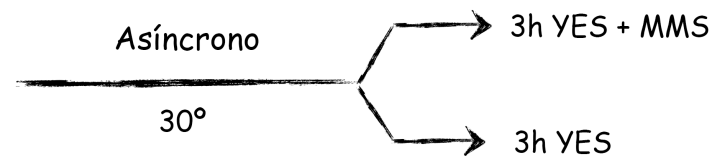

B

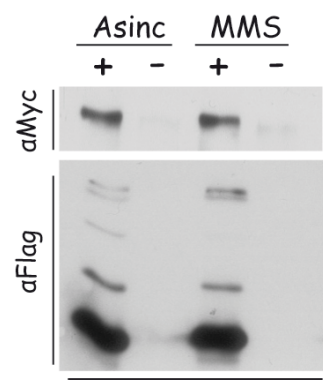

IP

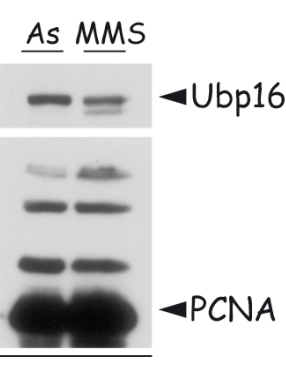

ET
C

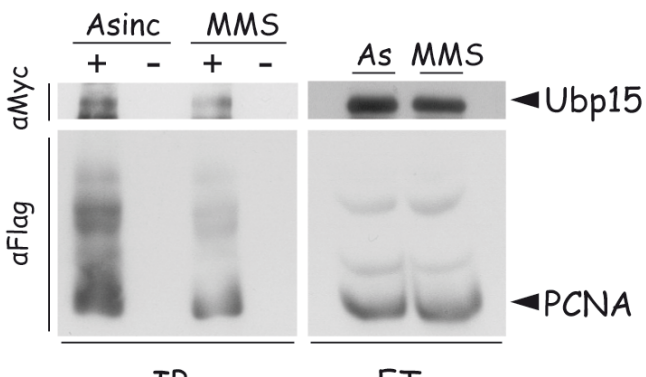

ET

Figura 26: Ubp15 y Ubp16 interaccionan con PCNA tanto en células asíncronas como en las dañadas con MMS. Se recogieron muestras asíncronas y tratadas con MMS (esquema mostrado en A) de células ubp15:13Myc pcn1:3Flag y ubp16:13Myc pcn1:3Flag. Después de la obtención de los extractos proteicos en condiciones nativas, se inmunoprecipitó PCNA en ambos casos utilizando el anticuerpo comercial anti-Myc. Después de la electroforesis de proteínas, se reveló el Western blot con los anticuerpos anti-Myc y anti-Flag, con el fin de averiguar la posible interacción entre las UBPs y la abrazadera. En la Figura 26B se muestra cómo efectivamente existe una interacción in vivo entre Ubp16 y PCNA tanto en la muestra de las células asíncronas como en las tratadas con MMS $0.01 \%$ durante 3horas. Los carriles marcados con el símbolo "menos (-)" muestran el resultado de las muestras incubadas sin el anticuerpo anti-Myc, lo que demuestra que dicha interacción es específica de la presencia de PCNA. En la Figura $\mathbf{2 6 C}$ se muestra el resultado para la interacción entre Ubp15 y la abrazadera. Aunque la figura muestre aparentemente más interacción en el carril correspondiente a la muestra asíncrona que en la tratada con MMS, creemos que se debe al hecho de que la inmunoprecipitación de PCNA en esas condiciones ha sido más efectiva. 
Para llevar a cabo el experimento de inmunoprecipitación, se partió de $30 \mathrm{ml}$ de cultivos crecidos a $30^{\circ} \mathrm{C}$ de cada una de las cepas etiquetadas. Una vez alcanzada la fase exponencial, se dividió a cada cultivo en dos, aumentando el volumen de cada uno hasta $50 \mathrm{ml}$, pero añadiendo sólo a uno de ellos MMS al $0.01 \%$. Después de 3 horas en cada una de las condiciones, con y sin daño, se recogieron las células por centrifugación para su posterior análisis.

A partir de estas muestras se obtuvieron los extractos proteicos en condiciones nativas, para a continuación llevar a cabo la inmunoprecipitación, tal y como se describe en el correspondiente apartado de Materiales y Métodos.

Ya que en el momento de la redacción de esta tesis tampoco se disponía de la cepa necesaria para demostrar la interacción física entre la abrazadera y Ubp12, de nuevo sólo podemos mostrar el resultado obtenido para las proteasas Ubp15 y Ubp16.

Como se observa en la Figura 26, ambas proteasas, Ubp15 y Ubp16, interaccionan con PCNA, apoyando la idea de que estas proteínas, son al menos 2 de las proteasas encargadas de desubiquitinar PCNA en la levadura de fisión.

\section{Ubp16 desubiquitina PCNA in vitro}

Los resultados anteriores demostraban que al menos las UBPs 15 y 16 (y muy posiblemente también la 12) eran las proteínas encargadas de regular la desubiquitinación de PCNA in vivo. Sin embargo, no disponíamos de ninguna evidencia in vitro que demostrase que efectivamente estas proteasas fuesen capaces de desubiquitinar PCNA directamente. Con tal propósito, decidimos realizar un ensayo de desubiquitinación in vitro, utilizando a cada una de las UBPs purificadas como enzimas de la reacción y como sustrato a inmunoprecipitados de PCNA. De nuevo, en el momento de la redacción de esta tesis, solo disponíamos de las construcciones necesarias para Ubp16, ya que los clonajes con Ubp12 y Ubp15 no fueron técnicamente posibles, probablemente debido al gran tamaño de estos genes $(2.9 \mathrm{~Kb}$ ubp12 y 3.4Kb ubp15). Por este motivo, a continuación sólo explicaremos el desarrollo y el resultado del ensayo realizado con la desubiquitinasa Ubp16.

Para poder llevar a cabo el ensayo de desubiquitinación, necesitábamos en primer lugar conseguir grandes cantidades de ambas proteínas. Ya que la ORF de Ubp16 no presentaba ningún intrón, decidimos purificarla a partir de $E$. coli. Para ello, clonamos las ORFs wt y CS (con el fin de utilizarla como control negativo) etiquetadas con 3 Flag, en el vector pGEX-6P-1. A continuación, se transformaron células de $E$. coli de la estirpe BL21 con cada una de las construcciones, con el fin de producir la sobreexpresión de dichas proteínas y su posterior purificación tal y como se describe en Materiales y Métodos.

En cuanto a la obtención del sustrato PCNA, contábamos con un gran problema de partida, y es que para llevar a cabo el ensayo con éxito, necesitábamos partir de una gran cantidad de PCNA ubiquitinado, y en condiciones normales, es decir, en 


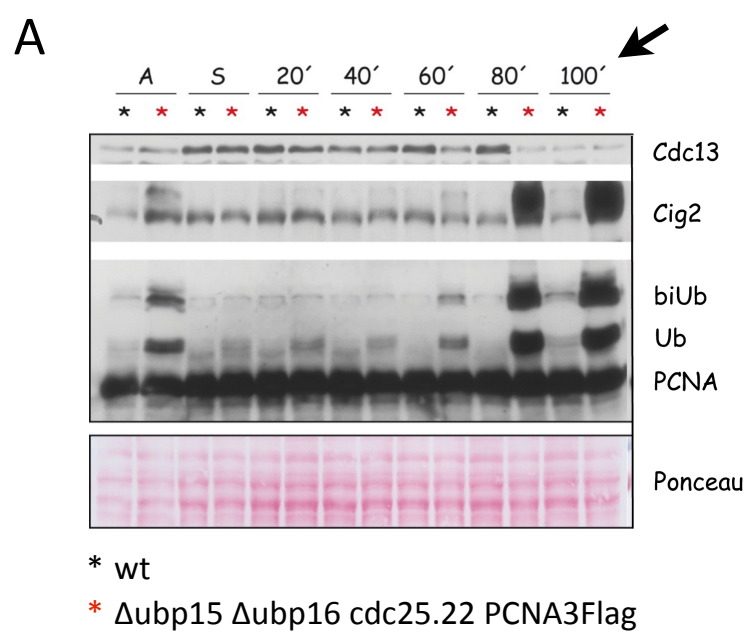

B
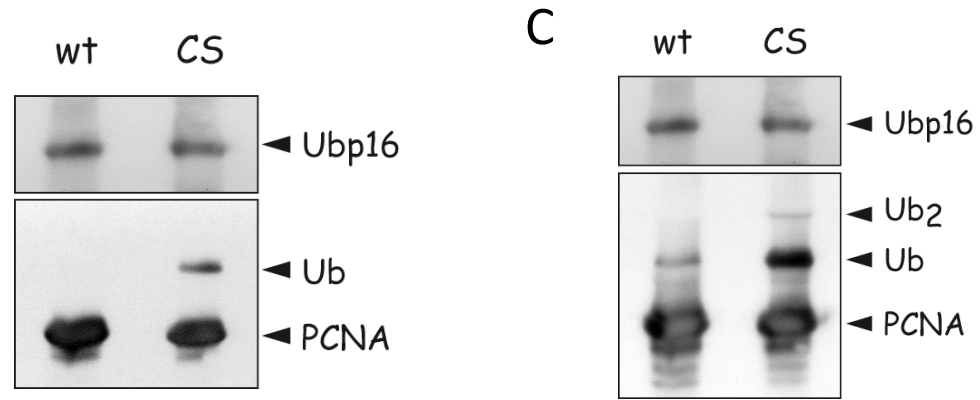

Figura 27: Ubp16 desubiquitina a PCNA in vitro. Con el fin de demostrar la actividad desubiquitinadora de Ubp16 sobre PCNA, se realizó un ensayo in vitro utilizando purificados a partir de $E$. coli de la versión wt de la proteasa, así como de la CS para utilizarla como control negativo de la reacción. Se inmunoprecipitó PCNA a partir de células mutantes $\triangle u b p 15 \Delta u b p 16$ cdc25.22 PCNA:3Flag, recogidas en el momento del ciclo señalado en $\mathbf{A}$ (100minutos), ya que era en ese mutante y en ese momento del ciclo celular cuando más PCNA modificado se podía inmunoprecipitar. En las Figuras $\mathbf{B}$ y $\mathbf{C}$ se muestra el resultado del ensayo in vitro llevado a cabo, en el que con dos exposiciones diferentes, se puede observar cómo sólo la versión wt de Ubp16, es capaz de desubiquitinar tanto las formas mono- como las poli-ubiquitinadas de PCNA.

células wt asíncronas, es muy poca la cantidad de éste que se encuentra modificado. Por lo tanto, tras revisar resultados de experimentos anteriores, decidimos inmunoprecipitar PCNA a partir de células mutantes $\triangle$ ubp15 $\triangle$ ubp16 cdc25.22 PCNA:3Flag, recogidas 100 minutos después de su liberación a $25^{\circ} \mathrm{C}$ (tras un bloqueo previo de 4 horas a $36^{\circ} \mathrm{C}$ ), ya que en ese mutante y en ese momento del ciclo celular, fue donde más cantidad de PCNA ubiquitinado pudimos observar. Tras la inmunoprecipitación de PCNA (ver Materiales y Métodos) se realizó el ensayo in vitro propiamente dicho. Para ello, se incubó la misma cantidad de PCNA en dos alícuotas diferentes, con cada una de las versiones de la proteína Ubp16, la wt y la 
CS, utilizando el tampón descrito en Huang et al 2006. La reacción se incubó a $30^{\circ} \mathrm{C}$ en agitación durante doce horas. A continuación, se separaron las proteínas por electroforesis en SDS-PAGE y tras la transferencia a membranas de nitrocelulosa y posterior incubación con los anticuerpos necesarios (anti-PCNA para la abrazadera y anti-Flag para Ubp16), comprobamos el resultado por auto-radiografía, donde pudimos observar como se muestra en la Figura 27, que solo la versión wt de Ubp16 es capaz de desubiquitinar a la abrazadera.

\section{Consecuencias celulares de la ausencia o de la so- bre-expresión de las desubiquitinasas de PCNA}

Una vez demostrado que Ubp12, Ubp15 y Ubp16 (aunque a falta de algún dato en el caso de Ubp12 y Ubp15) eran las proteasas encargadas de desubiquitinar PCNA en la levadura de fisión, decidimos averiguar qué consecuencias tendría para la célula, tanto la falta de ellas como su sobre-expresión, por estar probablemente implicadas a través de PCNA, en la regulación de las rutas de tolerancia al daño.

\subsection{Consecuencias de la sobre-expresión de las UBPs}

Como se ha mostrado en el apartado anterior, la sobre-expresión de estas proteasas se traduce en una ausencia total (en el caso de Ubp16 y Ubp12) o en una gran disminución (en el caso Ubp15) de PCNA ubiquitinado. Y como ya se mencionó en la introducción, de la ubiquitinación de la abrazadera depende la activación de las rutas de tolerancia al daño, por lo que la hipótesis obvia surgida a partir de estos datos, sugería que estas células, incapaces de ubiquitinar PCNA, deberían ser muy sensibles al daño.

A fin de demostrar tal hipótesis, decidimos realizar un ensayo de sensibilidad de dichas células (es decir, de aquellas que sobre-expresaban cada una de las UBPs) frente a diferentes agentes que dañan el ADN. Sin embargo, debido a la necesidad de pasar a las células por dos medios de cultivo diferentes (MM con y sin tiamina) para producir la sobre-expresión de las proteínas (siendo necesario un mínimo de 12 horas en MM sin tiamina, para inducir el promotor nmt1), resultaba imposible llevar a cabo dicho análisis por medio de un "ensayo de gota" tradicional en placas de YES. Por este motivo, decidimos realizar dicho ensayo de sensibilidad en placas Microtiter de 96 pocillos, donde sí era posible crecer a las células en las condiciones necesarias para llevar a cabo la inducción.

El desarrollo del experimento se hizo siguiendo el esquema mostrado en la Figura 28A. En primer lugar partimos de cultivos saturados en YES, de cada una de las cepas que sobre-expresaban las UBPs (Ubp15 y Ubp16, ya que en el momento de la realización de este experimento aún no se disponía de una cepa capaz de sobre-expresar Ubp12), junto con un wt y un mutante $\Delta$ rhp18 (E3 encargada de ubiquitinar a PCNA) llevado como control positivo, debido a su conocida hipersensibilidad a las 


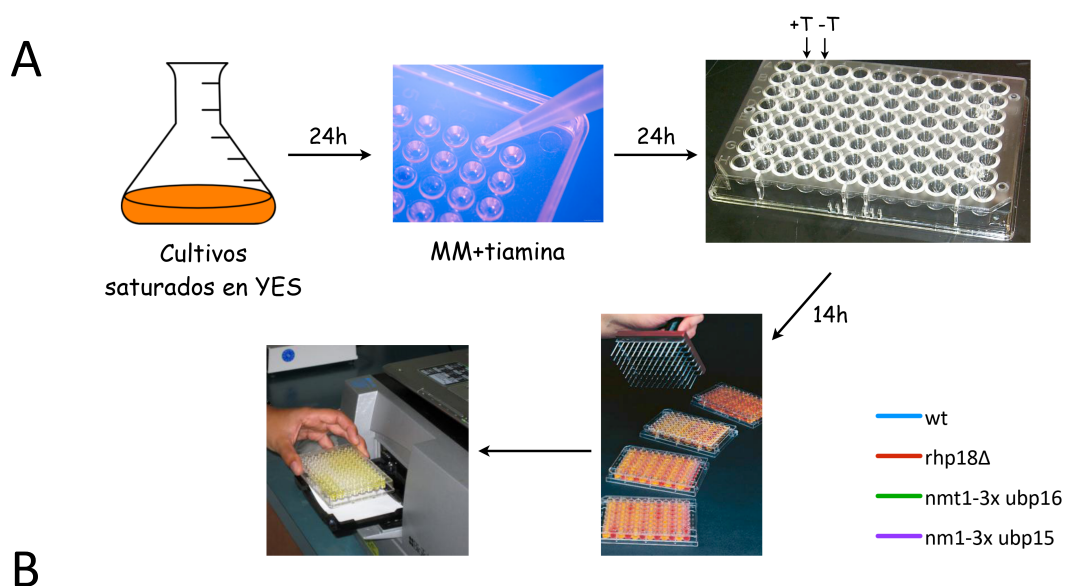

MMS +T

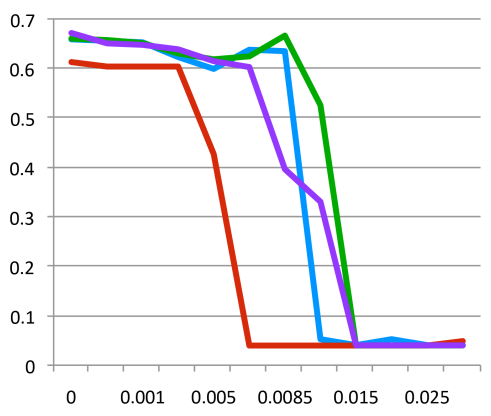

ET-743 +T

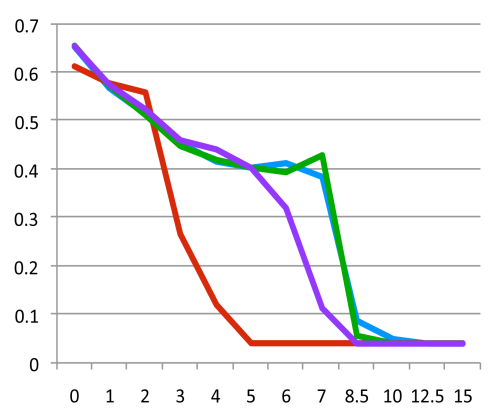

$Z+T$

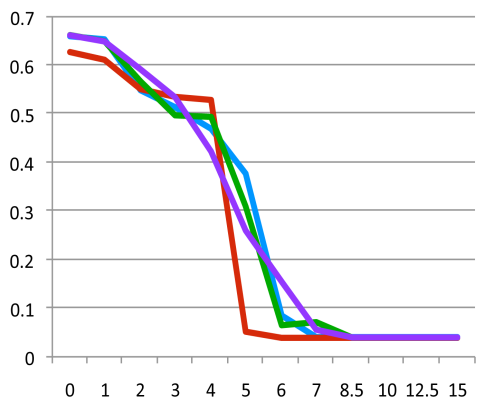

MMS -T

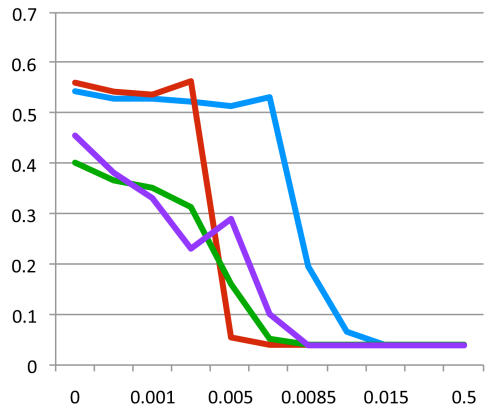

ET-743 -T
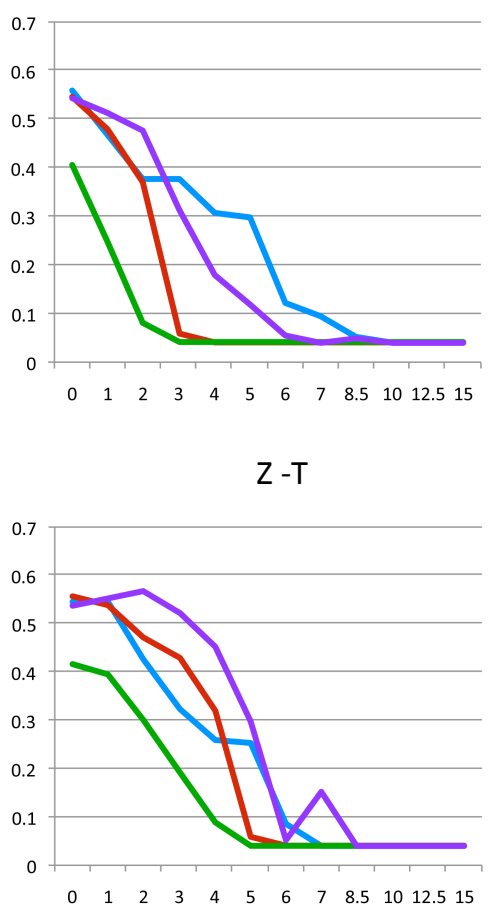
Cis $+\mathrm{T}$

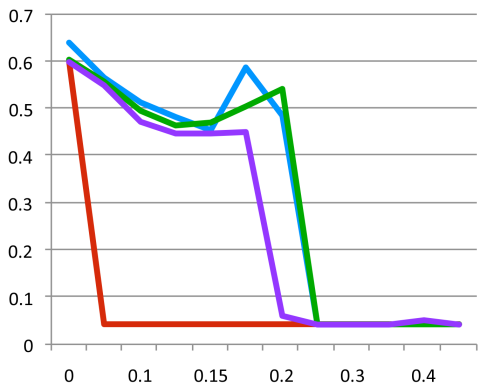

$\mathrm{NQO}+\mathrm{T}$

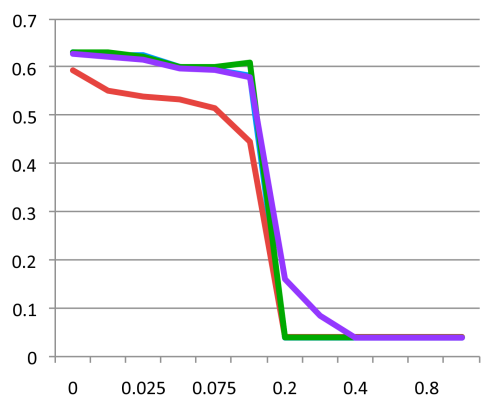

C

$\mathrm{ET}-743+\mathrm{T}$

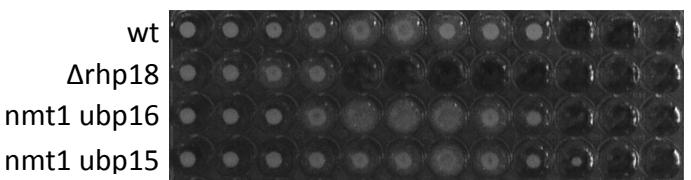

Cis - T

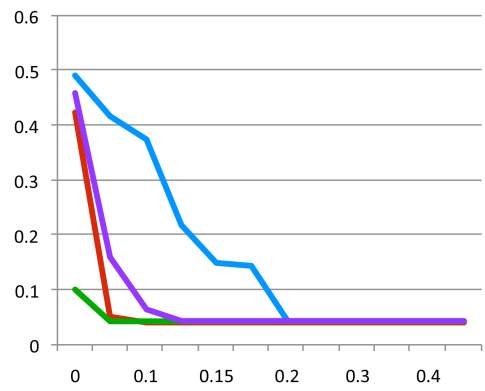

NQO -T

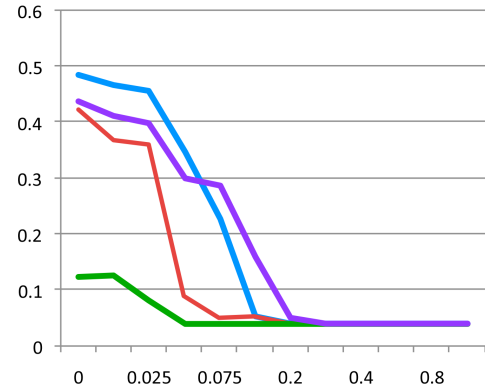

ET-743 - T

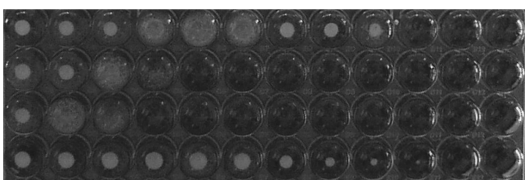

Figura 28: Ensayo de sensibilidad de las cepas que sobre-expresan las UBPs. A: Esquema seguido para el desarrollo del experimento. Tras medir todas las muestras a lo largo de 5 días, se analizaron todos los datos y se representaron en los gráficos mostrados en B, donde se puede observar cómo en ausencia de tiamina (condiciones en las que el promotor está inducido), el crecimiento de las células se ve muy disminuido, debido a que estas células no son capaces de activar las rutas de tolerancia al daño, por su incapacidad para mantener PCNA ubiquitinado. En C se muestran fotografías del crecimiento de dichas cepas en presencia de ET-743 (de menor a mayor concentración de izquierda a derecha), droga en la cual se observó uno de los fenotipos más acentuados para la cepa nmt1 ubp16.

drogas utilizadas en nuestro experimento. De cada cultivo saturado, sembramos $1 \mu \mathrm{l}$ por duplicado en dos columnas diferentes de una placa Microtiter (a la que previamente habíamos añadido $150 \mu$ l de volumen de MM más tiamina en cada pocillo), dejándolas crecer a $30^{\circ} \mathrm{C}$ durante toda la noche. Al día siguiente, con el fin de eli- 
minar la tiamina del medio, centrifugamos y lavamos tres veces las células con MM sin tiamina. Tras esos lavados, añadimos a una de las columnas de nuevo MM más tiamina, mientras que a la otra le añadimos MM sin tiamina, con el fin de producir la inducción del promotor nmt1. Una vez añadido el medio a todos los pocillos, se dejó crecer a las células a $30^{\circ} \mathrm{C}$ durante 14 horas, tiempo suficiente para que en las células crecidas en $\mathrm{MM}$ sin tiamina, se produjera la sobre-expresión de las proteínas a estudio y por lo tanto, para que pudieran desubiquitinar PCNA. Después de esas 14 horas por medio de un replicado se pasó a cada una de las cepas crecidas en las dos condiciones (con y sin tiamina) a sus correspondientes placas de MM (con y sin tamina), con 12 concentraciones diferentes de las drogas MMS, 4NQO, Cisplatino, ET-743 y Zalypsis (estas dos últimas cedidas por el Dr Moreno y el Dr Botet). Una vez terminadas todas las réplicas, se dejaron crecer todas las placas a $30^{\circ} \mathrm{C}$, controlando su crecimiento mediante análisis en espectofotómetro cada 12 horas durante las primeras 72 horas y cada $24 \mathrm{~h}$ a partir de entonces, durante un total de 5 días.

Tal y como esperábamos, el crecimiento de las células mutantes, fue muy diferente en función del medio de cultivo (Figura 28B). De forma que, mientras que no se observó ningún tipo de sensibilidad a ninguna de las drogas en las células crecidas en MM con tiamina (promotor apagado), sí pudimos observar una clara sensibilidad a todas ellas (siendo extremadamente sensibles a ET-743), en las células crecidas en ausencia de tiamina (promotor inducido). Aunque el patrón de crecimiento fue el mismo en ambas proteasas, es importante remarcar que de nuevo el fenotipo más extremo se observó en la sobre-expresión de Ubp16, resultado que concordaba con la hipótesis de que ésta era la proteasa que llevaba el mayor peso en la desubiquitinación de PCNA en S. pombe.

\subsection{Consecuencias de la falta de las UBPs}

Mucho más sencillo resultó el análisis de las consecuencias de la falta de las UBPs en la célula, ya que en esta ocasión sí fue posible realizar el tradicional ensayo de gota. Nuestra hipótesis de partida consistía en que, dado que la falta de estas proteínas producía un aumento de PCNA ubiquitinado, se debería producir en ellas una sobre-estimulación de las rutas de tolerancia al daño y por lo tanto una mayor resistencia a agentes que dañan el ADN.

El "ensayo de gota" se llevo a cabo tal y como se describe en Materiales y Métodos y el resultado final se muestra en la Figura 29, donde sólo Ubp16 mostró una ligera resistencia a MMS y cisplatino. Es importante señalar, que nuestro resultado contradice el trabajo publicado por Gatti y colaboradores, donde tras un análisis masivo de sensibilidad a cisplatino en la levadura de fisión, identifican al mutante $\Delta u b p 16$ como hipersensible a esta droga(Gatti et al. 2011). 


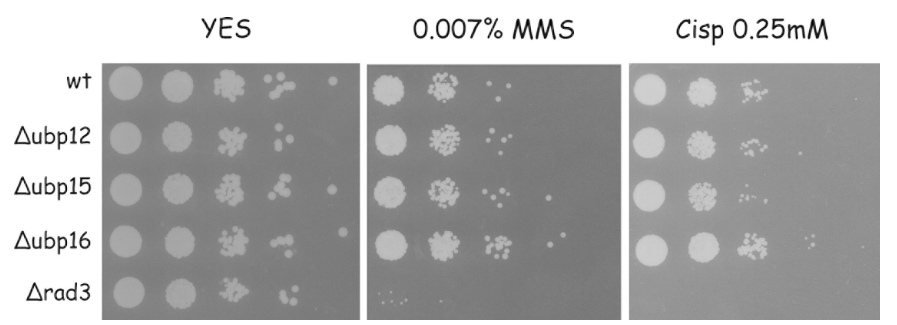

Figura 29: Ensayo de sensibilidad a MMS y cisplatino de los mutantes simples $\Delta u b p 12, \Delta u b p 15$ y $\Delta u b p 16$. En esta ocasión se utilizó el mutante $\Delta$ rad3 como control positivo, por su conocida sensibilidad a estas drogas. Como se observa, sólo el mutante $\Delta u b p 16$, presentó una ligera resistencia a las drogas mencionadas.

\section{Complementación en S. cerevisiae}

Gallego y colaboradores describieron recientemente a Ubp10 como la proteína encargada de desubiquitinar PCNA en la levadura de gemación. A pesar de la baja identidad, Ubp16 está considerada como la proteína ortóloga de Ubp10 en S. pombe (precisamente, la UBP que ha demostrado cumplir todos los requisitos para ser identificada como la desubiquitinasa de PCNA en la levadura de fisión).

Con el fin de demostrar la existencia de una homología funcional, decidimos clonar las UBPs identificadas en S. pombe, en S. cerevisiae. Sin embargo, una vez más, los clonajes de Ubp12 y Ubp15 en el plásmido de $S$. cerevisiae utilizado como vector (YIPG3), no fueron posibles, por lo que a continuación sólo se describirán los resultados obtenidos para la proteína Ubp16.

Siguiendo las técnicas de clonaje descritas en Materiales y Métodos, clonamos la ORF (obtenida por PCR a partir de ADN genómico) de las versiones wt y CS de Ubp16, en el plásmido de S. cerevisiae YIPG3, en el que se encuentra el promotor de sobre-expresión GAL (promotor reprimido en presencia de glucosa e inducido en presencia de Galactosa, GAL). Una vez clonadas ambas versiones de Ubp16, siguiendo el protocolo de transformación de $S$. cerevisiae, construimos cepas wt y $\Delta u b p 10$ de la levadura de gemación capaces de sobre-expresar las dos versiones de Ubp16 de S. pombe.

Para llevar a cabo el experimento, partimos de $30 \mathrm{ml}$ de cultivo de cada uno de los transformantes, junto con una cepa tipo silvestre y otra $\Delta u b p 10$ como controles, creciendo en YPA más Rafinosa 2\% (condiciones en las que el promotor GAL está apagado). Una vez alcanzada la fase exponencial se dividió al cultivo en dos con el fin de producir daño con MMS $0.02 \%$ en dos condiciones diferentes; por un lado con el promotor apagado (cultivo creciendo en las condiciones iniciales de Rafinosa $2 \%$ ), y por otro lado con el promotor inducido (cultivo creciendo en Galactosa 2\%). Una hora después se recogieron las muestras (5DO) y se prepararon los extractos 
proteicos siguiendo el mismo protocolo de TCA que para S. pombe. $8 \mu$ de esos extractos fueron analizados por Western blot utilizando para la detección de PCNA el anticuerpo anti-pol30 cedido por el Dr. Kaufmann.

Como se observa en la Figura 30, la sobre-expresión wt de Ubp16 de S. pombe en la levadura de gemación, desubiquitina el PCNA modificado (tanto mono- como poliubiquitinado) de dicha levadura (tanto en presencia como en ausencia de Ubp10), confirmando así que Ubp16 es la proteína equivalente a Ubp10.

A

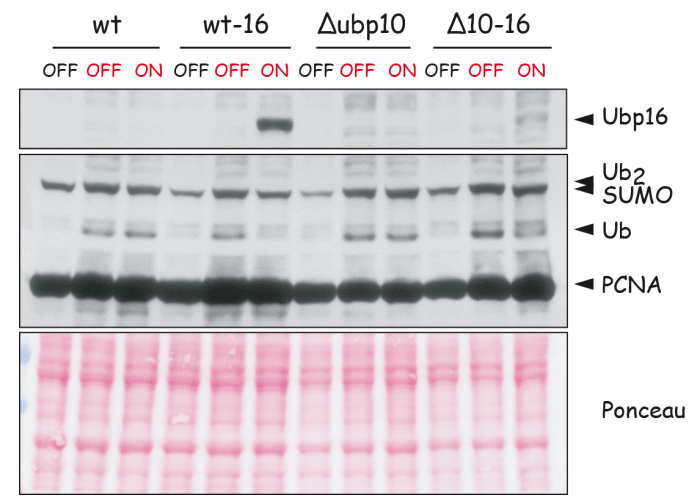

B

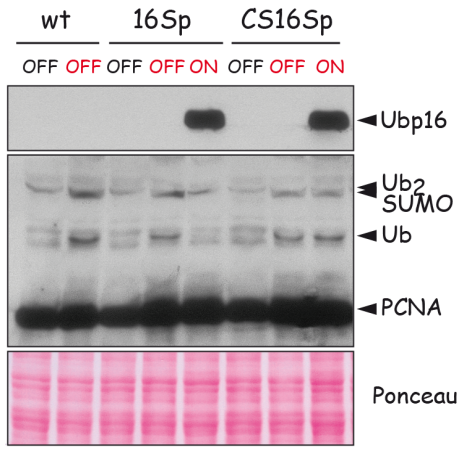

Figura 30: Ubp16 de S. pombe desubiquitina PCNA de S. cerevisiae. Una vez construidos los transformantes de $S$. cerevisiae capaces de sobre-expresar la UBP de $S$. pombe, analizamos el estado de ubiquitinación de PCNA en los mismos, en las condiciones de promotor apagado (OFF) e inducido (ON). Las muestras en "rojo" se corresponden con las células tratadas 1 hora con MMS 0.02\%. A: La sobre-expresión de Ubp16 desubiquitina PCNA mono y poliubiquitinado de la levadura de gemación, tanto en un fondo wt como $\triangle$ ubp10. B: La versión CS de la proteasa no es capaz de desubiquitinar PCNA de $S$. cerevisiae.

Como ya se mencionó en la introducción, antes del descubrimiento de Ubp10 como la enzima desubiquitinadora de PCNA en S. cerevisiae, ya se le había atribuido como sustrato (al igual que Ubp8) la histona H2B (Emre et al. 2005; Gardner et al. 2005; Schulze et al. 2011). Aunque fuera de nuestra línea argumental en el estudio de la tolerancia al daño, decidimos averiguar si la proteína ortóloga Ubp16, también tenía como sustrato a dicha histona en la levadura de fisión (ver Figura 38 Apéndice).

\subsection{Las células de $S$. cerevisiae que sobre-expresan Ubp16 de $S$. pombe también son muy sensibles a agentes que dañan el ADN}

Demostrada la homología funcional, el siguiente paso en nuestro trabajo, consistió en demostrar si dicha sobre-expresión en la levadura de gemación, se traducía al igual que en $S$. pombe, en una hipersensibilidad a los agentes que dañan el ADN.

Para ello realizamos un ensayo de sensibilidad a diferentes agentes, creciendo las células que sobre-expresan Ubp16 en las condiciones necesarias para mantener el 70 


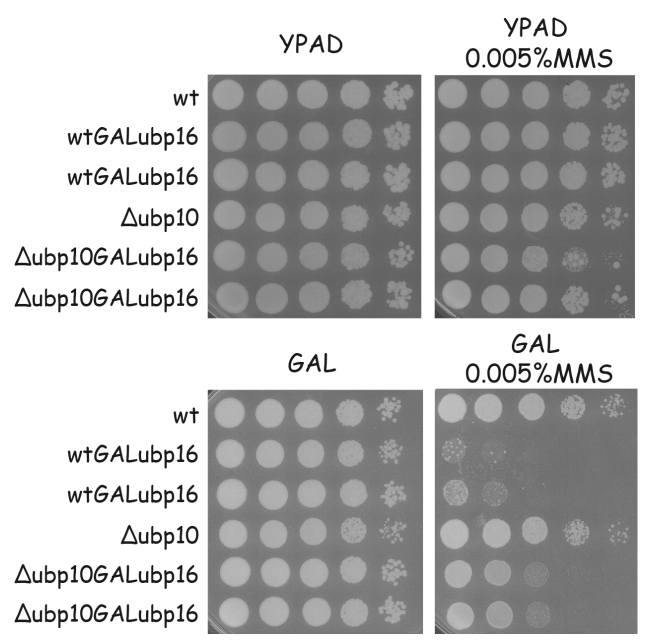

Figura 31: Ensayo de sensibilidad de la levadura de gemación. Las células de S. cerevisiae capaces de sobre-expresar Ubp16 de $S$. pombe, son sensibles a agentes que dañan el ADN.

promotor apagado (YPAD) o encendido (YPA con Galactosa). Como se muestra en la Figura 31, solo las células crecidas en presencia de galactosa (y que por tanto sobre-expresan Ubp16), presentan una gran sensibilidad a agentes que dañan el ADN, confirmando así que la sobre-expresión de Ubp16 de S. pombe, probablemente imposibilita a la levadura de gemación, para una correcta activación de las rutas de tolerancia.

\section{Análisis de la ubiquitinación de PCNA a lo largo del ciclo celular}

El modelo actualmente aceptado para la ubiquitinación de PCNA en respuesta al daño en el ADN, asume que se desencadena por el estancamiento de la maquinaria de replicación en esos sitios de daño, de forma que la monoubiquitinación de la abrazadera servirá para mediar el cambio entre las polimerasas replicativas y las TLS, y la poliubiquitinación para activar la ruta libre de daños (Hoege et al. 2002; Stelter and Ulrich 2003).

Está implícito por lo tanto en este modelo, que la ubiquitinación de PCNA en respuesta a los daños es un proceso específico de Fase $S$, y como tal se ha descrito en S. cerevisiae (Hoege et al. 2002), fibroblastos humanos (Kannouche and Lehmann 2004; Motegi et al. 2006; Brun et al. 2010), y Xenopus laevis (Leach and Michael 2005). Sin embargo, en S. pombe a diferencia de los anteriores, se ha publicado que estas modificaciones (tanto mono como poli-ubiquitinación) también ocurren tanto 
en una Fase $S$ sin daño exógeno, como en $G 2$ en presencia de daño exógeno (Frampton 2006).

Basándonos en estos datos, nos pareció interesante para nuestro trabajo, averiguar si la desubiquitinación de la abrazadera era un proceso específico de Fase $\mathrm{S}$ o por el contrario, también ocurría en algún otro momento del ciclo celular. Para ello, como primera aproximación, decidimos analizar el estado de ubiquitinación de PCNA en células $\triangle u b p 16$, sincronizadas y dañadas en diferentes fases del ciclo celular. La elección de este mutante en primer lugar y no de otro, se debió a su facilidad para trabajar con él (ya que los mutantes dobles presentaban un crecimiento mucho más lento) y al hecho de que era el mutante simple que más formas modificadas de PCNA acumulaba en presencia de daño.

Para llevar a cabo las sincronizaciones, hicimos uso de los mutantes termosensibles cdc25-22, cdc10-129 y $c d c 17-K 12$, por ser capaces de bloquearse en G2, G1 y Fase $S$ respectivamente. El esquema general de estos experimentos, consistió en sincronizar a las células en un momento del ciclo determinado, para a continuación producir daño con MMS en esas mismas condiciones de bloqueo.

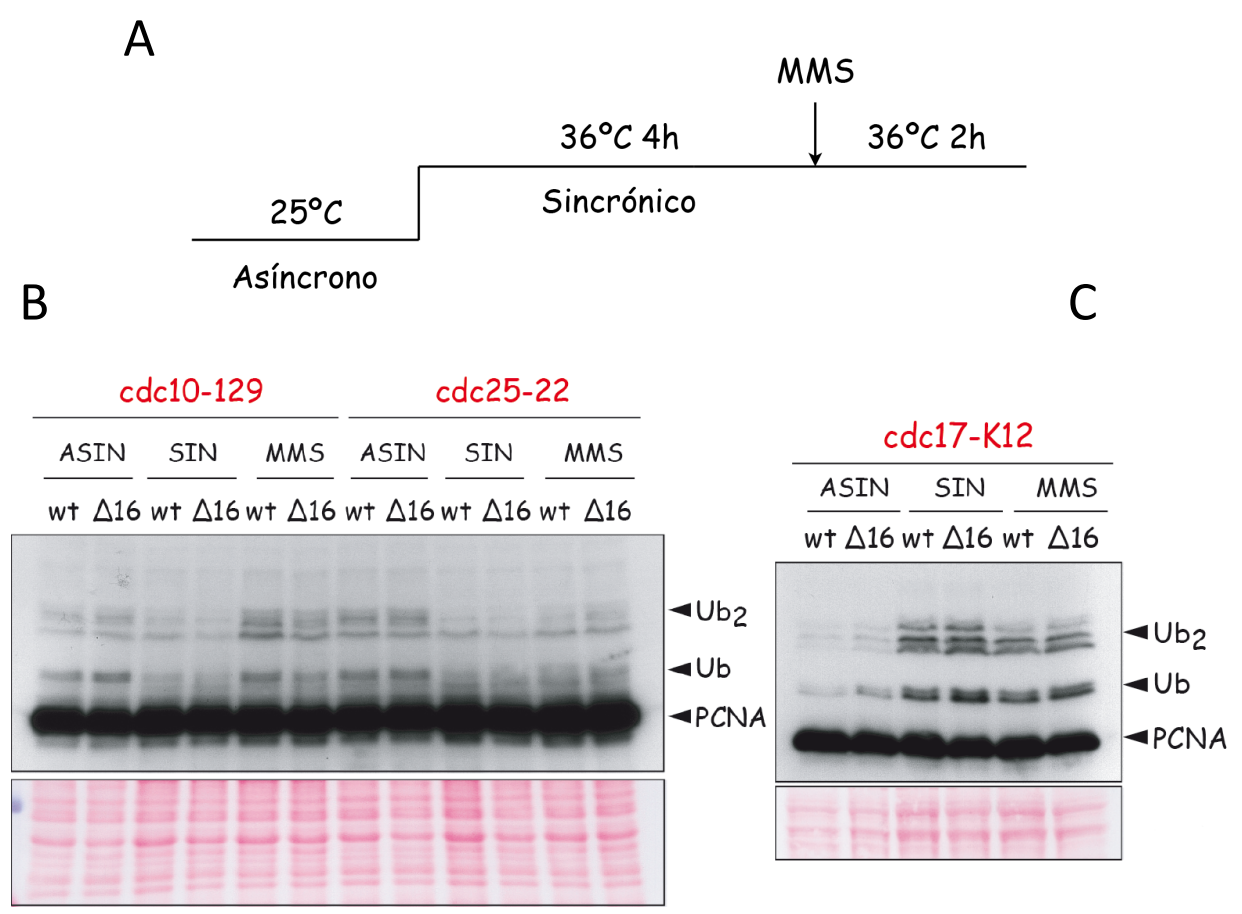

Figura 32: La ubiquitinación de PCNA en la levadura de fisión no es específica de Fase S. Se tomaron muestras de los mutantes de ciclo, tal y como se representa en el esquema mostrado en A. En contra de lo descrito para la levadura de gemación, las células de $S$. pombe bloqueadas en G1 o en G2 en presencia de daño, también son capaces de ubiquitinar a la abrazadera (siendo dicha ubiquitinación mayor en el mutante $\Delta u b p 16$, en el caso del bloqueo en G2) (B). En el caso del bloqueo en Fase S (C), la ubiquitinación de PCNA en este punto del ciclo es tan grande, que apenas se aprecia aumento en presencia de daño. 
La sincronización en G2 se llevó a cabo por medio del mutante termosensible cdc25-22. La proteína Cdc25 es la fosfatasa encargada de activar el complejo mitótico $\mathrm{Cdc} 2 / \mathrm{Cdc} 13$, siendo dicha activación imprescindible para que la levadura pueda entrar en mitosis (Millar et al. 1991). En el mutante $c d c 25-22$, a la temperatura restrictiva de $36^{\circ} \mathrm{C}$, se produce la inactivación de dicha fosfatasa, por lo que estas células serán incapaces de entrar en mitosis y quedarán bloqueadas en G2.

Para el bloqueo en G1 se utilizó el mutante $c d c 10-129$. Cdc10 es un factor de transcripción necesario para que se expresen genes imprescindibles en la transición G1/ S (Lowndes et al. 1992; Fernandez Sarabia et al. 1993; Kelly et al. 1993; Hofmann and Beach 1994; Obara-Ishihara and Okayama 1994), de ahí que el mutante con el alelo termosensible $c d c 10-129$, a la temperatura restrictiva de $36^{\circ} \mathrm{C}$, no sea capaz de iniciar la replicación y quede bloqueado en G1.

Por último, el bloqueo en Fase $S$, se llevo a cabo a través del mutante cdc17-K12, mutante en el que a su temperatura restrictiva $\left(36^{\circ} \mathrm{C}\right)$ se produce la inactivación de la ADN ligasa del mismo nombre, produciéndose por lo tanto un bloqueo en dicha Fase.

Para poder llevar a cabo nuestro estudio, en primer lugar construimos los dobles mutantes $\Delta u b p 16 c d c 25-22, \Delta u b p 16 c d c 10-129$ y $\Delta u b p 16 c d c 17-K 12$, por medio de análisis aleatorio de esporas. Una vez construidos, llevamos a cabo el experimento en todos los casos partiendo de cultivos exponenciales crecidos a $25^{\circ} \mathrm{C}$ (temperatura permisiva a la que estos mutantes $c d c$, son capaces de progresar correctamente a lo largo del ciclo celular). Tras recoger las muestras correspondientes (para FACS y Western blot), pusimos los cultivos a la temperatura restrictiva $\left(36^{\circ} \mathrm{C}\right.$ en todos los casos) durante 4 horas. Una vez producido el bloqueo, añadimos MMS $0.01 \%$ y dejamos crecer a las células en estas condiciones durante otras 2 horas más. En todos los casos comprobamos que el bloqueo fue efectivo a través del microscopio (observando que las células se alargaban considerablemente) y a través de FACS (datos no mostrados). La preparación de los extractos proteicos y análisis de los mismos, se llevó a cabo como las veces anteriores.

Como se muestra en la Figura 32, cuando las células están bloqueadas en Fase $\mathrm{S}$ se produce una gran acumulación de formas modificadas de PCNA, de tal forma que ni siquiera se aprecia un aumento cuando en esa fase se daña el ADN. Este dato apoya la idea de que el estancamiento espontáneo de las horquillas de replicación en $S$. pombe, es mucho más frecuente que en la levadura de gemación (Ulrich 2007a). Como esperábamos, el mutante $\triangle u b p 16$ acumuló más PCNA modificado que su control, apuntando este resultado a que Ubp16 efectivamente desubiquitina PCNA en dicha fase del ciclo.

Como ya describieron Frampton y colaboradores, a diferencia de otros organismos, en la levadura de fisión se produce ubiquitinación de PCNA en una Fase G2 en presencia de daño exógeno (Frampton et al. 2006). Ya que el mutante $\triangle u b p 16$ presentó en ese punto del ciclo (G2) más cantidad de PCNA modificado que su control 
cdc25-22, podemos concluir que Ubp16 también es capaz de desubiquitinar a la abrazadera en esa fase del ciclo (Figura 32B).

Respecto al bloqueo en $\mathrm{G} 1$, observamos algo no descrito hasta ahora, y es que en Fase G1 con daño, la levadura de fisión también es capaz de ubiquitinar a la abrazadera deslizante (Figura 32B).

Por lo tanto a raíz de estos resultados, podemos concluir que probablemente en la levadura de fisión, la ubiquitinación de PCNA es un proceso que ocurre mayoritariamente en Fase $S$, pero que también ocurre (aunque en menor medida) en G1 y G2.

\subsection{Análisis en los mutantes simples y dobles de las UBPs}

Con el fin de profundizar más en el análisis de la desubiquitinación de PCNA en la levadura de fisión, decidimos estudiar en detalle el estado de ubiquitinación de la abrazadera a lo largo del ciclo celular, en cepas carentes de una o de varias de las UBPs implicadas en el proceso.

Para poder llevar a cabo estos análisis de forma sincrónica, construimos nuevos mutantes cruzando los mutantes simples, dobles y triples de las UBPs, con los mutantes de ciclo $c d c 25-22$ y $c d c 10-129$.

El primer mutante analizado en detalle fue $\triangle$ ubp16, a través de un bloqueo en G2. Para ello hicimos uso del mutante $\Delta u b p 16 c d c 25-22$, así como de su control correspondiente $c d c 25-22$. Para llevar a cabo el experimento, partimos de cultivos de ambas cepas creciendo exponencialmente a la temperatura permisiva de $25^{\circ} \mathrm{C}$. A continuación se pasaron los cultivos a $36^{\circ} \mathrm{C}$ (temperatura restrictiva) durante 4 horas, para sincronizar las células en $\mathrm{G} 2$. Tras comprobar al microscopio que las células se habían alargado y que por lo tanto el bloqueo había sido efectivo, liberamos ambos cultivos de nuevo a la temperatura permisiva de $25^{\circ} \mathrm{C}$, con el fin de que progresasen de forma sincrónica a lo largo del ciclo celular. Se recogieron muestras para FACS y para Western blot al inicio del experimento, después del bloqueo a $36^{\circ} \mathrm{C}$ y tras la liberación a $25^{\circ} \mathrm{C}$ cada 20 minutos, durante un total de 4horas (Figura 33A), con el propósito de intentar abarcar dos ciclos celulares completos. Como se muestra en la Figura 33B, el mutante $\triangle$ ubp 16 acumula mucha más cantidad de PCNA ubiquitinado que su control. Sin embargo, como ya habíamos demostrado en experimentos con daño exógeno con MMS, esta acumulación desaparece en el tiempo, coincidiendo al igual que en su control, con la salida de Fase S. Para corroborar que el resultado era independiente del tipo de sincronización empleada, repetimos el experimento utilizando un bloqueo en G1 por medio del mutante $\Delta u b p 16$ cdc10129. Ver resultado en Figura 39 del Apéndice.

Siguiendo el mismo diseño experimental analizamos el mutante $\Delta u b p 15$ cdc25-22, comprobando al igual que en el caso anterior, que dicho mutante acumulaba más PCNA ubiquitinado, y que dicha acumulación también desaparecía coincidiendo con 
A $36^{\circ} \mathrm{C} 4 \mathrm{~h}$

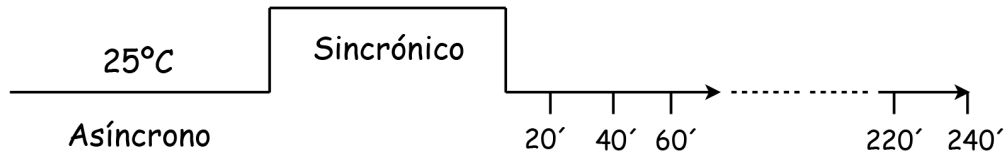

B

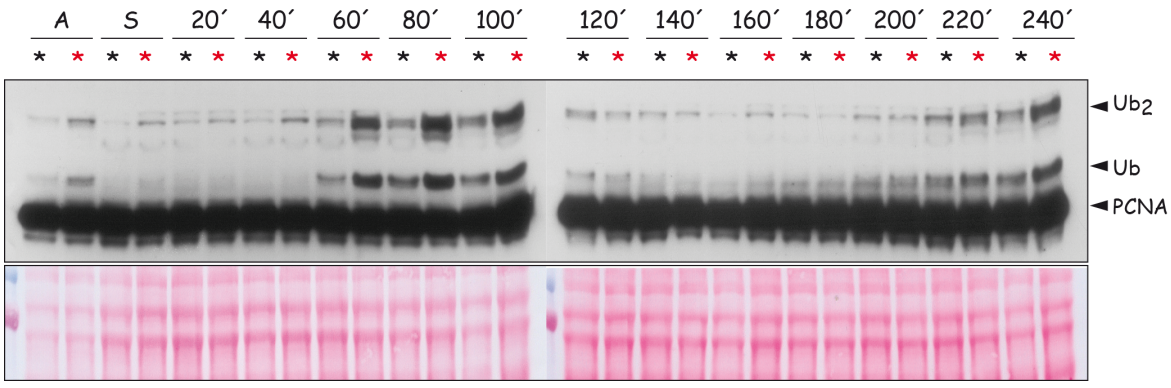

C

* cdc25-22

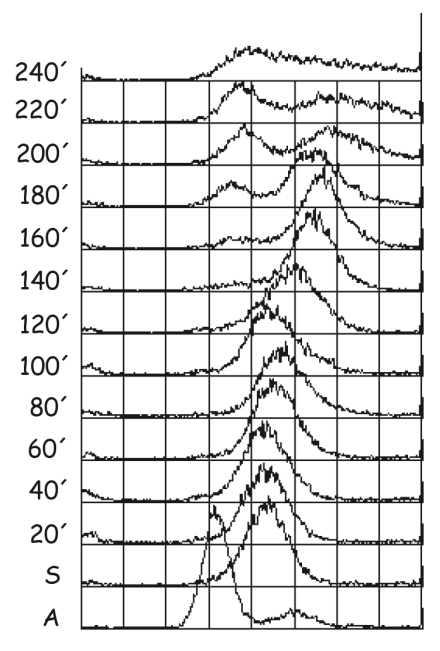

$2 \mathrm{C} \quad 4 \mathrm{C}$
* $\Delta u b p 16 c d c 25-22$

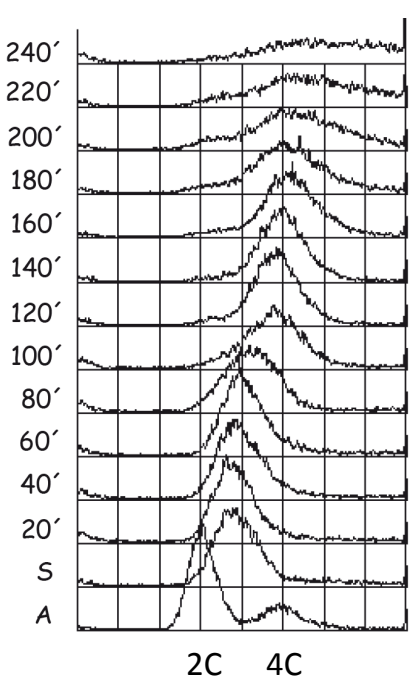

Figura 33: La acumulación de formas modificadas de PCNA en el mutante $\triangle$ ubp16 es específica de Fase S. A: Esquema del diseño experimental llevado a cabo. B: Western blot de las muestras recogidas de los mutantes cdc25.22 (muestras en negro) y $\Delta u b p 16$ cdc25.22 (muestras en rojo). Como se observa, las células $\Delta u b p 16$ acumulan más cantidad de PCNA modificado. Este patrón de acumulación, es coherente con un defecto específico de desubiquitinación durante Fase S. C: FACS de las muestras donde se observa un ligero retardo en la progresión por Fase $\mathrm{S}$ en el mutante $\Delta u b p 16$. 
el final de la Fase $S$ (Figura 34).

Como en el caso anterior, se repitió el experimento utilizando un bloqueo en G1 a través del mutante $c d c 10.129$, obteniendo resultados comparables a los observados en un fondo $c d c 25-22$ para ambos mutantes (datos no mostrados).

A $36^{\circ} \mathrm{C} 4 \mathrm{~h}$

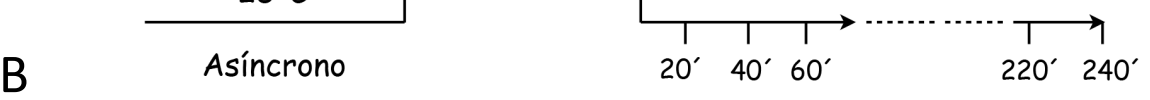

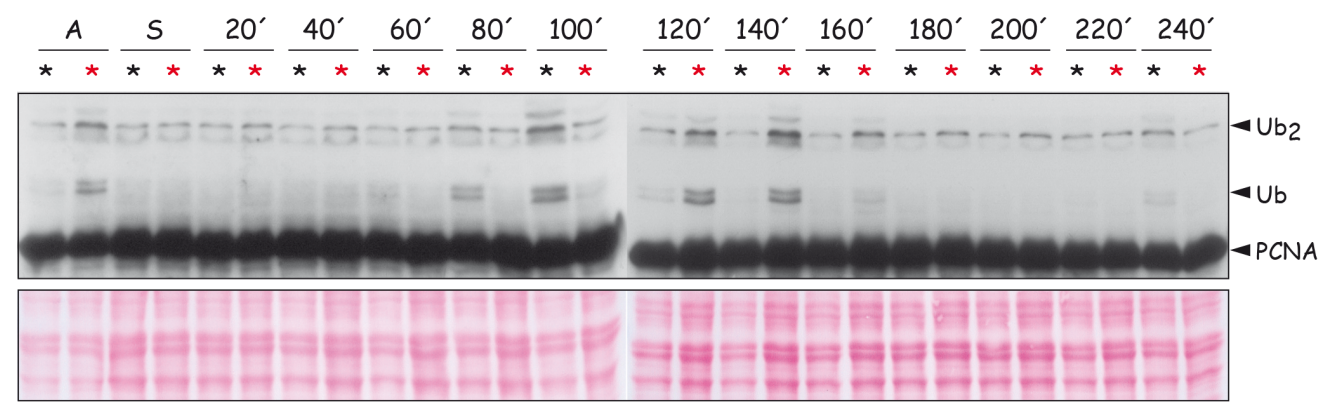

C

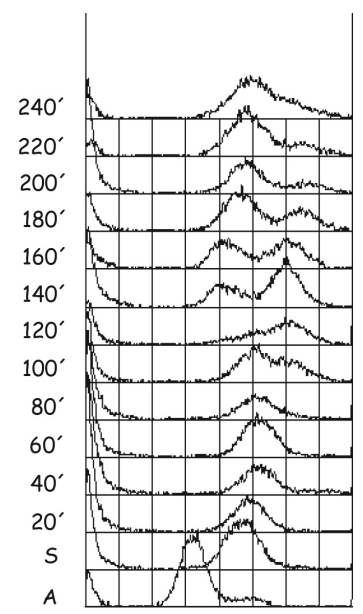

$2 \mathrm{C} \quad 4 \mathrm{C}$

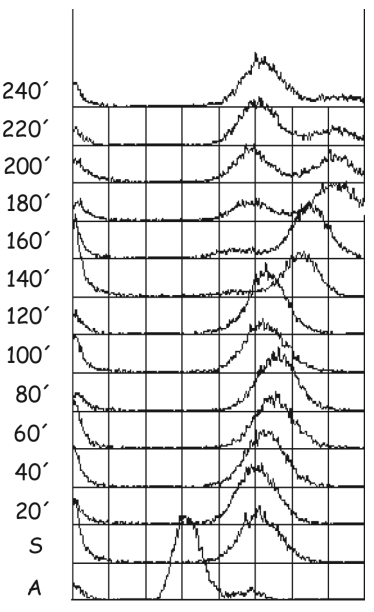

$2 \mathrm{C} \quad 4 \mathrm{C}$

Figura 34: La acumulación de formas modificadas de PCNA en el mutante $\triangle$ ubp15, también es específica de Fase $\mathbf{S}$. Siguiendo el diseño experimental mostrado en $\mathbf{A}$, se recogieron muestras de los mutantes cdc25.22 (muestras en negro) y $\Delta u b p 15$ cdc25.22 (muestras en rojo). Como se observa en el Western blot (B) la cantidad de ubiquitinación de entrada en el mutante $\Delta u b p 15 c d c 25-22$ es mucho mayor que en su control cdc25-22. En esta ocasión, tanto el Western blot como el FACS, revelaron que la entrada en Fase $S$ en el mutante $\Delta u b p 15$ es posterior al mutante $c d c 25-22$. 
El siguiente mutante a analizar fue el $\Delta u b p 15 \Delta u b p 16 c d c 10-129$. En esta ocasión la acumulación de PCNA ubiquitinado fue mucho mayor que en los mutantes simples $\Delta u b p 15$ y $\Delta u b p 16$, y aunque como en los casos anteriores ésta también oscilaba, nunca llegó a desaparecer (Figura 35). La mayor acumulación de PCNA ubiquitina-

A

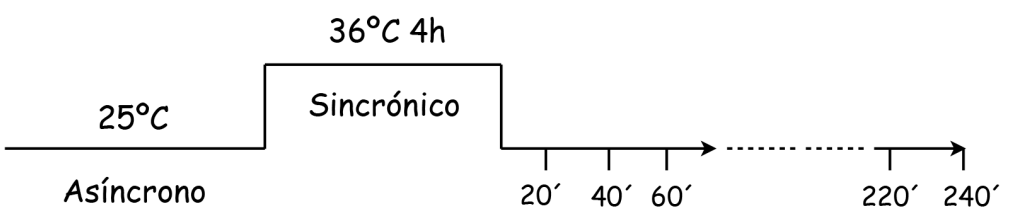

B

$\frac{A}{\star \star} \frac{S}{\star \star} \frac{20^{\prime}}{\star \star} \frac{40^{\prime}}{\star \star} \frac{60^{\prime}}{\star \star} \frac{80^{\prime}}{\star \star} \frac{100^{\prime}}{\star \star} \frac{120^{\prime}}{\star \star} \frac{140^{\prime}}{\star \star} \frac{160^{\prime}}{\star \star} \frac{180^{\prime}}{\star \star *} \frac{200^{\prime}}{\star \star} \frac{220^{\prime}}{\star \star} \frac{240^{\prime}}{\star \star}$

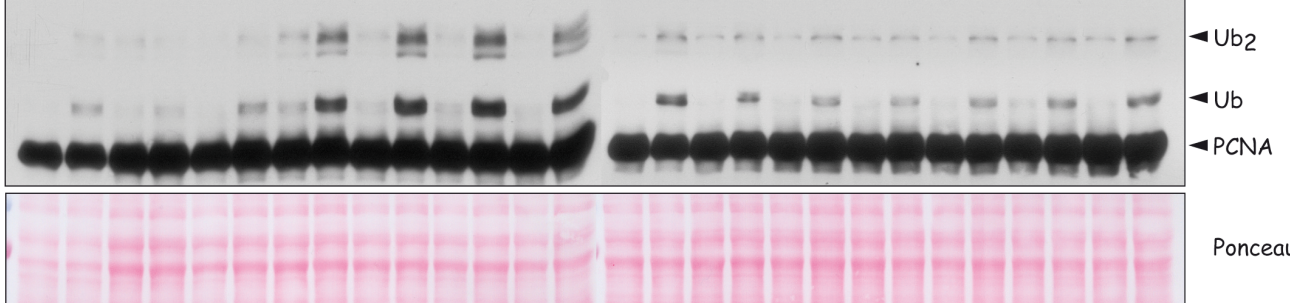

C

$$
\text { * } c d c 10.129
$$

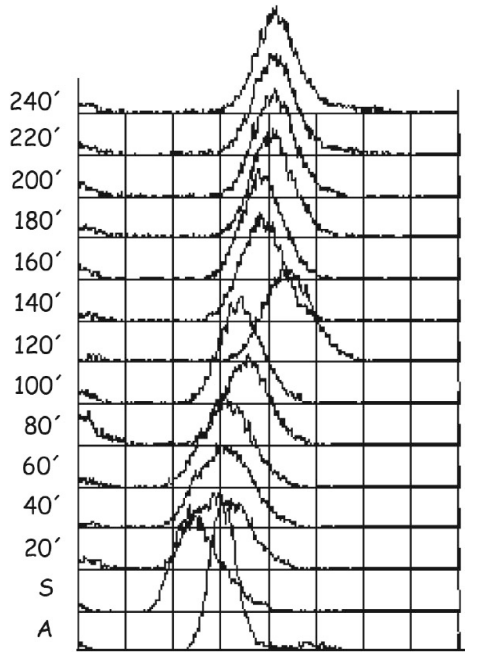

$2 \mathrm{C} \quad 4 \mathrm{C}$
* $\Delta u b p 15$ cdc10-129

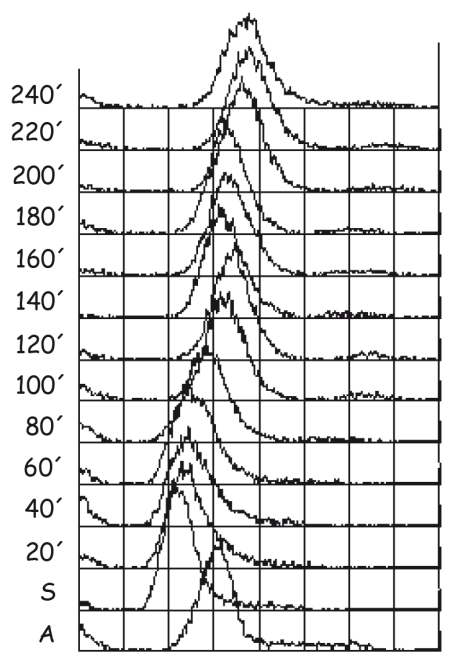

2C $4 \mathrm{C}$

Figura 35: Análisis de la ubiquitinación de PCNA en el mutante $\Delta u b p 15 \Delta u b p 16$. En esta ocasión se utilizó un bloqueo en G1 por medio del mutante cdc10.129. El Western blot reveló de nuevo cómo la ubiquitinación de PCNA era mucho mayor en el mutante carente de las UBPS (muestras en rojo) y que dicha acumulación también oscilaba, sin embargo, a diferencia de lo observado en los mutantes simples, ésta no llegaba a desaparecer. 
do, de nuevo coincidió con el paso por la Fase $\mathrm{S}$ del ciclo celular. El análisis de la ubiquitinación de PCNA en el mutante $\triangle u b p 15 \Delta u b p 16$, también se realizó por medio de un bloqueo en $\mathrm{G} 2$ a través del mutante $c d c 25-22$. El resultado confirmó una vez más, que el patrón de ubiquitinación era el mismo independientemente del bloqueo utilizado (ver Figura $\mathbf{4 0}$ del Apéndice).

\subsection{Análisis del triple mutante $\triangle u b p 12 \Delta u b p 15 \Delta u b p 16$}

Llegados a este punto, sólo nos faltaba analizar el estado de ubiquitinación de la abrazadera en el triple mutante $\Delta u b p 12 \Delta u b p 15 \Delta u b p 16$, probablemente el más importante por ser el que presentaba el fenotipo más fuerte (al menos en cuanto a la acumulación de ubiquitinación de PCNA). Al igual que en los casos anteriores, nuestra primera opción para llevar a cabo los experimentos de sincronización, fue la utilización de mutantes $c d c$, sin embargo en esta ocasión eso no llegó a ser posible, debido a que la construcción de los dos cuádruples mutantes necesarios para ello, resultó imposible. Por lo tanto, para lograr analizar el estado de ubiquitinación de la abrazadera de forma sincrónica en nuestro triple mutante, recurrimos a la segunda opción posible: la elutriación.

La elutriación es un método de separación de partículas, basado en la diferente velocidad de sedimentación de las mismas cuando se encuentran suspendidas en un fluido en movimiento. Dicha diferencia de velocidad de sedimentación, radica en la diferencia de tamaño que presentan las células según el momento del ciclo celular en el que se encuentran. Así, las células de $S$. pombe, al comienzo de G2 presentan un tamaño muy pequeño, siendo estas células fácilmente separables por dicha técnica.

Para llevar a cabo el experimento, partimos de un cultivo asíncrono a $30^{\circ} \mathrm{C}$, de 10 litros de volumen (aunque dividido en dos matraces) a una DO igual a 1 del triple mutante $\Delta u b p 12 \Delta u b p 15 \Delta u b p 16$. La necesidad de tanto volumen celular de partida se debe a que tras el proceso de elutriación son muy pocas las células recuperadas (sólo las que se encuentran al inicio de G2). Una vez realizada la elutriación, el volumen celular recuperado (2 litros a DO 0.25), fue liberado incubándose a $25^{\circ} \mathrm{C}$. A partir de este momento se recogieron muestras cada 15 minutos durante un total de 4 horas, para análisis bioquímico por Western blot así como para análisis microscópico de los índices mitóticos y de septación.

Como se muestra en la Figura 36, el triple mutante $\Delta u b p 12 \Delta u b p 15 \Delta u b p 16$ presentó la mayor cantidad de PCNA ubiquitinado observado hasta el momento, aunque una vez más, dicha modificación no era constante, siendo otra vez la Fase $\mathrm{S}$ el momento del ciclo celular en el que se observaba más acumulación. Sin embargo en esta ocasión, la disminución del patrón de ubiquitinación fue considerablemente menor que el observado en los mutantes simples y dobles (Figuras 33-35), por lo que en base a este resultado, pensamos que lejos de existir una cuarta desubiquitinasa implicada en dicho proceso, el descenso en la ubiquitinación de la abrazadera 
podría deberse al simple patrón de renovación de la proteína (ver discusión). El análisis de los marcadores de ciclo Cig2 (ciclina B cuyo pico máximo de expresión coincide con la transición G1/S, (Connolly and Beach 1994; Martin-Castellanos and Moreno 1996; Mondesert et al. 1996)) y Cdc13 (ciclina B cuyo pico máximo se observa en metafase, sufriendo un descenso muy pronunciado al final de ésta para que la célula pueda completar mitosis (Yamano et al. 1996)) sumado al análisis de núcleos y septos en ambas cepas (Figura 36A y 36B), reveló la incapacidad del triple mutante $\Delta u b p 12 \Delta u b p 15 \Delta u b p 16$ para progresar correctamente a lo largo del ciclo celular.

A

* $w t$

* $\Delta u b p 12 \Delta u b p 15 \Delta u b p 16$
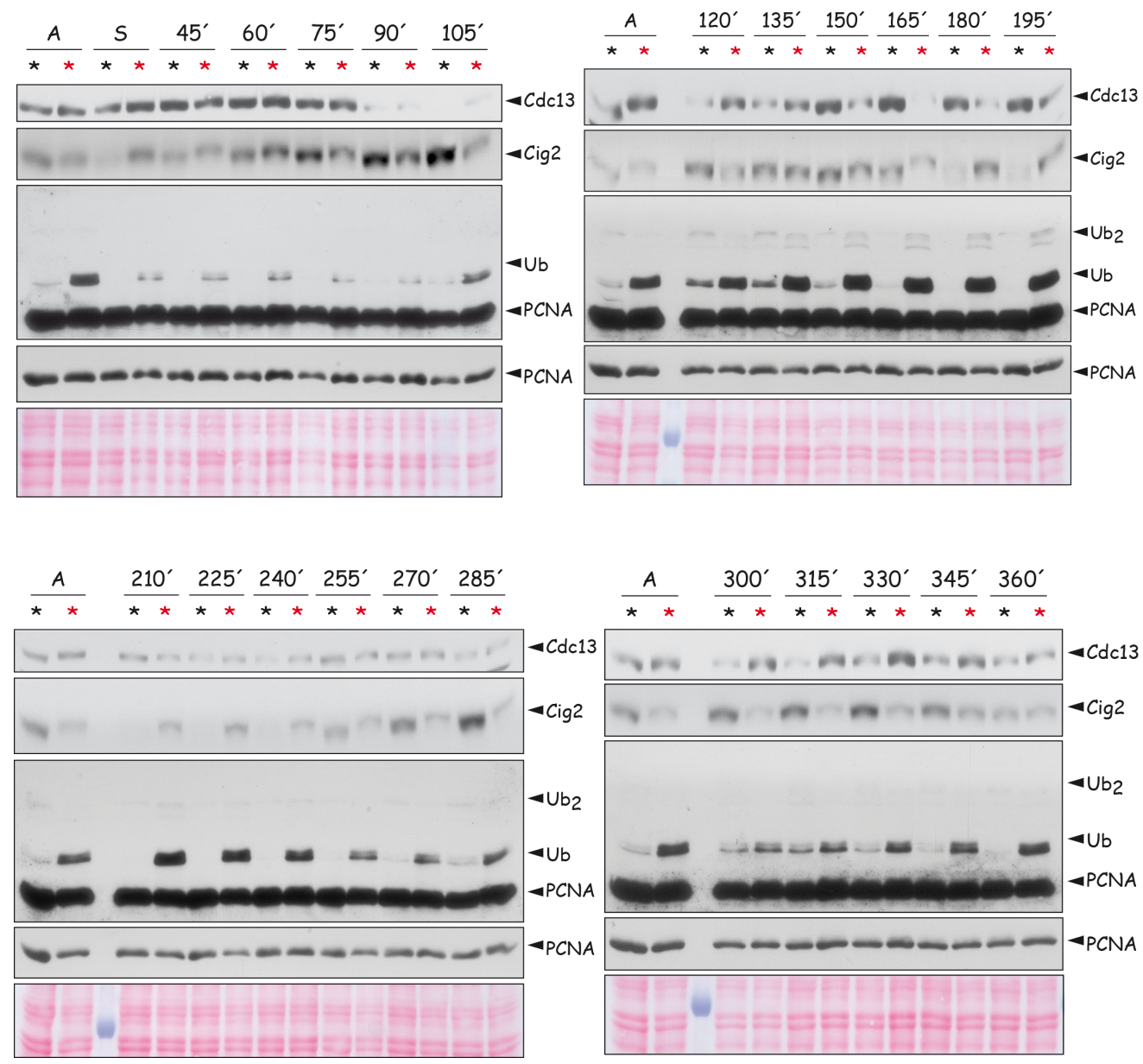

Figura 36: Análisis de la ubiquitinación de PCNA en el mutante $\triangle$ ubp12 $\Delta$ ubp15 $\Delta u b p 16$. Se sincronizaron las células en G2 por elutriación y se tomaron muestras cada 15 minutos para su análisis por Western blot y recuento de índices mitóticos y septación. A: La ubiquitinación de PCNA en el triple mutante aunque oscila nunca llega a desaparecer. Los marcadores de ciclo Cig2 y Cdc13 revelan la incapacidad del triple mutante para progresar correctamente a lo largo de ciclo celular, por permanecer después de la primera mitosis en una "constante" Fase $\mathrm{S}$. 
* $w t$

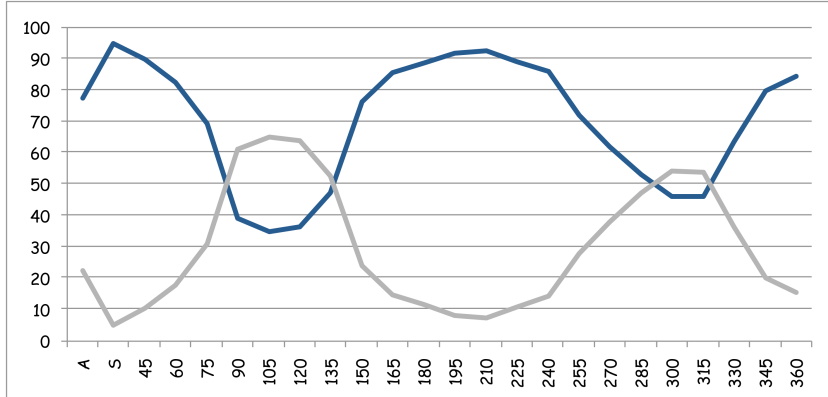

- mononucleadas

- binucleadas

* $\Delta u b p 12 \Delta u b p 15 \Delta u b p 16$

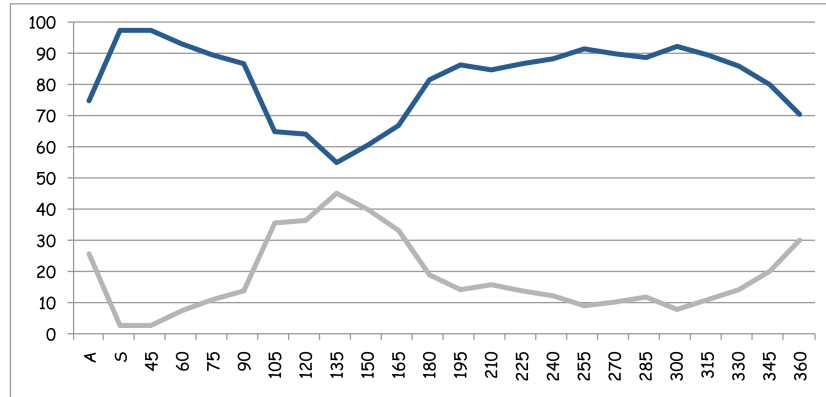

Figura 36B: Análisis de la ubiquitinación de PCNA en el mutante $\triangle u b p 12$ $\Delta u b p 15$ $\Delta u b p 16$. El recuento de núcleos y septos en ambas cepas, confirmo lo observado por Western blot. A diferencia del tipo silvestre, el cual es capaz de realizar dos ciclos celulares completos, el triple mutante $\Delta u b p 12 \Delta u b p 15 \Delta u b p 16$ después de hacer la primera mitosis (que ocurre mucho después que en el $w t$ ), no es capaz de completar otra Fase $\mathrm{S}$. 


\section{Discusión}

La tolerancia al daño, es el mecanismo del que dispone la célula para replicar los sitios dañados en el ADN que no consiguieron ser reparados antes del inicio de la replicación. Estos mecanismos son absolutamente necesarios para evitar un colapso de las horquillas, debido a la incapacidad de las polimerasas replicativas $\delta$ y $\varepsilon$, para replicar dichos sitios de daño (Baynton and Fuchs 2000). De forma general, la tolerancia se compone de dos rutas independientes llamadas error free y error pro$n e$, distinguibles entre sí por la fidelidad con que consiguen replicar esos sitios de ADN dañados.

La señal inicial de activación para ambas rutas, es la ubiquitinación de la abrazadera deslizante PCNA por medio del complejo ubiquitin ligasa E2-E3, formado por Rad6 y Rad18. Dicha modificación post-traduccional, constituye la señal necesaria y suficiente para la activación de la rama error prone o TLS de la tolerancia al daño (Hoege et al. 2002; Stelter and Ulrich 2003). A través de esta ruta, las polimerasas replicativas serán sustituidas por unas polimerasas especializadas llamadas polimerasas TLS (debido probablemente a que estas últimas presentan mayor afinidad que las primeras por PCNA ubiquitinado) (Shcherbakova and Fijalkowska 2006), que sí serán capaces de replicar el molde distorsionado del $A D N$, por disfrutar de amplios sitios activos preformados. La fidelidad de la replicación del molde, dependerá del tipo de polimerasa utilizada, siendo Poln la polimerasa más fiel descubierta hasta la fecha, encargándose de insertar dos adeninas enfrente de dímeros de timina (Johnson et al. 1999). Está descrito que alteraciones en dicha polimerasa, desencadenan el origen de la enfermedad Xerodermia pigmentosa variante o XPV (Masutani et al. 1999; Gratchev et al. 2003), enfermedad genética que predispone a los pacientes que la presentan, a un riesgo mucho mayor de padecer cáncer de piel respecto a la población normal (Kraemer et al. 1987). La existencia de la XPV, es uno de los 
ejemplos que pone de manifiesto la importancia del mecanismo de la tolerancia al daño en el desarrollo del cáncer.

La otra rama de la tolerancia está constituida por la vía error free, siendo la poliubiquitinación de PCNA la señal necesaria para su activación. En esta ocasión, el complejo encargado de dicha modificación post-traduccional, estará formado por las E2 Mms2-Ubc13 y la E3 Rad5. El sustrato de dichas enzimas será PCNA mono-ubiquitinado y las uniones de los monómeros de ubiquitina, se producirán por medio del residuo K63 (Xiao et al. 1998; Hofmann and Pickart 1999). A través de esta ruta, la célula replicará la zona dañada utilizando la información genética codificada por la cromátida hermana recién sintetizada sin daño, en una modo libre de errores (Cox 2002; McGlynn and Lloyd 2002). El mecanismo por el que se lleva a cabo esta alternativa de la tolerancia, continúa aún siendo una incógnita, aunque a raíz de varios trabajos, dos opciones diferentes han sido propuestas: intercambio de molde y regresión de la horquilla de replicación. A pesar de la falta de evidencias taxativas en pro de una opción u otra, sí se ha demostrado que esta alternativa de la tolerancia, está conservada en todos los organismos modelo estudiados hasta la fecha.

Una vez replicada la zona dañada, la célula tendrá que restaurar la horquilla de replicación normal reincorporando de nuevo a las polimerasas replicativas, con el fin de evitar los problemas producidos por un uso continuado de los mecanismos de la tolerancia. Se ha observado, cómo la ubiquitinación de PCNA desaparece al eliminar el daño del medio (Gallego-Sanchez et al. 2012), hecho que concuerda con la idea de que la desaparición de dicha modificación, sea necesaria para restablecer la condiciones normales de replicación. Ya que el proteasoma se ocupa principalmente de la degradación de proteínas, etiquetadas con cadenas de ubiquitinas unidas entre sí a través del residuo $\mathrm{K} 48$, debía ser otro el método utilizado por la célula, para eliminar ese PCNA modificado.

El descubrimiento de enzimas desubiquitinantes de PCNA, Usp1 en células humanas (Huang et al. 2006) y Ubp10 en la levadura de gemación (Gallego-Sanchez et al. 2012), puso de manifiesto que la reversión de la ubiquitinación de la abrazadera, era efectivamente el método utilizado por las células para conseguir limitar en el tiempo el uso de los mecanismos de la tolerancia.

\section{Ubp12, Ubp15 y Ubp16: desubiquitinasas de PCNA}

En esta Tesis Doctoral se demuestra que Ubp12, Ubp15 y Ubp16, son las proteasas encargadas de desubiquitinar a la abrazadera deslizante PCNA en la levadura de fisión. Nuestro trabajo pone de manifiesto, que dicha regulación en S. pombe, es más compleja que la llevada a cabo en $S$. cerevisiae, donde por los datos publicados hasta el momento, parece que sólo una proteasa (Ubp10) es la encargada de desubiquitinar a la abrazadera (Gallego-Sanchez et al. 2012). Una vez más por lo tanto, parece que la bioquímica de la levadura de fisión, es más parecida a la de las células 
humanas, ya que aunque hasta el momento solo se ha identificado una DUB capaz de desubiquitinar a PCNA (Usp1) en humanos, los resultados presentados en el trabajo de Huang y colaboradores, evidencian que deben existir más proteasas con PCNA como sustrato.

\section{Ubp16: principal enzima desubiquitinante de PCNA}

Los resultados presentados en este trabajo revelan a la proteasa Ubp16 como la principal enzima desubiquitinante de PCNA. Tras la realización de nuestro análisis inicial, con cepas delecionadas para cada una de las 16 UBPs existentes en S. pombe, observamos cómo sólo las células carentes de Ubp16, mostraban una clara acumulación de formas ubiquitinadas de PCNA en presencia de MMS. Este fenotipo era consistente con la idea de que dicha proteasa de ubiquitina, fuese la enzima encargada de desubiquitinar a PCNA in vivo en la levadura de fisión. Un análisis más profundo de la proteasa confirmó este resultado inicial.

Por otra parte, nuestros experimentos demostraron, cómo en las células que sobreexpresan Ubp16, no se observa ningún tipo de modificación de PCNA por ubiquitinación, ni siquiera en presencia de MMS. Además, dichas cepas presentaron un fenotipo de hipersensibilidad a agentes de daño al ADN (MMS, Cisplatino, 4NQO, Zalypsis y ET-743), resultado concordante con el observado para los mutantes que no son capaces de ubiquitinar a la abrazadera, como $\Delta r h p 18$. Este resultado ratificaba por lo tanto, cómo la activación de las rutas de Tolerancia por ubiquitinación de PCNA, son absolutamente necesarias para que las células puedan soportar condiciones de daño en el ADN.

El análisis de la cepa mutante Ubp16-C134S, reveló que la capacidad desubiquitinante de dicha enzima, dependía directamente de su actividad catalítica. Además, demostramos la existencia de una interacción física in vivo entre la proteasa Ubp16 y la abrazadera PCNA, tal y como se espera de un complejo enzima-sustrato. La demostración de que Ubp16 era capaz de desubiquitinar a PCNA in vitro, terminó de confirmar la función predicha para esta proteína tras el análisis inicial.

A pesar de la poca homología entre Ubp16 de S. pombe y Ubp10 de S. cerevisiae, un análisis de complementación con la levadura de gemación en condiciones de sobre-expresión, reveló que la enzima Ubp16 de S. pombe, era capaz de desubiquitinar a la abrazadera de $S$. cerevisiae. Un análisis de sensibilidad de células de $S$. cerevisiae que sobre-expresaban la UBP de S. pombe, reveló una vez más, cómo la ausencia total de ubiquitinación de PCNA, se traduce en hipersensibilidad celular a agentes que causan daño al ADN (Gallego-Sanchez et al. 2012).

Aunque el hallazgo de Ubp16 en realidad era esperado, (ya que dicha desubiquitinasa es la ortóloga de Ubp10 de S. cerevisiae), el análisis del estado de PCNA en cepas delecionadas para Ubp16 una vez eliminado el daño del medio, reveló que dichas células, todavía eran capaces de desubiquitinar a la abrazadera aún en au- 
sencia de Ubp16. Este resultado no coincidía con lo publicado hasta el momento para S. cerevisiae, ya que en el trabajo de Gallego y colaboradores, se había descrito que en ausencia de Ubp10, la cantidad de PCNA ubiquitinado permanecía constante aún eliminando el daño del medio. Por lo tanto, nuestro resultado revelaba cómo en la levadura de fisión, a diferencia de lo descrito en la levadura de gemación, debían existir más proteasas encargadas de la desubiquitinación de PCNA.

La identificación en el presente trabajo, de una mayor cantidad de histona $\mathrm{H} 2 \mathrm{~B}$ ubiquitinada en células $\Delta u b p 16$ así como en $\Delta u b p 8$ (tal y como se ha observado en la levadura de gemación, (Emre et al. 2005; Gardner et al. 2005; Schulze et al. 2011), abre una nueva línea de investigación para estas proteasas en su relación con los procesos de transcripción.

\section{Ubp15: papel secundario en la desubiquitinación de PCNA}

El análisis del estado de ubiquitinación de PCNA en dobles mutantes de UBPs ( $\triangle$ ubp16 $\triangle u b p X)$, reveló que la falta de Ubp15, sumada a la falta de Ubp16, provocaba una mayor acumulación de PCNA tanto en presencia como en ausencia de MMS, y tanto en las formas mono como en las poliubiquitinadas. Ya que en el análisis inicial de los mutantes simples, dicha proteasa no fue identificada como una posible enzima desubiquitinante de PCNA (debido a que solo las muestras no dañadas presentaban mayor acumulación que el $w t)$, pensamos que su papel en la desubiquitinación de la abrazadera debía de ser secundario al de Ubp16.

El análisis de PCNA en condiciones de sobre-expresión de Ubp15, reveló que efectivamente, dicha proteasa era capaz de desubiquitinar a la abrazadera en esas condiciones. Este resultado, sumado al fenotipo de acumulación observado en los mutantes simples y dobles, apoyaba la hipótesis de que dicha proteasa era capaz de desubiquitinar a la abrazadera in vivo. Además, el hecho de que la sobre-expresión de Ubp15 en un fondo carente de Ubp16, no fuese tan eficiente desubiquitinando PCNA respecto a un fondo $w t$, no solo ratificaba la idea de que el papel de Ubp15 podía ser secundario al de Ubp16, si no que marcaba la posibilidad de que la proteasa Ubp16, fuese necesaria para un perfecto funcionamiento de Ubp15. El fenotipo de menor hipersensibilidad (respecto al observado en las células nmt1-ubp16) observado en las células que sobre-expresan Ubp15, a los agentes que causan daño, confirmaba una vez más, que aunque dicha proteasa sí debía de desubiquitinar a PCNA in vivo, su implicación no era tan determinante como la de Ubp16.

Al igual que Ubp16, la capacidad desubiquitinante de la enzima Ubp15, depende de su actividad catalítica, ya que el mutante Ubp15-C239S, no fue capaz de desubiquitinar a la abrazadera deslizante.

La incapacidad para clonar Ubp15 en el vector de expresión pGEX-6P-1, impidió demostrar in vitro, la capacidad desubiquitinante de dicha proteína sobre PCNA.

84 


\section{Ubp12: tercera desubiquitinasa de PCNA}

La reversión de la ubiquitinación de PCNA al eliminar el daño del medio en el doble mutante $\Delta u b p 15 \Delta u b p 16$ (al igual que el tipo silvestre), puso de manifiesto que al menos otra UBP debía estar implicada en la desubiquitinación de la abrazadera. La sobre-expresión de todas las UBPs nucleares (Ubp6, Ubp8, Ubp9, Ubp12 y Ubp14), reveló a Ubp12 como la tercera desubiquitinasa de PCNA en la levadura de fisión, ya que al igual que ocurría con Ubp15 y Ubp16, la sobre-expresión de Ubp12 también se tradujo en un gran descenso de PCNA ubiquitinado. Este resultado, sumado al claro fenotipo de acumulación de formas ubiquitinadas de PCNA en el triple mutante $\Delta u b p 12 \Delta u b p 15 \Delta u b p 16$, confirmó su implicación en dicho proceso de regulación.

De nuevo la incapacidad para clonar Ubp12 en el vector de expresión pGEX-6P-1, impidió demostrar in vitro la capacidad desubiquitinante de dicha proteína sobre PCNA.

En la Figura 37 de esta discusión, se muestra a modo de esquema, el modelo propuesto para la desubiquitinación de PCNA en base a los resultados presentados en esta tesis.

\section{5. $\Delta u b p 12 \Delta u b p 15 \Delta u b p 16$}

El análisis del estado de ubiquitinación de la abrazadera en el triple mutante $\Delta u b p 12 \Delta u b p 15 \Delta u b p 16$, reveló dos cosas. Por un lado reveló cómo dicho mutante, acumulaba muchísima más cantidad de PCNA ubiquitinado que cualquier otro mutante simple o doble. Y en segundo lugar, cómo dicha ubiquitinación de PCNA, aunque nunca llegaba a desaparecer, seguía oscilando a lo largo del ciclo celular al igual que ocurría con el tipo silvestre. Ya que la sobre-expresión de ninguna otra UBP se tradujo en una disminución del estado de ubiquitinación de la abrazadera, pensamos que dicha oscilación no podía deberse entonces a la acción de otra desubiquitinasa, si no que probablemente se debiera a la propia tasa de renovación de PCNA.

En líneas celulares animales, se ha demostrado que PCNA se degrada vía proteasoma (Wang et al. 2006) y que dicha degradación no ocurre si PCNA es fosforilado en el residuo Y211, residuo conservado en todas las especies al igual que el K164. Una versión mutada a fenilalanina (residuo no fosforilable) en dicho residuo, será ubiquitinada y eliminada vía proteasoma. Aunque aún no se ha demostrado quién o quienes son los responsables de dicha ubiquitinación, sí se ha demostrado que esa ubiquitinación no es dependiente de la vía Rad6, por lo que otro complejo ubiquitinante tendrá como diana a la abrazadera, con el fin de ubiquitinarla para degradarla vía proteasoma. Una posible explicación por lo tanto para el resultado de oscilación en el triple mutante $\Delta u b p 12 \Delta u b p 15 \Delta u b p 16$, es que con nuestro anticuerpo (que no es específico para las formas ubiquitinadas por la vía Rad6) estemos detec- 
tando también la fracción de PCNA ubiquitinada para degradarse, y que esa fracción sea precisamente la que oscila y no la directamente relacionada con la tolerancia.
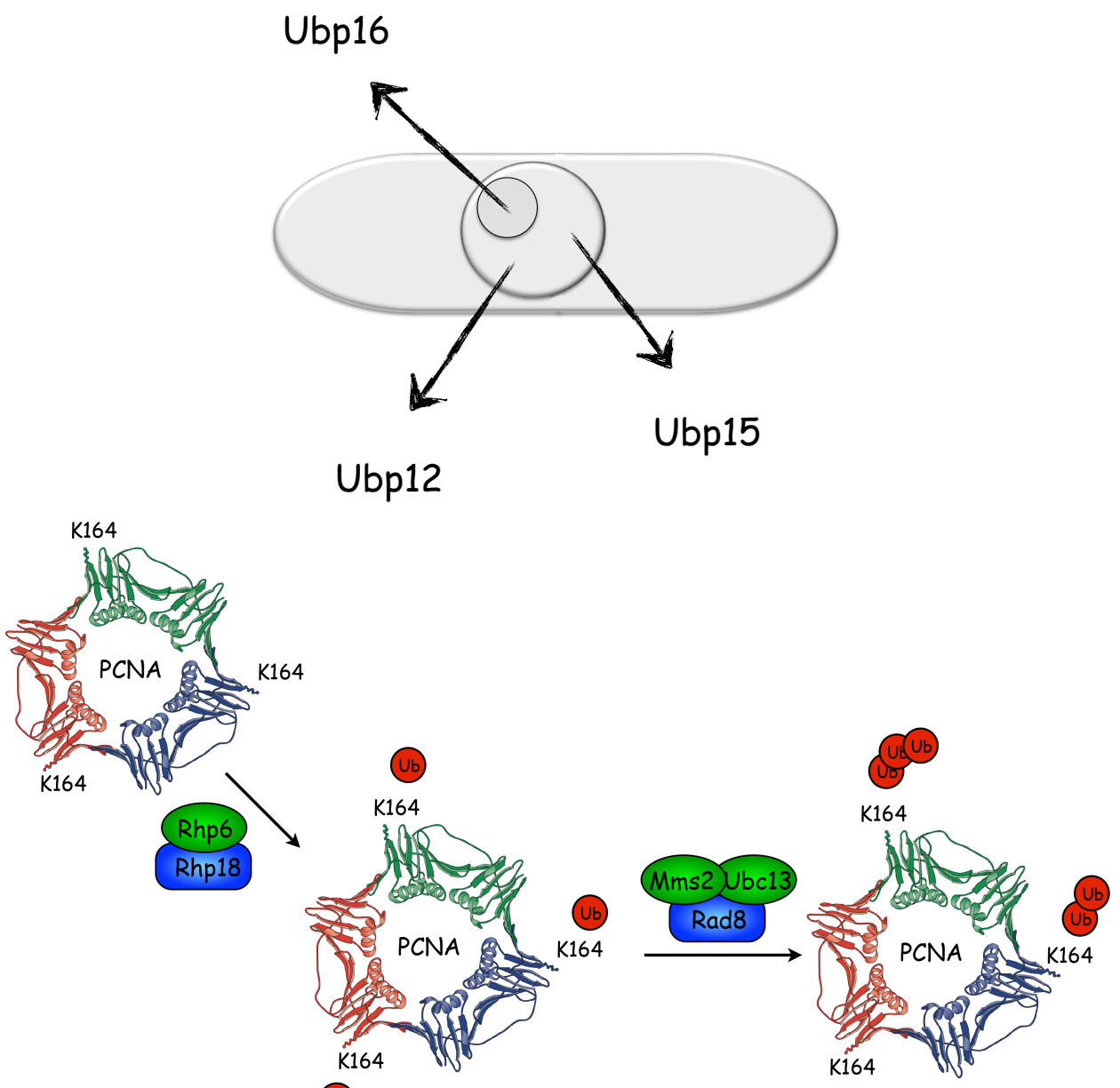

"Error prone"

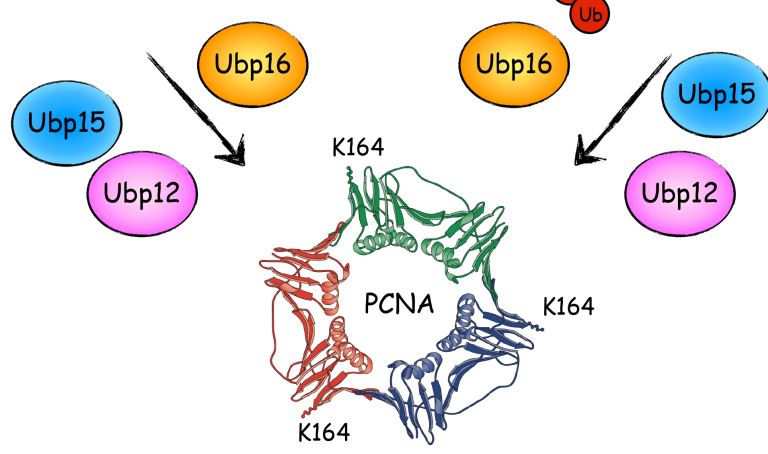

Figura 37: Modelo propuesto para la regulación de la desubiquitinación de PCNA en S. pombe. 


\section{Ubp2: ¿implicada o no en la tolerancia al daño?}

El fenotipo de acumulación de formas muy poliubiquitinadas de PCNA en células $\triangle u b p 2$ en presencia de MMS ( $\mathrm{y}$ otras drogas), posiblemente haya sido el fenotipo más espectacular mostrado en el presente trabajo. Sin embargo, la ausencia de fenotipo en células que sobre-expresan dicha proteasa, la localización citoplasmática descrita para la misma, así como el resultado negativo de la interacción física entre ambas proteínas, PCNA y Ubp2 (datos no mostrados), nos hizo pensar que dicha proteasa no debía tener una implicación directa en el proceso de desubiquitinación de PCNA en la levadura de fisión.

Recientemente se ha publicado en S. cerevisiae (Anton et al. 2013), que dicha proteasa es una de las enzimas encargadas de desubiquitinar la mitofusina Fzo1 (GTPasa de membrana implicada en la fusión mitocondrial) junto Ubp12. Sin embargo, la cadena de ubiquitinas diana de cada una de estas UBPs, es diferente. Así, Ubp12 reconoce las cadenas de ubiquitina que estabilizan Fzo1 y que promueven la fusión mitocondrial. Ubp2 en cambio, reconoce las cadenas de ubiquitina (unidas entre sí por K48) que provocarán la degradación de la mitofusina, inhibiendo por lo tanto la fusión mitocondrial. Se ha revelado además, que la formación de cada una de las cadenas de ubiquitinas, depende de dos complejos ubiquitinantes diferentes, siendo SCF ${ }^{\mathrm{Mdm} 30}$ el complejo que forma la cadena de ubiquitinas reconocida por Ubp12, y desconocido hasta el momento el que forma la cadena reconocida por Ubp2.

Aunque hasta el momento no existe ningún trabajo que demuestre que Ubp2 se ocupe exclusivamente de la desubiquitinación de cadenas formadas por enlaces K48, o que al menos sea capaz de ocuparse de ese tipo de cadenas en S. pombe, este descubrimiento podría explicar los fenotipos observados para Ubp2 en nuestro trabajo.

Una hipótesis interesante, sería que PCNA se ubiquitinase, al igual que la mitofusina Fzo1, en diferentes residuos de lisina para activar funciones diferentes. Así, la ubiquitinación en K164 activaría las rutas de tolerancia, mientras que el hipotético residuo $\mathrm{K}$ desconocido, se ubiquitinaría a través de uniones K48 para etiquetar a la abrazadera para su degradación vía proteasoma. Éstas precisamente, serían las cadenas reconocidas por Ubp2. Si tenemos en cuenta que la cantidad de PCNA unido a cromatina es muy pequeña en comparación con la cantidad total, pero que ése es el PCNA que se modifica para activar las rutas de tolerancia (así como la mayoría de las funciones en las que está implicada la abrazadera), nuestra hipótesis también explicaría la sensibilidad de las células $\triangle u b p 2$ a MMS. Así, células $\Delta u b p 2$, no serían capaces de desubiquitinar las cadenas que marcan a PCNA para su degradación, por lo que la fracción de PCNA unida a cromatina se degradaría y esas cepas no tendrían suficiente PCNA modificado para activar las rutas de tolerancia, mostrando así una clara sensibilidad a los agentes que dañan el ADN (ver Figura 41 Apéndice).

Es importante señalar que esta hipótesis sigue teniendo el inconveniente de la localización citoplasmática descrita para Ubp2. Sin embargo, esto sería explicable si una 
pequeña fracción de la proteasa (no detectable por microscopía) se localizase en el núcleo, o bien si la etiqueta GFP añadida para visualizar la proteína (Kouranti et al. 2010) estuviese alterando parcial o totalmente la verdadera localización de Ubp2. Otra posible explicación también sería que dicha regulación se llevase acabo a través de un posible intermediario aún no descubierto.

\section{Ubp5: proteasa no relacionada con la tolerancia}

El fenotipo observado en el doble mutante $\Delta u b p 5 \Delta u b p 16$, también dio lugar a muchas dudas acerca de la implicación o no de dicha proteasa en la desubiquitinación de PCNA. Sin embargo, tras analizar todos los resultados obtenidos (especialmente en los experimentos de localización forzada en el núcleo), concluimos que dicha proteína no podía estar implicada en el proceso de desubiquitinación de la abrazadera, explicando el fenotipo de acumulación del doble mutante, como el resultado de una lenta progresión a lo largo de Fase S.

\section{Desubiquitinación de PCNA en S. pombe}

Como se mencionó al principio de la discusión, pensamos que al existir varias enzimas desubiquitinantes de PCNA en la levadura de fisión, dicho mecanismo debía de ser más parecido al acaecido en células humanas que al de la levadura de gemación, ya que los resultados observados para Usp1, sugerían que debía existir alguna otra desubiquitinasa con PCNA como sustrato (Huang et al. 2006). Sin embargo, nuestro trabajo, al igual que el de $S$. cerevisiae, también mostró diferencias importantes respecto a la posible regulación llevada a cabo por Usp1. Se ha probado que en células humanas en ausencia de daño, PCNA es desubiquitinado por Usp1 de forma constitutiva, sin embargo, en presencia de luz ultravioleta, Usp1 se auto-degrada produciéndose entonces una acumulación de PCNA ubiquitinado (señal necesaria para la activación de las rutas de tolerancia al daño). Como ya se ha mencionado, ya que dicha degradación no se ha observado en presencia de otras drogas como Mitomicina C o MMS, es muy probable que otras proteasas también estén implicadas en este proceso de regulación.

A diferencia de lo descrito en células humanas (y al igual que lo observado para la levadura de gemación), en S. pombe la acumulación de PCNA ubiquitinado en los mutantes simples y dobles de las UBPs implicadas, se ha observado en presencia de varias drogas como MMS, UV y 4-NQO. Además, al igual que en S. cerevisiae, en la levadura de fisión tampoco se ha observado ningún tipo de degradación en ninguna de las proteasas en presencia de daño. 


\section{Ubiquitinación-desubiquitinación y ciclo celular.}

Otra diferencia significativa entre ambas levaduras, viene dada por el momento del ciclo celular en el que se produce la desubiquitinación de PCNA. Como ya se mencionó en la introducción, la tolerancia al daño es un mecanismo vinculado a la Fase $S$, ya que su finalidad consiste en permitir a la célula continuar con una replicación bloqueada por la presencia de algún tipo de daño en el ADN. Esta base hizo pensar, que tanto la ubiquitinación como la desubiquitinación, debían de ser procesos vinculados con la Fase S y como tal, se ha demostrado en S. cerevisiae. Así, en la levadura de gemación, la ubiquitinación de PCNA ocurre a lo largo de una Fase $S$ que transcurre en presencia de daño, siendo la SUMOilación, la modificación post traduccional que sufre la abrazadera en ausencia de daño exógeno. La ubiquitinación de PCNA será entonces la señal que active las rutas de tolerancia al daño, exclusivamente a lo largo de Fase $\mathrm{S}$. Además, en dicho organismo, también se ha demostrado que la desubiquitinación de la abrazadera por medio de la proteasa Ubp10, también ocurre exclusivamente en Fase $\mathrm{S}$, posiblemente después de que las zonas de daño hayan sido replicadas por las polimerasas TLS. Dicha modificación post-traduccional, la desubiquitinación de PCNA, será por lo tanto la señal de descargue de las polimerasas TLS y por consiguiente, la señal de recarga de las replicativas.

En contra de lo esperado, en la levadura de fisión se demostró que la ubiquitinación de la abrazadera ocurría tanto en una Fase $S$ sin daño exógeno, como en $G 2$ en presencia de daño exógeno (Frampton et al. 2006). Se cree que el hecho de que ocurra en Fase $\mathrm{S}$ en ausencia de daños, posiblemente se deba a que dicho organismo presenta mucha más inestabilidad que la levadura de gemación en esa fase (Ulrich 2007a), y que por lo tanto, necesite hacer uso de la tolerancia para terminar con la replicación. Respecto al hecho de que exista, fuera de todo pronóstico, ubiquitinación de la abrazadera en G2 con daño, podría explicarse a través de la existencia de complejos de transcripción estancados, aunque hasta la fecha no se haya demostrado la implicación de la abrazadera en dicho proceso de transcripción.

Los datos aportados en el presente trabajo, también revelan cómo en la levadura de fisión existe ubiquitinación de la abrazadera en Fase G1 en presencia de daño exógeno. Una vez más, la explicación también podría venir dada por la posible implicación de la abrazadera, en la resolución de los hipotéticos complejos de transcripción estancados.

Ya que en los momentos del ciclo celular en los que se ha observado ubiquitinación de la abrazadera, también se ha observado una mayor acumulación de la misma en los mutantes carentes de Ubp16, podemos concluir que la desubiquitinación de PCNA en S. pombe, al igual que la ubiquitinación, no es un proceso exclusivo de Fase $S$.

Todos estos datos sugieren que la regulación de los mecanismos de la tolerancia, deben de ser muy diferentes en cada organismo modelo, a pesar de la demostrada conservación de los requisitos genéticos entre todos ellos. De hecho, hasta la fecha, 
ya se ha demostrado cómo el dogma mantenido para la activación de cada una de las rutas de la tolerancia (monoubiquitinación de PCNA para TLS y poliubiquitinación para error free), no se ha conservado como tal en la levadura de fisión. Y es que, en contra de todo lo descrito hasta el momento, se ha probado que en $S$. pombe, la poliubiquitinación de la abrazadera mediada por Rad8 y Mms2-Ubc13, también activa eventos TLS (Coulon et al. 2010).

\section{Relación entre desubiquitinasas y polimerasas TLS}

Como ya se ha mencionado, el mecanismo aceptado para la resolución de los eventos de la tolerancia, es la desubiquitinación de la abrazadera por medio de las proteasas USPs/UBPs. Sin embargo, hasta el momento apenas existen evidencias experimentales que expliquen cómo media el proceso.

En la levadura de gemación se ha demostrado cómo la proteasa Ubp10, media la interacción entre PCNA y las polimerasas TLS Rev1 y Rev7. Así, la ausencia de Ubp10 en la célula se traduce en una mayor interacción entre Rev1 y PCNA, pero en una menor interacción entre la abrazadera y Rev7 (Gallego-Sanchez et al. 2012). Aunque hasta la fecha en la levadura de fisión no se hayan aportado datos al respecto, sí se conoce por un lado la existencia de un mayor número de polimerasas TLS, y a raíz de nuestro trabajo, también se conoce un mayor número de proteasas con PCNA como sustrato. Estos datos abren la puerta a una posible mayor especificidad en dicha levadura, entre el tipo de daño producido, la ubiquitinación de PCNA, las polimerasas TLS y cómo no, las desubiquitinasas. Se espera que estudios futuros puedan confirmar todas estas hipótesis o sugerir ideas nuevas.

\section{Ubicación de la desubiquitinación}

Dónde se produce la desubiquitinación de la abrazadera, será otra de las respuestas que tendrá que esperar a estudios posteriores, ya que los datos presentados en este trabajo, unidos a la localización de las UBPs descrita en Kouranti y colaboradores, no han conseguido arrojar luz al respecto. Las versiones etiquetadas con GFP de las UBPs (además de las versiones con RFP realizadas en nuestro trabajo) han revelado una localización nucleolar para Ubp16, y nuclear (fase no nucleolar) y citoplasmática para Ubp15 y Ubp12. Ya que se asume que PCNA se localiza en todo el núcleo, una posible teoría sería que cada una de las desubiquitinasas se ocupase de fracciones diferentes de PCNA. Sin embargo, dado que aún no se conoce con precisión cómo es la dinámica de la replicación, es muy probable que tengan que pasar muchos años hasta que se consiga demostrar con rigor cómo es el funcionamiento de dicho proceso. 


\section{Conclusiones}

1. Las proteasas de la familia UBP/USP, Ubp12, Ubp15 y Ubp16, son las enzimas encargadas de desubiquitinar PCNA en la levadura de fisión S. pombe.

2. La cisteína proteasa Ubp16, es la principal enzima desubiquitinante de PCNA.

i. Células mutantes carentes de dicha proteína, acumulan gran cantidad de PCNA ubiquitinado,especialmente en presencia de daño exógeno.

ii. Células mutantes capaces de sobre-expresar la versión catalíticamente activa de Ubp16, no presentan ningún tipo de modificación de PCNA.

iii. Ubp16 es capaz de desubiquitinar en condiciones de sobre-expresión PCNA de S. cerevisiae, confirmando así que dicha proteasa es la proteína ortóloga de Ubp10 de la levadura de gemación. El hecho de que células $\triangle$ ubp16 acumulen más histona H2B ubiquitinada, secunda esta idea.

3. Ubp12 y Ubp15 parecen tener papeles secundarios en el proceso de desubiquitinación de PCNA, ya que solo las células capaces de sobre-expresar ambas proteasas, presentan un diferente patrón de ubiquitinación de PCNA, siendo en el caso de Ubp15, dependiente de Ubp16.

4. A pesar de los fenotipos mostrados por los mutantes $\Delta u b p 2$ y $\Delta u b p 5$, la suma de resultados negativos apuntan a que estas proteasas, no están implicadas en la regulación de la desubiquitinación de PCNA en K164.

5. La hipersensibilidad a daño exógeno en el ADN, presentada por las cepas capaces de sobre-expresar dichas proteasas, confirma la importancia de la ubiquitinación de PCNA para activar las rutas de tolerancia y por ende, para ser capaces de sobrevivir en condiciones de daño.

6. La ubiquitinación de PCNA oscila a lo largo del ciclo celular, presentando su máximo pico en Fase $S$ aunque no exista ningún tipo de daño exógeno. Sin embargo, a diferencia de lo descrito en otros organismos hasta el momento, dicho proceso también ocurre en $\mathrm{G} 1$ y G2 en presencia de daño. 



\section{Materiales y Métodos}

\section{MICROORGANISMOS Y MEDIOS DE CULTIVO}

\subsection{Microorganismos}

El trabajo presentado en esta memoria, se ha realizado utilizando distintas cepas de la levadura de fisión Schizosaccharomyces pombe, de la levadura de gemación Saccharomyces cerevisiae, así como varias estirpes de la bacteria Escherichia coli. Las carácterísticas genéticas de estos organismos, su procedencia, así como el número de colección en nuestro cepario, se recogen en las Tablas M1, M2 y M3.

\subsection{Medios de cultivo}

\section{i. Medios y condiciones de cultivo para el crecimiento de S. pombe}

La composición de los medios de cultivo empleados en este trabajo, así como la descripción de las técnicas de cruce, análisis de tétradas y esporas al azar, han sido previamente descritos por Moreno y colaboradores (1991).

Las células de S. pombe se crecieron en YES (del inglés Yeast Extract with Supplement, medio rico con extracto de levadura $0.5 \%$ y glucosa $3 \%$, suplementado con $225 \mathrm{mg} / \mathrm{ml}$ de adenida, histidina, leucina, uracilo y lisina) o $\mathrm{MM}$ (medio mínimo compuesto por $\mathrm{C}_{8} \mathrm{H}_{5} \mathrm{KO}_{4} 14.7 \mathrm{mM}, \mathrm{NH}_{4} \mathrm{Cl} 93.5 \mathrm{mM}, \mathrm{Na}_{2} \mathrm{HPO}_{4} 15.5 \mathrm{mM}$, sales, vitaminas y minerales) en baños a $160 \mathrm{rpm}$, a una temperatura entre $25^{\circ} \mathrm{C}$ y $36^{\prime} 5^{\circ} \mathrm{C}$ dependiendo del experimento. Siempre que se pudo, se trabajó con cepas protótrofas y en caso contrario, se suplementó el MM con aminoácidos (leucina, histidina) y/o bases nitrogenadas (adenina, uracilo), según las auxotrofías de la cepa, a una con- 
centración final de $225 \mu \mathrm{g} / \mathrm{ml}$. Los experimentos en medio líquido se iniciaron con cultivos a una densidad óptica medida a $\lambda=595 \mathrm{~nm}$, de 0,2 a $0,4\left(2-4 \times 10^{6}\right.$ células/ $\mathrm{ml}$ ), correspondiente con cultivos en fase exponencial de crecimiento. Los medios se precalentaron siempre a la temperatura adecuada cuando hubo que diluir los cultivos.

Tabla 3: Cepas de S. pombe utilizadas en este trabajo.

\begin{tabular}{|c|c|c|}
\hline Genotipo & Cepario & Origen \\
\hline$h^{-} 972$ & $3.13 / 7.32$ & Dr. Bueno \\
\hline$h^{+} 975$ & 7.33 & Dr. Bueno \\
\hline$h^{-} w t$ & 52.20 & Dr. Bueno \\
\hline$h^{+} w t$ & 49.53 & Dr. Bueno \\
\hline$h^{+} c d c 10-129$ & 4.75 & Dr. Bueno \\
\hline$h^{+} c d c 25-22$ & 7.50 & Dr. Bueno \\
\hline$h^{+} c d c 17-k 12$ & 51.04 & Dr. Bueno \\
\hline$h^{+}$rad3::kanMX6 & 70.35 & Dr. Moreno \\
\hline$h^{-}$ubp1::hphMX6 & 64.39 & Este trabajo \\
\hline$h^{+}$ubp2::kanMX6 & 60.11 & Este trabajo \\
\hline$h^{-}$ubp3::hphMX6 & 62.74 & Este trabajo \\
\hline$h^{-}$ubp4::hphMX6 & 62.76 & Este trabajo \\
\hline$h^{-}$ubp5::kanMX6 & 62.72 & Este trabajo \\
\hline$h^{-}$ubp6::kanMX6 & 63.43 & Este trabajo \\
\hline$h^{-}$ubp7::natMX6 & 64.32 & Este trabajo \\
\hline$h^{-}$ubp8::kanMX6 & 63.45 & Este trabajo \\
\hline$h^{-}$ubp9::hphMX6 & 64.42 & Este trabajo \\
\hline$h^{-}$ubp10::hphMX6 & 64.40 & Este trabajo \\
\hline$h^{-}$ubp11::kanMX6 & 63.47 & Este trabajo \\
\hline$h^{+}$ubp12::kanMX6 & 63.40 & Este trabajo \\
\hline$h^{-}$ubp13::hphMX6 & 62.68 & Este trabajo \\
\hline$h^{-}$ubp14::kanMX6 & 63.48 & Este trabajo \\
\hline$h^{-}$ubp15::kanMX6 & 65.19 & Este trabajo \\
\hline$h^{+}$ubp15::kanMX6 & 66.23 & Este trabajo \\
\hline$h^{-}$ubp16::hphMX6 & 62.70 & Este trabajo \\
\hline$h^{+}$ubp16::hphMX6 & 63.39 & Este trabajo \\
\hline h? ubp16::hph ubp1::hphMX6 & 64.78 & Este trabajo \\
\hline h? ubp16::hph ubp2::kanMX6 & 62.78 & Este trabajo \\
\hline h? ubp16::hph ubp3::hphMX6 & 65.05 & Este trabajo \\
\hline h? ubp16::hph ubp4::hphMX6 & 64.74 & Este trabajo \\
\hline h ubp16::hph ubp5::kanMX6 & 64.48 & Este trabajo \\
\hline h ubp16::hph ubp6::kanMX6 & 64.72 & Este trabajo \\
\hline h ubp16::hph ubp7::natMX6 & 64.76 & Este trabajo \\
\hline h ubp16::hph ubp8::kanMX6 & 64.44 & Este trabajo \\
\hline h ubp16::hph ubp9::hphMX6 & 65.03 & Este trabajo \\
\hline h ubp16::hph ubp10::hphMX6 & 64.80 & Este trabajo \\
\hline$h^{+}$ubp16::hph ubp11::kanMX6 & 64.70 & Este trabajo \\
\hline h ubp16::hph ubp12::kanMX6 & 64.46 & Este trabajo \\
\hline
\end{tabular}




\begin{tabular}{|c|c|c|}
\hline Genotipo & Cepario & Origen \\
\hline h ubp16::hph ubp13::hphMX6 & 65.01 & Este trabajo \\
\hline$h^{-}$?? ubp16::hph ubp14::kanMX6 & 64.68 & Este trabajo \\
\hline$h^{-}$?? ubp16::hph ubp15::kanMX6 & 65.20 & Este trabajo \\
\hline h ubp5::kanMX6 ubp15::kanMX6 & 66.08 & Este trabajo \\
\hline h ubp5::kanMX6 ubp15::kanMX6 ubp16::hph & 65.46 & Este trabajo \\
\hline$h^{+}$ubp16::hphMX6 cdc10-129 & 63.27 & Este trabajo \\
\hline$h^{-}$ubp16::hphMX6 cdc25-22 & 63.29 & Este trabajo \\
\hline$h^{-}$ubp16::hphMX6 cdc17-k12 & 63.31 & Este trabajo \\
\hline$h^{+}$ubp5::kanMX6 cdc10-129 & 66.15 & Este trabajo \\
\hline$h^{-}$ubp5::kanMX6 cdc25-22 & 66.17 & Este trabajo \\
\hline$h^{+}$ubp15::kanMX6 cdc10-129 & 66.11 & Este trabajo \\
\hline$h^{+}-$ubp15::kanMX6 cdc25-22 & 66.13 & Este trabajo \\
\hline$h^{-}$ubp2::kanMX6 cdc10-129 & 64.52 & Este trabajo \\
\hline$h^{-}$ubp2::kanMX6 cdc25-22 & 64.50 & Este trabajo \\
\hline$h^{+}$ubp16::hphMX6 ubp15:: kanMX6 cdc10-129 & 66.28 & Este trabajo \\
\hline h- ubp16::hphMX6 ubp15::kanMX6 cdc25-22 & 66.30 & Este trabajo \\
\hline h ubp16::hph MX6ubp5::kanMX6 cdc10-129 & 66.19 & Este trabajo \\
\hline$h^{-}$ubp16::hphMX6 ubp5::kanMX6 cdc25-22 & 66.21 & Este trabajo \\
\hline h?? ubp16::hphMX6 ubp5:kanMX6 ubp15::kanMX6 cdc10-129 & 66.57 & Este trabajo \\
\hline h ubp16::hph ubp5::kanMX6 ubp15::kanMX6 cdc25-22 & 66.54 & Este trabajo \\
\hline h.?? ubp16:3Flag:kanMX6 & 63.33 & Este trabajo \\
\hline h.?? ubp2:3Flag:kanMX6 & 62.19 & Este trabajo \\
\hline h- ubp16:13Myc:hphMX6 & 66.07 & Este trabajo \\
\hline h ubp15:13Myc:hphMX6 & 66.34 & Este trabajo \\
\hline$h^{-}$nmt1-41:kanMX6 ubp16 & 63.37 & Este trabajo \\
\hline$h^{-} n m t 1-41: k a n M X 6$ ubp2 & 63.35 & Este trabajo \\
\hline$h^{-} n m t 1-41: k a n M X 6$ ubp8 & 65.31 & Este trabajo \\
\hline$h^{-}$nmt1-41:kanMX6 ubp15 & 65.33 & Este trabajo \\
\hline$h^{-} n m t 1-41: k a n M X 6$ ubp5 & 65.35 & Este trabajo \\
\hline h nmt1-3x:kanMX6 ubp16:13Myc:hphMX6 & 66.40 & Este trabajo \\
\hline h nmt1-3x:kanMX6 ubp15:13Myc & 66.38 & Este trabajo \\
\hline$h^{-}$nmt1-41:kanMX6 ubp16 cdc10-129 & 64.58 & Este trabajo \\
\hline h- nmt1-41:kanMX6 ubp16 cdc25-22 & 64.56 & Este trabajo \\
\hline$h^{+} n m t 1-41: k a n M X 6$ ubp16 cdc17-K12 & 64.60 & Este trabajo \\
\hline$h^{-} n m t 1-41: k a n M X 6$ ubp2 cdc10-129 & 64.64 & Este trabajo \\
\hline$h^{-}$nmt1-41:kanMX6 ubp2 cdc25-22 & 64.62 & Este trabajo \\
\hline$h^{+} n m t 1-41: k a n M X 6$ ubp2 cdc17-K12 & 64.66 & Este trabajo \\
\hline$h^{-}$rev1::natMX6 & 64.34 & Este trabajo \\
\hline$h^{+}$rhp18::kanMX6 & 61.48 & Dr. Vazquez \\
\hline$h^{+}$rhp8::kanMX6 & 61.46 & Dr. Vazquez \\
\hline h ubc13::kanMX6 & 61.47 & Dr. Vazquez \\
\hline h ubp2::kanMX6 rhp18::kanMX6 & 62.21 & Este trabajo \\
\hline h ubp2::kanMX6 rad8::kanMX6 & 62.24 & Este trabajo \\
\hline h ubp2::kanMX6 ubc13::kanMX6 & 62.23 & Este trabajo \\
\hline$h^{90}$ ubp16:GFP:kanMX6 & 61.27 & Dr. Bueno \\
\hline
\end{tabular}




\begin{tabular}{|c|c|c|}
\hline Genotipo & Cepario & Origen \\
\hline$h^{90}$ ubp15:GFP:kanMX6 & 61.28 & Dr. Bueno \\
\hline$h^{+}$ubp16:GFP:kanMX6 cdc10-129 & 65.40 & Este trabajo \\
\hline$h^{+}$ubp16:GFP:kanMX6 cdc25-22 & 65.37 & Este trabajo \\
\hline$h^{+}$ubp16:GFP:kanMX6.cdc17-K12 & 65.38 & Este trabajo \\
\hline h- ubp15::kanMX6 pREP3x-ubp15:3Flag & 69.63 & Este trabajo \\
\hline$h^{-}$ubp15::kanMX6 pREP3x-ubp15CS:3Flag & 69.65 & Este trabajo \\
\hline$h^{+}$PCNA:3Flag:kanMX6 & 66.09 & Este trabajo \\
\hline h PCNA:3Flag:kanMX6 ubp16:13Myc:hphMX6 & 66.24 & Este trabajo \\
\hline h cut11:mRFP & 66.26 & Dr Moreno \\
\hline h ubp16:GFP:kanMX6:cut11:mRFP:hph & 66.32 & Este trabajo \\
\hline ubp16:mRFP:kanMX6 & 66.42 & Este trabajo \\
\hline h PCNA:3Flag:kanMX6 ubp15:13Myc:hphMX6 & 66.46 & Este trabajo \\
\hline h ubp16:mRFP ubp15:GFP:kanMX6 & 66.44 & Este trabajo \\
\hline h nmt1-3x:kanMX6 ubp16:13Myc hphMX6 ubp15::kanMX6 & 66.48 & Este trabajo \\
\hline h nmt1-3x:kanMX6 ubp15:13Myc:hphMX6 ubp16::hph MX6 & 66.50 & Este trabajo \\
\hline ubp15::ubp15:GFP-HA-kanMX6 ubp16::hphMX6 & 66.52 & Este trabajo \\
\hline ubp5::kanMX ubp15::kanMX6 ubp16::hphMX6 cdc25.22 & 66.54 & Este trabajo \\
\hline ubp5::kanMX ubp15::kanMX6 ubp16::hphMX6 cdc10.129 & 66.57 & Este trabajo \\
\hline$h^{+}$ubp5:13Myc:hphMX6 & 66.59 & Este trabajo \\
\hline$h^{-} n m t 1-3 x$ ubp5 kanMX6 & 66.60 & Este trabajo \\
\hline h?? ubp16::hphMX6 PCNA:3Flag & 66.62 & Este trabajo \\
\hline h- nmt1-3xkanMX ubp5:13Myc:hphMX6 & 66.67 & Este trabajo \\
\hline$h^{+}$ubp5:13Myc:hphMX6 PCNA:3Flag:kanMX6 & 66.69 & Este trabajo \\
\hline$h^{+} f t p 105:: k a n M X 4$ & 66.73 & Dr Moreno \\
\hline ftp105::kanMX nmt1-3x:kanMX6 ubp5:13MyckanMX6 & 67.04 & Este trabajo \\
\hline ftp105::kanMX4 ubp5:13MychphMX6 & 67.15 & Este trabajo \\
\hline$h^{-} n m t 1-3 x k a n m M X 6$ ubp6 & 69.69 & Este trabajo \\
\hline$h^{-} n m t 1-3 x k a n m M X 6$ ubp9 & 69.71 & Este trabajo \\
\hline$h^{-} n m t 1-3 x k a n m M X 6$ ubp14 & 69.73 & Este trabajo \\
\hline$h^{-} n m t 1-3 x k a n m M X 6$ ubp12 & 69.74 & Este trabajo \\
\hline$h^{-} n m t 1-3 x k a n m M X 6$ ubp8 & 69.76 & Este trabajo \\
\hline$h^{-}$ubp16::hphMX6 pREP3xubp16 ${ }^{+}$ & 67.02 & Este trabajo \\
\hline$h^{-}$ubp16::hph pREP3x ubp16 CS & 67.03 & Este trabajo \\
\hline$h^{-}$ubp15::kanMX ubp16::hph PCNA:3Flag:kanMX6 & 67.06 & Este trabajo \\
\hline$h^{-}$ubp5:mRFP_NLS:kanMX6 & 66.74 & Este trabajo \\
\hline$h^{+}$ubp5:GFP_NLS:kanMX6 & 67.09 & Este trabajo \\
\hline$h^{-}$ubp5 mRFP_NES:kanMX6 & 67.13 & Este trabajo \\
\hline ubp15 mRFP_NES:kanMX6 & 67.17 & Este trabajo \\
\hline ubp15 GFP_NLS: kanMX6 & 67.19 & Este trabajo \\
\hline$h^{-}$ubp5:GFP KanMX6 & 67.21 & Este trabajo \\
\hline$h^{-}$ubp5:mRFP KanMX6 & 67.23 & Este trabajo \\
\hline$h^{+}$ubp15:RFP NLS KanMX6 & 67.25 & Este trabajo \\
\hline ubp15::KanMX6 ubp16::hph PCNA:3FlagKanMX6 cdc25.22 & 67.30 & Este trabajo \\
\hline h- ubp12::KanMX6 ubp15::KanMX6 & 70.33 & Este trabajo \\
\hline ubp12::KanMX6 ubp15::KanMX6 ubp16::hphMX6 & 70.36 & Este trabajo \\
\hline
\end{tabular}


Tabla 4: Cepas de S. cerevisiae utilizadas en este tabajo.

\begin{tabular}{|l|c|c|}
\hline \multicolumn{1}{|c|}{ Genotipo } & Cepario & Origen \\
\hline W303 MATa rad5 bar1::leu2 & 55.33 & Dr. Bueno \\
W303 MATa rad5 bar::leu2 ubp10::hphMX6 & 61.33 & Dr. Bueno \\
W303 MATa rad5 bar1::leu2 Uubp10 GAL1ubp16:3Flag & 65.21 & Este trabajo \\
W303 MATa rad5 bar1::leu2 Gal1.10 ubp163:Flag & 65.60 & Este trabajo \\
W303 MATa rad5+ bar1::leu2 Gal1.10 ubp16CS:3Flag & 65.62 & Este trabajo \\
W303 MATa rad5+ bar1::leu2 ubp10::hphMX ubp16CS:3Flag & 65.64 & Este trabajo \\
\hline
\end{tabular}

Tabla 5: Cepas de $E$. coli utilizadas en este trabajo.

\begin{tabular}{|c|c|}
\hline Genotipo & Origen \\
\hline Dh5 $\alpha$ & $\mathrm{CIC}$ \\
$B L 21$ & $\mathrm{CIC}$ \\
\hline
\end{tabular}

Los experimentos de sobre-expresión de genes bajo el control del promotor nmt1

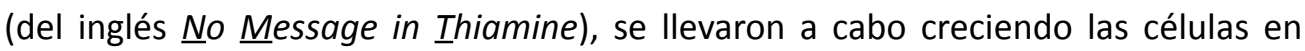
MM líquido con tiamina, a una concentración de $5 \mu \mathrm{g} / \mathrm{ml}$, para reprimir la expresión controlada por el promotor nmt1. Para inducir la expresión de los genes a estudio, se eliminó la tiamina residual del medio de cultivo. Para ello, se recogieron las células por centrifugación y se lavaron hasta tres veces con $\mathrm{MM}$ sin tiamina. Finalmente, las células se resuspendieron en MM sin tiamina, a la densidad óptica adecuada para obtener $2-4 \times 10^{6}$ células $/ \mathrm{ml}$ en el momento en el que comenzaba la inducción del gen a estudio (aproximadamente unas 12-14 horas después) (Maundrell 1990; Maundrell 1993).

Para el crecimiento en medio sólido, se utilizaron los mismos medios de cultivo a los que se les añadió agar al $2 \%$. Las placas fueron incubadas entre $25-36^{\circ} \mathrm{C}$ dependiendo del mutante.

El medio de cultivo utilizado para realizar los cruces entre cepas, fue extracto de malta (MEA).

Las cepas de levadura se conservaron por periodos no superiores a dos meses a $4^{\circ} \mathrm{C}$ en placas de agar con el medio adecuado. Para periodos prolongados, se conservaron a $-80^{\circ} \mathrm{C}$ en una solución de glicerol al $20 \%$. 


\section{ii. Medios y condiciones de cultivo para el crecimiento de S. cerevisiae}

Para las técnicas básicas de manipulación de S.cerevisiae, referirse a Guthrie y Fink (1991) y para las técnicas generales de biología molecular, a Sambrook y colaboradores (1989).

Las células de S.cerevisiae se cultivaron en medio rico YPAD (1\% extracto de levadura, $2 \%$ bactopeptona, $0.004 \%$ adenina y $2 \%$ glucosa) a $30^{\circ} \mathrm{C}$. Los experimentos en medio líquido se iniciaron con cultivos creciendo en fase exponencial a $0.5 \times 10^{7}$ células/ml.

En el caso de los experimentos de inducción en galactosa, las células se crecieron en medio YP ( $2 \%$ bactopeptona, $1 \%$ extracto de levadura) suplementado con $2 \%$ rafinosa y $0.05 \%$ glucosa a $30^{\circ} \mathrm{C}$, hasta que los cultivos alcanzaron la fase exponencial $\left(1 \times 10^{7}\right.$ células $\left./ \mathrm{ml}\right)$. Para inducir la expresión del promotor GAL1 se suplementó con galactosa al $2 \%$.

Para el crecimiento en medio sólido, así como su conservación para periodos cortos y largos, se utilizaron las mismas condiciones que las descritas para S. pombe.

\section{iii. Medios y condiciones de cultivo para el crecimiento de $E$. coli}

Las distintas estirpes de $E$. coli se crecieron a $37^{\circ} \mathrm{C}$, en los medios y condiciones de cultivo descritos en Sambrook y colaboradores (1989).

\section{TÉCNICAS DE TRANSFORMACIÓN EN LEVADURAS Y BACTERIAS}

Transformación de S. pombe: Las cepas de levadura se hicieron competentes según el método de acetato de litio y se transformaron con las distintas construcciones de ADN mediante choque térmico tal y como se describe en Moreno et al (1991).

Transformación de S. cerevisiae: Todas las cepas transformantes de la levadura de gemación, se construyeron mediante la técnica de modificación génica de un solo paso mediada por PCR, descrita en Longtine et al., 1998.

Transformación de $E$. coli: El método de transformación se realizó según el procedimiento descrito por Kushner (1978). Para incorporar plásmidos a cepas de E.coli receptoras, también se llevó a cabo la "transformación del minuto" según el protocolo diseñado por Golub (1988). 


\section{ENSAYOS DE SENSIBILIDAD A AGENTES GENOTÓXICOS}

\subsection{Ensayo de gota en S. pombe}

Para comprobar la sensibilidad de los mutantes construidos a diferentes tipos de drogas que causan daño en el ADN, se realizó un ensayo de sensibilidad con dichas cepas mutantes, así como con una cepa silvestre como control. Las cepas a analizar fueron crecidas en medio rico a $25^{\circ} \mathrm{C}$ hasta que alcanzaron una densidad óptica de 1 a $\lambda=595 \mathrm{~nm}$ (lo que corresponde a un cultivo en fase exponencial con $10^{7}$ células/ $\mathrm{ml})$. Posteriormente se contó el número de células de cada uno de los cultivos y se realizaron diluciones seriadas de los mismos, desde $10^{8}$ células $/ \mathrm{ml}$ hasta $10^{4}$ células $/ \mathrm{ml}$. $7 \mu \mathrm{l}$ de esas diluciones, se inocularon en forma de gota en varias placas de medio rico sólido con diferentes drogas a varias concentraciones (según se indica en cada experimento), de manera que en la primera gota se inocularon $10^{8}$ células y en la última $10^{4}$ células. Cada una de las placas se incubó a una temperatura diferente, en un rango de temperatura desde $25^{\circ} \mathrm{C}$ hasta $36^{\circ} \mathrm{C}$, para una vez crecidas, analizar la sensibilidad de cada una de las cepas mutantes.

\subsection{Ensayo de gota en S. cerevisiae}

Las cepas utilizadas se cultivaron en placas frescas de YPAD a $25^{\circ} \mathrm{C}$. Se picaron varias colonias y se inocularon en $1 \mathrm{ml}$ de agua miliQ, a fin de contar células y obtener una primera dilución de $10^{8}$ células $/ \mathrm{ml}$. A continuación, se hicieron diluciones seriadas desde $10^{8}$ hasta $10^{4}$ células $/ \mathrm{ml}$. $7 \mu \mathrm{l}$ de cada dilución se inocularon en forma de gota en placas control de YPAD o YP más galactosa, y en placas de YPAD o YP con galactosa, conteniendo distintas concentraciones de los agentes genotóxicos, según se especifica en cada experimento correspondiente. Las placas se incubaron durante 2 ó 3 días a $25^{\circ} \mathrm{C}$, según el tipo de agente genotóxico.

\subsection{Ensayo en placas microtiter para S. pombe}

Cuando la sensibilidad a estudiar, dependía de las condiciones de sobre-expresión de una determinada proteína, se llevó a cabo el ensayo de sensibilidad en medio líquido en placas microtiter de 96 pocillos; placas en las que sí es posible cambiar el medio a las células (con y sin tiamina para producir la sobre-expresión), a diferencias de las placas Petri con medio sólido utilizadas en el tradicional ensayo de gota.

Para ello se partió de cultivos saturados en YES de cada una de las cepas de interés, junto con una cepa silvestre como control. De cada cultivo saturado, se sembró $1 \mu l$ por duplicado en dos columnas diferentes de una misma placa microtiter (una con $150 \mu \mathrm{l}$ de $\mathrm{MM}$ con tiamina a una concentración de $5 \mu \mathrm{g} / \mathrm{ml}$ y otra con el mismo volumen pero sin tiamina), dejándolas crecer a $30^{\circ} \mathrm{C}$ durante toda la noche. Tras la incubación se centrifugaron y lavaron las células hasta tres veces con MM, con el fin de eliminar toda la tiamina del medio. Una vez lavadas las células, se añadió a una 
de las columnas de nuevo MM más tiamina y a la otra MM sin tiamina, dejándolas crecer en esas condiciones a $30^{\circ} \mathrm{C}$ durante 14 horas (tiempo suficiente para producir la sobre-expresión de las proteínas de interés). A continuación, por medio de un replicador se pasó a cada una de las cepas crecidas en las dos condiciones (con y sin tiamina), a sus correspondientes placas de $\mathrm{MM}$ con y sin tiamina, con diferentes drogas. Por último, las placas se incubaron en una estufa a $30^{\circ} \mathrm{C}$ controlando su crecimiento mediante análisis en un espectofotómetro Ultra Evolution TECAN cada 12 horas.

\section{SINCRONIZACIÓN DE CULTIVOS}

Para estudiar un determinado proceso biológico a lo largo del ciclo celular, es necesario que las células del cultivo estén sincronizadas, para que avancen a la vez por cada una de las fases del ciclo. Dicha sincronía en la levadura de fisión, se puede conseguir de diferentes maneras, como por ejemplo mediante el uso de mutantes de ciclo (los cuales se paran en momento determinado del ciclo a una temperatura restrictiva), eliminando el $\mathrm{N}_{2}$ del medio de cultivo, o mediante técnicas que seleccionen específicamente las células que están en un momento determinado del ciclo celular, como la elutriación. A continuación describiremos las utilizadas para la realización de este trabajo.

\section{i. Sincronización en la Fase G1}

Para sincronizar o bloquear las células en $\mathrm{G} 1$ en $\mathrm{S}$. pombe, utilizamos el mutante termosensible $c d c 10-129$. El gen $c d c 10^{+}$codifica un factor de transcripción necesario para que tenga lugar la expresión de genes requeridos para el inicio de la replicación del ADN, de ahí que los mutantes $c d c 10-129$ cuando se incuban a la temperatura restrictiva de $36^{\circ} \mathrm{C}$, se bloqueen en la fase $\mathrm{G} 1$.

Para llevar a cabo experimentos de "bloqueo y liberación" en este punto del ciclo, se partió de células del mutante $c d c 10-129$ creciendo exponencialmente a $25^{\circ} \mathrm{C}$. A continuación, esas células se incuban durante 4 horas a la temperatura restrictiva de $36^{\circ} \mathrm{C}$, para inducir su parada en G1. Tras ese tiempo se liberaron las células de ese bloqueo mediante su incubación de nuevo a $25^{\circ} \mathrm{C}$.

\section{ii. Sincronización en la Fase $\mathbf{G 2}$}

La sincronización de las células en la Fase $\mathrm{G} 2$ del ciclo celular, la conseguimos utilizando el mutante termosensible $c d c 25-22$. La proteína Cdc25 es la responsable de la activación de los complejos mitóticos $\mathrm{Cdc} 2 / \mathrm{Cdc} 13$ necesarios para el inicio de la mitosis; de manera que en el mutante termosensible $c d c 25-22$, a la temperatura restrictiva de $36^{\circ} \mathrm{C}$, se inactiva dicha proteína y por lo tanto se produce un bloqueo en $\mathrm{G} 2$ por ser incapaz de entrar en mitosis. De nuevo la liberación del cultivo se consiguió incubándolo otra vez a $25^{\circ} \mathrm{C}$. 


\section{iii. Sincronización en Fase $\mathbf{S}$}

El bloqueo en Fase $S$, se llevo a cabo a través del mutante $c d c 17-K 12$, mutante que a su temperatura restrictiva de $36^{\circ} \mathrm{C}$ (durante 4 horas) inactiva la ADN ligasa del mismo nombre, produciendo un bloqueo en dicha Fase. Una vez más, la liberación se produjo reincubando el cultivo a $25^{\circ} \mathrm{C}$.

\section{iv. Sincronización del cultivo en G2 por elutriación}

La elutriación es una técnica que permite separar células de diferentes tamaños mediante centrifugación. En nuestro caso nos quedamos con las células más pequeñas que son las que se encuentran al inicio de la Fase G2. La centrífuga utilizada fue Beckman Coulter Avanti-JM Centrifuge.

\section{TÉCNICAS DE MANIPULACIÓN DE ÁCIDOS NUCLEICOS}

\subsection{Construcción de plásmidos de ADN recombinante}

Los plásmidos y construcciones utilizados en este trabajo se detallan en la Tabla 6.

Estas construcciones se amplificaron por transformación de células competentes de E. coli (DH5 $\alpha)$, seleccionando las colonias transformantes con la resistencia asociada a cada vector (generalmente a ampicilina). La confirmación de que las colonias contenían el plásmido deseado, se realizó mediante el aislamiento del ADN plasmídico a partir de esas células y su análisis con enzimas de restricción y electroforesis de los fragmentos de ADN obtenidos. Posteriormente además, se corroboró mediante la secuenciación de dicho ADN.

\subsection{Aislamiento de ADN plasmídico a partir de células de $E$. coli}

La obtención de ADN plasmídico a partir de E. coli a pequeña escala, se llevó a cabo mediante el método de la lisis alcalina (Birnboim and Doly 1979), conocido comúnmente como "Minipreperación". Para obtener una preparación de ADN de más calidad, por ejemplo para su secuenciación, este ADN se trató con el sistema Pure Yield Plasmid Miniprep System (Promega). Para la obtención de ADN de calidad a gran escala (Maxiprep) se empleó el sistema comercial Pure Yield MaxiPrep System (Promega). En todos los casos se siguieron las especificaciones del fabricante.

\subsection{Aislamiento de ADN genómico de S.pombe y de S. cerevisiae}

La extracción de ADN genómico en ambas levaduras se realizó siguiendo el mismo protocolo en ambos casos.

Se recogieron las células por centrifugación a partir de cultivos crecidos en medio líquido. El pellet de células se resuspendió en $200 \mu \mathrm{l}$ de tampón de lisis $(100 \mathrm{mM}$ $\mathrm{NaCl}, 10 \mathrm{mM}$ Tris pH8.0, 1mM EDTA, 1\% SDS, 2\% Triton). A continuación, se añadió 
Tabla 6: Vectores y plásmidos utilizados en este trabajo.

\begin{tabular}{|c|c|}
\hline Nombre & Origen \\
\hline pFA6a-kanMX6 & Dr. Moreno \\
pFA6a-hphMX6 & Dr. Moreno \\
pFA6a-natMX6 & Dr. Moreno \\
pFA6a-GFPkanMX6 & Dr. Moreno \\
pFA6a-mRFPkanMX6 & Dr. Moreno \\
pFA6a-13Myc-kanMX6 & Dr. Moreno \\
pFA6a-3HA-kanMX6 & Dr. Moreno \\
pFA6a-3Flag-kanMX6 & Dr. Moreno \\
pFA6a-3Flag-hphMX6 & Dr. Moreno \\
pFA6a-P81 nmt1 & Dr. Moreno \\
pFA6a-P41 nmt1 & Dr. Moreno \\
pFA6a-P3nmt1 & Dr. Moreno \\
pGEMT & Promega \\
pGEX-6P-1 & Dr. Bueno \\
pGEX-6P-1-ubp16 3Flag:kanMX6 & Este trabajo \\
pGEX-6P-1-ubp16 CS 3Flag:kanMX6 & Este trabajo \\
YIPG3 & Dr Bueno \\
YIPG3-ubp16 & Este trabajo \\
YIPG3-ubp16 CS & Este trabajo \\
pREP3X & Dr. Moreno \\
pREP3X-ubp16 ${ }^{+}$ & Este trabajo \\
pREP3X--ubp16 CS & Este trabajo \\
pREP3X -ubp15 & Este trabajo \\
pREP3X--ubp15 CS & Este trabajo \\
pREP41 & Dr. Moreno \\
pREP81 & Dr. Moreno \\
pFA6a-GFP-NES kanMX6 & Este trabajo \\
pFA6a-GFP-NLS kanMX6 & Este trabajo \\
pFA6a-mRFP-NES kanMX6 & Este trabajo \\
pFA6a-mRFP-NLS kanMX6 & Este trabajo \\
\hline
\end{tabular}

$200 \mu \mathrm{l}$ de bolas de vidrio de $0,45 \mathrm{~mm}$ de diámetro e igual volumen de fenol/cloroformo isoamílico (Ambion). Toda la mezcla se agitó en vórtex durante 30 segundos, se añadió $200 \mu \mathrm{l}$ de TE y después de mezclarlo una vez más en vórtex, se centrifugó a máxima velocidad durante 2 minutos. El sobrenadante se recogió con cuidado de no arrastrar la solución de fenol. Para precipitar el ADN se añadió etanol $100 \%$, añadiendo el doble de etanol del volumen de sobrenadante recogido. Por último, tras lavar el pellet de ADN con etanol 70\%, éste se resuspendió en agua o en TE $1 \mathrm{X}$ 102 
con $50 \mu \mathrm{g} / \mathrm{ml}$ de RNAsa y se incubó a $37^{\circ} \mathrm{C}$ durante 1 hora con el fin de degradar el ARN.

\subsection{Determinación de la concentración de ácidos nucleicos}

La concentración de ADN se determinó midiendo la absorbancia a $\lambda=260 \mathrm{~nm}$ (en cubeta de cuarzo) en un espectrofotómetro U-2001 (Hitachi), y considerando la relación de absorbancia a $\lambda=260 / 280 \mathrm{~nm}$ para estimar el grado de pureza de la preparación. Posteriormente se corroboró la concentración de ADN, por medio del análisis de la fluorescencia emitida por la muestra, tras la electroforesis en un gel de agarosa (con bromuro de etidio).

\subsection{Digestión de ADN con endonucleasas de restricción}

La digestión con enzimas de restricción permite la caracterización física de fragmentos de ADN y por tanto, la comprobación de construcciones plasmídicas de ADN recombinante. Las enzimas de restricción y el $A D N$ se incubaron a $37^{\circ} \mathrm{C}$ o a $25^{\circ} \mathrm{C}$ (según la enzima) en el tampón adecuado suministrado por el fabricante junto con las enzimas. Roche Diagnostics, Fermentas, Takara y New England Biolabs, fueron las casas comerciales que suministraron las enzimas de restricción empleadas en este trabajo.

\subsection{Tratamiento de fragmentos de ADN con fosfatasa alcalina}

Este tratamiento se llevó a cabo para eliminar los grupos fosfato de los extremos 5' del plásmido linearizado e impedir así su religación. Para ello, el plásmido linearizado se incubó con fosfatasa alcalina (calf intestine alkaline phosphatase, Roche Diagnostics), en una proporción de una unidad de enzima por $\mu \mathrm{g}$ de $A D N$, en tampón

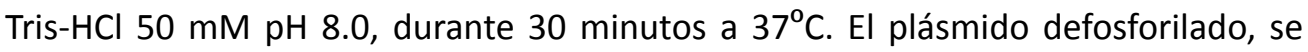
sometió a electroforesis en un gel de agarosa. La banda de interés se purificó tal y como se describe en el apartado $X$.

\subsection{Electroforesis de fragmentos de ADN}

Los fragmentos de ADN se separaron en función de su tamaño mediante electroforesis en geles de agarosa, preparados a la concentración adecuada (entre el 0,7\% y el $1,5 \%$, según el tamaño de los fragmentos a separar). A las muestras de ADN se les añadió tampón de carga $6 x$ (glicerol al $30 \%$ y el colorante azul de bromofenol al $0,25 \%)$ que permite seguir la migración del ADN en los geles. La electroforesis se llevó a cabo a voltaje constante (60-100V) y se empleó como tampón de carrera TAE (Tris- acetato $40 \mathrm{mM}$, EDTA $1 \mathrm{mM}$ ). Para la visualización del ADN, a los geles se les añadió bromuro de etidio $(0,3 \mu \mathrm{g} / \mathrm{ml})(S i g m a)$, ya que se intercala entre las bases nitrogenadas del ADN y emite fluorescencia al exponerse a luz ultravioleta. Como marcador de tamaño, se usó ADN $1 \mathrm{~Kb}$ ADN Ladder (Invitrogen) y las imágenes se 
captaron con una cámara digital acoplada al analizador de imagen Gel Doc 2000 de Bio-Rad.

\subsection{Purificación y ligación de fragmentos de ADN}

La purificación de fragmentos de ADN a partir de geles de agarosa, se llevó a cabo cortando la banda de interés y procesándola con el sistema Jet Quick Gel Extraction Spin kit de Genomed, según las instrucciones del fabricante.

Las construcciones de ADN recombinante se obtuvieron mediante ligación de los fragmentos purificados (el inserto y el vector plasmídico). En la reacción de ligación se utilizó la ligasa de ADN del fago T4, siguiendo las especificaciones del fabricante (Fermentas). La mezcla de la ligación se utilizó para transformar directamente células competentes de $E$. coli.

\subsection{Reacciones de amplificación de ADN (PCR)}

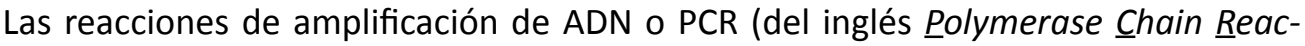
tion, reacción en cadena de la polimerasa) se realizaron en un termociclador $\mathrm{Mi}$ nicycler de Eppendorf. Las condiciones programadas fueron diferentes en función del tamaño de la secuencia a amplificar, así como de los oligonucleótidos utilizados. La PCR se llevó a cabo en presencia de los oligonucleótidos diseñados en cada caso, el ADN molde, los dNTPs (desoxinucleósidos trifosfato) y la Taq polimerasa (una polimerasa termorresistente). Dependiendo de la finalidad del producto de PCR, se utilizó la polimerasa High Fidelity de Roche Diagnostics, la Pfu de Stratagene o la polimerasa de Biotools. El resultado de la PCR se analizó mediante electroforesis en un gel de agarosa y los productos obtenidos se purificaron usando el sistema Jet Quick PCR Product Purification Spin Kit de Genomed.

A continuación se detalla la secuencia de los oligonucleótidos utilizados para la obtención de construcciones de ADN recombinante, su nombre y las aplicaciones para las que fueron diseñados.

\section{Lista de oligonucleótidos utilizados:}

ubp2 forward:

AGC TAA CAT TTA TCT AGT ACA TTA GGA AAG AGT ATC GAC ACA TAA TTG AAT GTG TTC ACC GTG AAC ACA ATC TTC TGC TTC GGA TCC CCG GGT TAA TTA A

Oligo 5'para delecionar el gen $u b p 2^{+}$

\section{ubp2 reverse:}

GAA AAA CGT TAC AAC TTC CAA CCT CCA TTC ATA GCA ATT GAT CAC GGA TGA TCC ATC CTA GTT TTT ACC CTT CAC ATA GTT TGA ATT CGA GCT CGT TTA AAC

Oligo 3'para delecionar el gen $u b p 2^{+}$ 
ubp2 sec forward:

GCT GTA TTT GTG CAT CGT GG

Oligo para comprobar la deleción del gen $u b p 2^{+}$

ubp2 entorno forward:

GCA TAC CTG GCT GGC ATA TG

Oligo para comprobar la deleción del gen $u b p 2^{+}$

ubp2 entorno reverse:

CCG TAC CGA TGT ATA AAG

Oligo para comprobar la deleción del gen $u b p 2^{+}$

ubp1 sec forward:

CAC CAT TTG GTA CAA CAA GT

Oligo para comprobar la deleción del gen $u b p 1^{+}$

ubp9 sec forward:

AGC TTC CCT TTG CGT TCA CTT C

Oligo para comprobar la deleción del gen $u b p 9^{+}$

ubp10 sec forward:

GAC GAG TGC AAT TAT GTG G

Oligo para comprobar la deleción del gen $u b p 10^{+}$

ubp12 sec forward:

TCC TCC CAT TTG AAC AAC GC

Oligo para comprobar la deleción del gen $u b 12^{+}$

ubp15 sec forward:

GTA CGC ATT TTC ATT CTA TC

Oligo para comprobar la deleción del gen ubp15

ubp2 $\mathrm{nmt}$ forward:

GGA CGT TTT TTC AAG TAT TTT TCA TAA TAA AAA ATT

TAA ATT TCT TTA TTA AAA TTA TTT ACA TCA AAC TAT AAA GAG GAG AAT TCG AGC

TCG TTT AAA C

Oligo para introducir el promotor nmt1 delante del gen $u b p 2^{+}$

ubp2 $\mathrm{nmt}$ reverse:

GAT GGA CTA TCA AAG ACG TCT AAA TCT TGA ATC AAC CGA TTA GGA CTT TTG CCA

ATT CGC AAG TTC TTT ACA GTT GCC ATG ATT TAA CAA AGC GAC TAT A

Oligo para introducir el promotor $n m t 1$ delante del gen $u b p 2^{+}$ 
ubp15 nmt forward:

AAT TAA TTG ACA ATT ATT TGT ACG CAT TTT CAT TCT ATC TTT GTT TTT GTT AAG

AAA CTG AAC AAG ATT GTA ATG ACA GCG AAT TCG AGC TCG TTT AAA C

Oligo para introducir el promotor $n m t 1$ delante del gen $u b p 15^{+}$

ubp15 nmt reverse:

TGA CTT CTT CAG CGT CTA CAT TTG AAA GCA CCT AAC GTT AAG TCA GAC TAA GCT CTC TAT GTA TAA AAA AGT AAA CTT ACC ATG ATT TAA CAA AGC GAC TAT A

Oligo para introducir el promotor $n m t 1$ delante del gen $u b p 15^{+}$

ubp1 hph forward:

CCA TTC CCC CAA TTT TTT GCA ATT TAT AAG AGT GGA ACT TGA AGA AAC AAA AAT ATA ACG AAT AAA TGA CCA TGT TTT GAG ACG GAT CCC CGG GTT AAT TAA

Oligo 5' para delecionar el gen $u b p 1^{+}$

ubp1 hph reverse:

TCC AGT TTC ATA CAT ATT CAA ACA AAC GAC ATT AGC CTT TAG TTA GAG TAA AGT TCA TAT CAC CTC TAT TAT ACG TCT CTG AAT TCG AGC TCG TTT AAA C

Oligo 3'para delecionar el gen $u b p 1^{+}$

ubp10 hph forward:

CTTA GAC GAG TGC AAT TAT GTG GAA GAT ACT TCC ATA CGA CTT AGT AAC TGA AGT TAT CGA TAG ATG GTA AAG CTT CAA AAC GGA TCC CCG GGT TAA TTA A Oligo 5'para delecionar el gen $u b p 10^{+}$

ubp10 hph reverse:

GAT AAA TAA AAT GAA TGT TTT TTA ATT TTG TCT CAC GTA GAG GAA ATT TTG TGA GAA ATC CAA AAA TTC CAC ATA TTA ACA GAA TTC GAG CTC GTT TAA AC

Oligo 3'para delecionar el gen $u b p 10^{+}$

ubp15 hph forward:

AAT TAA TTG ACA ATT ATT TGT ACG CAT TTT CAT TCT ATC TTT GTT TTT GTT AAG AAA CTG AAC AAG ATT GTA ATG ACA GCC GGA TCC CCG GGT TAA TTA A

Oligo 5'para delecionar el gen $u b p 15^{+}$

ubp15 hph reverse:

TGA AAC AAA ATT GCT TGG CTT CTA GTA AAT GGC ACC GCT AAC ATT CAA ATT GGA GGT TTA AAA AGG TGA TGT ATA AAC AAG AAT TCG AGC TCG TTT AAA C

Oligo 3'para delecionar el gen $u b p 15^{+}$

ubp2 sec 5' reverse:

CAG GCT CTT CAA TTA ATG GC

Oligo para secuenciar el gen $u b p 2^{+}$

106 
ubp2 sec 3' reverse:

CCA CGA TGC ACA AAT ACA GC

Oligo para secuenciar el gen $u b p 2^{+}$

ubp1 entorno reverse:

CCA CCT CTT CCT CGT CTT CG

Oligo para comprobar la deleción del gen $u b p 1^{+}$

ubp2 entorno reverse:

GAA AAA CGT TAC AAC TTC CAA C

Oligo para comprobar la deleción del gen $u b p 2^{+}$

ubp3 entorno reverse:

GTA TAT TCG GAG TAA GTT CC

Oligo para comprobar la deleción del gen $u b p 3^{+}$

ubp4 entorno reverse:

GCA TTC TGT TCA ACA TAA CG

Oligo para comprobar la deleción del gen $u b p 4^{+}$

ubp6 entorno reverse:

GTG AGA GTA AAC AAT GCC AC

Oligo para comprobar la deleción del gen $u b p 6^{+}$

ubp7 entorno reverse:

CTA GTT ATG AGG TGA AAT GAC

Oligo para comprobar la deleción del gen $u b p 7^{+}$

ubp8 entorno reverse:

ACG GTT CCA AAT CCA ATG CC

Oligo para comprobar la deleción del gen $u b p 8^{+}$

ubp9 entorno reverse:

CAT ATG GAT AAA TAG AGC GC

Oligo para comprobar la deleción del gen $u b p 9^{+}$

ubp10 entorno reverse:

CAA TCT GGT GTC TTG ATA CC

Oligo para comprobar la deleción del gen $u b p 10^{+}$

ubp11 entorno reverse:

CAG ATA CGG TGG ATA CAT AC

Oligo para comprobar la deleción del gen $u b p 11^{+}$ 
ubp12 entorno reverse:

GTA ATA CCG ATA CTT TGT CG

Oligo para comprobar la deleción del gen $u b p 12^{+}$

ubp13 entorno reverse:

CTA GTA GAC TAA CAT ATC GG

Oligo para comprobar la deleción del gen $u b p 13^{+}$

ubp14 entorno reverse:

GAA AGA CTT AAA TCC GGG TC

Oligo para comprobar la deleción del gen $u b p 14^{+}$

ubp16 entorno reverse:

AGT CTT ATG CAA TGC AGC GG

Oligo para comprobar la deleción del gen $u b p 16^{+}$

ubp15 entorno reverse:

CAT ATA ATG CGA AGC GTG C

Oligo para comprobar la deleción del gen $u b p 15^{+}$

ubp5 entorno reverse:

TAT GCA TCC TCA AAA GAT GC

Oligo para comprobar la deleción del gen $u b p 5^{+}$

ubp3 entorno forward:

CAC ACA ACA GCA GAA TAT CG

Oligo para comprobar la deleción del gen $u b p 3^{+}$

ubp4 entorno forward:

TTG CCG TTT GCA TGA ACT CT

Oligo para comprobar la deleción del gen $u b p 4^{+}$

ubp6 entorno forward:

GCT GAC TCT GGC GTT CTA CA

Oligo para comprobar la deleción del gen $u b p 6^{+}$

ubp7 entorno forward:

TCC TTT ACC GGA AGC AAC GC

Oligo para comprobar la deleción del gen $u b p 7^{+}$

ubp8 entorno forward:

GGA CAC TCA AGA ACT ACG AA

Oligo para comprobar la deleción del gen $u b p 8^{+}$ 108 
ubp11 entorno forward:

GTC GCA TTA CTC GAC AAC AT

Oligo para comprobar la deleción del gen $u b p 6^{+}$

ubp13 entorno forward:

TGT GAG ACA GGA GGT TTA CA

Oligo para comprobar la deleción del gen $u b p 13^{+}$

ubp14 entorno forward:

CAG TAT AGG TAG ACT CGA CA

Oligo para comprobar la deleción del gen ubp $14^{+}$

ubp16 entorno forward:

CTA TAG TGG CTG GTC ATT TC

Oligo para comprobar la deleción del gen $u b p 16^{+}$

ubp5 entorno forward:

TGT GAT TGT TCA GCG CTT GT

Oligo para comprobar la deleción del gen $u b p 5^{+}$

ubp2 hph forward:

GGA CGT TTT TTC AAG TAT TTT TCA TAA TAA AAA ATT TAA ATT TCT TTA TTA AAA TTA TTT ACA TCA AAC TAT AAA GAG GAC GGA TCC CCG GGT TAA TTA A

Oligo 5'para delecionar el gen $u b p 2^{+}$

ubp2 hph reverse:

AAA ACG TTA CAA CTT CCA ACC TCC ATT CAT AGC AAT TGA TCA CGG ATG ATC CAT CCT AGT TTT TAC CCT TCA CAT AGT TTG AAT TCG AGC TCG TTT AAA C

Oligo 3'para delecionar el gen $u b p 2^{+}$

ubp13 hph forward:

CAT TAG GTA AAC CTG GCT TGC TAT GAC CAA CAC TTC AAC TCC TAG AGA AAG AGG TTA TAG TCA ACT GTT TGA AAT GAG AGC GGA TCC CCG GGT TAA TTA A

Oligo 5'para delecionar el gen ubp $13^{+}$

ubp13 hph reverse:

CAA TGA AAT TGA TTA CTA CCA TTT CAG TAA ATA TAT AAA CAA TCT TTT TTA AAA AAA AGC CGA AGT AAT TTC CTA ATC ATG AAT TCG AGC TCG TTT AAA C

Oligo 3'para delecionar el gen $u b p 13^{+}$

ubp16 hph forward:

TTT TTT TTC TTC TTT TCT AAC ATT TTT CTT CAT AAT TTC AAA TTT TTG ATT GCT TGT TGT TTT TCC ATT CCG TTG TTG ACC GGA TCC CCG GGT TAA TTA A

Oligo 5'para delecionar el gen $u b p 16^{+}$ 
ubp16 hph reverse:

AAG AGA GAC ATT AGC ATA TTA AAA AAA AAG ATA GGC AAA AGG AAG CAA AAA

CTT TAA CTG CTC AAG CTA ACT GTA TCG CAG AAT TCG AGC TCG TTT AAA C

Oligo 3'para delecionar el gen $u b p 5^{+}$

ubp5 Kan forward:

ATT CAA ATC CAT TGT TTT ACA GTC ATT ACT TGT TCC TTT ATT ATT TGA AAG CCT CAC AAC TAA AAA AAT TCT AAG ATT TCC GGA TCC CCG GGT TAA TTA A

Oligo 5'para delecionar el gen $u b p 5^{+}$

ubp5 Kan reverse:

AAC CTG TAT AAA ACT TCA TGC ACC TTA TGC TCA ACA GGT AAG GAC CAA ACA ACC AGC AAG GAT TGT AAA GCC TTT AAA TAG AAT TCG AGC TCG TTT AAA C

Oligo 3'para delecionar el gen $u b p 5^{+}$

ubp4 hph reverse:

GGT TAT GAA TGC TAA GTT GAA CAT TTA TTC AAT AAC TAT ATT TGA GGT TTA TTG AAA ACA TTT TTC CTT TTT TTA TTT TGT TGA ATT CGA GCT CGT TTA AAC

Oligo 3'para delecionar el gen $u b p 4^{+}$

ubp7 hph forward:

CTT TTT TCC TTG CAT TAA TTT ATC CAT TGA TTT CCT CCT TGT TGA TCG TCT TTT TTT TGT CCC GTT TTC ATA TAT GCA TTA TAC GGA TCC CCG GGT TAA TTA A

Oligo 5'para delecionar el gen $u b p 7^{+}$

ubp7 hph reverse:

CTT TGC ATT TTA AAG ATA AAA ACC AGG GGT ATT GAA AAA TAT TGT TAA GCT AAA ATG AGG ATT TAA AGC AAT AGA AGT GAA TTC GAG CTC GTT TAA AC

Oligo 3'para delecionar el gen $u b p 7^{+}$

ubp3 hph forward:

CTT TTG AAG AGC AAA GCG AAC GAC AGC CAA CCA TCA AAT TAG TAA ACA AGA GTT CAA TCT TGC TAG AGT GTG CGT ATT TCC CGG ATC CCC GGG TTA ATT AA

Oligo 5'para delecionar el gen $u b p 3^{+}$

ubp3 hph reverse:

GAG TTG TTT ATT GAA GAA TAC ACA AAA CAA TTA AGG TTT TTA TTG GTT AAT TTT TTT TGG GAG GAA GGA ATC CAG ATG ACG AAT TCG AGC TCG TTT AAA C

Oligo 3'para delecionar el gen $u b p 3^{+}$

ubp4 hph forward:

AAC CAA AAA AGG CTA TAG TCT TGT AGT ATT TGG TTC AAT TCA GGT TAA GTC GCC

AAC ACA AAT ACT CGG TTC TTC CTC GGC GGA TCC CCG GGT TAA TTA A

Oligo 5'para delecionar el gen $u b p 4^{+}$

110 
ubp5 nmt forward:

ATT CAA ATC CAT TGT TTT ACA GTC ATT ACT TGT TCC TTT ATT ATT TGA AAG CCT CAC AAC TAA AAA AAT TCT AAG ATT TCG AAT TCG AGC TCG TTT AAA C

Oligo 3'para delecionar el gen $u b p 4^{+}$

ubp16 nmt forward:

TTT TTT TTC TTC TTT TCT AAC ATT TTT CTT CAT AAT TTC AAA TTT TTG ATT GCT TGT TGT TTT TCC ATT CCG TTG TTG ACG AAT TCG AGC TCG TTT AAA C

Oligo para introducir el promotor $n m t 1$ delante del gen $u b p 16^{+}$

ubp16 $\mathrm{nmt}$ reverse:

ACG GGA TTT TTA AGC AAA TCA TCT AGT GAA TGC TTG ACT GCA AAA TCT AGT GAC TGT CCT TGT AAA GTA GCA AGC GAC ATG ATT TAA CAA AGC GAC TAT A

Oligo para introducir el promotor $n m t 1$ delante del gen $u b p 16^{+}$

ubp9 hph forward:

GAG CGC GTG AAA GCT TCC CTT TGC GTT CAC TTC CCC GCT GTG CTT GGT TTG TAA ACT TAG CAT CCT TTA GTT CAA CTC AGC CGG ATC CCC GGG TTA ATT AA

Oligo 5'para delecionar el gen $u b p 9^{+}$

ubp9 hph reverse:

ATA TAA AGT AAA ACG ATG AGA GAT GAA AAC ATT AAA AGA ATT TCT CGA AAA GTG TAA TAA AAA ACA CAA ATA AGA ATT CTG AAT TCG AGC TCG TTT AAA C Oligo 3'para delecionar el gen $u b p 9^{+}$

ubp12 kanMX forward:

CTC TTA TCC TCC CAT TTG AAC AAC GCA ATT TTC CAT ATT GAG CTG GAC TTG TTG ACA TCG ACA AAA GAG ACT TCA TTT TAT CGG ATC CCC GGG TTA ATT AA

Oligo 5'para delecionar el gen $u b p 12^{+}$

ubp12 kanMX reverse:

TTA GTC ACA TTG ACA AGA ACC GTT TTT TAA TTA GCA TAT CAA AGA TTG ATG CAG TAA GTA CTA GTA TTG AAA ATT TCA TTG AAT TCG AGC TCG TTT AAA C

Oligo 3'para delecionar el gen $u b p 12^{+}$

ubp16 Flag forward:

CTT CAT CGT CTA AAC ACA AGC TAA ACA CCG AAA ACA CGG TTA CCA AAA CTT CTA ATA AAA AAC GGA GAA AAA TTT CAT TTG GGG GAG GCG GGG GTG GA

Oligo para etiquetar el gen $u b p 16^{+}$

ubp16 HA KanMX reverse:

AAG AGA GAC ATT AGC ATA TTA AAA AAA AAG ATA GGC AAA AGG AAG CAA AAA CTT TAA CTG CTC AAG CTA ACT GTA TCG CAG AAT TCG AGC TCG TTT AAA C

Oligo para etiquetar el gen $u b p 16^{+}$ 
ubp16 Flag KanMX reverse:

AAG AGA GAC ATT AGC ATA TTA AAA AAA AAG ATA GGC AAA AGG AAG CAA AAA

CTT TAA CTG CTC AAG CTA ACT GTA TCG CAG AAT TCG AGC TCG TTT TCG A

Oligo para etiquetar el gen $u b p 16^{+}$

ubp16 GFP forward:

CTT CAT CGT CTA AAC ACA AGC TAA ACA CCG AAA ACA CGG TTA CCA AAA CTT CTA ATA AAA AAC GGA GAA AAA TTT CAT TTC GGA TCC CCG GGT TAA TTA A

Oligo para etiquetar el gen $u b p 16^{+}$

ubp16 5'reverse:

GAT ATT GAA CCA ACG GTG

Oligo para secuenciar el gen $u b p 16^{+}$

ubp16 sec 3'forward:

GAC GAT GAT TTC GTT TCC

Oligo para secuenciar el gen $u b p 16^{+}$

ubp16 GAL forward:

CGG GAT CCA TGT CGC TTG CTA CTT TAC A

Oligo para clonar el gen $u b p 16^{+}$en YIPG3

ubp16 GAL reverse:

GCT CTA GAC CTC TAC ATT TGC AAA AAT TG

Oligo para clonar el gen $u b p 16^{+}$en YIPG3

nmt41 sec forward:

GTA AGT GCC TTA GCA TGT TA

Oligo para secuenciar el promotor $n m t 1^{+}$

nmt41 sec reverse:

ATG CCA GGA TTC CTC TTC CT

Oligo para secuenciar el promotor $n m t 1^{+}$

ubp6 del forward:

ATA ATT TGC AAA GAA TTA CAA AAA AAA TTA TAT TGG GCT TAA ACA AGT ATT TCT TTC ATT AAT TAC AAA AAC CAT TTA TGC GGA TCC CCG GGT TAA TTA A

Oligo 5'para delecionar el gen $u b p 6^{+}$

ubp6 del reverse:

TTG ATA TGA TAC GTT CTA GTT CTT TTC CCA TAA TAA ACA GTC AAA AGA AGG TTT TAA AAA AAA ATA AAG AAA TCG TAA GCG AAT TCG AGC TCG TTT AAA C

Oligo 3'para delecionar el gen $u b p 6^{+}$ 
ubp8 del forward:

GTT CGT CTA TTG TTG TCG TTT CAC CCT GCA TCG AAG CAG ATG CTT TTT AGT CTG AAA GGC CAA TTT TGT ACG TAT CAA GGC GGA TCC CCG GGT TAA TTA A

Oligo 5'para delecionar el gen $u b p 8^{+}$

ubp8 del reverse:

AAT AAG GAA CCT TTG AGT CAA TTA CTT TAC ATG GTT CAT AAT GAT TGT TCA TGA ACG GAT ATC TGA TCG CAT AAT CTA ACG AAT TCG AGC TCG TTT AAA C

Oligo 5'para delecionar el gen $u b p 8^{+}$

ubp11 del forward:

TTT TTT CTT TTG TAA ATT ATA TTC TCT GTT ACC TCT AAT AAT TTC TTT TCC CTA ATT CTT CAT TGC ATG CAT TCA TTA TCC GGA TCC CCG GGT TAA TTA A ubp11 del reverse: TCA GTC GGA ATC ATT AGG AGA AAT ATC AAG AAT TTT TTA TTA AGG TAC AAA AAC GTA TAC GAT TAA CTA GCA TAT ATG CGG AAT TCG AGC TCG TTT AAA C

Oligo 5'para delecionar el gen $u b p 11^{+}$

ubp14 del forward:

AAG ATG CAC GTA TAT TAT TAA CTA ATG TTA ATA TTC TGC CTA CCT CAT GTC CAT CCA TCC ATA AAC ACC TAT AGC AAC CCC GGA TCC CCG GGT TAA TTA A

Oligo 5'para delecionar el gen $u b p 14^{+}$

ubp14 del reverse:

ACC AAA TTC TGC TCA ACC CAA AAT TCA ATA AGA CGC TCC GAT GAT TGC TAT TAA AAA AAA AAA AAT GAT ATA AAT TAA TGG AAT TCG AGC TCG TTT AAA C

Oligo 3'para delecionar el gen ubp14+

ubp16 sec 420 forward:

CAG TTG ATG ACT CAA ACT CC

Oligo para secuenciar el gen $u b p 16^{+}$

ubp16 sec 850 forward:

CCT CCT TGG CAG ATT CCT TA

Oligo para secuenciar el gen $u b p 16^{+}$

ubp16 GAL Xbal:

GCT CTA GAA TGT CGC TTG CTA CTT TAC A

Oligo para clonar el gen ubp $16^{+}$enYIPG3

ubp1 ent forward:

CAC CAT TTG GTA CAA CAA GT

Oligo para comprobar la deleción del gen $u b p 1^{+}$ 
ubp9 ent forward:

AGC TTC CCT TTG CGT TCA CTT C

Oligo para comprobar la deleción del gen $u b p 9^{+}$

ubp10 ent forward:

GAC GAG TGC AAT TAT GTG G

Oligo para comprobar la deleción del gen $u b p 10^{+}$

ubp12 ent forward:

TCC TCC CAT TTG AAC AAC GC

Oligo para comprobar la deleción del gen $u b p 12^{+}$

ubp15 ent forward:

GTA CGC ATT TTC ATT CTA TC

Oligo para comprobar la deleción del gen $u b p 15^{+}$

ubp8 nmt forward:

GTT CGT CTA TTG TTG TCG TTT CAC CCT GCA TCG AAG CAG ATG CTT TTT AGT CTG AAA GGC CAA TTT TGT ACG TAT CAA GGG AAT TCG AGC TCG TTT AAA C

Oligo para introducir el promotor $n m t 1$ delante del gen $u b p 8^{+}$

ubp8 $\mathrm{nmt}$ reverse:

TGG GTA CAG ATC TTT TGA TAG TTT TCA ACA TCC GCC GGT TTA AGT TTA AGA TGC TGG CAA CCT TCT ACA TCC CCA GGC ATG ATT TAA CAA AGC GAC TAT A

Oligo para introducir el promotor $n m t 1$ delante del gen $u b p 8^{+}$

ubp5 $\mathrm{nmt}$ reverse:

GAG TCT ACT AAA GTT TCA CCC GTG ACC TAA ACA TTA TAA GTT AGA ATG GTC CGA

GAT ATCAAC AAA AAC TTC AAT ACC ATG ATT TAA CAA AGC GAC TAT A

Oligo para introducir el promotor $n m t 1$ delante del gen $u b p 5^{+}$

nmt41 sec F:

AGG AAG AGG AAT CCT GGC AT

Oligo para secuenciar el promotor $n m t 1^{+}$

ubp8 sec reverse:

AGC GAC GTG GGA CAA ACT AA

Oligo para secuenciar el gen $u b p 8^{+}$

ubp15 sec reverse:

GGT TCC TGA GAG CTT TCT TC

Oligo para secuenciar el gen $u b p 8^{+}$ 
ubp5 sec reverse:

CAC ACT AAG TGG TCA CAC C

Oligo para secuenciar el gen $u b p 5^{+}$

ubp16 CS forward:

CTC GGT AAT ACT AGT TTC ATG AAT TCA GTA C

Mutagénesis dirigida del gen ubp $16^{+}$

ubp16 CS reverse:

GTA CTG AAT TCA TGA AAC TAG TAT TAC CGA G

Mutagénesis dirigida del gen ubp $16^{+}$

Pcn1 tag reverse 2:

AAA AGT AAA CAA AAG TAT GTT TAT AAT GAT GCT AGC TCG TCA ATT GCA AAG AGA TTA CTA AAA GAT ATT GAT TCC GTA ATG AAT TCG AGC TCG TTT AAA C

Oligo para etiquetar el gen $p c n 1^{+}$

ubp16 Myc forward:

CTT CAT CGT CTA AAC ACA AGC TAA ACA CCG AAA ACA CGG TTA CCA AAA CTT CTA ATA AAA AAC GGA GAA AAA TTT CAT TTC GGA TCC CCG GGT TAA TTA A

Oligo para etiquetar el gen $u b p 16^{+}$

Pcn1 tag forward:

CAC TTC TTG TGG AGT ATA AAA TGG AAT CCG GAT TTT TAC GAT TTT ATC TTG CCC

CAA AAA TTG GTG AGG AGG ATG AGG AGG GGG GAG GCG GGG GTG GA

Oligo para etiquetar el gen $p c n 1^{+}$

Pcn1 sec forward:

CAC GCT GAA ACA ACA TAC CG

Oligo para secuenciar el gen $p c n 1^{+}$

Pcn1 sec reverse:

CTC TTA CGC GGT TAG CCA TA

ubp15 Myc hph forward:

CAC ATA TCT TGG GAC TCG ATC ATC CAC CAG CTA ATG GTA GTG CTC AAT ACC ATG GTA TGG ACC AAG CAA TAA GAA TGA AAC GGA TCC CCG GGT TAA TTA A

Oligo para etiquetar el gen $u b p 15^{+}$

ubp15 Myc hph reverse:

GA AAC AAA ATT GCT TGG CTT CTA GTA AAT GGC ACC GCT AAC ATT CAA ATT GGA GGT TTA AAA AGG TGA TGT ATA AAC AAG AAT TCG AGC TCG TTT TCG A

Oligo para etiquetar el gen $u b p 15^{+}$ 
ubp15 sec-end forward:

ACG GCT GCA AAA ACG ATT GG

Oligo para secuenciar el gen $u b p 15^{+}$

Xma ubp16-GST forward:

CTT CCC GGG TAT GTC GCT TGC TAC TTT AC

Oligo para clonar el gen ubp $16^{+}$en pGEX-6P-1

Xma ubp16-GST reverse:

CC CCC CGG GCT ACT TGT CAT CGT CAT C

Oligo para clonar el gen $u b p 16^{+}$en pGEX-6P-1

ubp5 sec end forward:

GCT CGC ACA CAG TAT CCA GA

Oligo para secuenciar el gen $u b p 15^{+}$

ubp5 Myc hph forward:

ACG GTA CAT TGG CTT TGG ATC GTG CTA AGA AAG ATA GTA AGA AGC CGA ATA TAC TCG ACC GTG CTA TTC AGA TGA AAA ATC GGA TCC CCG GGT TAA TTA A

Oligo para etiquetar el gen $u b p 15^{+}$

ubp5 Myc hph reverse:

AAC CTG TAT AAA ACT TCA TGC ACC TTA TGC TCA ACA GGT AAG GAC CAA ACA ACC AGC AAG GAT TGT AAA GCC TTT AAA TAG AAT TCG AGC TCG TTT TCG A

Oligo para etiquetar el gen $u b p 15^{+}$

ubp16 wt forward:

CTC GGT AAT ACT TGT TTC ATG AAT TCA GTA C

Mutagénesis dirigida del gen $u b p 16^{+}$

ubp16 wt reverse:

GTA CTG AAT TCA TGA AAC AAG TAT TAC CGA G

Mutagénesis dirigida del gen ubp16 ${ }^{+}$

GFP_NES forward:

GGC ATG GAT GAA CTA TAC AAA GCA GCT GCC TTA GCG TTA AAG CTA GCT GGG TTG AAT ATC TAG GGC GCG CCA CTT CTA AAT AAG CG

Oligo para clonar la señal de localización NES

GFP_NLS forward:

GGC ATG GAT GAA CTA TAC AAA GCT GCT GCA CCA AAA AAG AAG CGT AAG GTC GGC TAG GGC GCG CCA CTT CTA AAT AAG CG

Oligo para clonar la señal de localización NLS 
RFP_NES forward:

G GGC CGC CAC TCC ACC GGC GCC GCA GCT GCT TTA GCA TTA AAA CTA GCT GGA TTA AAT ATA TAA GGC GCG CCA CTT CTA AAT AAG CG

Oligo para clonar la señal de localización NES

RFP_NLS forward:

G GGC CGC CAC TCC ACC GGC GCC GCT GCT GCA CCA AAA AAA AAA CGT AAA GTT GGA TAA GGC GCG CCA CTT CTA AAT AAG CG

Oligo para clonar la señal de localización NLS

RFP_NLS reverse:

CG CTT ATT TAG AAG TGG CGC GCC TTA TCC AAC TTT ACG TTT TTT TTT TGG TGC AGC AGC AGC GGC GCC GGT GGA GTG GCG GCC C

Oligo para clonar la señal de localización NLS

GFP_NES reverse:

CG CTT ATT TAG AAG TGG CGC GCC CTA GAT ATT CAA CCC AGC TAG CTT TAA CGC TAA GGC AGC TGC TTT GTA TAG TTC ATC CAT GCC

Oligo para clonar la señal de localización NES

GFP_NLS reverse:

CG CTT ATT TAG AAG TGG CGC GCC CTA GCC GAC CTT ACG CTT CTT TTT TGG TGC AGC AGC TTT GTA TAG TTC ATC CAT GCC

Oligo para clonar la señal de localización NLS

RFP_NES reverse:

G GGC CGC CAC TCC ACC GGC GCC GCA GCT GCT TTA GCA TTA AAA CTA GCT GGA TTA AAT ATA TAA GGC GCG CCA CTT CTA AAT AAG CG

Oligo para clonar la señal de localización NES

ubp16 seq 244 forward:

CTT CAG GAA CAA GGG GTG ATG

Oligo para sequenciar el gen $u b p 16^{+}$

ubp16 seq 167 forward:

GCC GTA AGT CAT TTT CAG CG

Oligo para sequenciar el gen $u b p 16^{+}$

ftp105 entorno forward:

CAG CAG GTA GCT GAA GTC TC

Oligo para comprobar la deleción del gen ftp $105^{+}$

ftp105 entorno reverse:

CAG AAG ATT CTC CAA GCC AG 
Oligo para comprobar la deleción del gen ftp105+

GFP-NES/NLS forward:

CCG GAT CCC CGG GTT AAT TAA CGG CGG CCG CGG AAT GAG TAA AG

Oligo para comprobar la señal NES/NLS

GFP-NES/NLS reverse:

TGG CGC GCC GGT ACC GGG CCC CCC CTC GAG GT

Oligo para comprobar la señal NES/NLS

UBP15 3Flag forward:

CAC ATA TCT TGG GAC TCG ATC ATC CAC CAG CTA ATG GTA GTG CTC AAT ACC ATG GTA TGG ACC AAG CAA TAA GAA TGA AAG GGG GAG GCG GGG GTG GA

Oligo para etiquetar el gen $u b p 16^{+}$

ubp15 CS forward:

CCA AGG TGC AAC GAG TTA TAT GAA CTC GCT AC

Mutagénesis dirigida del gen $u b p 15^{+}$

ubp15 CS reverse:

GTA GCG AGT TCA TAT AAC TCG TTG CAC CTT GG

Mutagénesis dirigida del gen ubp15+

Xma ubp15GST forward:

CTT CCC GGG TAT GGT GCT TTC AAA TGT AG

Oligo para clonar el gen $u b p 15^{+}$en pGEX-6P-1

ubp2 13Myc forward:

TAA CAT TTA TCT AGT ACA TTA GGA AAG AGT ATC GAC ACA TAA TTG AAT GTG TTC ACC GTG AAC ACA ATC TTC TGC TTC GGA TCC CCG GGT TAA TTA A

Oligo para etiquetar el gen $u b p 12^{+}$

ubp2 13Myc reverse:

AAA ACG TTA CAA CTT CCA ACC TCC ATT CAT AGC AAT TGA TCA CGG ATG ATC CAT CCT AGT TTT TAC CCT TCA CAT AGT TTG AAT TCG AGC TCG TTT TCG A

Oligo para etiquetar el gen $u b p 12^{+}$

ubp8 13 Myc forward:

CAG ATT ATA GTT ACC TAT TAT TTT ACC ATG AGC GTC AAA TCC TAT ACA GTG ATG AAA TGA CTG TTA AAA CGG AAA ATC GGA TCC CCG GGT TAA TTA A

Oligo para etiquetar el gen $u b p 8^{+}$ 
ubp8 13Myc reverse:

AAT AAG GAA CCT TTG AGT CAA TTA CTT TAC ATG GTT CAT AAT GAT TGT TCA TGA ACG GAT ATC TGA TCG CAT AAT CTA ACG AAT TCG AGC TCG TTT TCG A

Oligo para etiquetar el gen $u b p 8^{+}$

ubp15 sec 4F:

CAG CCG ATA AAA GTG AAT CCC

Oligo para secuencir el gen $u b p 15^{+}$

ubp15 sec 5F:

GTT AGA GTT GAC CTT CCA A

Oligo para secuencir el gen $u b p 15^{+}$

ubp15 sec 6F:

GAT ATG GCT CGA GCA GTG

Oligo para secuencir el gen $u b p 15^{+}$

ubp15 sec 7F:

GAC TTA TCA CGG TTG CAT G

Oligo para secuencir el gen $u b p 15^{+}$

ubp15 sec 1F:

GAA TAC GCG TCC GTT TTC TTA G

Oligo para secuencir el gen $u b p 15^{+}$

ubp15 sec 2R:

CAG TTG GAT CCT GAA CAT TCG

ubp15 sec 3F:

CCT ACC GAT AAT GAT GAT TC

Oligo para secuencir el gen $u b p 15^{+}$

Xma REP ubp15unspl F:

TCC CCC CGG GAT GGT AAG TTT ACT TTT TTA

Oligo para clonar el gen $u b p 15^{+}$en $\mathrm{pREP} 3 \mathrm{X}$

Xma REP ubp15splic F:

TCC CCC CGG GAT GGT GCT TTC AAA TGT AG

Oligo para clonar el gen $u b p 15^{+}$en $\mathrm{pREP} 3 \mathrm{X}$

Xbal YIPG3 ubp15splic F:

GCT CTA GAA TGG TGC TTT CAA ATG TAG

Oligo para clonar el gen $u b p 15^{+}$en $\mathrm{PREP} 3 \mathrm{X}$ 
ubp15 G124C forward:

CAATTCATTAGTGCATCATGAACCCGAC

Mutagénesis dirigida del gen $u b p 15^{+}$

ubp15 G124C reverse:

GTCGGGTTCATGATGCACTAATGAATTG

Mutagénesis dirigida del gen $u b p 15^{+}$

\subsection{Secuenciación de ADN}

Las construcciones de ADN recombinante obtenidas, en las que el inserto fue sometido a amplificación por la técnica de PCR, fueron comprobadas mediante secuenciación. La secuenciación de ADN se realizó de forma automática utilizando un secuenciador ABI Prism 377 de Perkin-Elmer en el Servicio de Análisis Genómico del Centro de Investigación del Cáncer.

\subsection{Extracción de ARN total y RT-PCR}

La obtención de ARN total se realizó empleando el sistema RNeasy Kit (Quiagen) siguiendo las recomendaciones del fabricante. La síntesis de ADNc se llevó a cabo con el sistema SuperScript First-Strand Kit (Invitrogen).

El análisis mediante RT-PCR (del inglés Real Iime-Polymerase Chain Reaction) se llevó a cabo con el iQ5 Multicolor Real-Time PCR Detection System (Bio-Rad).

\section{CITOMETRÍA DE FLUJO (FACS)}

La citometría de flujo o FACS (del inglés Fluorescence-Activated $\underline{\text { Cell }}$ Sorting) permite determinar el contenido de ADN de las células, lo que nos informa acerca de la fase del ciclo celular en que se encuentran.

Este análisis permite diferenciar distintas poblaciones dentro de las partículas analizadas, en nuestro caso células de $S$. pombe, en función de su tamaño y de su contenido en ADN. Para determinar el contenido en ADN de las células, se empleó como fluorocromo el yoduro de propidio (Sigma), que se une a la doble cadena de ADN. Este análisis por FACS se realizó en un equipo FACScalibur (Becton-Dickinson).

En el perfil de FACS típico de células de $S$. pombe creciendo asincrónicamente, sólo se aprecia claramente un pico de contenido $2 C$ de $A D N$, como consecuencia de la corta duración de las fases $\mathrm{G} 1$ y $\mathrm{S}$ en el ciclo celular de esta levadura, y de que la citoquinesis se completa cuando la Fase $S$ casi ha sido completada.

La preparación de las muestras para su análisis por FACS se llevó a cabo del siguiente modo: se recogieron muestras de $10^{7}$ células por centrifugación, se lavaron con 1 
$\mathrm{ml}$ de agua miliQ estéril y se resuspendieron en $1 \mathrm{ml}$ de etanol al 70\% para su fijación. Hasta el momento de su análisis fueron guardadas a $4^{\circ} \mathrm{C}$. La mitad de las células fijadas fueron lavadas con $1 \mathrm{ml}$ de citrato sódico $50 \mathrm{mM}$. A continuación, se resuspendieron e incubaron en $0,5 \mathrm{ml}$ de citrato sódico $50 \mathrm{mM}$ con $50 \mu \mathrm{g}$ de RNAsa (Roche) durante 2 horas a $37^{\circ} \mathrm{C}$. Finalmente, se añadió $0,5 \mathrm{ml}$ de citrato sódico 50 $\mathrm{mM}$ y $2 \mu \mathrm{g}$ de yoduro de propidio para analizar las muestras.

\section{TÉCNICAS DE PROTEÍNAS}

\subsection{Preparación de extractos proteicos}

Se siguieron dos métodos diferentes para la preparación de extractos proteicos totales, en función del destino final de los mismos. En el caso de ser utilizados para un simple análisis de proteínas, se procedió a una extracción en condiciones desnaturalizantes, mientras que la extracción en condiciones nativas fue el método utilizado para los estudios de interacciones entre proteínas (coinmunoprecipitaciones).

\section{i. Preparación de extractos proteicos de S. pombe: condiciones desnaturali- zantes}

Se recogieron en cada caso 8 densidades ópticas de células por centrifugación. Se lavaron 2 veces con $5 \mathrm{ml}$ de TCA (ácido tricloro acético) al 20\% y se resuspendieron en 100 $\mu$ l de TCA a la misma concentración. En este punto se pueden congelar las células a $-80^{\circ} \mathrm{C}$ indefinidamente, o se puede proceder directamente a la preparación de los extractos totales.

Para la preparación de los extractos totales de proteínas, se añadieron 200mg de Ballotini con el fin de romper las células mediante el uso de un aparato Fast-Prep (Bio101) durante 10 segundos a una potencia de 5.5. Esta operación se repitió tres veces. Los extractos totales se recogieron añadiendo $200 \mu \mathrm{l}$ de TCA al 5\%. A continuación se centrifugaron a 3000rpm durante $5 \mathrm{~min}$, para producir la precipitación de los extractos con el TCA. El sobrenadante fue eliminado mientras que el pellet de proteínas fue resuspendido en $100 \mu \mathrm{l}$ de tampón de carga (Tris- $\mathrm{HCl} \mathrm{pH} \mathrm{6,8,80mM,}$ DTT $5 \mathrm{mM}$, SDS $2 \%$, glicerol 7,5\%, EDTA $5 \mathrm{mM}$, azul de bromofenol 0,002\%) y en $50 \mu \mathrm{l}$ de TRIS base. Antes de la carga en el gel de acrilamida, se hirvieron las muestras a $100^{\circ} \mathrm{C}$ durante 5 min y se centrifugaron a máxima velocidad durante 1 minuto.

\section{ii. Preparación de extractos proteicos de S. cerevisiae: condiciones desna- turalizantes}

Para la preparación de los extractos proteicos de S. cerevisia, se siguió el mismo protocolo que para $S$. pombe, con la única diferencia de que sólo se recogieron 5 densidades ópticas de células en cada caso. 


\section{iii. Preparación de extractos proteicos de S. pombe: condiciones nativas}

En esta ocasión el número de células recogidas por centrifugación fue de tal. Estas células se congelaron inmediatamente en nitrógeno líquido o hielo seco y se almacenaron a $-80^{\circ} \mathrm{C}$ hasta su procesamiento. Con el fin de preparar los extractos, se resuspendieron las células en el tampón HB (MOPS $25 \mathrm{mM}, \mathrm{MgCl} 215 \mathrm{mM}$, DTT 1 mM, Tritón-X100 1\%, EGTA $5 \mathrm{mM}$ ) con los inhibidores de proteasas leupeptina 10 $\mu \mathrm{g} / \mathrm{ml}$, aprotinina $10 \mu \mathrm{g} / \mathrm{ml}$ y PMSF $100 \mu \mathrm{M}$. A continuación, se añadieron $750 \mathrm{mg}$ de bolas de vidrio Ballotini (0,4 $\mathrm{mm}$ Sigma) y se rompieron en un aparato Fast-Prep (Bio101) durante 15 segundos a una potencia de 4, operación que se repitió dos veces. Los extractos totales se recogieron en $1 \mathrm{ml}$ de HB con los inhibidores de proteasas. Para eliminar los restos de membranas y paredes celulares, se centrifugaron los extractos dos veces durante 10 minutos a $15000 \mathrm{rpm}$ a $4^{\circ} \mathrm{C}$ en una centrífuga Microfuge ${ }^{\circledR} R$ (Beckman) y se desecharon los precipitados. La concentración de proteína se determinó colorimétricamente utilizando el sistema BCA (Pierce).

\subsection{Valoración de la concentración de proteína en los extractos tota- les}

Para cuantificar la concentración de proteína de los extractos totales utilizamos el sistema colorimétrico BCA (Pierce), siguiendo las indicaciones del fabricante. La intensidad de color de cada reacción colorimétrica, que depende de la cantidad de proteína presente en cada muestra, fue cuantificada en espectrofotómetro a $\lambda=562$ $\mathrm{nm}$. A continuación, la concentración de proteínas de cada muestra, se determinó a partir de una recta patrón de concentraciones conocidas de albúmina sérica bovina (BSA).

\subsection{Electroforesis de proteínas en SDS-PAGE}

Mediante la electroforesis en una dimensión en geles de SDS-PAGE (del inglés ŚSodium-Dodecyl Sulfate-PolyA_crilamide Gel Electrophoresis, geles de SDS-poliacrilamida), se pueden separar las proteínas de una muestra en función de su peso molecular (Laemmli 1970), ya que el SDS es un detergente aniónico que rodea a las proteínas confiriéndoles una carga negativa proporcional a su tamaño.

Los geles SDS-PAGE pueden contener distintos porcentajes de poliacrilamida, de manera que altos porcentajes de poliacrilamida son adecuados para separar proteínas de bajo peso molecular y viceversa. En nuestro caso los geles utilizados fueron del 10 y del $12 \%$.

El volumen de extractos totales cargados en cada caso, fue de $4 \mu$ l para S. pombe y $8 \mu \mathrm{l}$ para $S$. cerevisiae, de una concentración no conocida. Como marcadores de peso molecular, se cargaron marcadores preteñidos de Invitrogen. La electroforesis en una dimensión se llevó a cabo utilizando el sistema Mini-Protean de Bio-Rad, en condiciones desnaturalizantes debido al tampón de carrera empleado (Tris- $\mathrm{HCl} 25$ $\mathrm{mM}$, glicina $192 \mathrm{mM}$, SDS 0,1\%, a pH 8,3), con un voltaje constante (120V). Finali122 
zada la electroforesis, estos geles se pueden fijar y teñir con azul de Coomassie, o bien ser sometidos a electrotransferencia e inmunodetección, por la técnica de Western blot.

\subsection{Análisis de proteínas por la técnica de Western blot}

Los geles SDS-PAGE se electrotransfirieron durante 1,5 horas a amperaje constante (300mA) a una membrana de nitrocelulosa (Hybond ECL de Amersham) utilizando el sistema Mini-Transblot de Bio-Rad. Empleamos como tampón de transferencia CAPS (ácido 3-(ciclohexil-amino)-1-propanosulfónico $10 \mathrm{mM}$, metanol 10\%, a pH $11)$.

A continuación, la membrana de nitrocelulosa fue saturada durante 1 hora a temperatura ambiente o RT, (del inglés Room Iemperature) en una solución con PBS (tampón fosfato $10 \mathrm{mM} \mathrm{pH} \mathrm{7,2,} \mathrm{NaCl} 145 \mathrm{mM}$ ), leche en polvo al 5\% (Sveltesse Nestlé) y detergente Tween-20 al 0,1\%.

La inmunodetección de proteínas consiste en su detección utilizando anticuerpos monoclonales o policlonales específicos (Tabla). Se utilizan dos anticuerpos, uno primario que reconoce específicamente a la proteína problema y otro secundario que reconoce al anterior y que está conjugado con una enzima, como la peroxidasa, que cataliza la reacción de detección. La incubación con el anticuerpo primario se llevó a cabo en la solución de bloqueo, bien a RT durante 2 horas, o a $4^{\circ} \mathrm{C}$ durante toda la noche dependiendo del tipo de anticuerpo. Después del periodo de incubación, se lavó la membrana cuatro veces durante 5 minutos con una solución de PBS con Tween-20 al 0,1\%. La incubación con el anticuerpo secundario (anti-ratón o anti-conejo conjugados con peroxidasa de rábano, Amersham-Pharmacia) se realizó también en la misma solución de bloqueo durante una hora a RT. El exceso de anticuerpo se retiró mediante tres lavados de 5 minutos en PBS con Tween-20 al 0,1\%. Antes de revelar, se retiró el exceso de detergente lavando la membrana dos veces durante 5 minutos con PBS. Para revelar el Western blot se utilizó en función de la proteína, el sistema de quimioluminiscencia ECL (Amersham Pharmacia Biotech) o el de Super Signal (Pierce), siguiendo las indicaciones de los fabricantes. La quimioluminiscencia se detectó mediante exposición de películas de auto-radiografía (Hyperfilm ECL de Amersham).

En la mayoría de los casos se cuantificó la intensidad de las bandas proteicas de interés con el programa Quantity One de Bio-Rad.

\subsection{Tinción con Azul de Coomassie}

Tras la electroforesis, los geles de poliacrilamida se tiñeron con solución de azul de Coomassie (azul de Coomassie al 0,5\%, metanol al 20\% y ácido acético al $10 \%$ ) durante 10 minutos en agitación a RT. A continuación se destiñeron en solución de destinción (metanol al $20 \%$ y ácido acético al 10\%) en agitación a RT, cambiando 
periódicamente dicha solución, hasta distinguir con nitidez las bandas correspondientes a las proteínas de interés.

\subsection{Inmunoprecipitación}

Las inmunoprecipitaciones permiten purificar proteínas por su unión a un anticuerpo específico, formando inmuno-complejos. La purificación de estos inmuno-complejos se realiza gracias a la utilización de las proteína A o G, ya que presentan afinidad por la región constante de las cadenas de las inmunoglobulinas.

En todos los casos las inmunoprecipitaciones se realizaron a partir de extractos de proteínas obtenidos en condiciones nativas, tal y como se describe en el apartado correspondiente.

La proteína PCNA-3Flag, se inmunoprecipitó a partir de $2 \mathrm{mg}$ de extractos celulares totales. Se utilizaron Dynabeads ${ }^{\circledR}$ Proteína $G$ de Invitrogen $(20 \mu \mathrm{l} / \mathrm{mg}$ de proteína), previamente equilibradas, las cuales fueron incubadas con el anticuerpo anti-Flag $(2 \mathrm{mg} / \mathrm{mg}$ extracto) durante 30 minutos a temperatura ambiente. Posteriormente, se añadió la cantidad de extracto indicada y se realizó una incubación durante 3 horas a $4^{\circ} \mathrm{C}$. Antes de cargar los inmunoprecipitados, se lavaron entre 5 y 6 veces con $1 \mathrm{ml}$ del tampón de lisis, para eliminar uniones inespecíficas. A continuación se resuspendieron en $50 \mu \mathrm{l}$ de tampón de carga $2 \mathrm{X}$ y se desnaturalizaron hirviendo durante 5 minutos. Finalmente, las muestras se resolvieron en una electroforesis en gel de poliacrilamida del $10 \%$ y se analizó, mediante Western blot, si las proteínas de interés se detectaban en los inmunoprecipitados.

\subsection{Anticuerpos utilizados}

En la Tabla 7 aparecen recogidos todos los anticuerpos utilizados en este trabajo, su procedencia, así como su aplicación y condiciones de uso (dilución o concentración final).

\subsection{Purificación de proteínas a partir de células de $E$. coli}

La purificación de las proteínas de fusión con GST, se realizó a partir de células de $E$. coli transformadas con plásmidos pGEX-6P-1 que contenían el ADNc de la proteína a purificar. Para ello, las células de E. coli se cultivaron primero en LB con $100 \mu \mathrm{g} / \mathrm{ml}$ de ampicilina y posteriormente se indujo la síntesis de la proteína por medio de la incubación de este cultivo durante 4 horas a $37^{\circ} \mathrm{C}$, en presencia de IPTG $(0,5 \mathrm{mM})$. Tras este tiempo, las células fueron recogidas por centrifugación (a 8000rpm durante 10 minutos) y se resuspendieron en un tampón de lisis (PBS frío, Tritón X-100 al $1 \%$, Lisozima $0,2 \mu \mathrm{g} / \mathrm{ml}$, DTT $2 \mathrm{mM}$, y los inhibidores de proteasas PMSF $1 \mathrm{mM}$, aprotinina $10 \mu \mathrm{g} / \mathrm{ml}$ y leupeptina $10 \mu \mathrm{g} / \mathrm{ml}$ ). Tras la incubación de la suspensión celular durante 30 minutos a $4^{\circ} \mathrm{C}$, ésta fue sonicada con el sonicador Misonic XL2010, y después se centrifugó a 15000 rpm durante 30 minutos a $4^{\circ} \mathrm{C}$. El sobrena- 
dante fue incubado con bolas de Glutatión-sefarosa (Amersham) durante 1 hora a $4^{\circ} \mathrm{C}$, las cuales fueron recuperadas y lavadas posteriormente 5 veces con PBS (al que se le añadieron inhibidores de proteasas). La pureza de la proteína y el rendimiento del proceso se comprobaron mediante electroforesis en SDS-PAGE y posterior tinción con Azul de Coomassie.

Tabla 7: Anticuerpos utilizados en este trabajo.

\begin{tabular}{|cccc|}
\hline Anticuerpo & Procedencia & Tipo/Especie & Utilización \\
\hline $\begin{array}{c}\text { anti-PCNA } \\
\text { (S. pombe) } \\
\text { anti-PCNA } \\
\text { (S. cerevisiae) } \\
\text { anti-Flag }\end{array}$ & Dr. Lehman & Policlonal/Conejo & $1: 2500$ \\
Anti-Myc & Sigma Aldrich & Monoclonal/Ratón & $1: 500$ \\
Anti-HA & Roche & Moliclonal/Conejo & $1: 2500$ \\
Anti-H2B & Active Motif & Policlonal/Conejo & $1: 100$ \\
Anti-Cig2 & Dr. Bueno & Policlonal/Conejo & $1: 750$ \\
Anti-Cdc13 & Dr. Bueno & Policlonal/Conejo & $1: 500$ \\
\hline Anticuerpo & Procedencia & Enzima asociada & Utilización \\
\hline Anti-ratón & Amersham & HRP Peroxidasa & $1: 2000$ \\
Anti-conejo & Amersham & HRP Peroxidasa & $1: 3000$ \\
\hline
\end{tabular}

\subsection{Ensayo in vitro de desubiquitinación de PCNA por Ubp16}

Tras la purificación de las proteínas GST-Ubp16 3Flag y GST-Ubp16CS 3Flag a partir de células de $E$. coli, así como de la purificación de PCNA por inmunoprecipitación, se realizó el ensayo de desubiquitinación in vitro, incubando ambas proteínas a $30^{\circ} \mathrm{C}$ en agitación durante toda la noche, en el tampón DUB descrito en Huang et al. 2006, de composición HEPES $60 \mathrm{mM}$ pH $7.65 \mathrm{mM}, \mathrm{Mg}_{2} \mathrm{Cl} 5 \mathrm{mM}$ y glicerol $4 \%$. A continuación se centrifugaron las muestras y se añadió el tampón de carga (Tris- $\mathrm{HCl}$ pH $6,8,80 \mathrm{mM}$, DTT 5mM, SDS 2\%, glicerol 7,5\%, EDTA 5mM, Azul de bromofenol $0,002 \%)$. Por último se hirvieron las muestras durante 5 minutos a $100^{\circ} \mathrm{C}$ y se separaron las proteínas mediante electroforesis en SDS-PAGE. 


\section{MICROSCOPÍA}

\subsection{Microscopía de contraste de fases}

Cuando fue necesaria la observación de las levaduras S. pombe o S. cerevisiae, se realizaron preparaciones húmedas y se observaron en un microscopio Leyca $D M$ $6000 B$ o en un microscopio de Olympus BX60.

\subsection{Microscopía de contraste interferencial y de fluorescencia}

Las fotografías de células de $S$. pombe se realizaron mediante microscopía de epifluorescencia y de contraste por interferencia diferencial (DIC) en los microscopios Zeiss Axioplan 2, Nikon Eclipse TE 2000E, DeltaVision by Applied Precision, y Leica $D M 6000 B$., acoplados a cámaras tipo CCD para la captura de las imágenes (Delta Photometrics Cool Snap HQ2, en el caso de DeltaVision, y Hamamatsu mod. ORCA para el resto de microscopios.

Los programas de captura utilizados fueron Openlab improvision, Metamorph Molecular Devices, y SoftWorkx de imsol.

Cada fluorocromo utilizado en este trabajo, GFP, DAPI (4,6-diamidino-2-fenilindol, Sigma D- 9542), calcofluor, CY3 o FITC, tiene diferente longitud de onda de excitación y emisión, por lo que fue necesario utilizar diferentes filtros.

\subsection{Tinciones de núcleos y septos}

Las células se fijaron en etanol al 70\% y, a continuación, se rehidrataron eliminando el etanol y añadiendo $50 \mu \mathrm{l}$ de PBS.

Para observar los septos, las células se tiñeron añadiendo $1 \mu \mathrm{l}$ de una solución de calcofluor a $50 \mu \mathrm{g} / \mathrm{ml}$. Las tinciones de núcleos se realizaron añadiendo $1 \mu \mathrm{l}$ de DAPI (4,6- diamidino-2-fenilindol, Sigma D-9542) a 0,1 mg/ml (Moreno et al., 1991). Finalmente, las células se extendieron en un cubreobjetos $y$, una vez que se secó la muestra, el cubre objetos se colocó en un portaobjetos sobre una gota $(3 \mu \mathrm{l})$ de glicerol al 50\% con $1 \mathrm{mg} / \mathrm{ml}$ de para-fenilendiamina (Sigma P-1519).

\subsection{Micromanipulación}

El micromanipulador utilizado para la construcción de los dobles, triples y cuádruples mutantes de este trabajo fue Singer MSM System 200. 


\section{TRATAMIENTO INFORMÁTICO DE SECUENCIAS Y PRE- SENTACIÓN DE DATOS}

\subsection{Tratamiento informático de secuencias de ADN y proteína}

Para la edición detallada de las secuencias, así como las comparaciones de secuencias, se utilizaron los programas Strider 1.1, DNA cloner y Sequencher.

La búsqueda de secuencias de ADN o de proteínas se efectuó en las bases de datos GeneDB, PomBase, GenBank, SWISSPROT, YeastGenome y Centro Sanger.

\subsection{Presentación de datos}

La redacción del presente trabajo se efectuó con el procesador de texto Pages 4.1 (Apple). Las representación gráfica de datos se realizaron con la aplicación Microsoft Excel (Microsoft Office 2008). Las ilustraciones y esquemas presentados, se realizaron con el programa Adobe Illustrator CS6 (Adobe). Las imágenes que aparecen en esta memoria se adquirieron con un escáner Hewlett Packard ScanJet 3c (Hewlett Packard). Dichas imágenes se manipularon con el programa Adobe Photoshop CS6 (Adobe). Para la gestión de las citas bibliográficas se utilizó la aplicación EndNote X2 (Niles and associates).

La búsqueda de referencias se realizó a través de la página web Medline (National Library of Medicine con dirección http://www.ncbi.nlm.nih.gov:80/). 



\section{Apéndice}

\section{Células carentes de Ubp16 acumulan más histona H2B ubiquitinada}

En S. cerevisiae existen dos proteasas de ubiquitina relacionadas con el silenciamiento de genes: Ubp8 y Ubp10. Aunque poseen funciones diferentes, conjuntamente parece que se encargan de desubiquitinar a la histona $\mathrm{H} 2 \mathrm{~B}$, ya que la supresión de ambos genes se traduce en un aumento sinérgico de los niveles de ubiquitinación de dicha histona (Emre et al. 2005; Gardner et al. 2005; Schulze et al. 2011). Dado que Ubp16 de S. pombe es el ortólogo de Ubp10 de S. cerevisiae y que la función desubiquitinadora de PCNA también se ha mantenido en esta proteína, decidimos comprobar si también ocurría lo mismo con la función desubiquitinadora sobre la histona mencionada en la levadura de fisión.

Para ello analizamos el estado de ubiquitinación de la histona H2B, en los mutantes de las proteínas homólogas de $S$. pombe, $\Delta u b p 8$ y $\Delta u b p 16$, así como en un doble mutante $\Delta u b p 8 \Delta u b p 16$, construido mediante micromanipulación. Como se muestra en la Figura 26, tanto en presencia como en ausencia de daño, la falta de Ubp16 y/o Ubp8 en la célula, se traduce en un aumento de la histona H2B ubiquitinada, mostrando el doble mutante $\Delta u b p 8 \Delta u b p 16$, mayor cantidad de ubiquitinación que los mutantes simples. Este resultado, al igual que en $S$. cerevisiae (Schulze et al. 2011), hace pensar que aunque ambas proteínas tengan como objetivo común a la histona H2B, su ruta de acción es diferente.

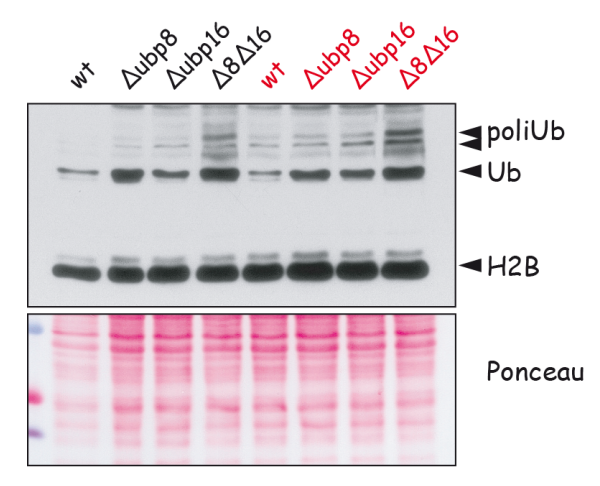

Figura 38: Células carentes de las proteasas Ubp8 y/o Ubp16, acumulan mayor cantidad de histona H2B ubiquitinada. Se recogieron muestras asíncronas y dañadas durante 3 horas con MMS $0.01 \%$, de los mutantes $\Delta u b p 6, \Delta u b p 8$ y $\Delta u b p 6 \Delta u b p 8$. Se prepararon extractos proteicos con TCA y se analizaron a continuación por Western blot, utilizando el anticuerpo $\alpha-\mathrm{H} 2 \mathrm{~B}$. Como se observa en la figura, la falta de ambas UBPs se traduce en un aumento sinérgico en el estado de ubiquitinación de la histona $\mathrm{H} 2 \mathrm{~B}$. 


\section{Análisis del mutante $\Delta u b p 16$ cdc10-129}

A

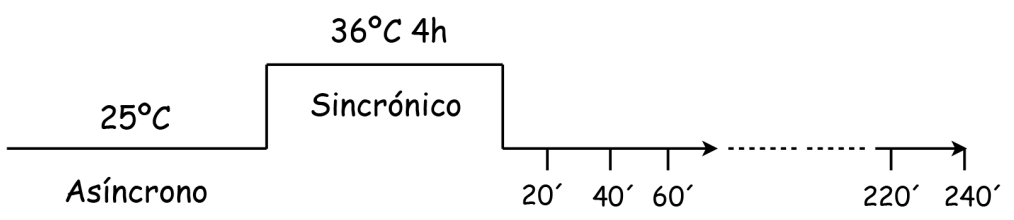

B

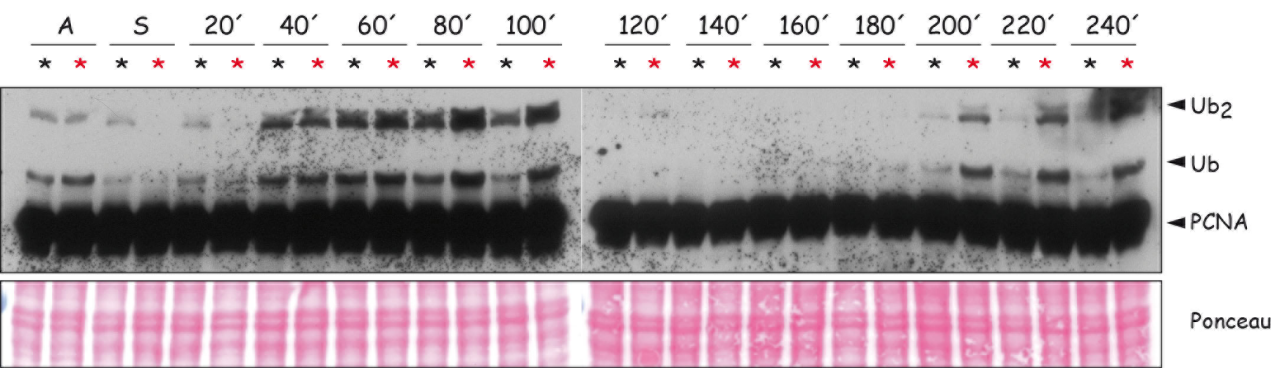

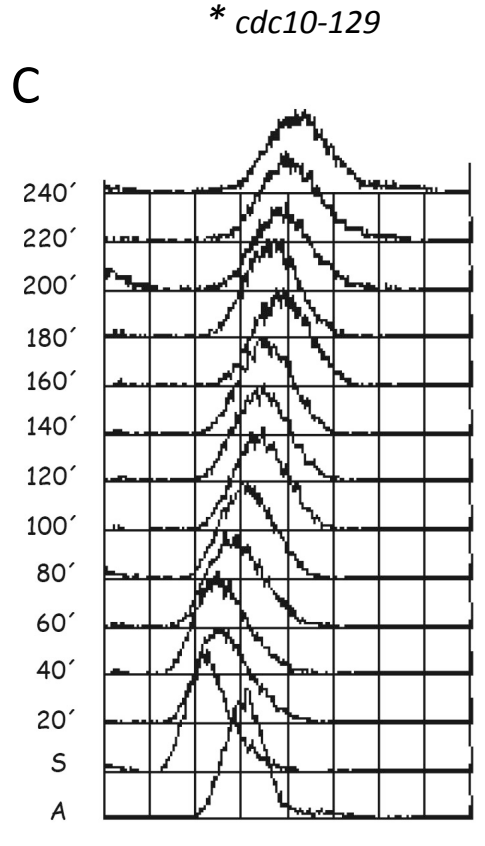

2C $4 \mathrm{C}$
* $\Delta u b p 16$ cdc10-129

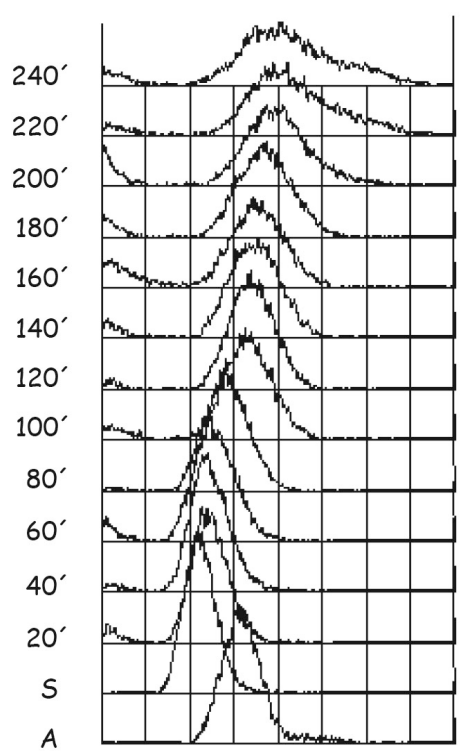

2C $4 \mathrm{C}$

Figura 39: Análisis de la ubiquitinación de PCNA a lo largo del ciclo celular en el mutante $\Delta u b p 16$ cdc10-129. 


\section{Análisis del mutante $\Delta u b p 15 \Delta u b p 16$ cdc25-22}

A

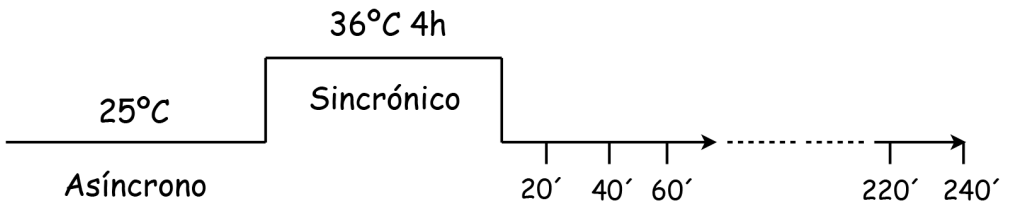

B

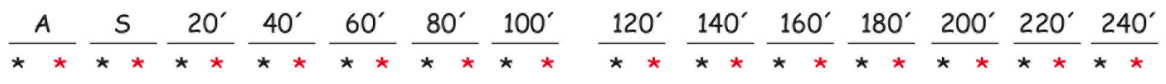

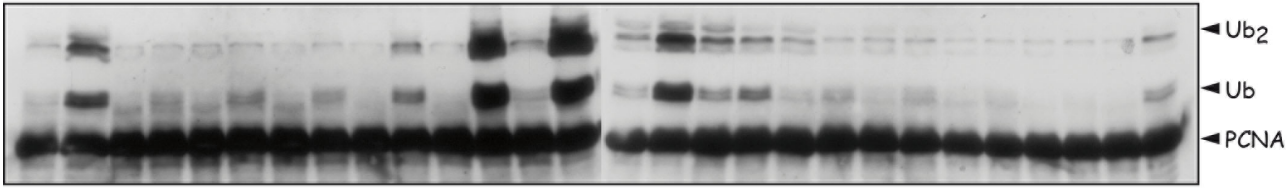

C

* $c d c 25-22$

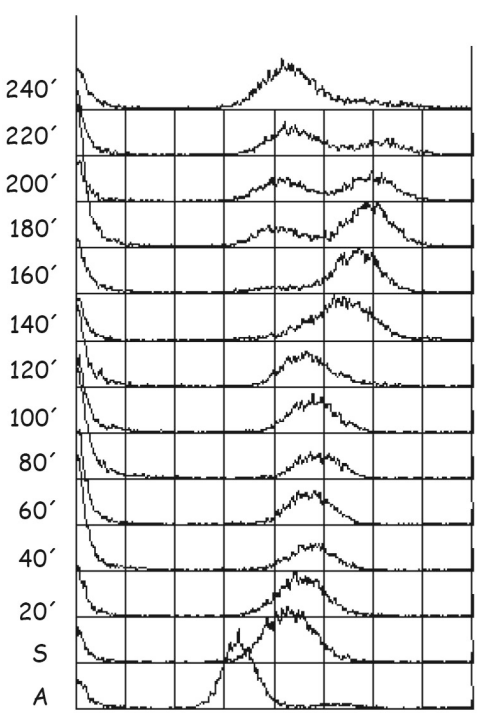

$2 C \quad 4 C$
* $\Delta u b p 15 \Delta u b p 16 c d c 25-22$

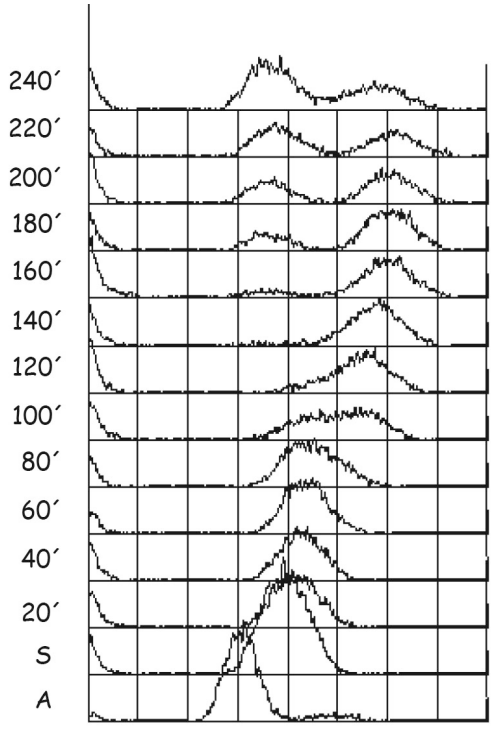

$2 \mathrm{C} \quad 4 \mathrm{C}$

Figura 40: Análisis de la ubiquitinación de PCNA a lo largo del ciclo celular en el mutante $\Delta$ ubp15 $\Delta$ ubp16 cdc25-22. 


\section{Sensibilidad del mutante $\triangle u b p 2$ a MMS}

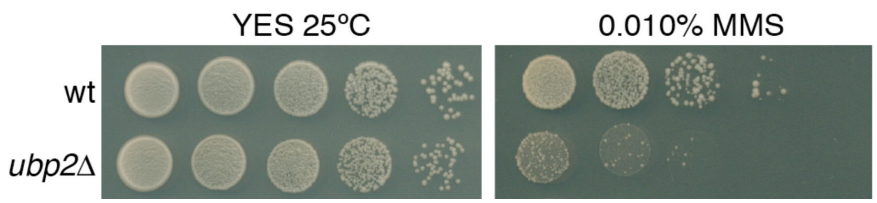

Figura 41: Cepas carentes de Ubp2 muestran una gran sensibilidad a MMS. 
En esta memoria se ha tratado de evitar el uso de anglicismos. Sin embargo, en algunos casos se ha preferido mantener el término original, por no existir aún una correspondencia adecuada en castellano.

Error prone: rama de las rutas de tolerancia al daño "propensa al error". Error free: rama de las rutas de tolerancia al daño "libre de errores". 



\section{Bibliografía}

Amerik, A. Y. and M. Hochstrasser (2004) Mechanism and function of deubiquitinating enzymes. Biochim Biophys Acta. 1695, 189-207.

Andersen, P. L., F. Xu and W. Xiao (2008) Eukaryotic DNA damage tolerance and translesion synthesis through covalent modifications of PCNA. Cell Res. 18, 162-73.

Andersen, P. L., H. Zhou, L. Pastushok, T. Moraes, S. McKenna, B. Ziola, M. J. Ellison, V. M. Dixit and W. Xiao (2005) Distinct regulation of Ubc13 functions by the two ubiquitin-conjugating enzyme variants Mms2 and Uev1A. J Cell Biol. 170, 745-55.

Anton, F., G. Dittmar, T. Langer and M. Escobar-Henriques (2013) Two deubiquitylases act on mitofusin and regulate mitochondrial fusion along independent pathways. Mol Cell. 49, 487-98.

Arakawa, H., G. L. Moldovan, H. Saribasak, N. N. Saribasak, S. Jentsch and J. M. Buerstedde (2006) A role for PCNA ubiquitination in immunoglobulin hypermutation. PLoS Biol. 4, e366.

Arias, E. E. and J. C. Walter (2006) PCNA functions as a molecular platform to trigger Cdt1 destruction and prevent re-replication. Nat Cell Biol. 8, 84-90.

Atkinson, J. and P. McGlynn (2009) Replication fork reversal and the maintenance of genome stability. Nucleic Acids Res. 37, 3475-92.

Aylon, Y., B. Liefshitz and M. Kupiec (2004) The CDK regulates repair of doublestrand breaks by homologous recombination during the cell cycle. Embo J. 23, 4868-75.

Bailly, V., J. Lamb, P. Sung, S. Prakash and L. Prakash (1994) Specific complex formation between yeast RAD6 and RAD18 proteins: a potential mechanism for targeting RAD6 ubiquitin-conjugating activity to DNA damage sites. Genes Dev. 8, 811-20. 
Baynton, K. and R. P. Fuchs (2000) Lesions in DNA: hurdles for polymerases. Trends Biochem Sci. 25, 74-9.

Beard, W. A. and S. H. Wilson (2003) Structural insights into the origins of DNA polymerase fidelity. Structure. 11, 489-96.

Bebenek, K. and T. A. Kunkel (2004) Functions of DNA polymerases. Adv Protein Chem. 69, 137-65.

Berdichevsky, A., L. Izhar and Z. Livneh (2002) Error-free recombinational repair predominates over mutagenic translesion replication in E. coli. Mol Cell. 10, 917-24.

Bergink, S. and S. Jentsch (2009) Principles of ubiquitin and SUMO modifications in DNA repair. Nature. 458, 461-7.

Bi, X., L. R. Barkley, D. M. Slater, S. Tateishi, M. Yamaizumi, H. Ohmori and C. Vaziri (2006) Rad18 regulates DNA polymerase kappa and is required for recovery from S-phase checkpoint-mediated arrest. Mol Cell Biol. 26, 3527-40.

Bienko, M., C. M. Green, N. Crosetto, F. Rudolf, G. Zapart, B. Coull, P. Kannouche, G. Wider, M. Peter, A. R. Lehmann, K. Hofmann and I. Dikic (2005) Ubiquitin-binding domains in $\mathrm{Y}$-family polymerases regulate translesion synthesis. Science. 310, 1821-4.

Birnboim, H. C. and J. Doly (1979) A rapid alkaline extraction procedure for screening recombinant plasmid DNA. Nucleic Acids Res. 7, 1513-23.

Blastyak, A., L. Pinter, I. Unk, L. Prakash, S. Prakash and L. Haracska (2007) Yeast Rad5 protein required for postreplication repair has a DNA helicase activity specific for replication fork regression. Mol Cell. 28, 167-75.

Bloom, L. B. (2009) Loading clamps for DNA replication and repair. DNA Repair (Amst). 8, 570-8.

Bomar, M. G., M. T. Pai, S. R. Tzeng, S. S. Li and P. Zhou (2007) Structure of the ubiquitin-binding zinc finger domain of human DNA Y-polymerase eta. EMBO Rep. 8, 247-51.

Bowman, G. D., M. O'Donnell and J. Kuriyan (2004) Structural analysis of a eukaryotic sliding DNA clamp-clamp loader complex. Nature. 429, 724-30.

Branzei, D. and M. Foiani (2007) Interplay of replication checkpoints and repair proteins at stalled replication forks. DNA Repair (Amst). 6, 994-1003.

Bravo, R., S. J. Fey, J. Bellatin, P. M. Larsen and J. E. Celis (1982) Identification of a nuclear polypeptide ("cyclin") whose relative proportion is sensitive to 
changes in the rate of cell proliferation and to transformation. Prog Clin Biol Res. 85 Pt A, 235-48.

Bridges, B. A. (2005) Error-prone DNA repair and translesion DNA synthesis. II: The inducible SOS hypothesis. DNA Repair (Amst). 4, 725-6, 739.

Broomfield, S., B. L. Chow and W. Xiao (1998) MMS2, encoding a ubiquitin-conjugating-enzyme-like protein, is a member of the yeast error-free postreplication repair pathway. Proc Natl Acad Sci U S A. 95, 5678-83.

Broomfield, S., T. Hryciw and W. Xiao (2001) DNA postreplication repair and mutagenesis in Saccharomyces cerevisiae. Mutat Res. 486, 167-84.

Brun, J., R. K. Chiu, B. G. Wouters and D. A. Gray (2010) Regulation of PCNA polyubiquitination in human cells. BMC Res Notes. 3, 85.

Bruning, J. B. and Y. Shamoo (2004) Structural and thermodynamic analysis of human PCNA with peptides derived from DNA polymerase-delta p66 subunit and flap endonuclease-1. Structure. 12, 2209-19.

Brusky, J., Y. Zhu and W. Xiao (2000) UBC13, a DNA-damage-inducible gene, is a member of the error-free postreplication repair pathway in Saccharomyces cerevisiae. Curr Genet. 37, 168-74.

Byun, T. S., M. Pacek, M. C. Yee, J. C. Walter and K. A. Cimprich (2005) Functional uncoupling of MCM helicase and DNA polymerase activities activates the ATR-dependent checkpoint. Genes Dev. 19, 1040-52.

Chang, D. J. and K. A. Cimprich (2009) DNA damage tolerance: when it's OK to make mistakes. Nat Chem Biol. 5, 82-90.

Chang, D. J., P. J. Lupardus and K. A. Cimprich (2006) Monoubiquitination of proliferating cell nuclear antigen induced by stalled replication requires uncoupling of DNA polymerase and mini-chromosome maintenance helicase activities. J Biol Chem. 281, 32081-8.

Chapados, B. R., D. J. Hosfield, S. Han, J. Qiu, B. Yelent, B. Shen and J. A. Tainer (2004) Structural basis for FEN-1 substrate specificity and PCNA-mediated activation in DNA replication and repair. Cell. 116, 39-50.

Chen, J., W. Bozza and Z. Zhuang (2011) Ubiquitination of PCNA and its essential role in eukaryotic translesion synthesis. Cell Biochem Biophys. 60, 47-60.

Chiu, R. K., J. Brun, C. Ramaekers, J. Theys, L. Weng, P. Lambin, D. A. Gray and B. G. Wouters (2006) Lysine 63-polyubiquitination guards against translesion synthesis-induced mutations. PLoS Genet. 2, e116. 
Cimprich, K. A. and D. Cortez (2008) ATR: an essential regulator of genome integrity. Nat Rev Mol Cell Biol. 9, 616-27.

Cobb, J. A. and L. Bjergbaek (2006) RecQ helicases: lessons from model organisms. Nucleic Acids Res. 34, 4106-14.

Connolly, T. and D. Beach (1994) Interaction between the Cig1 and Cig2 B-type cyclins in the fission yeast cell cycle. Mol Cell Biol. 14, 768-76.

Coulon, S., S. Ramasubramanyan, C. Alies, G. Philippin, A. Lehmann and R. P. Fuchs (2010) Rad8Rad5/Mms2-Ubc13 ubiquitin ligase complex controls translesion synthesis in fission yeast. Embo J. 29, 2048-58.

Courcelle, J., J. R. Donaldson, K. H. Chow and C. T. Courcelle (2003) DNA damageinduced replication fork regression and processing in Escherichia coli. Science. 299, 1064-7.

Coux, O., K. Tanaka and A. L. Goldberg (1996) Structure and functions of the 20S and 26S proteasomes. Annu Rev Biochem. 65, 801-47.

Cox, M. M. (2002) The nonmutagenic repair of broken replication forks via recombination. Mutat Res. 510, 107-20.

Cox, M. M., M. F. Goodman, K. N. Kreuzer, D. J. Sherratt, S. J. Sandler and K. J. Marians (2000) The importance of repairing stalled replication forks. Nature. 404, 37-41.

Czyzewska, J., K. Guzinska-Ustymowicz, A. Lebelt, B. Zalewski and A. Kemona (2004) Evaluation of proliferating markers Ki-67, PCNA in gastric cancers. Rocz Akad Med Bialymst. 49 Suppl 1, 64-6.

Daigaku, Y., A. A. Davies and H. D. Ulrich (2010) Ubiquitin-dependent DNA damage bypass is separable from genome replication. Nature. 465, 951-5.

Das-Bradoo, S., H. D. Nguyen and A. K. Bielinsky (2010) Damage-specific modification of PCNA. Cell Cycle. 9, 3674-9.

Davies, A. A., D. Huttner, Y. Daigaku, S. Chen and H. D. Ulrich (2008) Activation of ubiquitin-dependent DNA damage bypass is mediated by replication protein a. Mol Cell. 29, 625-36.

Dianov, G., A. Price and T. Lindahl (1992) Generation of single-nucleotide repair patches following excision of uracil residues from DNA. Mol Cell Biol. 12, 1605-12.

Diffley, J. F. (2004) Regulation of early events in chromosome replication. Curr Biol. 14, R778-86. 
Echols, H. and M. F. Goodman (1990) Mutation induced by DNA damage: a many protein affair. Mutat Res. 236, 301-11.

Echols, H. and M. F. Goodman (1991) Fidelity mechanisms in DNA replication. Annu Rev Biochem. 60, 477-511.

Emre, N. C., K. Ingvarsdottir, A. Wyce, A. Wood, N. J. Krogan, K. W. Henry, K. Li, R. Marmorstein, J. F. Greenblatt, A. Shilatifard and S. L. Berger (2005) Maintenance of low histone ubiquitylation by Ubp10 correlates with telomereproximal Sir2 association and gene silencing. Mol Cell. 17, 585-94.

Fanning, E., V. Klimovich and A. R. Nager (2006) A dynamic model for replication protein A (RPA) function in DNA processing pathways. Nucleic Acids Res. 34, 4126-37.

Fernández Sarabia, M. J., C. McInerny, P. Harris, C. Gordon and P. Fantes (1993) The cell cycle genes cdc22+ and suc22+ of the fission yeast Schizosaccharomyces pombe encode the large and small subunits of ribonucleotide reductase. Mol Gen Genet. 238, 241-51.

Ferreira, M. G. and J. P. Cooper (2004) Two modes of DNA double-strand break repair are reciprocally regulated through the fission yeast cell cycle. Genes Dev. 18, 2249-54.

Fortini, P., B. Pascucci, E. Parlanti, M. D'Errico, V. Simonelli and E. Dogliotti (2003) The base excision repair: mechanisms and its relevance for cancer susceptibility. Biochimie. 85, 1053-71.

Fox, J. T., K. Y. Lee and K. Myung (2011) Dynamic regulation of PCNA ubiquitylation/deubiquitylation. FEBS Lett. 585, 2780-5.

Fraile, J. M., V. Quesada, D. Rodriguez, J. M. Freije and C. López-Otín (2012) Deubiquitinases in cancer: new functions and therapeutic options. Oncogene. 31, 2373-88.

Frampton, J., A. Irmisch, C. M. Green, A. Neiss, M. Trickey, H. D. Ulrich, K. Furuya, F. Z. Watts, A. M. Carr and A. R. Lehmann (2006) Postreplication repair and PCNA modification in Schizosaccharomyces pombe. Mol Biol Cell. 17, 297685.

Friedberg, E. C. (2001) How nucleotide excision repair protects against cancer. Nat Rev Cancer. 1, 22-33.

Friedberg, E. C. (2005) Suffering in silence: the tolerance of DNA damage. Nat Rev Mol Cell Biol. 6, 943-53. 
Friedberg, E. C., A. R. Lehmann and R. P. Fuchs (2005) Trading places: how do DNA polymerases switch during translesion DNA synthesis? Mol Cell. 18, 499505.

Fukuda, K., H. Morioka, S. Imajou, S. Ikeda, E. Ohtsuka and T. Tsurimoto (1995) Structure-function relationship of the eukaryotic DNA replication factor, proliferating cell nuclear antigen. J Biol Chem. 270, 22527-34.

Gallego-Sanchez, A., S. Andres, F. Conde, P. A. San-Segundo and A. Bueno (2012) Reversal of PCNA ubiquitylation by Ubp10 in Saccharomyces cerevisiae. PLoS Genet. 8, e1002826.

Gallego-Sanchez, A., F. Conde, P. San Segundo and A. Bueno (2010) Control of PCNA deubiquitylation in yeast. Biochem Soc Trans. 38, 104-9.

García-Higuera, I., T. Taniguchi, S. Ganesan, M. S. Meyn, C. Timmers, J. Hejna, M. Grompe and A. D. D'Andrea (2001) Interaction of the Fanconi anemia proteins and BRCA1 in a common pathway. Mol Cell. 7, 249-62.

Gardner, R. G., Z. W. Nelson and D. E. Gottschling (2005) Ubp10/Dot4p regulates the persistence of ubiquitinated histone $\mathrm{H} 2 \mathrm{~B}$ : distinct roles in telomeric silencing and general chromatin. Mol Cell Biol. 25, 6123-39.

Gary, R., D. L. Ludwig, H. L. Cornelius, M. A. Maclnnes and M. S. Park (1997) The DNA repair endonuclease XPG binds to proliferating cell nuclear antigen (PCNA) and shares sequence elements with the PCNA-binding regions of FEN-1 and cyclin-dependent kinase inhibitor p21. J Biol Chem. 272, 245229.

Gatti, L., K. L. Hoe, J. Hayles, S. C. Righetti, N. Carenini, L. D. Bo, D. U. Kim, H. O. Park and P. Perego (2011) Ubiquitin-proteasome genes as targets for modulation of cisplatin sensitivity in fission yeast. BMC Genomics. 12, 44.

Glickman, M. H. and A. Ciechanover (2002) The ubiquitin-proteasome proteolytic pathway: destruction for the sake of construction. Physiol Rev. 82, 373-428.

Goldberg, A. L. and K. L. Rock (1992) Proteolysis, proteasomes and antigen presentation. Nature. 357, 375-9.

Golub, E. I. (1988) 'One minute' transformation of competent E. coli by plasmid DNA. Nucleic Acids Res. 16, 1641.

Gratchev, A., P. Strein, J. Utikal and G. Sergij (2003) Molecular genetics of Xeroderma pigmentosum variant. Exp Dermatol. 12, 529-36.

Gulbis, J. M., Z. Kelman, J. Hurwitz, M. O'Donnell and J. Kuriyan (1996) Structure of the C-terminal region of $\mathrm{p} 21(\mathrm{WAF} 1 / \mathrm{CIP} 1)$ complexed with human PCNA. Cell. 87, 297-306. 
Guo, C., P. L. Fischhaber, M. J. Luk-Paszyc, Y. Masuda, J. Zhou, K. Kamiya, C. Kisker and E. C. Friedberg (2003) Mouse Rev1 protein interacts with multiple DNA polymerases involved in translesion DNA synthesis. Embo J. 22, 6621-30.

Guo, C., T. S. Tang, M. Bienko, J. L. Parker, A. B. Bielen, E. Sonoda, S. Takeda, H. D. Ulrich, I. Dikic and E. C. Friedberg (2006) Ubiquitin-binding motifs in REV1 protein are required for its role in the tolerance of DNA damage. Mol Cell Biol. 26, 8892-900.

Guthrie, C. y. F., G.R., eds. (1991) Guide to yeast genetics and molecular biology. Methods Enzymol. 194, 1-863.

Hanahan, D. and R. A. Weinberg (2000) The hallmarks of cancer. Cell. 100, 57-70.

Heller, R. C. and K. J. Marians (2006) Replication fork reactivation downstream of a blocked nascent leading strand. Nature. 439, 557-62.

Hershko, A. and A. Ciechanover (1998) The ubiquitin system. Annu Rev Biochem. 67, 425-79.

Higgins, N. P., K. Kato and B. Strauss (1976) A model for replication repair in mammalian cells. J Mol Biol. 101, 417-25.

Hochstrasser, M. (2009) Origin and function of ubiquitin-like proteins. Nature. 458, 422-9.

Hoege, C., B. Pfander, G. L. Moldovan, G. Pyrowolakis and S. Jentsch (2002) RAD6dependent DNA repair is linked to modification of PCNA by ubiquitin and SUMO. Nature. 419, 135-41.

Hofmann, J. F. and D. Beach (1994) cdt1 is an essential target of the Cdc10/Sct1 transcription factor: requirement for DNA replication and inhibition of mitosis. Embo J. 13, 425-34.

Hofmann, R. M. and C. M. Pickart (1999) Noncanonical MMS2-encoded ubiquitinconjugating enzyme functions in assembly of novel polyubiquitin chains for DNA repair. Cell. 96, 645-53.

Huang, T. T., S. M. Nijman, K. D. Mirchandani, P. J. Galardy, M. A. Cohn, W. Haas, S. P. Gygi, H. L. Ploegh, R. Bernards and A. D. D'Andrea (2006) Regulation of monoubiquitinated PCNA by DUB autocleavage. Nat Cell Biol. 8, 339-47.

Huen, M. S. and J. Chen (2008) The DNA damage response pathways: at the crossroad of protein modifications. Cell Res. 18, 8-16.

Hussain, S., Y. Zhang and P. J. Galardy (2009) DUBs and cancer: the role of deubiquitinating enzymes as oncogenes, non-oncogenes and tumor suppressors. Cell Cycle. 8, 1688-97. 
Iftode, C., Y. Daniely and J. A. Borowiec (1999) Replication protein A (RPA): the eukaryotic SSB. Crit Rev Biochem Mol Biol. 34, 141-80.

Ikeda, F. and I. Dikic (2008) Atypical ubiquitin chains: new molecular signals. 'Protein Modifications: Beyond the Usual Suspects' review series. EMBO Rep. 9, 536-42.

Ira, G., A. Pellicioli, A. Balijja, X. Wang, S. Fiorani, W. Carotenuto, G. Liberi, D. Bressan, L. Wan, N. M. Hollingsworth, J. E. Haber and M. Foiani (2004) DNA end resection, homologous recombination and DNA damage checkpoint activation require CDK1. Nature. 431, 1011-7.

J, O. W., K. Kawamura, Y. Tada, H. Ohmori, H. Kimura, S. Sakiyama and M. Tagawa (2001) DNA polymerase kappa, implicated in spontaneous and DNA damage-induced mutagenesis, is overexpressed in lung cancer. Cancer Res. 61, 5366-9.

Jentsch, S., J. P. McGrath and A. Varshavsky (1987) The yeast DNA repair gene RAD6 encodes a ubiquitin-conjugating enzyme. Nature. 329, 131-4.

Jiricny, J. (2006) The multifaceted mismatch-repair system. Nat Rev Mol Cell Biol. 7, 335-46.

Johnson, R. E., S. Prakash and L. Prakash (1999) Efficient bypass of a thyminethymine dimer by yeast DNA polymerase, Poleta. Science. 283, 1001-4.

Kadyrov, F. A., L. Dzantiev, N. Constantin and P. Modrich (2006) Endonucleolytic function of MutLalpha in human mismatch repair. Cell. 126, 297-308.

Kannouche, P., A. R. Fernández de Henestrosa, B. Coull, A. E. Vidal, C. Gray, D. Zicha, R. Woodgate and A. R. Lehmann (2002) Localization of DNA polymerases eta and iota to the replication machinery is tightly co-ordinated in human cells. Embo J. 21, 6246-56.

Kannouche, P. L. and A. R. Lehmann (2004) Ubiquitination of PCNA and the polymerase switch in human cells. Cell Cycle. 3, 1011-3.

Kannouche, P. L., J. Wing and A. R. Lehmann (2004) Interaction of human DNA polymerase eta with monoubiquitinated PCNA: a possible mechanism for the polymerase switch in response to DNA damage. Mol Cell. 14, 491-500.

Karanjawala, Z. E., N. Murphy, D. R. Hinton, C. L. Hsieh and M. R. Lieber (2002) Oxygen metabolism causes chromosome breaks and is associated with the neuronal apoptosis observed in DNA double-strand break repair mutants. Curr Biol. 12, 397-402. 
Kato, T. and Y. Shinoura (1977) Isolation and characterization of mutants of Escherichia coli deficient in induction of mutations by ultraviolet light. Mol Gen Genet. 156, 121-31.

Kelly, T. J., G. S. Martín, S. L. Forsburg, R. J. Stephen, A. Russo and P. Nurse (1993) The fission yeast cdc18+ gene product couples $S$ phase to START and mitosis. Cell. 74, 371-82.

Kim, J. M., K. Parmar, M. Huang, D. M. Weinstock, C. A. Ruit, J. L. Kutok and A. D. D'Andrea (2009) Inactivation of murine Usp1 results in genomic instability and a Fanconi anemia phenotype. Dev Cell. 16, 314-20.

Kirchmaier, A. L. (2011) Ub-family modifications at the replication fork: Regulating PCNA-interacting components. FEBS Lett. 585, 2920-8.

Klein, H. L. (2006) A SUMOry of DNA replication: synthesis, damage, and repair. Cell. 127, 455-7.

Komander, D., F. Reyes-Turcu, J. D. Licchesi, P. Odenwaelder, K. D. Wilkinson and D. Barford (2009) Molecular discrimination of structurally equivalent Lys 63-linked and linear polyubiquitin chains. EMBO Rep. 10, 466-73.

Kouranti, I., J. R. McLean, A. Feoktistova, P. Liang, A. E. Johnson, R. H. RobertsGalbraith and K. L. Gould (2010) A global census of fission yeast deubiquitinating enzyme localization and interaction networks reveals distinct compartmentalization profiles and overlapping functions in endocytosis and polarity. PLOS Biol. 8.

Kraemer, K. H., M. M. Lee and J. Scotto (1987) Xeroderma pigmentosum. Cutaneous, ocular, and neurologic abnormalities in 830 published cases. Arch Dermatol. 123, 241-50.

Krishna, T. S., D. Fenyo, X. P. Kong, S. Gary, B. T. Chait, P. Burgers and J. Kuriyan (1994) Crystallization of proliferating cell nuclear antigen (PCNA) from Saccharomyces cerevisiae. J Mol Biol. 241, 265-8.

Kunkel, T. A. (2004) DNA replication fidelity. J Biol Chem. 279, 16895-8.

Kunkel, T. A., Y. I. Pavlov and K. Bebenek (2003) Functions of human DNA polymerases eta, kappa and iota suggested by their properties, including fidelity with undamaged DNA templates. DNA Repair (Amst). 2, 135-49.

Kushner, S. (1978) An improved method for transformation of Escherichia coli with colE1 derived plasmids. Elsevier, Amsterdam (Holanda).

Laemmli, U. K. (1970) Cleavage of structural proteins during the assembly of the head of bacteriophage T4. Nature. 227, 680-5. 
Lambert, S., A. Watson, D. M. Sheedy, B. Martín and A. M. Carr (2005) Gross chromosomal rearrangements and elevated recombination at an inducible site-specific replication fork barrier. Cell. 121, 689-702.

Lawrence, C. W. (2004) Cellular functions of DNA polymerase zeta and Rev1 protein. Adv Protein Chem. 69, 167-203.

Lawrence, C. W. and D. C. Hinkle (1996) DNA polymerase zeta and the control of DNA damage induced mutagenesis in eukaryotes. Cancer Surv. 28, 21-31.

Leach, C. A. and W. M. Michael (2005) Ubiquitin/SUMO modification of PCNA promotes replication fork progression in Xenopus laevis egg extracts. J Cell Biol. 171, 947-54.

Lehmann, A. R. (2002) Replication of damaged DNA in mammalian cells: new solutions to an old problem. Mutat Res. 509, 23-34.

Lehmann, A. R., A. Niimi, T. Ogi, S. Brown, S. Sabbioneda, J. F. Wing, P. L. Kannouche and C. M. Green (2007) Translesion synthesis: Y-family polymerases and the polymerase switch. DNA Repair (Amst). 6, 891-9.

Liang, J., Y. Saad, T. Lei, J. Wang, D. Qi, Q. Yang, P. E. Kolattukudy and M. Fu (2010) MCP-induced protein 1 deubiquitinates TRAF proteins and negatively regulates JNK and NF-kappaB signaling. J Exp Med. 207, 2959-73.

Lieber, M. R. (2008) The mechanism of human nonhomologous DNA end joining. J Biol Chem. 283, 1-5.

Lindahl, T. (1990) Repair of intrinsic DNA lesions. Mutat Res. 238, 305-11.

Lindahl, T. and R. D. Wood (1999) Quality control by DNA repair. Science. 286, 1897-905.

Ling, H., F. Boudsocq, B. S. Plosky, R. Woodgate and W. Yang (2003) Replication of a cis-syn thymine dimer at atomic resolution. Nature. 424, 1083-7.

Ling, H., F. Boudsocq, R. Woodgate and W. Yang (2001) Crystal structure of a Y-family DNA polymerase in action: a mechanism for error-prone and lesionbypass replication. Cell. 107, 91-102.

Longtine, M. S., A. McKenzie, 3rd, D. J. Demarini, N. G. Shah, A. Wach, A. Brachat, P. Philippsen and J. R. Pringle (1998) Additional modules for versatile and economical PCR-based gene deletion and modification in Saccharomyces cerevisiae. Yeast. 14, 953-61.

Lowndes, N. F., C. J. Mclnerny, A. L. Johnson, P. A. Fantes and L. H. Johnston (1992) Control of DNA synthesis genes in fission yeast by the cell-cycle gene cdc10+. Nature. 355, 449-53. 
Ma, L., S. Broomfield, C. Lavery, S. L. Lin, W. Xiao and S. Bacchetti (1998) Up-regulation of CIR1/CROC1 expression upon cell immortalization and in tumorderived human cell lines. Oncogene. 17, 1321-6.

Maga, G. and U. Hubscher (2003) Proliferating cell nuclear antigen (PCNA): a dancer with many partners. J Cell Sci. 116, 3051-60.

Majka, J. and P. M. Burgers (2004) The PCNA-RFC families of DNA clamps and clamp loaders. Prog Nucleic Acid Res Mol Biol. 78, 227-60.

Marians, K. J. (2000) Replication and recombination intersect. Curr Opin Genet Dev. 10, 151-6.

Martín-Castellanos, C. and S. Moreno (1996) Regulation of G1 progression in fission yeast by the rum1+ gene product. Prog Cell Cycle Res. 2, 29-35.

Masutani, C., R. Kusumoto, A. Yamada, N. Dohmae, M. Yokoi, M. Yuasa, M. Araki, S. Iwai, K. Takio and F. Hanaoka (1999) The XPV (xeroderma pigmentosum variant) gene encodes human DNA polymerase eta. Nature. 399, 700-4.

Maundrell, K. (1990) nmt1 of fission yeast. A highly transcribed gene completely repressed by thiamine. J Biol Chem. 265, 10857-64.

Maundrell, K. (1993) Thiamine-repressible expression vectors pREP and pRIP for fission yeast. Gene. 123, 127-30.

McCulloch, S. D., R. J. Kokoska, C. Masutani, S. Iwai, F. Hanaoka and T. A. Kunkel (2004) Preferential cis-syn thymine dimer bypass by DNA polymerase eta occurs with biased fidelity. Nature. 428, 97-100.

McDonald, J. P., A. S. Levine and R. Woodgate (1997) The Saccharomyces cerevisiae RAD30 gene, a homologue of Escherichia coli dinB and umuC, is DNA damage inducible and functions in a novel error-free postreplication repair mechanism. Genetics. 147, 1557-68.

McGlynn, P. and R. G. Lloyd (2002) Recombinational repair and restart of damaged replication forks. Nat Rev Mol Cell Biol. 3, 859-70.

McLean, J. R., I. Kouranti and K. L. Gould (2011) Survey of the phosphorylation status of the Schizosaccharomyces pombe deubiquitinating enzyme (DUB) family. J Proteome Res. 10, 1208-15.

Meetei, A. R., J. P. de Winter, A. L. Medhurst, M. Wallisch, Q. Waisfisz, H. J. van de Vrugt, A. B. Oostra, Z. Yan, C. Ling, C. E. Bishop, M. E. Hoatlin, H. Joenje and W. Wang (2003) A novel ubiquitin ligase is deficient in Fanconi anemia. Nat Genet. 35, 165-70. 
Michel, B., S. D. Ehrlich and M. Uzest (1997) DNA double-strand breaks caused by replication arrest. Embo J. 16, 430-8.

Michel, B., M. J. Flores, E. Viguera, G. Grompone, M. Seigneur and V. Bidnenko (2001) Rescue of arrested replication forks by homologous recombination. Proc Natl Acad Sci U S A. 98, 8181-8.

Michel, B., G. Grompone, M. J. Flores and V. Bidnenko (2004) Multiple pathways process stalled replication forks. Proc Natl Acad Sci U S A. 101, 12783-8.

Millar, J. B., C. H. McGowan, G. Lenaers, R. Jones and P. Russell (1991) p80cdc25 mitotic inducer is the tyrosine phosphatase that activates p34cdc2 kinase in fission yeast. EMBO J. 10, 4301-9.

Mills, K. D., D. O. Ferguson and F. W. Alt (2003) The role of DNA breaks in genomic instability and tumorigenesis. Immunol Rev. 194, 77-95.

Miyachi, K., M. J. Fritzler and E. M. Tan (1978) Autoantibody to a nuclear antigen in proliferating cells. J Immunol. 121, 2228-34.

Modrich, P. (2006) Mechanisms in eukaryotic mismatch repair. J Biol Chem. 281, 30305-9.

Moldovan, G. L., B. Pfander and S. Jentsch (2006) PCNA controls establishment of sister chromatid cohesion during S phase. Mol Cell. 23, 723-32.

Moldovan, G. L., B. Pfander and S. Jentsch (2007) PCNA, the maestro of the replication fork. Cell. 129, 665-79.

Mondesert, O., C. H. McGowan and P. Russell (1996) Cig2, a B-type cyclin, promotes the onset of S in Schizosaccharomyces pombe. Mol Cell Biol. 16, 1527 33.

Morell-Quadreny, L., F. Clar-Blanch, B. Fenollosa-Enterna, M. Pérez-Bacete, A. Martínez-Lorente and A. Llombart-Bosch (1998) Proliferating cell nuclear antigen (PCNA) as a prognostic factor in renal cell carcinoma. Anticancer Res. 18, 677-82.

Moreno, S., A. Klar and P. Nurse (1991) Molecular genetic analysis of fission yeast Schizosaccharomyces pombe. Methods Enzymol. 194, 795-823.

Morgan, W. F., J. P. Day, M. I. Kaplan, E. M. McGhee and C. L. Limoli (1996) Genomic instability induced by ionizing radiation. Radiat Res. 146, 247-58.

Motegi, A., H. J. Liaw, K. Y. Lee, H. P. Roest, A. Maas, X. Wu, H. Moinova, S. D. Markowitz, H. Ding, J. H. Hoeijmakers and K. Myung (2008) Polyubiquitination of proliferating cell nuclear antigen by HLTF and SHPRH prevents 
genomic instability from stalled replication forks. Proc Natl Acad Sci U S A. $105,12411-6$.

Motegi, A., R. Sood, H. Moinova, S. D. Markowitz, P. P. Liu and K. Myung (2006) Human SHPRH suppresses genomic instability through proliferating cell nuclear antigen polyubiquitination. J Cell Biol. 175, 703-8.

Naryzhny, S. N. (2008) Proliferating cell nuclear antigen: a proteomics view. Cell Mol Life Sci. 65, 3789-808.

Naryzhny, S. N. and H. Lee (2007) Characterization of proliferating cell nuclear antigen (PCNA) isoforms in normal and cancer cells: there is no cancer-associated form of PCNA. FEBS Lett. 581, 4917-20.

Nijman, S. M., T. T. Huang, A. M. Dirac, T. R. Brummelkamp, R. M. Kerkhoven, A. D. D'Andrea and R. Bernards (2005) The deubiquitinating enzyme USP1 regulates the Fanconi anemia pathway. Mol Cell. 17, 331-9.

Obara-Ishihara, T. and H. Okayama (1994) A B-type cyclin negatively regulates conjugation via interacting with cell cycle 'start' genes in fission yeast. Embo J. 13, 1863-72.

Oestergaard, V. H., F. Langevin, H. J. Kuiken, P. Pace, W. Niedzwiedz, L. J. Simpson, M. Ohzeki, M. Takata, J. E. Sale and K. J. Patel (2007) Deubiquitination of FANCD2 is required for DNA crosslink repair. Mol Cell. 28, 798-809.

Oh, C. E., R. McMahon, S. Benzer and M. A. Tanouye (1994) bendless, a Drosophila gene affecting neuronal connectivity, encodes a ubiquitin-conjugating enzyme homolog. J Neurosci. 14, 3166-79.

Ohashi, E., Y. Murakumo, N. Kanjo, J. Akagi, C. Masutani, F. Hanaoka and H. Ohmori (2004) Interaction of hREV1 with three human Y-family DNA polymerases. Genes Cells. 9, 523-31.

Ohmori, H., E. C. Friedberg, R. P. Fuchs, M. F. Goodman, F. Hanaoka, D. Hinkle, T. A. Kunkel, C. W. Lawrence, Z. Livneh, T. Nohmi, L. Prakash, S. Prakash, T. Todo, G. C. Walker, Z. Wang and R. Woodgate (2001) The Y-family of DNA polymerases. Mol Cell. 8, 7-8.

Otsuka, C., D. Loakes and K. Negishi (2002) The role of deoxycytidyl transferase activity of yeast Rev1 protein in the bypass of abasic sites. Nucleic Acids Res Suppl, 87-8.

Oyama, M., M. Wakasugi, T. Hama, H. Hashidume, Y. Iwakami, R. Imai, S. Hoshino, H. Morioka, Y. Ishigaki, O. Nikaido and T. Matsunaga (2004) Human NTH1 physically interacts with p53 and proliferating cell nuclear antigen. Biochem Biophys Res Commun. 321, 183-91. 
Pages, V. and R. P. Fuchs (2002) How DNA lesions are turned into mutations within cells? Oncogene. 21, 8957-66.

Pan, Q., Y. Fang, Y. Xu, K. Zhang and X. Hu (2005) Down-regulation of DNA polymerases kappa, eta, iota, and zeta in human lung, stomach, and colorectal cancers. Cancer Lett. 217, 139-47.

Papouli, E., S. Chen, A. A. Davies, D. Huttner, L. Krejci, P. Sung and H. D. Ulrich (2005) Crosstalk between SUMO and ubiquitin on PCNA is mediated by recruitment of the helicase Srs2p. Mol Cell. 19, 123-33.

Pascal, J. M., P. J. O'Brien, A. E. Tomkinson and T. Ellenberger (2004) Human DNA ligase I completely encircles and partially unwinds nicked DNA. Nature. 432, 473-8.

Pastushok, L. and W. Xiao (2004) DNA postreplication repair modulated by ubiquitination and sumoylation. Adv Protein Chem. 69, 279-306.

Paulsen, R. D. and K. A. Cimprich (2007) The ATR pathway: fine-tuning the fork. DNA Repair (Amst). 6, 953-66.

Pfander, B., G. L. Moldovan, M. Sacher, C. Hoege and S. Jentsch (2005) SUMO-modified PCNA recruits Srs2 to prevent recombination during S phase. Nature. 436, 428-33.

Plosky, B. S., A. E. Vidal, A. R. Fernández de Henestrosa, M. P. McLenigan, J. P. McDonald, S. Mead and R. Woodgate (2006) Controlling the subcellular localization of DNA polymerases iota and eta via interactions with ubiquitin. Embo J. 25, 2847-55.

Postow, L., C. Ullsperger, R. W. Keller, C. Bustamante, A. V. Vologodskii and N. R. Cozzarelli (2001) Positive torsional strain causes the formation of a fourway junction at replication forks. J Biol Chem. 276, 2790-6.

Prakash, L. (1981) Characterization of postreplication repair in Saccharomyces cerevisiae and effects of rad6, rad18, rev3 and rad52 mutations. Mol Gen Genet. 184, 471-8.

Prakash, S., R. E. Johnson and L. Prakash (2005) Eukaryotic translesion synthesis DNA polymerases: specificity of structure and function. Annu Rev Biochem. 74, 317-53.

Prakash, S. and L. Prakash (2002) Translesion DNA synthesis in eukaryotes: a oneor two-polymerase affair. Genes Dev. 16, 1872-83.

Prakash, S., P. Sung and L. Prakash (1993) DNA repair genes and proteins of Saccharomyces cerevisiae. Annu Rev Genet. 27, 33-70. 
Quesada, V., A. Díaz-Perales, A. Gutierrez-Fernández, C. Garabaya, S. Cal and C. López-Otín (2004) Cloning and enzymatic analysis of 22 novel human ubiquitin-specific proteases. Biochem Biophys Res Commun. 314, 54-62.

Rajagopalan, M., C. Lu, R. Woodgate, M. O'Donnell, M. F. Goodman and H. Echols (1992) Activity of the purified mutagenesis proteins UmuC, UmuD', and RecA in replicative bypass of an abasic DNA lesion by DNA polymerase III. Proc Natl Acad Sci U S A. 89, 10777-81.

Rechkoblit, O., L. Malinina, Y. Cheng, V. Kuryavyi, S. Broyde, N. E. Geacintov and D. J. Patel (2006) Stepwise translocation of Dpo4 polymerase during error-free bypass of an oxoG lesion. PLOS Biol. 4, e11.

Reuven, N. B., G. Arad, A. Maor-Shoshani and Z. Livneh (1999) The mutagenesis protein UmuC is a DNA polymerase activated by UmuD', RecA, and SSB and is specialized for translesion replication. J Biol Chem. 274, 31763-6.

Reyes-Turcu, F. E., K. H. Ventii and K. D. Wilkinson (2009) Regulation and cellular roles of ubiquitin-specific deubiquitinating enzymes. Annu Rev Biochem. 78, 363-97.

Roush, A. A., M. Suarez, E. C. Friedberg, M. Radman and W. Siede (1998) Deletion of the Saccharomyces cerevisiae gene RAD30 encoding an Escherichia coli DinB homolog confers UV radiation sensitivity and altered mutability. Mol Gen Genet. 257, 686-92.

Sakurai, S., K. Kitano, H. Yamaguchi, K. Hamada, K. Okada, K. Fukuda, M. Uchida, E. Ohtsuka, H. Morioka and T. Hakoshima (2005) Structural basis for recruitment of human flap endonuclease 1 to PCNA. Embo J. 24, 683-93.

Sambrook, J., Fritsch, E.F. and Maniatis, T. (1989) Molecular cloning : a laboratory manual. Cold Spring Harbor Laboratory Press. New York (USA).

Sancar, A., L. A. Lindsey-Boltz, K. Unsal-Kacmaz and S. Linn (2004) Molecular mechanisms of mammalian DNA repair and the DNA damage checkpoints. Annu Rev Biochem. 73, 39-85.

Saurin, A. J., K. L. Borden, M. N. Boddy and P. S. Freemont (1996) Does this have a familiar RING? Trends Biochem Sci. 21, 208-14.

Schofield, M. J. and P. Hsieh (2003) DNA mismatch repair: molecular mechanisms and biological function. Annu Rev Microbiol. 57, 579-608.

Schulze, J. M., T. Hentrich, S. Nakanishi, A. Gupta, E. Emberly, A. Shilatifard and M. S. Kobor (2011) Splitting the task: Ubp8 and Ubp10 deubiquitinate different cellular pools of H2BK123. Genes Dev. 25, 2242-7. 
Shcherbakova, P. V. and I. J. Fijalkowska (2006) Translesion synthesis DNA polymerases and control of genome stability. Front Biosci. 11, 2496-517.

Shinohara, A. and T. Ogawa (1995) Homologous recombination and the roles of double-strand breaks. Trends Biochem Sci. 20, 387-91.

Silvian, L. F., E. A. Toth, P. Pham, M. F. Goodman and T. Ellenberger (2001) Crystal structure of a DinB family error-prone DNA polymerase from Sulfolobus solfataricus. Nat Struct Biol. 8, 984-9.

Simpson, L. J., A. L. Ross, D. Szuts, C. A. Alviani, V. H. Oestergaard, K. J. Patel and J. E. Sale (2006) RAD18-independent ubiquitination of proliferating-cell nuclear antigen in the avian cell line DT40. EMBO Rep. 7, 927-32.

Singhal, R. K., R. Prasad and S. H. Wilson (1995) DNA polymerase beta conducts the gap-filling step in uracil-initiated base excision repair in a bovine testis nuclear extract. J Biol Chem. 270, 949-57.

Smogorzewska, A., S. Matsuoka, P. Vinciguerra, E. R. McDonald, 3rd, K. E. Hurov, J. Luo, B. A. Ballif, S. P. Gygi, K. Hofmann, A. D. D'Andrea and S. J. Elledge (2007) Identification of the FANCI protein, a monoubiquitinated FANCD2 paralog required for DNA repair. Cell. 129, 289-301.

Sonoda, E., H. Hochegger, A. Saberi, Y. Taniguchi and S. Takeda (2006) Differential usage of non-homologous end-joining and homologous recombination in double strand break repair. DNA Repair (Amst). 5, 1021-9.

Steinborn, G. (1978) Uvm mutants of Escherichia coli K12 deficient in UV mutagenesis. I. Isolation of uvm mutants and their phenotypical characterization in DNA repair and mutagenesis. Mol Gen Genet. 165, 87-93.

Steinborn, G. (1979) Uvm mutants of Escherichia coli K12 deficient in UV mutagenesis. II. Further evidence for a novel function in error-prone repair. Mol Gen Genet. 175, 203-8.

Steitz, T. A., S. J. Smerdon, J. Jager and C. M. Joyce (1994) A unified polymerase mechanism for nonhomologous DNA and RNA polymerases. Science. 266, 2022-5.

Stelter, P. and H. D. Ulrich (2003) Control of spontaneous and damage-induced mutagenesis by SUMO and ubiquitin conjugation. Nature. 425, 188-91.

Sung, P., E. Berleth, C. Pickart, S. Prakash and L. Prakash (1991) Yeast RAD6 encoded ubiquitin conjugating enzyme mediates protein degradation dependent on the $\mathrm{N}$-end-recognizing E3 enzyme. Embo J. 10, 2187-93. 
Tang, M., X. Shen, E. G. Frank, M. O'Donnell, R. Woodgate and M. F. Goodman (1999) UmuD'(2)C is an error-prone DNA polymerase, Escherichia coli pol V. Proc Natl Acad Sci U S A. 96, 8919-24.

Tissier, A., P. Kannouche, M. P. Reck, A. R. Lehmann, R. P. Fuchs and A. Cordonnier (2004) Co-localization in replication foci and interaction of human Y-family members, DNA polymerase pol eta and REVI protein. DNA Repair (Amst). 3, 1503-14.

Torres-Ramos, C. A., B. L. Yoder, P. M. Burgers, S. Prakash and L. Prakash (1996) Requirement of proliferating cell nuclear antigen in RAD6-dependent postreplicational DNA repair. Proc Natl Acad Sci U S A. 93, 9676-81.

Trincao, J., R. E. Johnson, C. R. Escalante, S. Prakash, L. Prakash and A. K. Aggarwal (2001) Structure of the catalytic core of S. cerevisiae DNA polymerase eta: implications for translesion DNA synthesis. Mol Cell. 8, 417-26.

Tsuchimoto, D., Y. Sakai, K. Sakumi, K. Nishioka, M. Sasaki, T. Fujiwara and Y. Nakabeppu (2001) Human APE2 protein is mostly localized in the nuclei and to some extent in the mitochondria, while nuclear APE2 is partly associated with proliferating cell nuclear antigen. Nucleic Acids Res. 29, 2349-60.

Uljon, S. N., R. E. Johnson, T. A. Edwards, S. Prakash, L. Prakash and A. K. Aggarwal (2004) Crystal structure of the catalytic core of human DNA polymerase kappa. Structure. 12, 1395-404.

Ulrich, H. D. (2004) How to activate a damage-tolerant polymerase: consequences of PCNA modifications by ubiquitin and SUMO. Cell Cycle. 3, 15-8.

Ulrich, H. D. (2007a) Conservation of DNA damage tolerance pathways from yeast to humans. Biochem Soc Trans. 35, 1334-7.

Ulrich, H. D. (2007b) PCNASUMO and Srs2: a model SUMO substrate-effector pair. Biochem Soc Trans. 35, 1385-8.

Ulrich, H. D. (2009) Regulating post-translational modifications of the eukaryotic replication clamp PCNA. DNA Repair (Amst). 8, 461-9.

Ulrich, H. D. (2011) Timing and spacing of ubiquitin-dependent DNA damage bypass. FEBS Lett. 585, 2861-7.

Ulrich, H. D. and S. Jentsch (2000) Two RING finger proteins mediate cooperation between ubiquitin-conjugating enzymes in DNA repair. Embo J. 19, 338897.

Umar, A., A. B. Buermeyer, J. A. Simon, D. C. Thomas, A. B. Clark, R. M. Liskay and T. A. Kunkel (1996) Requirement for PCNA in DNA mismatch repair at a step preceding DNA resynthesis. Cell. 87, 65-73. 
Unk, I., I. Hajdu, K. Fatyol, B. Szakal, A. Blastyak, V. Bermudez, J. Hurwitz, L. Prakash, S. Prakash and L. Haracska (2006) Human SHPRH is a ubiquitin ligase for Mms2-Ubc13-dependent polyubiquitylation of proliferating cell nuclear antigen. Proc Natl Acad Sci U S A. 103, 18107-12.

Unk, I., L. Haracska, X. V. Gomes, P. M. Burgers, L. Prakash and S. Prakash (2002) Stimulation of 3'-->5' exonuclease and 3'-phosphodiesterase activities of yeast apn2 by proliferating cell nuclear antigen. Mol Cell Biol. 22, 6480-6.

Wang, S. C., Y. Nakajima, Y. L. Yu, W. Xia, C. T. Chen, C. C. Yang, E. W. Mclntush, L. Y. Li, D. H. Hawke, R. Kobayashi and M. C. Hung (2006) Tyrosine phosphorylation controls PCNA function through protein stability. Nat Cell Biol. 8, 1359-68.

Warbrick, E. (2000) The puzzle of PCNA's many partners. Bioessays. 22, 997-1006.

Ward, J. F. (2000) Complexity of damage produced by ionizing radiation. Cold Spring Harb Symp Quant Biol. 65, 377-82.

Watanabe, K., S. Tateishi, M. Kawasuji, T. Tsurimoto, H. Inoue and M. Yamaizumi (2004) Rad18 guides poleta to replication stalling sites through physical interaction and PCNA monoubiquitination. Embo J. 23, 3886-96.

Waters, L. S., B. K. Minesinger, M. E. Wiltrout, S. D'Souza, R. V. Woodruff and G. C. Walker (2009) Eukaryotic translesion polymerases and their roles and regulation in DNA damage tolerance. Microbiol Mol Biol Rev. 73, 134-54.

Watts, F. Z. (2006) Sumoylation of PCNA: Wrestling with recombination at stalled replication forks. DNA Repair (Amst). 5, 399-403.

Welchman, R. L., C. Gordon and R. J. Mayer (2005) Ubiquitin and ubiquitin-like proteins as multifunctional signals. Nat Rev Mol Cell Biol. 6, 599-609.

Wilkinson, K. D. (1997) Regulation of ubiquitin-dependent processes by deubiquitinating enzymes. Faseb J. 11, 1245-56.

Witkin, E. M. (1967) Mutation-proof and mutation-prone modes of survival in derivatives of Escherichia coli B differing in sensitivity to ultraviolet light. Brookhaven Symp. Biol. 20, 17-55.

Woodgate, R. (2001) Evolution of the two-step model for UV-mutagenesis. Mutat Res. 485, 83-92.

Xia, L., L. Zheng, H. W. Lee, S. E. Bates, L. Federico, B. Shen and T. R. O'Connor (2005) Human 3-methyladenine-DNA glycosylase: effect of sequence context on excision, association with PCNA, and stimulation by AP endonuclease. J Mol Biol. 346, 1259-74. 
Xiao, W., B. L. Chow, T. Fontanie, L. Ma, S. Bacchetti, T. Hryciw and S. Broomfield (1999) Genetic interactions between error-prone and error-free postreplication repair pathways in Saccharomyces cerevisiae. Mutat Res. 435, 1-11.

Xiao, W., S. L. Lin, S. Broomfield, B. L. Chow and Y. F. Wei (1998) The products of the yeast MMS2 and two human homologs (hMMS2 and CROC-1) define a structurally and functionally conserved Ubc-like protein family. Nucleic Acids Res. 26, 3908-14.

Xu, H., P. Zhang, L. Liu and M. Y. Lee (2001) A novel PCNA-binding motif identified by the panning of a random peptide display library. Biochemistry. 40, 4512 20.

Yamano, H., J. Gannon and T. Hunt (1996) The role of proteolysis in cell cycle progression in Schizosaccharomyces pombe. EMBO J. 15, 5268-79.

Yang, W. (2003) Damage repair DNA polymerases Y. Curr Opin Struct Biol. 13, 23-30.

Yang, W. (2005) Portraits of a Y-family DNA polymerase. FEBS Lett. 579, 868-72.

Yang, W. and R. Woodgate (2007) What a difference a decade makes: insights into translesion DNA synthesis. Proc Natl Acad Sci U S A. 104, 15591-8.

Zachariae, W. and K. Nasmyth (1999) Whose end is destruction: cell division and the anaphase-promoting complex. Genes Dev. 13, 2039-58.

Zhang, W., Z. Qin, X. Zhang and W. Xiao (2011) Roles of sequential ubiquitination of PCNA in DNA-damage tolerance. FEBS Lett. 585, 2786-94.

Zhang, Z., K. Shibahara and B. Stillman (2000) PCNA connects DNA replication to epigenetic inheritance in yeast. Nature. 408, 221-5.

Zou, Y., Y. Liu, X. Wu and S. M. Shell (2006) Functions of human replication protein A (RPA): from DNA replication to DNA damage and stress responses. J Cell Physiol. 208, 267-73. 



\section{Agradecimientos}

Estoy tan emocionada... y tan cansada lo reconozco, que no sé por donde empezar... Puede que sea cosa del estrés y los nervios de las últimas semanas (o más bien meses) que me tienen embotada... o puede que... simplemente... cueste empezar a escribir las palabras que se disponen a cerrar esta etapa... Sea como sea, aquí estoy... delante de esta página que ya no está en blanco, para plasmar la enorme gratitud que siento hacia todos los que habéis hecho posible esto, así que allá voy!!

Como ya sabéis, me gusta empezar las historias desde el principio, así que esta vez no iba a ser menos... (Jorge!! no seas malo!!) Siento remontarme tan atrás en el tiempo, pero es que realmente no ha sido fácil para míllegar hasta aquí. Y es que si esta pequeña enfermera está por fin a sólo un paso de convertirse en doctora, ha sido porque todos vosotros habéis estado ahí, ayudando, apoyando y tirando de mí... así que comencemos desde el principio...

Todo esto comenzó mi primer día de clase en la Facultad de Biología, cuando la peregrina más guapa del mundo se me acercó a decirme que mi cara le sonaba... sin ti Elena y sin todas las que vinisteis detrás: María, Ana, Eva y por supuesto Cris, yo no habría llegado hasta el final. Gracias por miles de apuntes prestados, por estar siempre ahí, por toda la paciencia que tuvisteis y tenéis conmigo... realmente sin vosotras yo hoy no podría estar haciendo esto... cuánto os he echado de menos en mi recta final!!!! Gracias también al resto de "charros" que aparecieron en mi camino por vosotras... en especial a Lorena, Sergio y Laura... gracias por estar en el final!!!

Gracias a todos mis compañeros de mis años en Sierrallana y Son Dureta. Gracias por todos los turnos cambiados para que yo pudiese ir a Salamanca. Gracias por hacérmelo tan fácil. La verdad es que aún no entiendo cómo no salías corriendo cada vez que aparecía con el planning para pediros cambios. Gracias sobre todo a Raquel e Isidro... porque fuisteis los mejores! 
Gracias a mis primeros "padres científicos": Guti y Jordi. Gracias por brindarme la oportunidad de descubrir qué era esto de la "la ciencia". Gracias por creer en mi valía y por haberme seguido la pista.

Y ahora sí, vamos con los del 5!!

Gracias a Avelino. Primero como profesor porque fuiste el único que realmente me puso fácil lo de trabajar y estudiar a la vez. Y segundo como jefe, por darme la oportunidad de formar parte de tu grupo, por descubrirme el maravilloso mundo de las levaduras y por esforzarte tanto en hacerme ver (aunque no lo hayas conseguido) que la biología no son matemáticas. Gracias a María por haber sido mucho más que una jefa... sobre todo en el final. Gracias por llenar el laboratorio de alegría, por celebrar como nadie los resultados positivos con esos meneos que nos das (nunca entenderé cómo alguien tan delgado puede tener tanta fuerza!!). No imaginas lo que echaré de menos tus gritos cada vez que un niño entre en una habitación. Gracias a los que estuvieron en el principio: A Arturo por ensenarme tanto y sobre todo por hacerlo con tanta ilusión. A Teresa, Lola, Alfonso, Helena (ojalá hubieses estado más), Pilar (no se puede tener un corazón más grande) y cómo no, a Sandra!! cuánto dolió tu marcha!! Y ahora sí, a mis chicas. Las "Maris" (en serio, quién empezó esto??). A MariSonix, por millones de cosas... por ser nuestra "mami", por hacernos bizcochos, por tener siempre un abrazo para mí... y por haberme ayudado tanto en estos últimos meses que tan difíciles han sido para mí. A Sara, mi "marichurri", mi Pucelana... por todo lo que me haces reír con tu humor ácido, qué suerte haberte conocido!!... por favor, te digan lo que te digan, que no se te olvide ser feliz!! A MariPatri, por estar siempre pendiente de que comiese los días de "muestras"...por tu empatía, porque eres un cielo, porque me ayudas a ordenar la cabeza... y por tus chanclas!!! Y por supuesto, a mi pupila (lo de MariVane ya me parece excesivo). Nunca imaginé que una galleguiña pudiese traerme tanta luz. No sé cómo lo hiciste, pero me devolviste la ilusión... y eso no tiene precio. En serio, chicas, se me quedan cortas las palabras para expresaros lo que os quiero. GRACIAS POR TODOS ESTOS AÑOS!!!!

Gracias a TODOS los ex-vecinos de enfrente (para mí siempre seréis los del 10). Realmente no sé qué habría sido de mí sin vosotros. De nuevo me faltan las palabras para agradeceros todo lo que habéis hecho por mí... y es que no ha sido nada fácil ser "la pombera" del 5. Gracias por todo lo que me habéis enseñado, por todas las cepas y plásmidos prestados, por todo el tiempo que me habéis dedicado... pero sobre todo, gracias por cómo lo habéis hecho, siempre parando lo vuestro para ayudar... SIEMPRE. Estoy segura de que sin 
vosotros esto habría costado 5 años más!! Gracias en especial a Sergio por abrirme las puertas de su despacho para explicarme cualquier cosa y sobre todo por volver a "cacharrear" para mí ayudándome con mi último experimento. Gracias a Botet por ayudarme y enseñarme millones de cosas... MILLONES!! la de horas que has echado conmigo... a Irene por ser mi ejemplo a seguir... a Noelia por tanta ayuda proteica y por seguir pendiente de mí en la distancia. A Nathalia, Javi, Marta, Myriam... Cristina, Anal... AnaB... gracias por darme el mejor consejo de las últimas semanas!! Y por supuesto, a mis dos chicas favoritas del 10. A Livia, mi Libro gordo de Petete, mi otro ejemplo a seguir. Gracias por ser mi MAESTRA en todo esto, por todas las dudas resueltas al instante y por todas las que hemos resuelto juntas. Gracias por toda la ilusión que has puesto en mi proyecto, por no hacerme sentir una carga... por todas las veces que has ido a mi labo a preguntarme si las cosas fueron bien... pero sobre todo, gracias por hacerlo siempre con una sonrisa en los labios... ha sido un verdadero lujo tenerte ahí!! Y cómo no, a AnaE... por toda tu ayuda profesional... pero sobre todo por la personal. Gracias por tirar de mí, por tu infinita paciencia, porque nadie como tú ha sufrido mis penurias... porque aunque parezca mentira, eso ha hecho que las cosas duelan un poco menos. Gracias también por todas las sonrisas que siempre consigues sacarme... porque no sé cómo lo haces, pero contigo todo es... FENOMENAL!! No imaginas lo afortunada que me siento por tenerte en mi vida. No te alejes nunca!! ni tú, ni Rosendo!!.

Gracias al resto de gente que formáis parte de esta gran familia del CIC. A Alicia por todas las charlas compartidas sobre nuestros fatídicos proyectos y por ayudarme hasta el infinito en este tramo final. Gracias a Sonia y Pablo porque vuestra ayuda siempre va más lejos de lo que os toca. A Celso por hacerme reír con su "glamour". A Carlos por todas las risas que nos hemos echado comiendo... y sí!! me dan miedo los pájaros!!! A Paco por preguntar siempre "qué tal?". Y por supuesto, a los chicos de microscopía: a María, y al charro más charro del mundo!! Ange!!! qué suerte haber currado contigo!! Gracias por todo lo que me has ayudado, incluso fuera de hora. Gracias por lo que me haces reír, por esforzarte hasta el infinito en que consigamos lo que queremos. Eres un profesional como la copa de un pino!!! ya sólo te queda apreciar las puestas de sol... y Pucela!!!

Gracias a los de siempre... a mis Pucelanos.

A los parroquianos, porque aunque cada vez más lejos, seguís estando ahí. A Frito por haber sido el único valiente que se ha atrevido a preguntar de qué iba mi tesis. A Sara por esas quedadas cada vez más fugaces que siempre me ayudan a ordenar ideas. A Miguel 
por ser mi lingüista personal. Que viva el castellano!!! A Jorge por ayudarme a creer que conseguiría terminar esto. A Diego y Maite por ser los mejores anfitriones. Y por supuesto, a Fernando: gracias por todo lo que llevas enseñándome toda la vida... porque sea la hora que sea siempre estás ahí para echar un cable... porque mucho de lo que sé hoy en día te lo debo a ti... por ser mi compañero de alegrías y penurias... porque ni el Atlántico ha conseguido que te separases de mí... por quererme tanto y por dejar que te quiera tanto... y sobre todo, por recordarme que "la paciencia es la madre de la ciencia"!!

A todo el clan del "Lourdes" (y "apósitas") por todo lo que me habéis ayudado a desconectar en la recta final. Por todas esas conversaciones tan interesantes sobre LEDs... por todo lo que me hacéis reír. A Sara porque eres de esa clase de gente que infunde alegría... ya verás como todo sale bien!! Y por supuesto a Ánder. Puf!! lo que ha costado eh?? pero esto ya está ingeniero!! Lo hemos conseguido!!! Siiiiiii... gracias por tu "inestimable ayuda", por prestarme el ordenador que me ha dado la vida!! Por esforzarte hasta el infinito en que esta bióloga soñadora aprenda a ser un poco más práctica. Gracias por los empujones y por las zancadillas... por tu paciencia... por esforzarte infinito en comprender este mundo... pero sobre todo, por haberme sacado de la caverna en que estaba metida ayudándome a llegar al final.

Gracias a ti Goñalons... porque aunque las cosas hayan cambiado tanto, realmente sin ti esto no habría sido posible......Gracias por tu infinita paciencia, por todos esos fines de semana que no pudieron "ser"... y gracias por aprender, siempre riendo, que no trabajar un "finde" significaba poner cultivos los domingos. Gracias por salir de tu isla por mí. Por todo lo que has sufrido este "mundillo de la ciencia"... sobre todo ese año tan horrible que por fin ha pasado... Gracias porque no dudo que realmente eres una de las mejores personas de este mundo y yo he tenido la suerte de tenerte a mi lado... de veras que sin ti no lo habría conseguido... Esto también es tuyo!!

Y por último, gracias a familia... a TODOS!!! A mis tíos... a mis tías... a toooooodos mis prim@s.... Gracias por vuestras visitas todos estos años... por las innumerables mudanzas en las que habéis participado... Gracias por estar siempre cuando se os necesita y cuando no, también. Gracias a mi tío Angel por haber sido "mi carpintero", a mi tía Mari por estar tan orgullosa de su sobrina y por meterme tanta caña para que me ponga a trabajar de una vez!! A mi prima Natalia por ser mi amiga, mi otra hermana... Gracias por preocuparte siempre tanto de mí... porque sin ti no habría podido seguir adelante estos últimos meses... gracias por quererme tanto!! ERES LA MEJOR!! 
Y ahora sí... (esto se acaba)... A los de casa. A mis padres y a mi hermana. Gracias por apoyarme en esta locura de hacer un doctorado. Gracias porque nunca me habéis cuestionado... gracias porque de vosotros ni una sola vez he escuchado que por qué no dejaba de complicarme la vida y me ponía a trabajar en "algo" que diese más dinero. Gracias papá por estar orgulloso de mí... por dejar que te de tanta "guerra"... por haber haber sido mi chófer un millón de veces y por haber montado y desmontado mi escritorio otras tantas... Gracias Raquel por todo lo que me cuidas... por las risas que no echamos juntas... porque siempre estás ahí apoyándome en todo sin cuestionar ni juzgar nada de lo que hago... No sólo eres la mejor maestra del mundo, también eres la mejor hermana del mundo!! Y a ti mamá. Por ser mi ejemplo en la vida... por quererme tanto... por acompañarme en tantas noches de insomnio... porque es muy fácil seguir adelante teniendo una madre que siempre te recuerda que te mires al espejo y que te repitas lo que vales... nada de esto habría sido posible si tú no hubieses estado a mi lado... Y para terminar, a mi abuela, la otra mujer de mi vida... porque aunque ya no estés, en mi corazón nunca dejarás de estar. Ojalá estuvieses aquí para ver esto... seguro que estarías orgullosa de mí...

En fin chicos... que por fin he terminado!!! No tengo ni idea de lo que vendrá ahora y si os soy sincera, tengo que reconocer que eso me da pánico... pero estoy segura de que vosotros haréis que las cosas sean más fáciles...

Así que lo dicho... Gracias a todos!!... os quiero... hasta el infinito... y más allá!!!!! 


